\title{
Die Rolle der beiden Transkriptionsfaktoren AtbZIP1 und AtbZIP53 aus Arabidopsis thaliana in der Anpassung des pflanzlichen Metabolismus an Energiemangelbedingungen
}

\author{
Dissertation \\ zur Erlangung des Doktorgrades \\ der Mathematisch-Naturwissenschaftlichen Fakultäten \\ der Georg-August-Universität zu Göttingen
}

vorgelegt von

Katrin Dietrich

aus Wilhelmshaven

Göttingen 2010 
D7

Referent: Prof. Dr. Wolfgang Dröge-Laser

Korreferent: Prof. Dr. Christiane Gatz

Tag der mündlichen Prüfung: 29.04.2010 



\section{Inhaltsverzeichnis}

1

2

2.1 Die Auswirkungen von Zuckerverfügbarkeit und Energiemangel auf das Wachstum der Pflanze

2.2 Die Anpassung der Genexpression an Energiemangelbedingungen ist nicht nur abhängig vom Zuckerstatus der Pflanze, sondern auch eng verknüpft mit anderen Faktoren wie Stickstoffverfügbarkeit und Licht ................................ 4

2.3 Zuckererkennung und zuckervermittelte Signaltransduktion ........................... 6

2.4 Die SnRK-Kinasen KIN10 und KIN11 aus Arabidopsis als zentrale Regulatoren des Primärstoffwechsels unter Energiemangelbedingungen .......... 9

2.5 Pflanzliche bZIP Transkriptionsfaktoren ...................................................... 14

2.6 Die Bedeutung der Gruppe S1 und C AtbZIP Transkriptionsfaktoren für die Anpassung an Energiemangelbedingungen .............................................. 18

2.7 Fragestellung und Zielsetzung der Arbeit................................................... 21

3

Material. 23

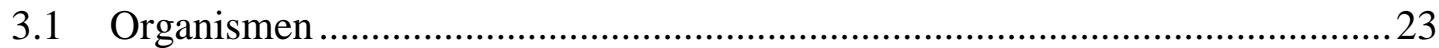

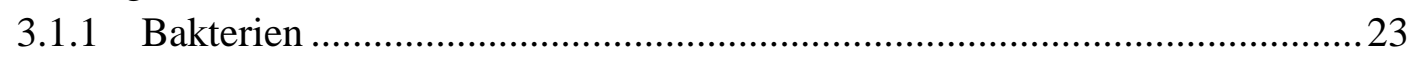

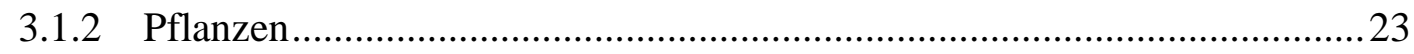

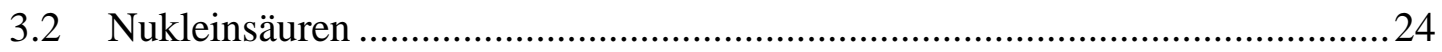

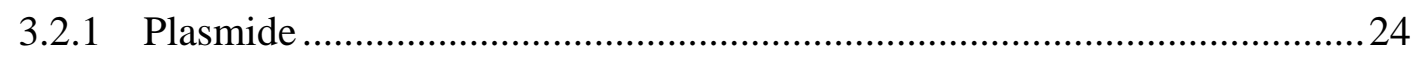

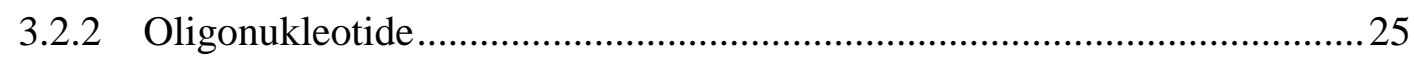

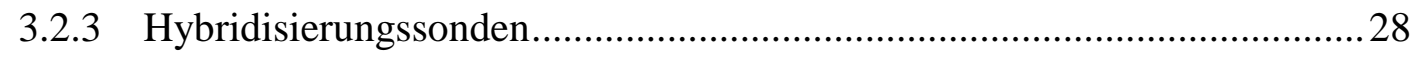

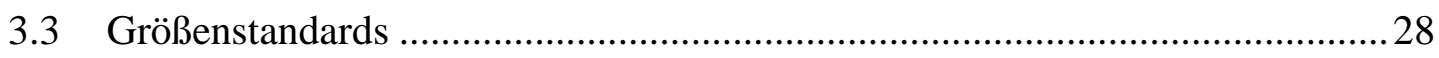

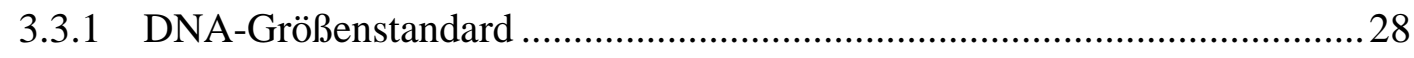

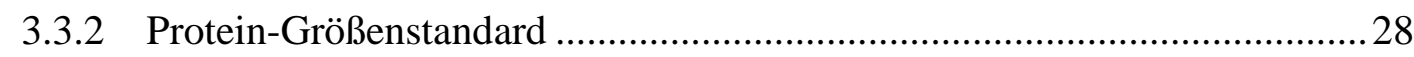

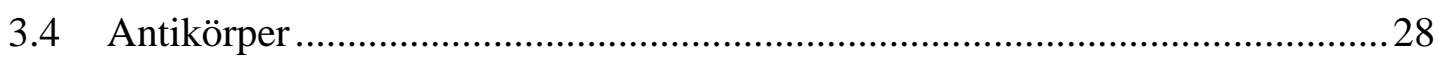

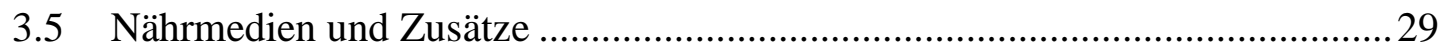

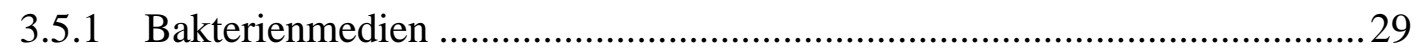

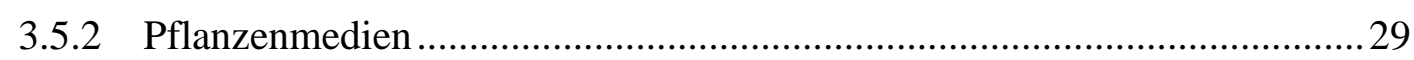

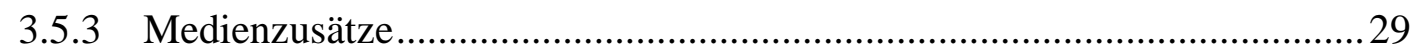

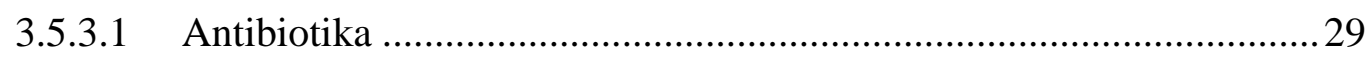

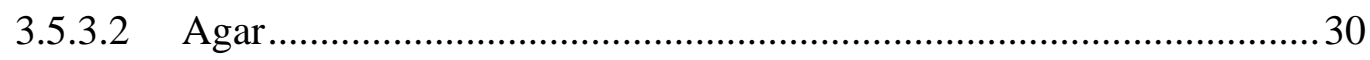

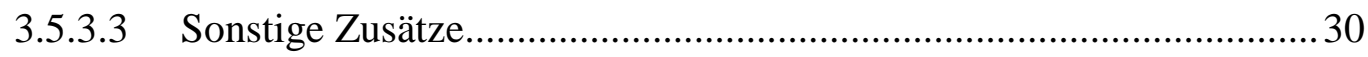




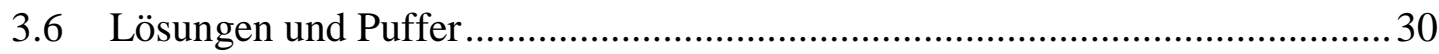

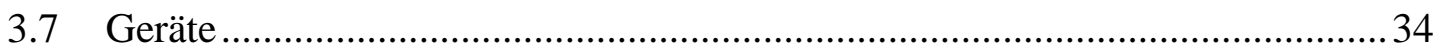

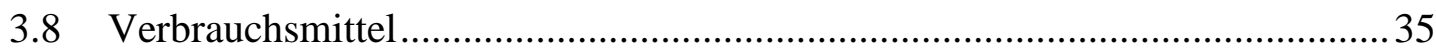

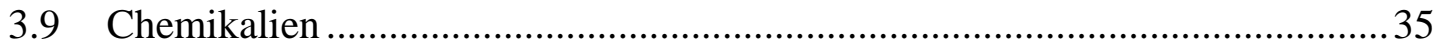

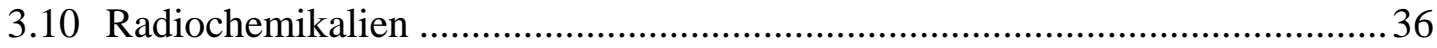

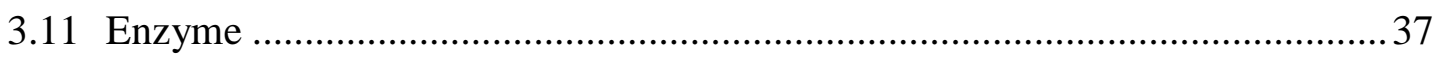

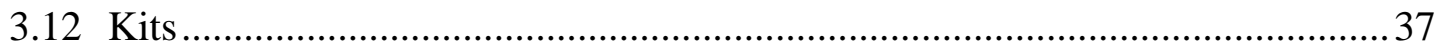

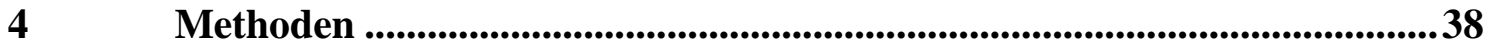

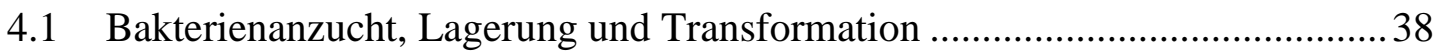

4.1.1 Anzucht von Escherichia coli ................................................................ 38

4.1.2 Anzucht von Agrobacterium tumefaciens .................................................. 38

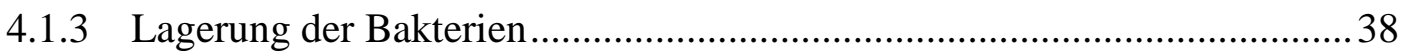

4.1.4 Herstellung kompetenter Escherichia coli ................................................ 38

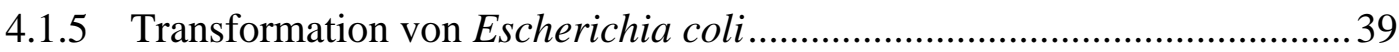

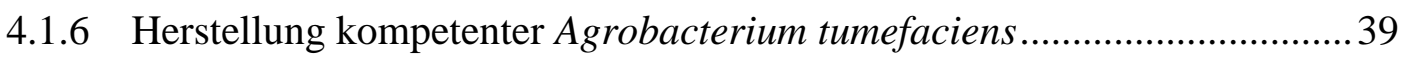

4.1.7 Transformation von Agrobacterium tumefaciens......................................... 39

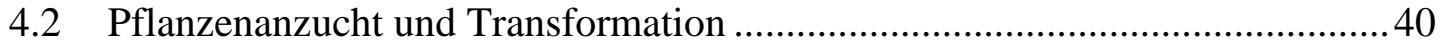

4.2.1 Anzucht von Arabidopsis thaliana auf Erde ........................................... 40

4.2.2 Oberflächensterilisation und sterile Anzucht von Arabidopsis thaliana auf

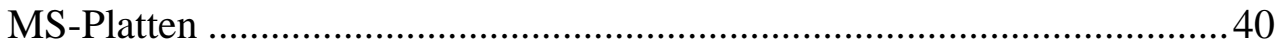

4.2.3 Dunkelinduzierte Seneszenz ............................................................. 41

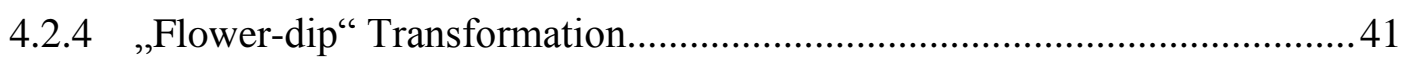

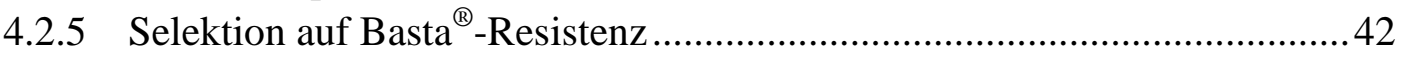

4.2.6 Selektion auf Hygromycin-Resistenz.................................................... 42

4.2.7 Kreuzen von Arabidopsis thaliana Pflanzen................................................ 43

4.2.8 Arabidopsis thaliana-Protoplasten-Transformation.................................. 43

4.2.8.1 Arabidopsis thaliana-Protoplasten-Gewinnung................................ 43

4.2.8.2 Arabidopsis thaliana-Protoplasten-PEG-Transformation.................... 44

4.2.8.3 Arabidopsis thaliana-Protoplasten-Ernte............................................ 44

4.2.8.4 Messung der $\beta$-Glucuronidase (GUS)-Aktivität ................................ 45

4.2.8.5 Messung der NAN-Aktivität und NAN-Abgleich ............................ 45

4.3 Extraktion genomischer DNA aus Arabidopsis thaliana .................................46

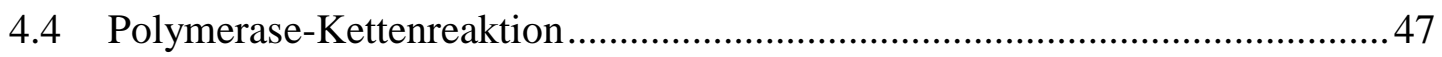

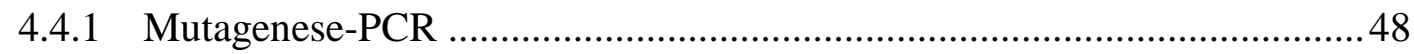

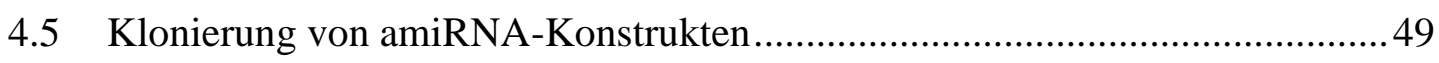

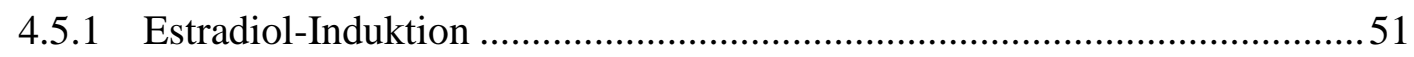

4.6 Konzentrationsbestimmung von Nukleinsäuren ...........................................51 


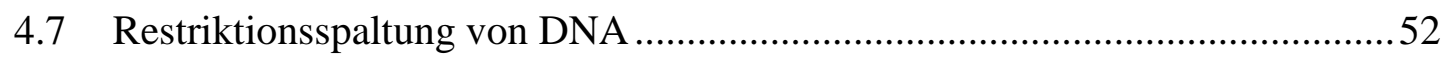

4.8 Agarosegelelektrophorese von DNA-Molekülen .........................................52

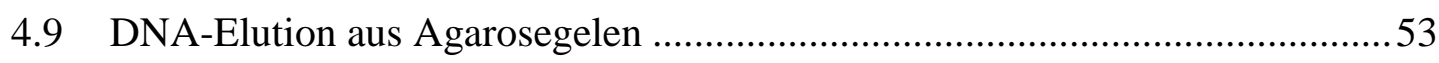

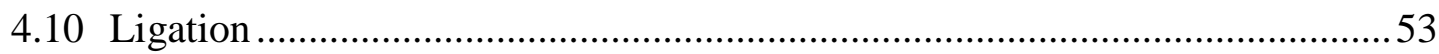

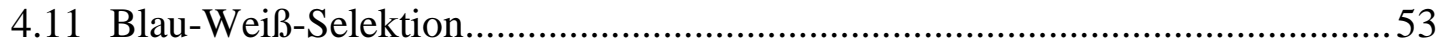

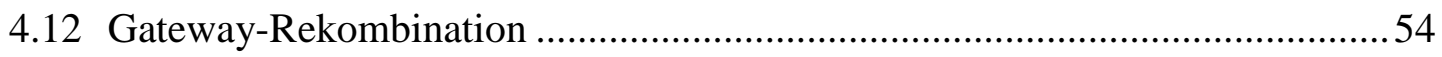

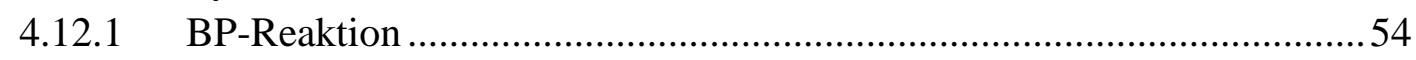

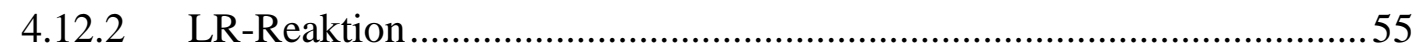

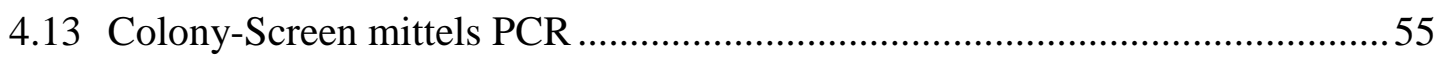

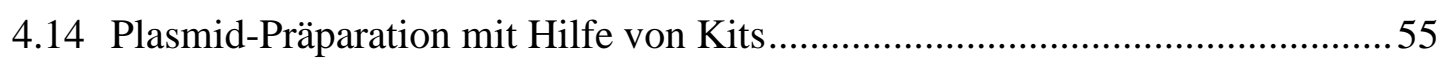

4.15 Plasmid-Präparation durch alkalische Lyse ..................................................56

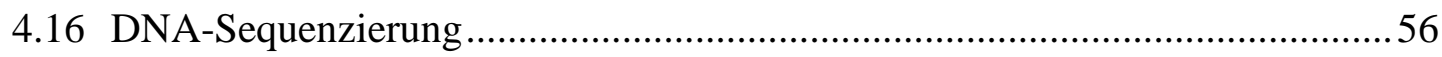

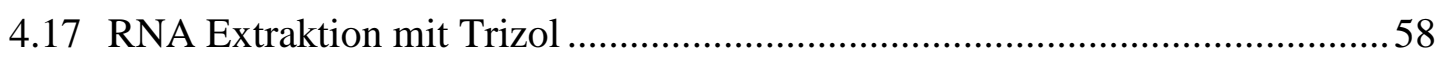

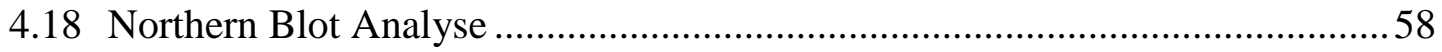

4.18.1 Auftrennung von RNA in denaturierenden Agarosegelen ......................58

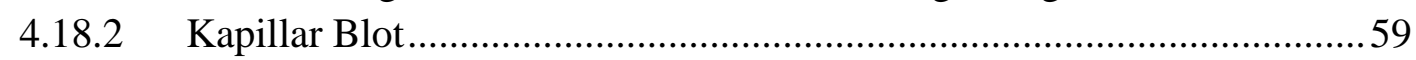

4.18.3 Herstellen einer radioaktiv markierten DNA-Sonde...............................59

4.18.4 Hybridisierung der Northern Blot Membran ...........................................6 60

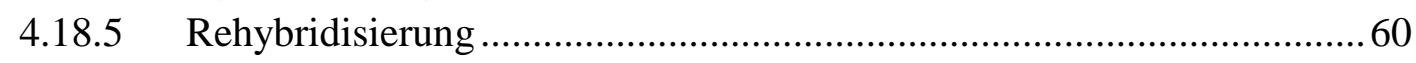

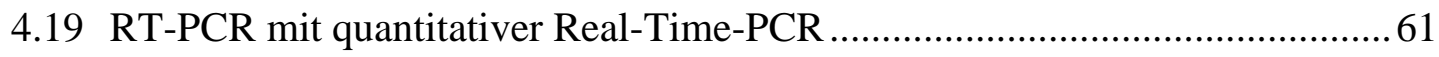

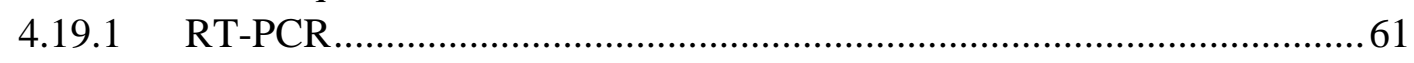

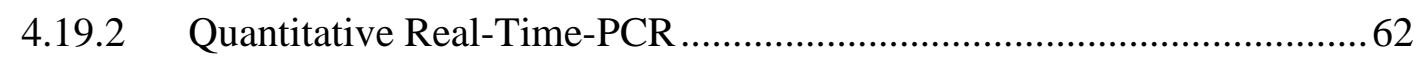

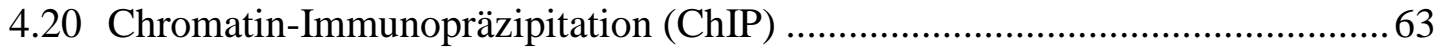

4.20.1 Kreuzvernetzung der DNA-Protein Komplexe .....................................63

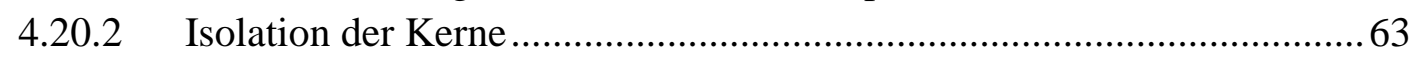

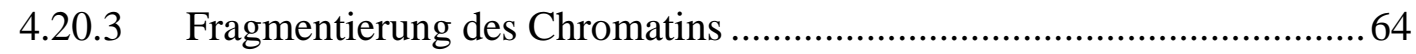

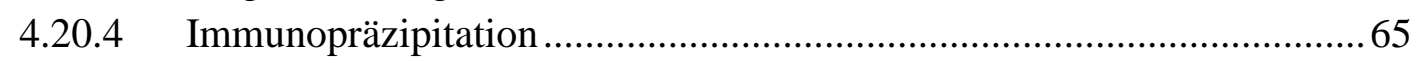

4.21 Herstellung von Proteinextrakten aus Pflanzen ...............................................66

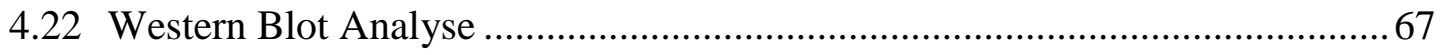

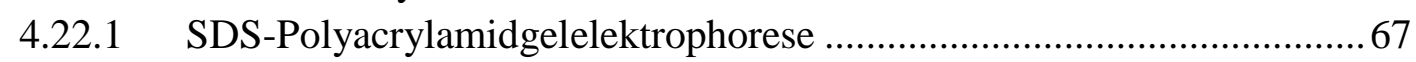

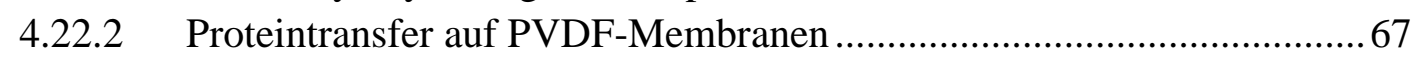

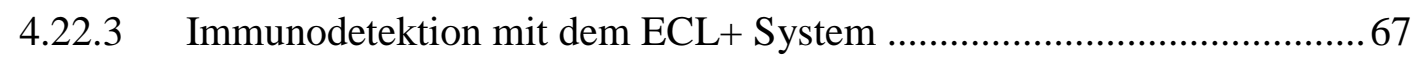

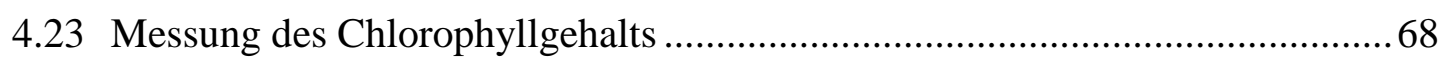

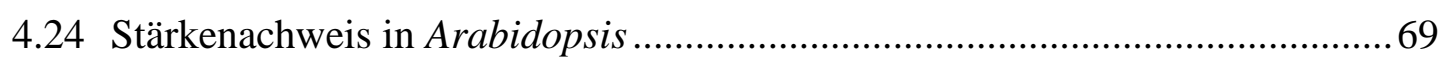

4.24.1 Stärkefärbung von Arabidopsis Pflanzen...............................................69

4.24.2 Quantitative Messung des Stärkegehalts...............................................6 69 
4.25 Bestimmung des Aminosäuregehalts mittels HPLC

4.26 Massenspektrometrische Bestimmung der Metabolitgehalte .70

4.27 Verwendete Computerprogramme

5.1 Eine verlängerte Dunkelphase als experimentelles Modellsystem für Studien der Energieverarmung in Pflanzen.

5.2 Viele bZIP Transkriptionsfaktoren werden während der verlängerten Nacht transkriptionell induziert.

5.3 AtbZIP1 und AtbZIP53 werden während der verlängerten Nacht transkriptionell aktiviert.

5.4 Die Überexpression von AtbZIPl bzw. AtbZIP53 führt zu einem verfrühten Eintritt in die dunkelinduzierte Seneszenz.

5.5 Die Überexpression von AtbZIP1 bzw. AtbZIP53 führt zu einer verstärkten Expression von Genen des Primärstoffwechsels 80

5.5.1 Gene des Lipidstoffwechsels werden durch AtbZIP1 und AtbZIP53 reguliert

5.5.2 Der Kohlenhydratmetabolismus wird durch AtbZIP1 und AtbZIP53 beeinflusst ....

5.5.3 Die Überexpression von AtbZIP1 und AtbZIP53 führt zu einer veränderten

Expression von Genen aus Aminosäureabbau und -Biosynthese 92

5.5.3.1 Die verstärkte Expression der ProDH in den Überexpremierern führt zu einem reduzierten Prolingehalt dieser Pflanzen während der verlängerten Nacht

5.5.3.2 Die BCAT2 wird in den Überexpremierern von AtbZIP1 und AtbZIP53 verstärkt expremiert und führt zu einer Reduktion der verzweigten Aminosäuren

5.5.3.3 Die Überexpression von AtbZIP1 und AtbZIP53 führt zu einer verstärkten Expression der Gene der Asparagin Biosynthese während der verlängerten Nacht

5.6 ASN1 und ProDH werden auch im Protoplasten-System durch dunkelinduzierte Energieverarmung aktiviert

5.6.1 Auch andere bZIP Transkriptionsfaktoren können im Protoplastensystem

ProDH und ASN1 aktivieren.

5.6.2 Eine G-Box im ASN1 Promotor sowie zwei ACTCAT Motive und eine CBox im ProDH Promotor sind notwendig für die Aktivierung der beiden Gene durch Dunkelheit

5.7 Verschiedene ,loss-of-function“ Ansätze führen zu einer Reduktion der bZIP vermittelten Expression der Zielgene des Aminosäuremetabolismus 
5.7.1 Die Expression einer Fusion aus AtbZIP1 bzw. AtbZIP53 mit der EARRepressor-Domäne kann die dunkelinduzierte Aktivierung der $\mathrm{ProDH}$ verhindern ....

5.7.2 Vierfachmutanten von AtbZIP1, AtbZIP53 und Mitgliedern der Gruppe C der bZIP Transkriptionsfaktoren führen zu einer deutlichen Reduktion der Expression von ProDH, BCAT2 und ASN1

5.8 Bedeutung der beiden SnRK1-Kinasen KIN10 und KIN11 als mögliche Regulatoren der bZIP Transkriptionsfaktoren in der Anpassung an Energieverarmung

5.8.1 Die Expression von KIN10 bzw. KIN11 führt zu einer Aktivierung von ProDH und ASN1 im Protoplastensystem

5.8.2 KIN10 und KIN11 regulieren nicht die Transkription von AtbZIP1 und AtbZIP53

5.8.3 Die Mutation putativer SnRK-Phosphorylierungsstellen in AtbZIP1 bzw. AtbZIP53 hat keinen Einfluss auf die Aktivierung der ProDH.

5.8.4 Die Mutation putativer SnRK-Phosphorylierungsstellen in AtbZIP63 führt zu einer Reduktion der ProDH Expression.

6.1 Protoplasten und transgene Pflanzen: Vor- und Nachteile zweier Modellsysteme zur Untersuchung von Energiemangel in Pflanzen

6.2 Die beiden Transkriptionsfaktoren AtbZIP1 und AtbZIP53 werden transkriptionell und posttranskriptionell durch Energieverarmung aktiviert.. 138

6.3 AtbZIP1 und AtbZIP53 führen unter Energiemangelbedingungen zu einer Umprogrammierung des pflanzlichen Kohlenhydratmetabolismus 140

6.4 AtbZIP1 und AtbZIP53 aktivieren unter Energiemangel Gene des Lipid- und Aminosäurestoffwechsels

6.5 AtbZIP1 und AtbZIP53 kontrollieren die Transkription von Genen des Aminosäurestoffwechsels über Bindung an G-Box-, C-Box- und ACTCATPromotorelemente

6.6 Unter Energiemangelbedingungen zeigen bZIP Transkriptionsfaktoren des C/S1-Netzwerks eine partielle Redundanz

6.7 Die SnRK1 Kinasen KIN10 und KIN11 aktivieren unter Energiemangel das C/S1-bZIP Transkriptionsfaktor-Netzwerk wahrscheinlich über eine Phosphorylierung von AtbZIP63

6.8 Modell: SnRK1 Kinasen und bZIP Faktoren des C/S1 Netzwerks vermitteln eine Reprogrammierung des pflanzlichen Metabolismus unter Energiemangelbedingungen 


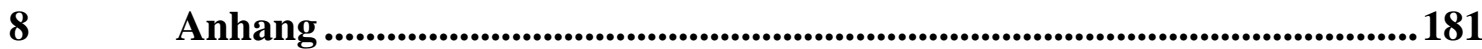

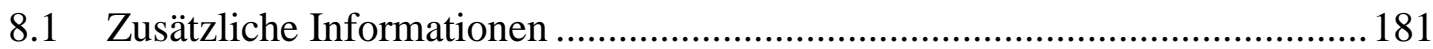

8.1.1 Northern Analyse der Expression der Lipoxygenasen LOX3, LOX4, LOX5

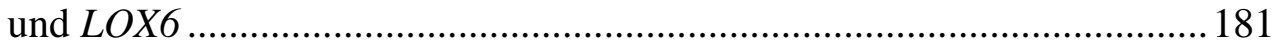

8.1.2 Expression der $\beta$-Amylasen BAM1-4 und BAM6-9 ................................ 182

8.1.3 Expression von AtbZIP1 und AtbZIP53 in Wildtyp, AtbZIP1 und AtbZIP53 Überexpremierern und Doppelmutante .................................................. 183

8.1.4 Aminosäuresequenz von AtbZIP1 …........................................................ 184

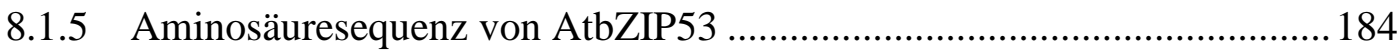

8.1.6 Aminosäuresequenz von AtbZIP63 …................................................ 185

8.1.7 ACGT Elemente in den Promotoren der untersuchten Aminosäuregene . 186

8.1.8 Charakterisierung der AtbZIP Einzel- und Mehrfachmutanten ................ 187

8.2 Tabellarische Darstellung der Originaldaten aus der Aminosäuremessung ... 188

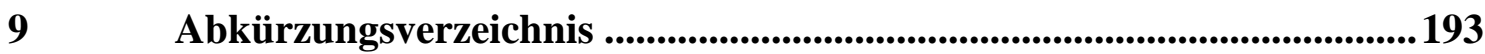

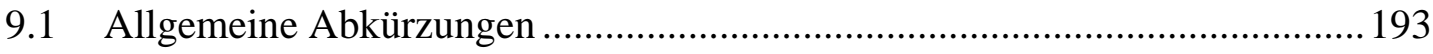

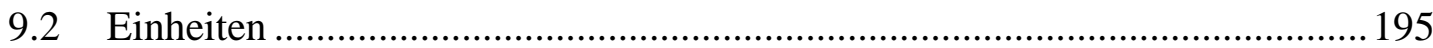

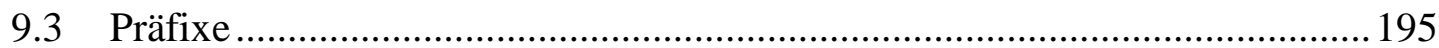

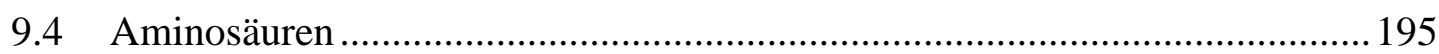

9.5 Nukleotide 


\section{$1 \quad$ Zusammenfassung}

Energiemangelbedingungen, wie sie während langanhaltender Dunkelheit auftreten, führen zu einer massiven Umprogrammierung des pflanzlichen Metabolismus. Dies hat den Abbau von Proteinen, Aminosäuren und Nukleinsäuren sowie die Hydrolyse von Polysacchariden und Oxidation von Fettsäuren zur Folge, die unter diesen Bedingungen als alternative Energiequellen genutzt werden. Zentrale Regulatoren dieser pflanzlichen Anpassung an Energiemangel sind die SnRK1 (Snf1 RELATED KINASES) Kinasen KIN10 und KIN11. In dieser Arbeit werden die beiden bZIP (basic leucine zipper) Transkriptionsfaktoren (TF) AtbZIP1 und AtbZIP53 identifiziert, die ein Teil dieses SnRK1 Signalweges sind. Besonders AtbZIP1, aber auch AtbZIP53, werden sowohl transkriptionell als auch posttranskriptionell durch Energiemangel aktiviert.

Die Überexpression von AtbZIP1 und AtbZIP53 führt zu einem verfrühten Eintritt in die dunkelinduzierte Seneszenz. Unter diesen Bedingungen kommt es in den Überexpremierern zu einem verstärkten Abbau von Aminosäuren wie Prolin, Leucin, Isoleucin und Valin. Die Aminosäure Asparagin, die als Transportform für Kohlenstoff und Stickstoff unter Mangelbedingungen dient, wird dagegen in AtbZIP53 Überexpremierern verstärkt gebildet. Dagegen werden in den AtbZIP53 Überexpressionspflanzen die Stärke- und Saccharosereserven trotz Energiemangel nur begrenzt als Energiequelle genutzt.

Die Unterschiede in den Metaboliten des Primärstoffwechsels zwischen Überexpremierern und Wildtyp kommen durch eine veränderte Genexpression zustande. Gene wie PROLIN DEHYDROGENASE (ProDH) und BRANCHED CHAIN AMINO ACID TRANSAMINASE 2 (BCAT2), deren Genprodukte zum Abbau von Aminosäuren führen, werden in beiden Überexpremierern ebenso transkriptionell aktiviert wie die ASPARAGIN SYNTHETASE 1 (ASN1) und andere Gene der Asparagin Biosynthese. Gene, die für Enzyme des Lipidabbaus wie verschiedene Lipasen und Lipoxygenasen codieren, werden in beiden Überexpremierern aktiviert, während die Genexpression stärkeabbauender Enzyme wie der B-AMYLASE5 (BAM5), vor allem in den AtbZIP53 Überexpremierern stark reduziert ist. 
ChIP (Chromatin Immunopräzipitation) Analysen belegen eine direkte Bindung von AtbZIP1 und AtbZIP53 an die Promotoren von ProDH und ASN1. In Experimenten mit Promotormutanten konnte zudem gezeigt werden, dass typische bZIP-Bindestellen wie eine G-Box im ASN1 Promotor und zwei ACTCAT Motive im ProDH Promotor essentiell für die Induktion dieser Gene unter Energiemangelbedingungen sind.

Da die bZIP TF teilweise redundante Funktionen übernehmen, zeigen „loss-offunction"-Ansätze mit Einzelmutanten von AtbZIP1 und AtbZIP53 oder der Doppelmutante atbzipl atbzip53 in der Expression ihrer Zielgene nur geringe Unterschiede zum Wildtyp. Vierfachmutanten von AtbZIP1 und AtbZIP53 mit je zwei der vier heterodimerisierenden Gruppe C Faktoren führen dagegen zu einer deutlichen Reduktion der dunkelinduzierten Expression von ProDH, BCAT2 und ASN1.

Versuche zur Energieverarmung im Protoplastensystem zeigen deutlich den Einfluss der Kinasen KIN10 und KIN11 auf die Expression von ASN1 und ProDH. Co-Expression der Kinasen mit AtbZIP1 und AtbZIP53 hat einen synergistischen Effekt auf die Aktivierung der beiden Gene, was zeigt, dass AtbZIP1 und AtbZIP53 Teil des kinaseabhängigen Signalweges zur Aktivierung von ASNI und ProDH unter Energiemangelbedingungen sind. Durch Mutation putativer SnRK1Phosphorylierungsmotive in der Aminosäuresequenz von AtbZIP1 und AtbZIP53 kann aber eine Aktivierung durch eine direkte Phosphorylierung an diesen Motiven ausgeschlossen werden. Die Mutation von in vivo phosphorylierten Serinen ihres Heterodimerisierungspartners AtbZIP63 führt allerdings zu einer deutlichen Reduktion der KIN10 vermittelten ProDH-Aktivierung. Es wird deshalb postuliert, dass die SnRK1-Kinasen Heterodimere des C/S1-Netzwerks posttranslational aktivieren und so zur Änderung der Genexpression und damit zur Umprogrammierung des Metabolismus unter Energiemangelbedingungen beitragen. 


\section{$2 \quad$ Einleitung}

\subsection{Die Auswirkungen von Zuckerverfügbarkeit und Energie- mangel auf das Wachstum der Pflanze}

Pflanzen sind in ihrer Umwelt ständig wechselnden Bedingungen ausgesetzt, in denen auch die Verfügbarkeit von Energie stark schwankt. Ein Beispiel dafür ist der tägliche Wechsel von Licht und Dunkelheit. Pflanzen sind darauf angewiesen, das Licht während des Tages zu nutzen um Photosynthese zu betreiben, in der aus Kohlendioxid $\left(\mathrm{CO}_{2}\right)$ und Wasser $\left(\mathrm{H}_{2} \mathrm{O}\right)$ Zucker produziert werden. Diese Zucker benötigt die Pflanze zum Leben und Wachsen. Auch während der Nacht finden weiterhin energieverbrauchende Stoffwechselprozesse statt, die ein Wachstum der Pflanze gewährleisten (Schurr et al., 2006). Dies ist nur möglich, weil ein Teil des fixierten Kohlenstoffs während des Tages in Form von Stärke gespeichert wird. Die Stärke kann dann im Verlauf der Nacht remobilisert und bis zum Beginn der nächsten Lichtphase fast vollständig verbraucht werden (Fondy und Geiger, 1985; Geiger und Servaites, 1994; Matt et al., 1998; Smith et al., 2004).

Änderungen der Umweltbedingungen wie längere Dunkelphasen während des Herbstes führen dazu, dass kurzzeitig am Ende der längeren Nacht ein Mangel an Kohlenstoff entsteht. Die Pflanze kann ihren Metabolismus aber an diese neuen Umweltbedingungen anpassen. Die Stärkesynthese während des Tages wird erhöht und gleichzeitig der Stärkeabbau und die Wachstumsrate während der Nacht herabgesetzt (Gibon et al., 2004; Smith und Stitt, 2007; Usadel et al., 2008). So wird vermieden, dass über längere Zeiträume hinweg Versorgungslücken im Kohlenstoffhaushalt entstehen, die zu einem Wachstumsstop führen würden. Denn schon kurze Zeiträume der Kohlenstoffverarmung führen zu einer Inhibierung des Wachstums, die nicht sofort reversibel ist, wenn Kohlenstoff wieder verfügbar ist (Smith und Stitt, 2007; Usadel et al., 2008).

Welche wichtige Rolle Stärke als Speicherstoff bei dieser Anpassung der Pflanze an die täglich wechselnde Verfügbarkeit von Kohlenstoff hat, zeigen zwergwüchsige Stärkemutanten wie die pgm (PHOSPHOGLUCOMUTASE) Mutante. Jede Nacht sind 
sie einem Mangel an Kohlenstoff ausgesetzt, der zu einer Inhibierung des Wachstums führt, die noch bis in den nächsten Tag hinein anhält (Gibon et al., 2004; Caspar et al., 1985). Ein hoher Stärkegehalt korreliert aber nicht unbedingt mit einem starken Wachstum der Pflanzen. Langsam wachsende Pflanzen akkumulieren viel Stärke, während schnell wachsende Pflanzen mit viel Biomasse ihre Kohlenstoffreserven in Wachstumsprozesse investieren und dadurch niedrige Stärke- und Zuckermengen aufweisen (Sulpice et al., 2009).

Generell führen Änderungen im Kohlenstoff-/Energiegehalt der Pflanze zu einer massiven Änderung der Genexpression. Ein hoher Zuckergehalt induziert dabei Gene, die für Biosynthese und Wachstum verantwortlich sind, während Zuckermangel zu einer Aktivierung von Genen führt, die zur weiteren Kohlenstoffassimilation beitragen oder für den Abbau von alternativen Kohlenstoffquellen sorgen (Koch, 1996; Usadel et al., 2008). Energiemangel während einer verlängerten Nacht führt so zu einer Umprogrammierung des Metabolismus, die letztendlich zum Abbau von Proteinen, Aminosäuren und Nukleinsäuren sowie zur Hydrolyse von Polysacchariden und zur Oxidation von Fettsäuren führt (Smart, 1994). Die koordinierte Expression der hierfür verantwortlichen Gene wird durch eine komplexe Signalverarbeitung vermittelt.

\subsection{Die Anpassung der Genexpression an Energiemangel- bedingungen ist nicht nur abhängig vom Zuckerstatus der Pflanze, sondern auch eng verknüpft mit anderen Faktoren wie Stickstoffverfügbarkeit und Licht}

Das Wachstum der Pflanze ist abhängig von vielen Faktoren, eine besondere Rolle spielt jedoch die Verfügbarkeit von Zuckern. Zucker werden von der Pflanze nicht nur für ihr Wachstum benötigt, sondern dienen auch als Signalmoleküle (zur Übersicht: Ramon et al., 2008).

Die Identifizierung von Signalwegen des Zuckerstoffwechsels der Pflanze ist kompliziert, da diese eng verknüpft sind mit der Lichtwahrnehmung, der inneren Uhr, Nährstoffverfügbarkeit, Hormonen oder auch dem allgemeinen Entwicklungsstand der Pflanze (zur Übersicht: Rolland et al., 2006; Smith und Stitt, 2007). So ist z.B. bekannt, dass Zucker die Phytochrom gesteuerte Wahrnehmung von Licht und die darauf 
folgende Signalvermittlung beeinflussen können (Dijkwel et al., 1997). Gene die für typische Enzyme der Photosynthese, wie das CHLOROPHYLL A/B BINDENDE PROTEIN, PLASTOCYANIN oder die kleine Untereinheit der RUBISCO codieren, werden stark durch Licht induziert, dagegen aber durch Zucker reprimiert (Koch, 1996). Andere Gene werden sowohl durch Zucker als auch durch Licht induziert. Dazu gehören z.B. die GLUTAMIN SYNTHETASE, die NITRAT REDUKTASE und die ASPARAGIN SYNTHETASE 2 (Koch, 1996; Lam et al., 1998; Oliveira und Coruzzi, 1999).

Auch zwischen der zucker- und der stickstoffvermittelten Signaltransduktion besteht eine enge Verbindung. Viele Gene von Stickstofftransportern sind z.B. auch durch Zucker induzierbar (Lejay et al., 1999; Lejay et al., 2008). Auch viele andere Gene werden durch Zucker, Stickstoff oder eine Kombination von beiden induziert, wie genomweite Transkriptionsanalysen gezeigt haben (Wang et al., 2003; Palenchar et al., 2004; Price et al., 2004; Scheible et al., 2004; Gutiérrez et al., 2007).

Ein gutes Beispiel für die komplexe Integration vieler verschiedener Signale ist die Regulation der Asparagin und Glutamin Biosynthese. Die Expression der für diese Enzyme codierenden Gene wird durch Zucker, Licht, die innere Uhr und die Stickstoffverfügbarkeit bestimmt (Melo-Oliveira et al., 1996; Oliveira und Coruzzi, 1999; Lam et al., 1994; Lam et al., 1998; Gutierrez et al., 2008).

Während tagsüber hauptsächlich Glutamin als Transportform für Stickstoff und Kohlenstoff in der Pflanze dient, übernimmt nachts, wenn der Zuckergehalt niedrig ist, Asparagin diese Funktion. Der Grund hierfür liegt in der Struktur dieser beiden Aminosäuren. Während Glutamin aus fünf Kohlenstoffatomen und zwei Stickstoffatomen besteht, hat Asparagin bei gleicher Menge Stickstoff ein Kohlenstoffatom weniger. Unter Kohlenstoffmangelbedingungen während der Dunkelheit wird deshalb bevorzugt Asparagin gebildet und transportiert (Lam et al., 1994).

Die Verfügbarkeit von Glutamin während des Tages und Asparagin während der Nacht wird durch eine koordinierte Expression ihrer Biosynthesegene gewährleistet. So induziert Licht während des Tages die Expression der GLUTAMIN SYNTHETASE 2 (GLNS2) und sorgt so für hohe Glutaminmengen. Die Expression der ASPARAGIN SYNTHETASE 1 (ASN1) wird dagegen durch Licht reprimiert. Auch Zucker führen zu 
einer Induktion der GLNS2. Im Gegensatz dazu wird die Expression der ASN1 durch Zucker reprimiert (Thum et al., 2003). Sowohl von der GLUTAMIN SYNTHETASE als auch von der ASPARAGIN SYNTHETASE gibt es mehrere Isoformen (z.B. ASN1, ASN2, ASN3), die jeweils unterschiedlich, teils sogar gegenläufig, durch Licht, Zucker und Stickstoff reguliert werden (Lam et al., 1998). Die Endprodukte der Stickstoffassimilation, Glutamat und Glutamin, dienen ihrerseits wieder als Signalmoleküle, die den Stickstoffstatus der Pflanze anzeigen und durch eine „Feedback“-Hemmung die Expression der beteiligten Synthesegene regulieren.

Die Mengen von Asparagin und Glutamin in der Pflanze sind aber nicht nur abhängig von Zucker, Licht und Stickstoff, sondern auch von der Expression des wichtigsten Kontrollgens der inneren Uhr CCAl (CIRCADIAN CLOCK ASSOCIATED 1). Die Expression von CCA1 reduziert die Asparaginmengen indem die Transkription des bZIP Transkriptionsfaktors AtbZIP1 reprimiert wird (siehe Kapitel 2.6). AtbZIP1 ist ein positiver Regulator der ASN1 Transkription (Baena-Gonzales et al., 2007). CCA1 induziert aber auch direkt die Expression einer GLUTAMIN SYNTHETASE (GLNS1.3; Gutierrez et al., 2008) und sorgt dadurch für eine Erhöhung des Glutamingehalts.

Die Regulation der Glutamin- und Asparaginsynthese ist ein gutes Beispiel für die komplexe Integration der verschiedenen Signale. Sie zeigt, wie schwierig es tatsächlich ist, die Effekte eines einzelnen Signalweges zu untersuchen.

\subsection{Zuckererkennung und zuckervermittelte Signaltransduktion}

Zucker sind sehr potente Signalmoleküle und können die Expression von tausenden von Genen beeinflussen (Price et al., 2004; Thimm et al., 2004; Thum et al., 2004; Bläsing et al., 2005; Li et al., 2006; Osuna et al., 2007).

Die am besten beschriebenen Zuckerrezeptoren in Arabidopsis sind zwei Hexokinasen (HXK1 und HXK2) (Rolland et al., 2002). Die HXK1 phosphoryliert Glukose und Fruktose zu Hexose-6-Phosphaten und katalysiert damit den ersten Schritt der Glykolyse. Neben der metabolischen Funktion dient die HXK1 auch als Glukoserezeptor und initiiert damit die weitere Signaltransduktion. Die Expression vieler Zucker regulierter Gene wird über einen Hexokinase abhängigen Signalweg 
moduliert. Ein Beispiel dafür ist die Hexokinase vermittelte Reprimierung von Photosynthese-Genen durch Glukose.

Allerdings existiert auch eine ganze Reihe von Genen, deren Expression nicht Hexokinase abhängig ist. So werden einige dunkelinduzierte (DIN) Gene wie z.B. die ASN1 bei Zuckermangel auch noch in der $h x k 1$ Nullmutante reprimiert (Baena-Gonzales und Sheen, 2008). RGS1 (REGULATOR OF G-PROTEIN SIGNALING 1) ist ein Plasmamembran gebundenes Protein, das eine Rolle in der pflanzlichen Zellvermehrung spielt und möglicherweise als Hexokinase unabhängiger Glukoserezeptor fungiert (Chen et al., 2003; Chen und Jones, 2004).

Auch andere Zucker können eine Funktion als Signalmolekül in der Pflanze übernehmen. Ein Beispiel ist Trehalose-6-Phosphat (T6P). T6P ist ein Zwischenprodukt der Trehalosesynthese, das nur in sehr geringen Mengen in der Pflanze vorliegt. In vielen Experimenten konnte gezeigt werden, dass die T6P Mengen in der Pflanze sehr stark mit dem Saccharosegehalt korrelieren, sogar stärker als die Mengen von Glukose und Fruktose (Lunn et al., 2006; Paul, 2008). T6P ist damit ein Indikator für die Saccharosemenge in der Zelle und kann in dieser Funktion möglicherweise Prozesse wie die Stärkesynthese regulieren (Kolbe et al., 2005). Erst vor kurzem konnte gezeigt werden, dass T6P die Aktivität von SnRK Kinasen (Snf1 RELATED KINASES) inhibiert (Zhang et al., 2009), die zentrale Regulatoren des primären Metabolismus während Energiemangel sind (Baena-Gonzales et al., 2007; siehe Kapitel 2.4).

Ein weiterer Zucker, der auch als Signalmolekül wirken kann, ist Fruktose-2,6Bisphosphat (Stitt, 1990). Durch Fruktose-2,6-Bisphosphat werden u.a. wichtige Enzyme der Glykolyse wie die PHOSPHOFRUCTOKINASE (PFK1) und FRUCTOSE-1,6-BISPHOSPHATASE (FBPase1) allosterisch kontrolliert (Stryer, Biochemie).

Auch Disaccharide, wie die Saccharose, können eine Funktion als Signalmolekül haben. Viele der durch Saccharose ausgelösten Effekte sind zwar auf die Eigenschaften ihrer monomeren Bestandteile Glukose und Fruktose zurückzuführen, es gibt aber auch eine saccharosespezifische Regulation von Transkription und Translation. So wird die Expression von UDP-GLUKOSE PYROPHOSPHORYLASE, ANTHOCYANIN BIOSYNTHESIS ENZYME und einem putativen chloroplastidären GLUCOSE-6- 
PHOSPHATE/PHOSPHATE TRANSLOCATOR durch Saccharose induziert (Wenzler et al., 1989; Yokoyama et al., 1994; Ciereszko et al., 2001; Teng et al., 2005; Gonzali et al., 2006; Solfanelli et al., 2006). Die Expression eines PROTON-SUCROSE SYMPORTER Gens aus Zuckerrübe wird dagegen durch Saccharose reprimiert (Chiou und Bush, 1998; Vaughn et al., 2002).

Nach der Erkennung der Zucker durch verschiedene Rezeptoren wird die Information über eine komplexe Signaltransduktion weitergeleitet und führt schließlich zur Änderung der oben beschriebenen Genexpression, oder auch zu einer Veränderung von Enzymaktivitäten.

Eine molekulare Komponente der zuckervermittelten Signaltransduktion sind Protein Phosphatasen. Erste Hinweise auf eine Beteiligung von Phosphatasen am Zuckersignalweg lieferten Versuche mit PP1 und PP2A Phosphatase Inhibitoren, die, wie die Behandlung mit Zuckern, zu einer Repression von Photosynthese-Genen in Maisprotoplasten führten (Sheen, 1993). Auch die saccharoseinduzierte Expression von Genen wie der $\beta$-AMYLASE aus Süßkartoffel konnte durch Phosphatase Inhibitoren verhindert werden (Takeda et al., 1994).

Studien mit dem Calciumkanal-Blocker $\mathrm{LaCl}_{3}$ und Calmodulin Inhibitoren in Süßkartoffel zeigten, dass $\mathrm{Ca}^{2+}$ eine wichtige Funktion in der zuckerinduzierten Expression von Genen wie der $\beta$-AMYLASE hat. Möglicherweise wirkt $\mathrm{Ca}^{2+}$ dadurch, dass es die Proteinphosphorylierung im Zuckersignalweg ermöglicht (Boudsocq und Sheen, 2008), denn Saccharose kann den cytosolischen Calciumeinstrom induzieren und so die Expression einer calciumabhängigen Protein Kinase aus Tabak verstärken (Iwata et al., 1998; Furuichi et al., 2001).

Auch Protein Kinasen haben eine wichtige Bedeutung in der Zuckersignaltransduktion. Dies konnte durch Versuche mit dem Protein Kinase Inhibitor Staurosporin gezeigt werden (Ehness et al., 1997). Erst kürzlich wurden die beiden Kinasen KIN10 und KIN11 aus Arabidopsis beschrieben, die als Masterregulatoren eines Netzwerks aus Transkriptionsfaktoren die Genexpression unter Energiemangelbedingungen regulieren (Baena-Gonzalez et al., 2007; Baena-Gonzalez und Sheen, 2008). 


\subsection{Die SnRK-Kinasen KIN10 und KIN11 aus Arabidopsis als zentrale Regulatoren des Primärstoffwechsels unter Energie- mangelbedingungen}

Die beiden Kinasen KIN10 (SnRK1.1) und KIN11 (SnRK1.2) gehören zur SnRK1 Untergruppe der SnRK (Snf1 RELATED KINASES) Genfamilie. Diese Genfamilie besteht in Arabidopsis aus 3 Untergruppen (SnRK1, SnRK2 und SnRK3), von denen die SnRK1 Protein Kinasen das pflanzliche Ortholog zu Snf1 (Sucrose nonfermenting1) aus Hefe (Saccharomyces cerevisiae) und den AMPKs (AMPACTIVATED PROTEINE KINASES) aus Säugetieren sind (Abb. 2.1). Die beiden anderen Untergruppen SnRK2 und SnRK3 kommen dagegen nur in Pflanzen vor und spielen z.B. eine Rolle in der ABA-Antwort (zur Übersicht: Halford und Hey, 2009).

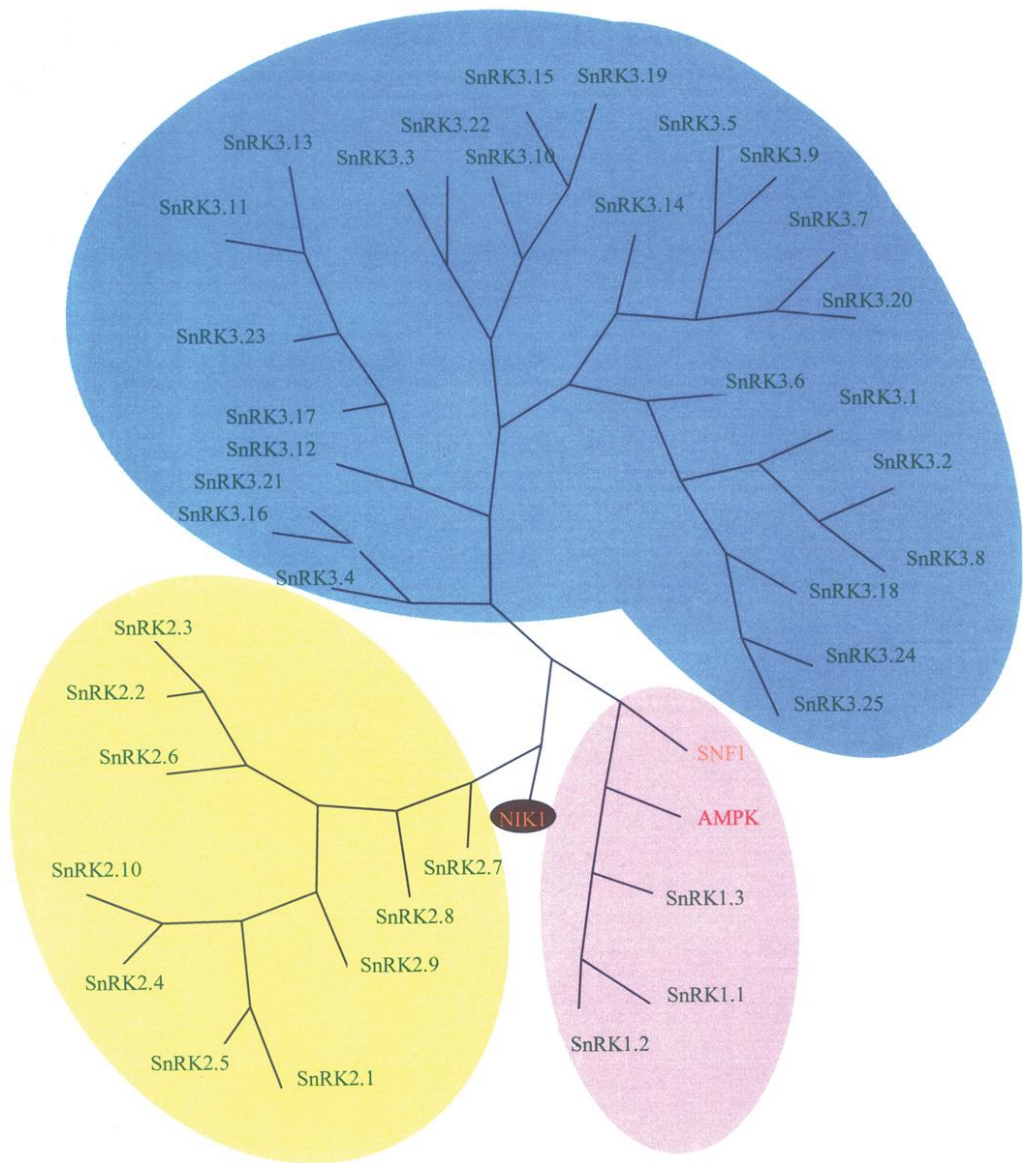

Abb. 2.1: Stammbaum der Mitglieder der SnRK Familie aus Arabidopsis (Halford und Hay, 2009) Gezeigt sind die Untergruppen SnRK1, SnRK2 und SnRK3 aus Arabidopsis sowie Snf1 (Saccharomyces cerevisiae) und AMPK (Homo sapiens). 
Aufbau, Struktur und Funktion von SnRK1, Snf1 und AMPKs sind in Pflanzen, Hefe und Säugetieren stark konserviert. Experimente konnten zeigen, dass SnRK1 aus Arabidopsis von einer Protein Kinase aktiviert werden kann, die im tierischen System für die AMPK Aktivierung zuständig ist (Mackintosh et al., 1992). Für Regulatoren der SnRK1 konnte dagegen gezeigt werden, dass sie auch Snf1 aus Hefe aktivieren (Hey et al., 2007).

SnRK1/Snf1/AMPK sind heterotrimere Enzyme, die aus drei Untereinheiten bestehen (Abb. 2.2). Die $\alpha$-Untereinheit ist dabei die katalytisch aktive Kinase, während die beiden anderen Untereinheiten ( $\beta$ und $\gamma$ ) eine regulatorische Funktion besitzen (Amodeo et al., 2007). In Säugetieren konnte gezeigt werden, dass die Bildung des Heterotrimers notwendig für die AMPK Aktivität ist (Woods et al., 1996). Auch in Hefe führt eine Deletion der $\gamma$-Untereinheit (Snf4) oder aller drei $\beta$-Untereinheiten (Sip1, Sip2, Gal83) zu einer Inaktivierung der Snf1 Aktivität in vivo (Carlson et al., 1981; Schmidt und McCartney, 2000) und verdeutlicht damit die Bedeutung der einzelnen Komponenten für die Funktion des Komplexes.

A
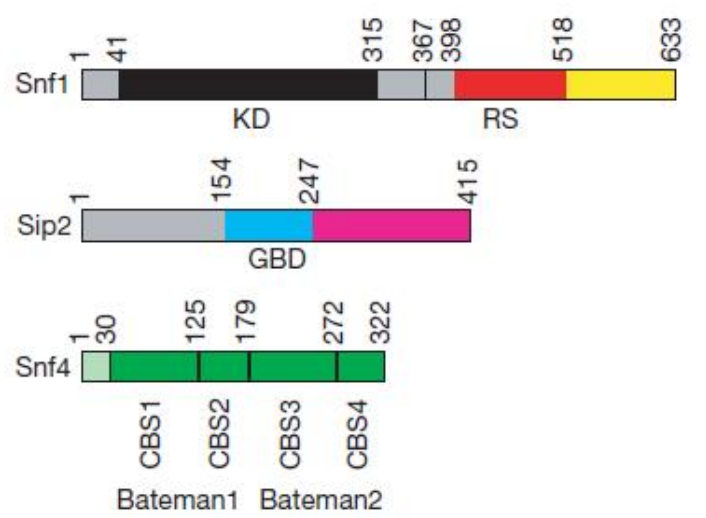

B

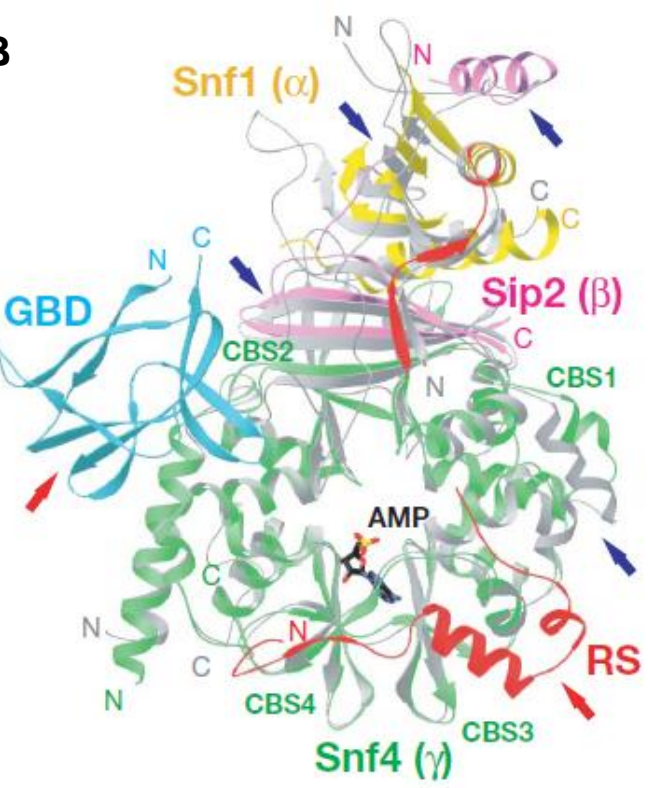

Abb. 2.2: Struktur des heterotrimeren Komplexes von Snf1 aus Saccharomyces cerevisiae (Amodeo et al., 2007)

A: Die Domänen der Snf1 Untereinheiten. KD = Proteinkinase Domäne; RS = regulatorische Sequenz; GBD = Glykogen-Bindedomäne; CBS = Cystathionin-B-Synthase (auch Bateman Domäne genannt) B: Schema der Struktur des heterotrimeren Snf1 Komplexes 
Snf4 aktiviert in Hefe die Snf1 Kinase und ist notwendig für die maximale Kinase Aktivität (Celenza und Carlson, 1989; Woods et al., 1994). Die beiden Proteine interagieren aber nur in Abwesenheit von Glukose. Die drei verschiedenen $\beta$ Untereinheiten spielen eine wichtige Rolle in der Erkennung der zu phosphorylierenden Substrate und der Lokalisierung des Kinase-Komplexes (Vincent et al., 2001; Warden et al., 2001). Sie besitzen eine C-terminale ASC (Association with Snf1 Complex)Domäne, welche eine Snf1 unabhängige Interaktion mit Snf4 erlaubt (Jiang und Carlson, 1997). Diese Domäne könnte auch für die Interaktion der Kinase mit dem Zielprotein verantwortlich sein (Vincent und Carlson, 1999). Die $\beta$-Untereinheit besitzt außerdem eine sogenannte KIS-Region (Kinase Interacting Sequence), welche die Interaktion von $\beta$-Untereinheit und Snf4 erlaubt. Sie überlappt mit einer weiteren konservierten Sequenz, der GBD (Glykogen-Bindedomäne), deren Funktion noch nicht bekannt ist (Hudson et al., 2003).

Homologe $\beta$ - und $\gamma$-Untereinheiten mit möglicherweise ähnlichen Funktionen existieren auch in Arabidopsis (Li et al., 2009). Zusätzlich haben sich in Pflanzen die Untereinheiten AKIN $\beta 3$ und AKIN $\beta \gamma$ entwickelt. AKIN $\beta 3$-Typ Proteinen fehlt die gesamte GBD sowie die N-terminale Region. Dennoch können diese Proteine eine Dreifachmutante der $\beta$-Untereinheiten in Hefe komplementieren, was zeigt, dass die grundlegende Funktion konserviert ist (Gissot et al., 2004). AKIN $\beta \gamma$ Untereinheiten könnten durch eine Fusion eines $\gamma$-Typ Proteins mit einer KIS-verwandten Sequenz entstanden sein (Lumbreras et al., 2001). Im Gegensatz zu AKIN $\gamma$ kann AKIN $\gamma \beta$ die snf4 Mutante in Hefe komplementieren (Bouly et al., 1999).

Die Funktion der Proteine SnRK1/Snf1/AMPK ist stark konserviert. Alle drei sind zentrale Regulatoren des Kohlenstoffmetabolismus in ihrem jeweiligen System und werden für die Aufrechterhaltung des Energiegleichgewichts benötigt (zur Übersicht: Halford und Hey, 2009; Polge und Thomas, 2007).

Der Snf1 Komplex in Hefe wird durch Glukoseverarmung aktiviert. Unter diesen Bedingungen phosphoryliert Snf1 transkriptionelle Aktivatoren wie Cat8, Sip4 und Repressoren wie Mig1, die zu einer Umprogrammierung des Metabolismus führen, und so das Energiegleichgewicht aufrecht erhalten (zur Übersicht: Polge und Thomas, 2007; Halford und Hey, 2009; Schüller, 2003). Auch die Aktivität der RNA-Polymerase II 
(Kuchin et al., 2000) und die Chromatin Struktur (Shirra et al., 2005; Lo et al., 2005; Lo et al., 2001; Liu et al., 2005) wird durch Snf1 modifiziert. Dies führt zu einer Snf1 abhängigen Expression von bis zu einem Viertel der 2160 Hefe-Gene (De Risi et al., 1997), viele davon aus dem Kohlenhydratmetabolismus.

Erst vor kurzem wurden auch die beiden SnRK1 Kinasen KIN10 und KIN11 aus Arabidopsis als zentrale Regulatoren eines Netzwerkes aus Transkriptionsfaktoren beschrieben, welches die Genexpression unter Energiemangelbedingungen beeinflusst (Baena-Gonzalez et al., 2007; Baena-Gonzalez und Sheen, 2008). Die Expression von Genen der Protein- und Aminosäurebiosynthese wird reprimiert, Gene die zur weiteren Kohlenstoffassimilation beitragen, oder für den Abbau von alternativen Kohlenstoffquellen sorgen, werden dagegen aktiviert (Baena-Gonzalez et al., 2007; Abb. 2.3).

SnRK1 Kinasen kontrollieren den pflanzlichen Metabolismus aber nicht nur als Regulatoren eines Netzwerkes von Transkriptionsfaktoren, sondern phosphorylieren auch direkt wichtige Enzyme des Kohlenstoff- und Stickstoffhaushalts. So werden 3HYDROXY-3-METHYLGLUTARYL-CoA-REDUKTASE (HMG-CoAR), NITRATREDUKTASE (NR) und SACCHAROSE PHOSPHAT SYNTHASE (SPS) in vitro durch SnRK1 phosphoryliert und inaktiviert wodurch anabole Prozesse wie die Saccharose und Isoprenoid Biosynthese sowie die Stickstoffassimilation gehemmt werden (Abb. 2.3; Hardie et al., 1998; Sugden et al., 1999a; Sugden et al., 1999b; Polge und Thomas, 2007).

Schon kleinste Schwankungen im Kohlenstoffhaushalt reichen aus, um die KIN10 und KIN11 abhängige Genexpression zu modulieren (Usadel et al., 2008). Zucker inhibieren dabei die SnRK1 Aktivität (Toroser et al., 2000). Um auch auf kleinste Änderungen im Energiestatus der Pflanze reagieren zu können, sollte die Aktivität der Kinasen regulierbar sein. Dies kann z.B. durch eine Phosphorylierung der SnRK1 geschehen. Ein konserviertes Threonin der SnRK1 kann in Arabidopsis durch die zwei Protein Kinasen SnAK1 und SnAK2 (SnRK1-ACTIVATING KINASE) phosphoryliert werden. Diese beiden Protein Kinasen können auch einen Hefe-Stamm komplementieren, der keinerlei Kinase Aktivität oberhalb von Snf1 mehr zeigt (Hey et al., 2007). Auch andere Proteine, wie die Phosphatase PTPKIS1 (Fordham-Skelton et al., 2002) aus Arabidopsis, können mit SnRK1 interagieren. 


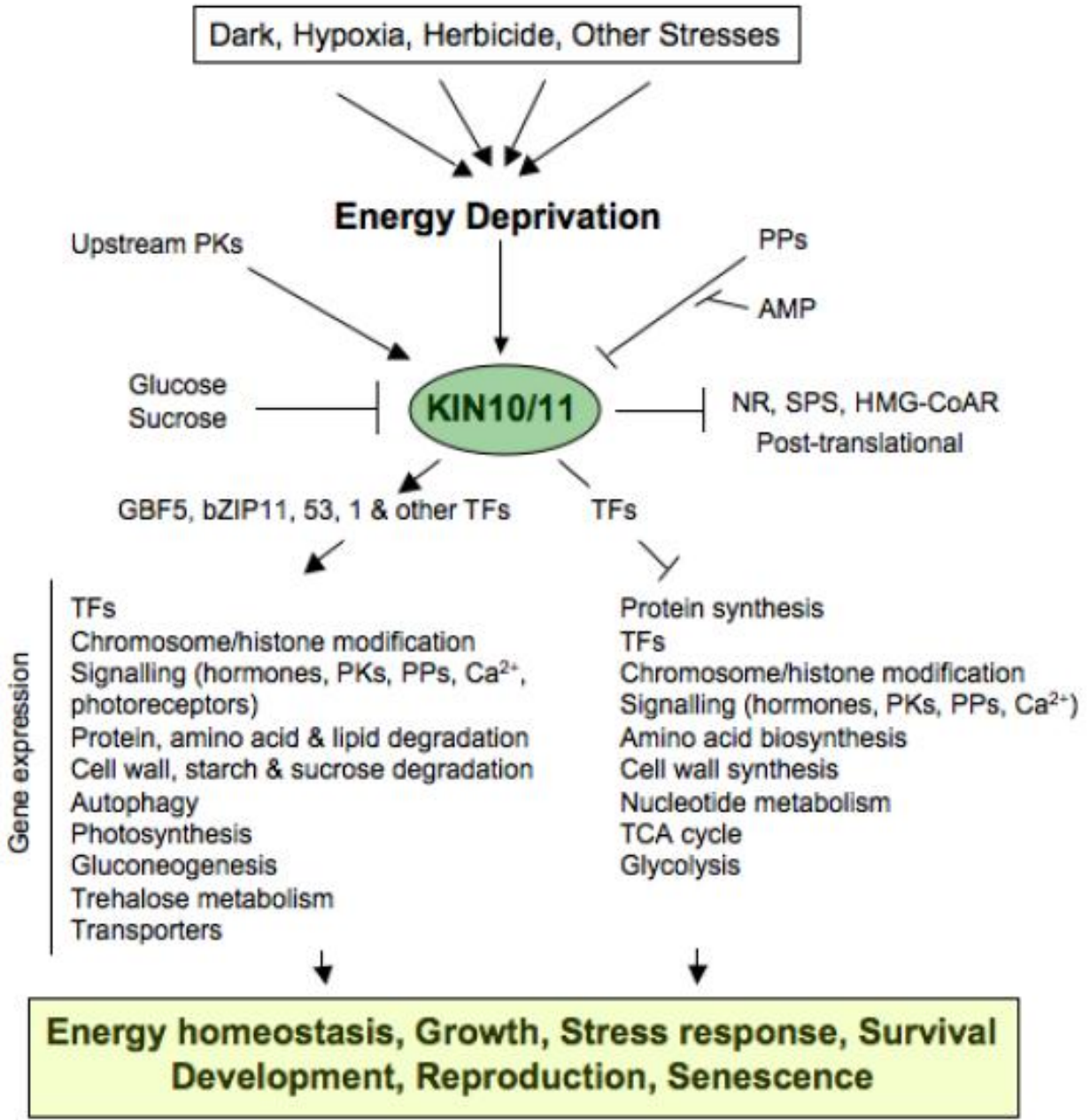

Abb. 2.3: Eine Übersicht über die Rolle der Protein Kinasen KIN10 und KIN11 in der Energieverarmung (Baena-Gonzales et al., 2007)

Dunkelheit und andere Stressbedingungen führen zu einem Energiemangel, der die beiden Kinasen KIN10 und KIN11 aktiviert. Auch eine Reihe anderer Komponenten wie Protein Kinasen (PK) und Phosphatasen (PP) sowie Zucker tragen zur Regulation der beiden Kinasen bei. Diese aktivieren ihrerseits eine Reihe von Transkriptionsfaktoren (TF), die zur Anpassung der Genexpression an diese Bedingungen führen, und phosphorylieren auch direkt wichtige Enzyme des Kohlenstoff- und Stickstoffhaushaltes (NR, SPS, HMG-CoAR), die so inaktiviert werden.

Zumindest ein Teil der durch KIN10 und KIN11 veränderten Genexpression unter Energiemangelbedingungen wird über eine Gruppe von Transkriptionsfaktoren (TF), die zur Gruppe der bZIP (basische Leucinzipper) Transkriptionsfaktoren zählen, vermittelt (Abb. 2.3; Baena-Gonzalez et al., 2007; Hanson et al., 2008). 


\subsection{Pflanzliche bZIP Transkriptionsfaktoren}

bZIP Transkriptionsfaktoren wurden in allen bisher untersuchten eukaryotischen Organismen gefunden. In Pflanzen regulieren sie viele Prozesse wie z.B. die Photomorphogenese und die Entwicklung von Blüten und Samen (Jacoby et al., 2002). Auch an einer Vielzahl von biotischen und abiotischen Stressantworten sowie an der im letzten Kapitel beschriebenen Aufrechterhaltung des Energiegleichgewichts unter Energiemangelbedingungen sind sie beteiligt (Weltmeier et al., 2006; Kaminaka et al., 2006; Pontier et al., 2001; Baena-Gonzales et al., 2007).

Im Genom von Arabidopsis thaliana wurden von Jakoby et al. (2002) 75 putative bZIPProteine identifiziert und mit AtbZIP1 bis AtbZIP75 benannt. Anhand von Sequenzhomologien der basischen DNA-Bindedomänen und zusätzlicher konservierter Motive wurden diese 75 Proteine mit Hilfe des MEME Analyse-Programms (http://meme.sdsc.edu/meme/website/meme.html) in insgesamt 10 Gruppen unterteilt (Abb. 2.5). Allgemein werden bZIP Faktoren durch ihre basische DNA-Bindedomäne und einen benachbarten Leucinzipper definiert (Abb. 2.4).

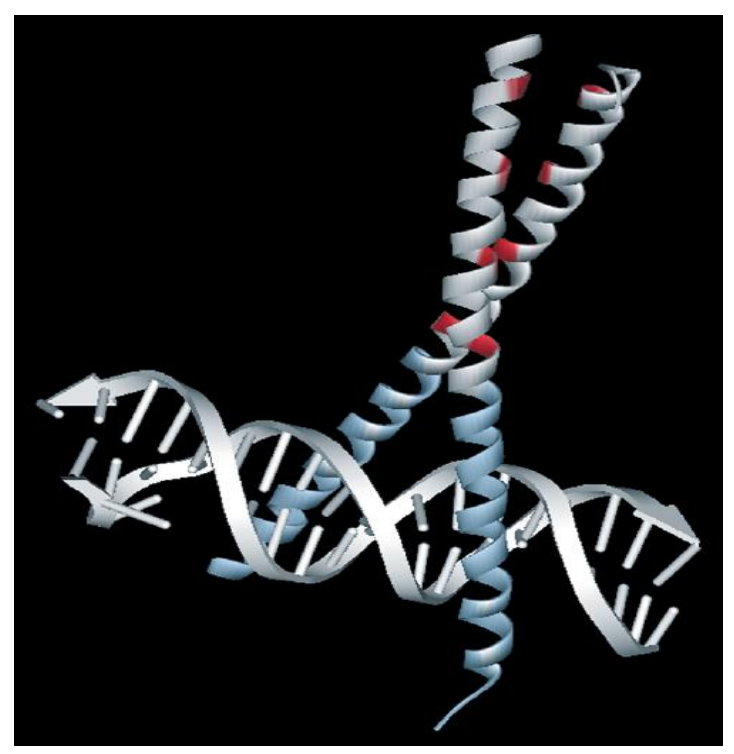

Abb. 2.4: Dreidimensionale Struktur der an die DNA gebundenen bZIP-Domäne des Transkriptionsfaktors GCN4 aus Hefe (Jakoby et al., 2002)

Über die Leucinzipper-Domäne (hydrophobe Aminosäuren in rot dargestellt) wird die Dimerisierung zweier bZIP-TF vermittelt. Die $\alpha$-Helices bilden dabei eine doppelt gewundene Struktur. Die Bindung an die DNA erfolgt über die basische DNA-Bindedomäne. 
AtbZIFno. Gene code Published nameGenBank Acc

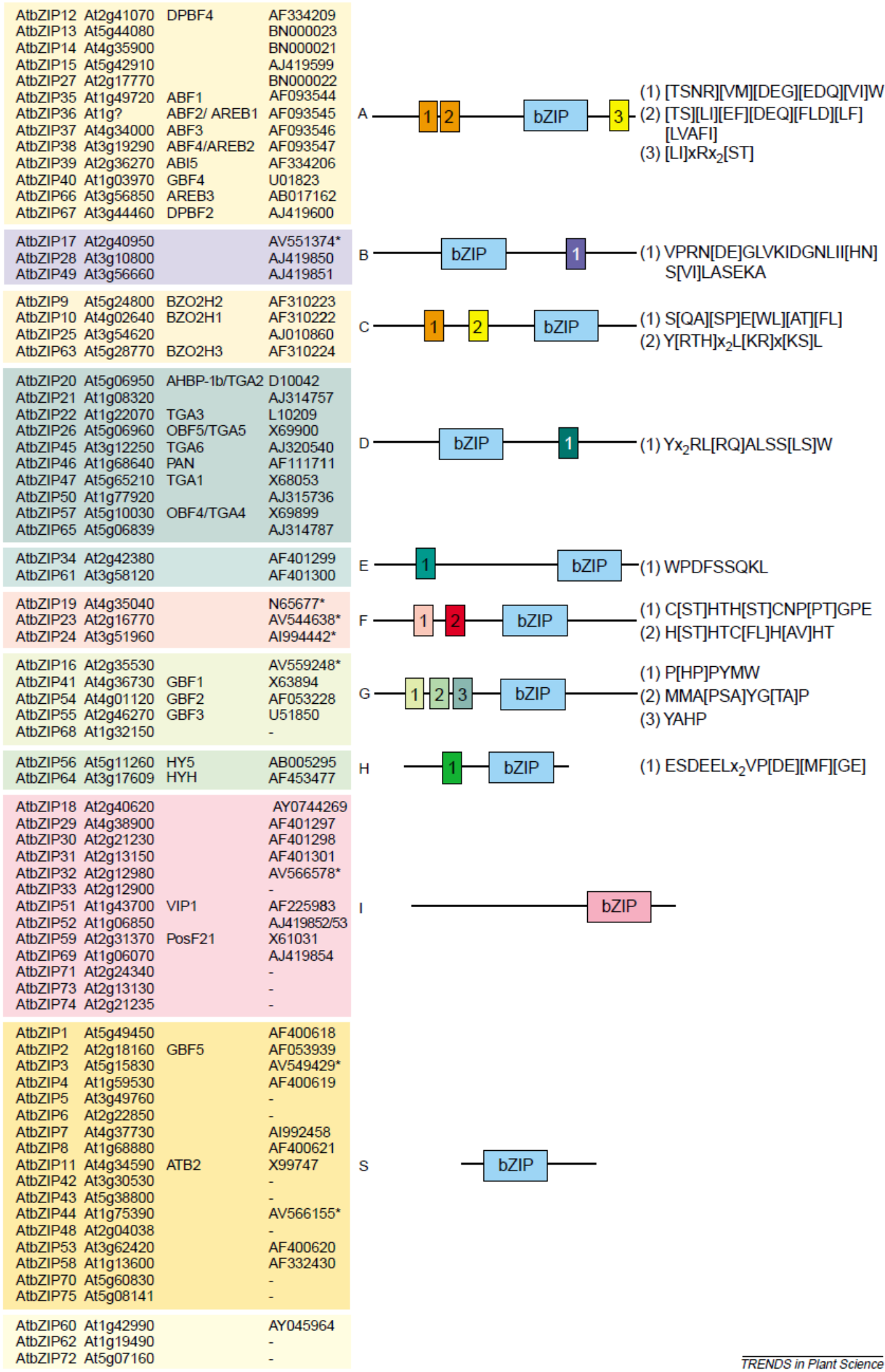


Dieser enthält in heptameren Wiederholungen Leucin oder eine andere hydrophobe Aminosäure wie Phenylalanin, Isoleucin, Valin oder Methionin. Durch die $\alpha$-helikale Struktur des Proteins bilden diese hydrophoben Aminosäuren auf einer Seite einen hydrophoben Bereich, der als Kontaktfläche zu anderen bZIP Proteinen dient und durch hydrophobe Wechselwirkung eine Homo- oder Heterodimerisierung zwischen ihnen ermöglicht (Landschulz et al., 1988; O'Shea et al., 1989; Vinson et al., 2002).

Da die hydrophobe Aminosäuren leicht zueinander versetzt sind, winden sich die beiden Alpha-Helices zu einer linksgängigen Super-Helix (engl. Coiled-Coil; Baxevanis und Vinson, 1993; Lupas, 1996). An der DNA-Binderegion endet die Verwindung und bildet eine Gabel. Die Superhelixarme stehen etwas auseinander, sodass die hier häufig anzutreffenden positiv geladenen Aminosäuren Arginin und Lysin an das negativ geladene Phosphat-Rückgrat der DNA binden. Das Dimer richtet sich dabei so aus, dass zu beiden Seiten der DNA jeweils eine Helix mit der basischen Domäne in die große Furche reicht. Die Bindung an die DNA erfolgt fast immer als Dimer (Landschultz et al, 1988), kann bei einigen bZIP Proteinen aber auch als Monomer erfolgen (Metallo und Schepartz, 1997).

Die Bindung der bZIP Transkriptionsfaktoren erfolgt meist an regulatorische cisElemente mit einer ACGT-Konsensussequenz (Schindler et al., 1992; Siberil et al., 2001). Einige bZIP-Faktoren erkennen aber auch von diesem Motiv abweichende Sequenzen wie z. B. das ACTCAT Kernmotiv aus dem Promotor der PROLINDEHYDROGENASE (ProDH; Satoh et al., 2004; de Pater et al., 1994). Für eine effiziente DNA-Bindung sind zusätzlich die flankierenden Sequenzen des Kernmotivs von Bedeutung (Foster et al., 1994; Izawa et al., 1993). Meist wird dabei eine palindromische Sequenz wie z. B. die A-Box (TACGTA), die C-Box (GACGTC) oder die G-Box (CACGTG) als Bindemotiv der bZIP Transkriptionsfaktoren bevorzugt (Izawa et al., 1993). Es gibt jedoch auch Beispiele für die Bindung an nicht palindromische Motive (Choi et al., 2000; Fukazawa et al., 2000).

Für die Spezifität der DNA-Bindung ist nicht nur die basische DNA-Binde-Domäne des Transkriptionsfaktors entscheidend, auch ein kurzer Bereich von circa fünf Aminosäuren zwischen basischer Domäne und Leucin-Zipper kann eine DNABindespezifität vermitteln (Niu und Guiltinan, 1994). Die Affinität zu verschiedenen cis-Elementen sowie die Aktivität, Stabilität und Lokalisation der 
Transkriptionsfaktoren kann auch abhängig sein von zusätzlichen posttranslationalen Modifikationen der bZIP Faktoren. Die Fähigkeit mit sich selbst oder mit verschiedenen anderen bZIPs zu dimerisieren ist dabei nur eine Möglichkeit der Regulation. Eine andere Möglichkeit ist die Interaktion mit anderen Proteinen wie z.B. die der TGA (TGACG MOTIF-BINDING) Faktoren der Gruppe D mit NPR1 (NONEXPRESSER OF PR GENES 1), oder auch eine Phosphorylierung der bZIPs, wie sie z.B. bei den Gruppe A Faktoren TRAB1 und OREB1 (ABA-RESPONSIVE ELEMENT BINDING FACTORS) aus Reis durch eine SnRK2 Kinase zu beobachten ist (zur Übersicht: Schütze et al., 2008). Auch die Gruppe A bZIP Transkriptionsfaktoren aus Arabidopsis, zu denen ABI5 (ABA INSENSITIVE5) zählt, ändern während der ABA Antwort ihren Phosphorylierungsstatus (Chae et al., 2007; Kagaya et al., 2002; Kobayashi et al., 2005).

Es wird postuliert, dass ein Teil der durch die beiden SnRK Kinasen KIN10 und KIN11 veränderten Genexpression unter Energiemangelbedingungen durch die Gruppe S1 der bZIP Transkriptionsfaktoren vermittelt wird (Baena-Gonzalez et al., 2007; Hanson et al., 2008). Ob diese allerdings direkt durch die Kinasen phosphoryliert werden ist bisher nicht bekannt. In der Studie von Baena-Gonzalez et al., (2007) wurden transiente Assays in Protoplasten durchgeführt, in denen verschiedene Mitglieder der bZIP Transkriptionsfaktoren mit einem ProASN1:LUC-Reporterkonstrukt co-transformiert wurden. Dies führte vor allem bei Mitgliedern der Gruppe S1 wie AtbZIP2, AtbZIP11 und AtbZIP53, zu einem deutlicher Anstieg der Luciferase (LUC)-Aktivität. Die zusätzliche Expression von KIN10 zeigt einen synergistischen Effekt und führte zu einer verstärkten Aktivität des ProASN1:LUC Konstrukts, nicht nur bei AtbZIP2, 11 und 53, sondern auch bei AtbZIP1 und dem Gruppe C Faktor AtbZIP63 (BaenaGonzalez et al., 2007). Die Überexpression der Gruppe S1 AtbZIP Transkriptionsfaktoren verstärkt also zumindest im artifiziellen Protoplastensystem die KIN10/KIN11 vermittelte Expression der ASN1, die den zentralen Schritt der Biosynthese von Asparagin katalysiert. Für AtbZIP11 konnte in einer anderen Studie ebenfalls gezeigt werden, dass es die Transkription der ASN1 aktiviert (Hanson et al., 2008). Die Kinasen KIN10 und KIN11 aktivieren also möglicherweise unter Energiemangel verschiedene Gruppe S1 und C bZIP Transkriptionsfaktoren, die dann 
$\mathrm{zu}$ einer veränderten Genexpression und damit zur Anpassung des pflanzlichen Metabolismus an Energiemangel beitragen.

\subsection{Die Bedeutung der Gruppe S1 und C AtbZIP Transkriptions- faktoren für die Anpassung an Energiemangelbedingungen}

Die Gruppe S (small) ist die größte Gruppe der bZIP Transkriptionsfaktoren in Arabidopsis thaliana. Sie umfasst 17 kleine Transkriptionsfaktoren mit einer Masse von 15 bis $20 \mathrm{kDa}$, die hauptsächlich aus einer zentralen basischen DNA-Bindedomäne und einem langen Leucinzipper mit acht heptameren Wiederholungen bestehen (Jakoby et al., 2002). Daneben gibt es nur noch kurze N- und C-terminale Bereiche. Introns sind in den Genen dieser Gruppe nicht zu finden.

Die Mitglieder der Gruppe S werden in drei Untergruppen unterteilt. Die Gruppe S1 besteht aus den fünf Transkriptionsfaktoren AtbZIP1, 2, 11, 44 und 53. Sie verfügen alle über einen ungewöhnlich langen 5'-untranslatierten Bereich (5'-UTR) mit offenen Leserahmen (uORFs), die eine posttranskriptionale Repression der fünf AtbZIP Transkriptionsfaktoren durch Saccharose vermitteln (Rook et al., 1998a; Wiese et al., 2004, Weltmeier et al., 2009). Dieser Mechanismus wird auch als SIRT (Sucrose induced repression of translation) Mechanismus bezeichnet. Er konnte gezeigt werden, indem ein etwa 500 bp großer Bereich um die uORFs des 5'UTR mit einem GUS-Gen fusioniert und unter Kontrolle eines konstitutiven UBQ10 Promotors expremiert wurde. Behandlung mit Saccharose führte dabei zu einer stark reduzierten GUS-Aktivität im Vergleich zur Kontrolle (Weltmeier et al., 2009). Die restlichen AtbZIP Transkriptionsfaktoren der Gruppe S besitzen diese uORFs nicht. Auch bezüglich ihrer Funktion in der Pflanze ist bisher wenig bekannt. Aufgrund von Sequenzhomologien werden sie in die Untergruppen S2 und S3 eingeteilt.

Im Gegensatz zur Gruppe S der AtbZIP Transkriptionsfaktoren besteht die Gruppe C nur aus den vier Proteinen AtbZIP9, 10, 25 und 63. Sie teilen sich mit der Gruppe S das Merkmal des langen Leucinzippers mit acht heptamere Wiederholungen, haben mit 30 bis $40 \mathrm{kDa}$ aber eine etwas höhere Masse (Jakoby et al., 2002). Auf genomischer Ebene 
zeigen sie im Gegensatz zur Gruppe $\mathrm{S}$ eine konservierte Intron-Exon-Struktur (Heinekamp et al., 2002).

Von den Transkriptionsfaktoren der Gruppen S1 und C ist bekannt, dass sie spezifisch Heterodimere formen. Dies konnte bereits für homologe Proteine aus Petersilie (Petroselinum crispum; Rugner et al., 2001) und Tabak (Nicotiana tabacum; Strathmann et al., 2001) gezeigt werden. In Hefe wurde auch für die Arabidopsis bZIP Transkriptionsfaktoren der Gruppe S1 eine starke Protein-Protein Interaktion mit den Faktoren der Gruppe C gefunden (Ehlert et al., 2006), die mit Hilfe von ProtoplastenTwo-Hybrid- (P2H; Ehlert et al., 2006; Abb. 2.6) und BIFC- (Bimolecular Fluorescence) Analysen (Weltmeier et al., 2006; Kang et al., 2010) in Arabidopsis bestätigt wurde. Innerhalb der einzelnen Gruppen fanden sich dagegen nur schwache Interaktionen.

Weitere Analysen in Protoplasten zeigten, dass das Aktivierungspotenzial der Gruppe S1 und C bZIP Faktoren relativ gering ist, wenn sie allein expremiert werden. Nur AtbZIP2, 11 und 44 zeigen auch ohne Dimerisierungspartner eine starke Aktivierung.

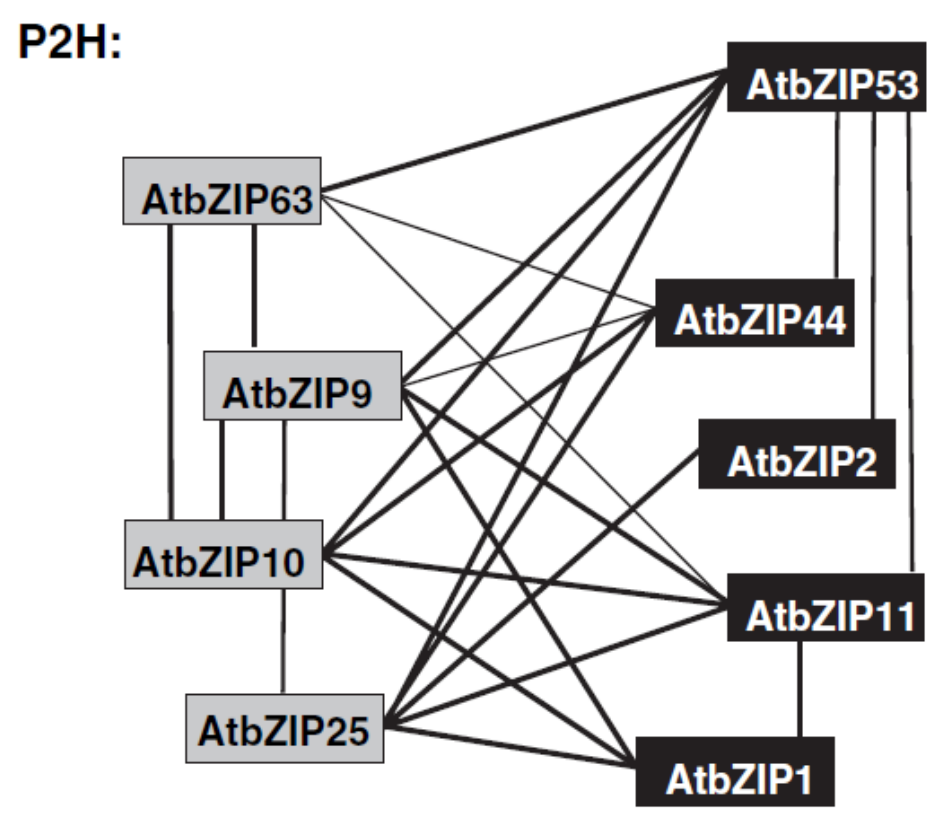

Abb. 2.6: Heterodimerisierung der Gruppe C und S1 AtbZIP Transkriptionsfaktoren in ArabidopsisProtoplasten-Assays

Schwache und starke Interaktionen werden durch dünne bzw. dicke Linien dargestellt (nach Ehlert et al., 2006). 
Co-expremiert man zwei der bZIPs, die in der Lage sind Heterodimere zu formen, erhöht sich ihr Aktivierungspotenzial um ein Vielfaches. So können Heterodimere von AtbZIP53 mit AtbZIP10 oder mit AtbZIP25 z.B. an das ACTCAT-Element des ProDH Promotors binden und dieses sehr viel stärker aktivieren, als es einzelne der bZIP Faktoren tun würden (Weltmeier et al., 2006). Dieser sogenannte HIT-Mechanismus (Heterodimer Induced Transactivation) wurde auch für die Aktivierung von Samenspeicherproteinen beschrieben (Alonso et al., 2009). Eine mögliche Erklärung ist, dass beide bZIP Proteine notwendig sind, um das Epitop einer Aktivierungsdomäne zu bilden. Eine andere mögliche Erklärung ist, dass durch die Heterodimerisierung eine Interaktionsfläche gebildet wird, welche die Rekrutierung eines Koaktivators ermöglicht (Noble et al., 2006).

Durch die Kombination verschiedener Transkriptionsfaktoren der Gruppen S1 und C können, abhängig von der Verfügbarkeit der einzelnen Proteine in verschiedenen Geweben und Umweltbedingungen, Dimere mit unterschiedlichstem DNABindungsverhalten und Aktivierungseigenschaften entstehen, die eine Integration der Umweltsignale und damit eine gezielte Anpassung der Genexpression ermöglichen. Durch zusätzliche posttranskriptionale und posttranslationale Modifikationen der bZIPs, wie z.B. der Zuckerrepression der Gruppe S1, Interaktion mit anderen Proteinen oder mögliche Phosphorylierungen kann die Stabilität, Lokalisation und Aktivität der einzelnen bZIP Transkriptionsfaktoren weiter beeinflusst, und eine gezielte Anpassung an unterschiedliche Stressbedingungen erreicht werden (Naar et al., 2001).

Unter Energiemangelbedingungen wäre die Phosphorylierung der bZIPs durch die Kinasen KIN10 und KIN11 eine Möglichkeit ihre Aktivität posttranslational zu beeinflussen. Ob eine direkte Interaktion zwischen ihnen und den bZIP Faktoren besteht ist bisher allerdings noch unklar. Auch welche bZIP Transkriptionsfaktoren unter diesen Bedingungen tatsächlich eine Rolle für die Anpassung der Genexpression spielen ist noch nicht vollständig geklärt. Zwar finden Baena-Gonzales et al. (2007), dass Mitglieder der Gruppe S1 in der Lage sind im artifiziellen Protoplastensystem die KIN10 vermittelte Aktivität eines ProASN1:LUC Konstrukts zu verstärken, ob genau diese Faktoren aber auch in der Pflanze eine Bedeutungen für die Anpassung des Metabolismus haben, ist bisher nicht bekannt. So zeigten bereits vor dieser Veröffentlichung Versuche in unserem Labor, dass nicht alle Gruppe S1 Faktoren auch 
durch Energiemangelbedingungen aktiviert werden. Dafür finden sich in Northern Analysen auch bZIP Transkriptionsfaktoren der Gruppe C, die während der Dunkelheit verstärkt expremiert werden (Weltmeier, 2005; Dietrich, 2006). Die Induktion von Genen des Primärmetabolismus in Transkriptomanalysen verschiedener bZIP Überexpressionspflanzen der Gruppen S1 und C im Vergleich zum Wildtyp (Weltmeier, 2005) deutet aber bereits auf eine Beteiligung der Gruppe S1 und C bZIPs an der Reprogrammierung des pflanzlichen Metabolismus unter Energiemangelbedingungen hin.

\subsection{Fragestellung und Zielsetzung der Arbeit}

Energiemangelbedingungen wie sie während langanhaltender Dunkelheit auftreten, führen zu einer massiven Änderung der Genexpression in der Pflanze. Dies wird durch Transkriptionsfaktoren vermittelt. Die Expression einiger bZIP Faktoren wird durch Energiemangel unter diesen Bedingungen aktiviert (Weltmeier, 2005). Ein erstes Ziel dieser Arbeit besteht daher darin, herauszufinden ob und wenn ja welche der 75 bZIP Transkriptionsfaktoren in Arabidopsis eine Rolle in der Anpassung an Energiemangelbedingungen spielen.

Erste Hinweise auf eine Beteiligung der Gruppe S1 bZIP Transkriptionsfaktoren an der KIN10/KIN11 vermittelten dunkelinduzierten Aktivierung der ASN1 lieferten BaenaGonzales et al. (2007). Bei den gezeigten Daten handelt es sich allerdings ausschließlich um transiente Überexpressionen der bZIP Faktoren und Kinasen im artifiziellen Protoplastensystem. Studien in transgenen Pflanzen sowie ein „loss-of-function“ Ansatz fehlen dagegen völlig. Dies soll im Verlauf dieser Arbeit nachgeholt werden. Überexpressionspflanzen der relevanten bZIP Transkriptionsfaktoren sollen dabei sowohl phänotypisch als auch auf eine veränderte Genexpression und daraus resultierende veränderte Metabolitgehalte hin untersucht werden. Transkriptomanalysen dieser Pflanzen (Weltmeier, 2005) zeigten, dass sich putative Zielgene sowohl im Aminosäurestoffwechsel (ASN1 und ProDH) als auch in anderen Bereichen des Primärmetabolismus wie z.B. dem Lipid- oder Kohlenhydratstoffwechsel finden. 
Die Expression der entsprechenden Gene sowie die Metabolitgehalte sollen auch in Mutanten der relevanten bZIP Transkriptionsfaktoren getestet werden. Da bekannt ist, dass gerade die bZIP Transkriptionsfaktoren der Gruppe S1 und C heterodimerisieren und teilweise redundante Funktionen ausüben, ist es sinnvoll dabei auch multiple Mutanten zu generieren und in die Untersuchungen mit einzubeziehen.

Parallel zu den Versuchen in transgenen Pflanzen soll auch das in Baena-Gonzales et al. (2007) gezeigte Protoplastensystem für Versuche der Energieverarmung in unserem Labor etabliert werden. Dieses ermöglicht eine schnelle Analyse vieler verschiedener Transkriptionsfaktoren und kann für die Promotoranalyse der putativen Zielgene ebenso verwendet werden wie für die Identifizierung möglicher Signalkomponenten die zur Aktivierung der bZIP Faktoren beitragen.

In diesem Zusammenhang werden vor allem die beiden Kinasen KIN10 und KIN11 näher untersucht werden. $\mathrm{Ob}$ eine direkte Interaktion zwischen ihnen und den bZIP Faktoren besteht, ist bisher noch weitestgehend unklar. Phosphorylierungsmutanten der bZIPs in denen mögliche Phosphorylierungsmotive der SnRK1-Kinasen KIN10 und KIN11 ausgetauscht werden, könnten hier erste Hinweise auf eine Bedeutung der Kinasen für die Aktivierung der bZIP Transkriptionsfaktoren liefern. 


\section{$3 \quad$ Material}

\subsection{Organismen}

\subsubsection{Bakterien}

\begin{tabular}{|c|c|c|}
\hline Stamm & Eigenschaften & Referenz \\
\hline $\begin{array}{l}\text { Escherichia coli } \\
\text { DH5 } \alpha\end{array}$ & $\begin{array}{l}\text { recA1 relA1 thi-1 } \Delta \text { lacU } 16980 \\
\left(\text { lacZ } \Delta \text { M15) hsdR17 }\left(\mathrm{r}_{k} \mathrm{~m}_{k}+\right)\right.\end{array}$ & Hanahan, 1983 \\
\hline $\begin{array}{l}\text { Escherichia coli } \\
\text { DB3.1 }\end{array}$ & $\begin{array}{l}\text { F- gyrA462 endA1 D( sr1- recA) } \\
\left.\text { mcrB mrr hsdS20( } \mathrm{r}^{-}, \mathrm{m}_{\mathrm{B}^{-}}\right) \text {supE44 } \\
\text { ara-14 galK2 lacY1 proA2 } \\
\text { rpsL20 }\left(\mathrm{Sm}^{\mathrm{r}}\right) \text { xyl-5 } \lambda \text { - leu mtl-1 }\end{array}$ & $\begin{array}{l}\text { Bernard et al., } \\
1993\end{array}$ \\
\hline $\begin{array}{l}\text { Agrobacterium tumefaciens } \\
\text { GV3101 }\end{array}$ & pMP90RK, Rif ${ }^{\mathrm{r}}, \mathrm{Gm}^{\mathrm{r}}$ & $\begin{array}{l}\text { Koncz und Schell, } \\
1986\end{array}$ \\
\hline
\end{tabular}

\subsubsection{Pflanzen}

\begin{tabular}{|l|l|l|}
\hline Kultivar & Eigenschaften & Herkunft \\
\hline Columbia Col-0 N1092 & Wildtyp & Kultursorte \\
\hline atbzip1 (SALK_059343) & AtbZIP1 Knock Out & NASC Stock Center \\
\hline atbzip53 (SALK_069883) & AtbZIP53 Knock Down & NASC Stock Center \\
\hline atbzip9 (SALK_093416) & AtbZIP9 Knock Out & NASC Stock Center \\
\hline atbzip63 (SALK_066531) & AtbZIP63 Knock Down & NASC Stock Center \\
\hline bzip10 (SALK_106031) & AtbZIP10 Knock Out & NASC Stock Center \\
\hline bzip25 (SALK_119931) & AtbZIP25 Knock Out & NASC Stock Center \\
\hline atbzip1 atbzip53 & s.o. & Dietrich, 2006 \\
\hline atbzip1 atbzip53 atbzip10 atbzip25 & s.o. & Diese Arbeit \\
\hline atbzip1 atbzip53 atbzip9 atbzip63 & s.o. & Diese Arbeit \\
\hline Prom35S:AtbZIP1 L.5 & $\begin{array}{l}\text { AtbZIP1 Überexpression } \\
\text { ohne HA-Tag }\end{array}$ & Weltmeier,2005 \\
\hline Prom35S:AtbZIP1 L.C.2 & $\begin{array}{l}\text { AtbZIP1 Überexpression mit } \\
\text { HA-Tag, pAlligator2, } \\
\text { samenspezifisches GFP }\end{array}$ & Weltmeier,2005 \\
\hline Prom35S:AtbZIP53 10.1 & $\begin{array}{l}\text { AtbZIP53 Überexpression } \\
\text { ohne HA-Tag }\end{array}$ & Weltmeier,2005 \\
\hline $\begin{array}{l}\text { Prom35S:AtbZIP53 (verschieden } \\
\text { Linien, verlieren alle ihre gute } \\
\text { Überexpression in der nächsten } \\
\text { Generation) }\end{array}$ & $\begin{array}{l}\text { AtbZIP53 Überexpression } \\
\text { mit HA-Tag, pAlligator2, } \\
\text { samenspezifisches GFP }\end{array}$ & Weltmeier,2005 \\
\hline
\end{tabular}




\subsection{Nukleinsäuren}

\subsubsection{Plasmide}

\begin{tabular}{|c|c|c|}
\hline Plasmid & Eigenschaften & Referenz \\
\hline pHBT GUS NCO & $\begin{array}{l}\text { pUC ori, 35S Promotor, NcoI } \\
\text { Schnittstelle, Amp }\end{array}$ & $\begin{array}{l}\text { Corinna Thurow } \\
\text { (unveröffentlicht) }\end{array}$ \\
\hline pROK219-NAN & $\begin{array}{l}\text { pUC19-Derivat, 35S-Minimal- } \\
\text { promotor, NAN-Reportergen, nos, } \\
\text { Amp }^{\mathrm{R}}\end{array}$ & $\begin{array}{l}\text { Kirby und Kavanagh } \\
\text { (2002) }\end{array}$ \\
\hline pHBTL- $\Delta$ GFP & $\begin{array}{l}\text { pHBTL-sGFP-Derivat (Sheen, } \\
\text { unveröffentlicht); Entfernung des } \\
s G F P \text { Gens durch NcoI/NotI- } \\
\text { Verdau, Klenow ,fill in“ und } \\
\text { Religation, } \\
\text { pUC ori, Amp }{ }^{\mathrm{R}} \text {, 35S-Promotor }\end{array}$ & $\begin{array}{l}\text { Heinekamp et al. } \\
(2002)\end{array}$ \\
\hline pBT10 & $\begin{array}{l}\text { pUC ori, 35S-Minimalpromotor, } \\
G U S \text { - Reportergen, Amp }\end{array}$ & $\begin{array}{l}\text { Sprenger-Haussels } \\
\text { und Weisshaar, } 2000\end{array}$ \\
\hline pBT10-Asn1-GUS & $\begin{array}{l}\text { pUC ori, 1630bp des Asn1 } \\
\text { Promotors, GUS-Reportergen, Amp }\end{array}$ & Diese Arbeit \\
\hline pBT10-ProDH-GUS & $\begin{array}{l}\text { pUC ori, 1500bp des ProDH } \\
\text { Promotors, GUS-Reportergen, Amp }\end{array}$ & Diese Arbeit \\
\hline pBKS-LEA76-GUS & $\begin{array}{l}\text { LEA76-Promotor, BamHI/NcoI } \\
\text { Schnittstelle, GUS-Reporter, Amp }\end{array}$ & $\begin{array}{l}\text { Jesus Vincente- } \\
\text { Carbajosa } \\
\text { (unveröffentlicht) }\end{array}$ \\
\hline pDON201 & $\begin{array}{l}\text { pUC ori, } \mathrm{Km}^{\mathrm{R}}, \text { attL1, } \mathrm{Cm}^{\mathrm{R}}, \mathrm{ccdB}, \\
\text { attL2 }\end{array}$ & Invitrogen, 2001 \\
\hline $\begin{array}{l}\text { pDON201-bZIPx }(x=1,2,11, \\
44,53,9,10,25,63)\end{array}$ & $\begin{array}{l}\text { pUC ori, } \mathrm{Km}^{\mathrm{R}} \text {, attL1, bZIPx, ccdB, } \\
\text { attL2 }\end{array}$ & $\begin{array}{l}\text { Weltmeier, Smeekens, } \\
\text { Vincente-Carbajosa } \\
\text { (unveröffentlicht) }\end{array}$ \\
\hline pHBTL- HAGW & $\begin{array}{l}\text { 3x HA- tag, pUC ori, } \mathrm{Amp}^{\mathrm{R}}, \text { attR1, } \\
\operatorname{ccdB}, \mathrm{Cm}^{\mathrm{R}}, \text { attR2 }\end{array}$ & Ehlert, 2004 \\
\hline $\begin{array}{l}\text { pHBTL-HA-bZIPx } \quad(x=1,2, \\
11,44,53,9,10,25,63)\end{array}$ & $\begin{array}{l}\text { 3x HA- tag, pUC ori, } \mathrm{Amp}^{\mathrm{R}} \text {, attR1, } \\
\text { bZIPx, attR2 }\end{array}$ & Ehlert, 2004 \\
\hline pHBTL-HA-Kin10 & $\begin{array}{l}\text { 3x HA- tag, pUC ori, } \mathrm{Amp}^{\mathrm{R}} \text {, attR1, } \\
\text { KIN10, attR2 }\end{array}$ & $\begin{array}{l}\text { Laura Hartmann } \\
\text { (unveröffentlicht) }\end{array}$ \\
\hline pHBTL-HA-Kin 11 & $\begin{array}{l}\text { 3x HA- tag, pUC ori, Amp }{ }^{\mathrm{R}} \text {, attR1, } \\
\text { KIN11, attR2 }\end{array}$ & $\begin{array}{l}\text { Laura Hartmann } \\
\text { (unveröffentlicht) }\end{array}$ \\
\hline pHBTL-HA-bZIP1 Ala & $\begin{array}{l}\text { 3x HA- tag, pUC ori, } \mathrm{Amp}^{\mathrm{R}} \text {, attR1, } \\
\text { bZIP1Ala, attR2 }\end{array}$ & Lendner, 2009 \\
\hline pHBTL-HA-bZIP53 Ala & $\begin{array}{l}\text { 3x HA- tag, pUC ori, } \mathrm{Amp}^{\mathrm{R}} \text {, attR1, } \\
\text { bZIP53Ala, attR2 }\end{array}$ & Lendner, 2009 \\
\hline $\begin{array}{l}\text { pHBTL-HA-bZIP63 Ala (Ser } \\
19,59,261,300)\end{array}$ & $\begin{array}{l}\text { 3x HA- tag, pUC ori, Amp }{ }^{\mathrm{R}} \text {, attR1, } \\
\text { bZIP63Ala, attR2 }\end{array}$ & $\begin{array}{l}\text { Christina Chaban } \\
\text { (unveröffentlicht) }\end{array}$ \\
\hline pGEM- T & Kloniervektor, lacZ $\alpha, \mathrm{amp}^{\mathrm{R}}$ & Promega, 1999 \\
\hline pGEM-T-Lox 1 & $\begin{array}{l}\text { pGEM-T-Vektor mit Lox1 } \\
\text { Fragment (ca. } 1100 \mathrm{~kb} \text { ) }\end{array}$ & Gärtner, 2003 \\
\hline pGEM-T-Lox 2 & $\begin{array}{l}\text { pGEM-T-Vektor mit Lox2 } \\
\text { Fragment (ca. 1200kb) }\end{array}$ & Gärtner, 2003 \\
\hline
\end{tabular}




\subsubsection{Oligonukleotide}

\begin{tabular}{|c|c|c|c|}
\hline Oligonukleotid & Sequenz $(5 \rightarrow 3)$ & Zweck & $\begin{array}{l}\text { Nr. in } \\
\text { Oligo- } \\
\text { bank }\end{array}$ \\
\hline SAG103 for & AGCTCGAGTGCTGGGATG & $\mathrm{qPCR}$ & 890 \\
\hline SAG103 rev & CGGATTCACAGATCCTTCCT & qPCR & 891 \\
\hline $\mathrm{CAB}$ for & TCAATCTTTTGAATTCGAGTGAGA & qPCR & 1050 \\
\hline CAB rev & TCCACCACAAACACAAACCTAC & qPCR & 1051 \\
\hline YLS3 for & GACATCACTAAGTGCCCTGCT & qPCR & 1048 \\
\hline YLS3 rev & ACTGTTTCGTTCAGACCTTTAGC & qPCR & 1049 \\
\hline Asn1 for & TTCTTGAGCTTTCTCGCAGAT & qPCR & 882 \\
\hline Asn1 rev & CCGTTCTGATATAAGCCACTCC & qPCR & 883 \\
\hline ProDH for & CGCCAGTCCACGACACAATTCA & qPCR & 664 \\
\hline ProDH rev & CGAATCAGCGTTATGTGTTGCG & qPCR & 665 \\
\hline Asparaginase for & TTCCGATCAGCATTTACGC & qPCR & 904 \\
\hline $\begin{array}{l}\text { Asparaginase } \\
\text { rev }\end{array}$ & CAATGTCCTTTCCCGTCAAC & qPCR & 905 \\
\hline BCAT2 & QuantiTect $^{\circledR}$ Primer QT00854875 & qPCR & - \\
\hline GDH2 qPCR for & ACAGATCCAGATGCTGATGAGA & qPCR & 884 \\
\hline GDH2 qPCR rev & TCTGCACCCACTCGAAGTAA & qPCR & 885 \\
\hline Real HA for & TTCTTTGGGTGGTTCTAGCC & qPCR & 186 \\
\hline Real HA rev & ATAGTCCGGGACGTCATAGG & qPCR & 187 \\
\hline bZIP1 for & TCAGCGTTAAACTCGTCGTAGCAA & qPCR & 589 \\
\hline bZIP1 rev & AACGCGGGTCTTAGATCGGAGAAG & qPCR & 590 \\
\hline bZIP53 for & TGGGGTCGTTGCAAATGCAAACAA & qPCR & 591 \\
\hline bZIP53 rev & CCGTGGCGTACCTCGGATCATTAT & qPCR & 592 \\
\hline bZIP9 for & CGAAAAGGTCCAGCCGGAAACAAT & qPCR & 649 \\
\hline bZIP9 rev & TCGACCTCATGAACCGGGATTACA & qPCR & 650 \\
\hline bZIP10 for & TTTTTCGGCCATGCTGAATCGTTC & qPCR & 647 \\
\hline bZIP10 rev & TTACTCCAAGCGCCAACCCGTA & qPCR & 648 \\
\hline bZIP25 for & AGGAGGATGCTCTCAAACCGAGAA & qPCR & 645 \\
\hline bZIP25 rev & CGGCTCTTAATTGGCCTACCTGTG & qPCR & 646 \\
\hline bZIP63.2 for & AAAAGGGGAACTTTCATCAAACCTCAGG & qPCR & 1025 \\
\hline bZIP63.2 rev & CTGAGGCATATTGTGGAACATTGGGT & qPCR & 1027 \\
\hline Ubq5 for & GACGCTTCATCTCGTCC & qPCR & 874 \\
\hline Ubq5 rev & GTAAACGTAGGTGAGTCCA & qPCR & 875 \\
\hline $\begin{array}{l}\text { B-Amylase } 1 \\
\text { (Bam1) for }\end{array}$ & GTTTCATCAGTGTGGTGGCAACG & qPCR & 1028 \\
\hline Bam1 rev & ACCCACTGAGGCAGAGGAATAGTG & qPCR & 1029 \\
\hline Bam2 for & GATTCCTCAAACGAATGCATGGTG & qPCR & 1030 \\
\hline Bam2 rev & TCTTGTGTCCCTGGAGCCAAAC & qPCR & 1031 \\
\hline Bam3 for & AAAGCACGGTCTCAAACTCCAG & qPCR & 1032 \\
\hline Bam3 rev & ACTGCAAGAGTCTCCTACGTTTCC & qPCR & 1033 \\
\hline Bam4 for & CGGGAACAGCCGAATCTTTAGC & qPCR & 1034 \\
\hline Bam4 rev & TGGACACCCAGAAGCATCAATTCC & qPCR & 1035 \\
\hline Bam5 for & CCCGTTTACGTTATGCTTCC & qPCR & 970 \\
\hline Bam5 rev & ACGTTTAAGCTGCGTTTCAAG & qPCR & 971 \\
\hline Bam6 for & ACGAATGCATGCGAACCAAGAG & qPCR & 1036 \\
\hline
\end{tabular}




\begin{tabular}{|c|c|c|c|}
\hline Bam6 rev & GATCTTTCCAACGGAAGCAGCTC & qPCR & 1037 \\
\hline Bam7 for & TCCAGGTGTTGGAGAGTTTCAGTG & qPCR & 1038 \\
\hline Bam7 rev & TGTAGGAGCCGGTGTTATCTGG & qPCR & 1039 \\
\hline Bam8 for & TGGGCAACACAATCACGGGAATC & qPCR & 1040 \\
\hline Bam8 rev & AGGATATTTCAGCTCACCGTCTGG & qPCR & 1041 \\
\hline Bam9 for & CCGGTATCGGTGAGTTTCAGTG & qPCR & 1042 \\
\hline Bam9 rev & GTGAATCCTCGTGACTTTGCTTCC & qPCR & 1043 \\
\hline Kin10 qPCR for & TGAGTTTCAAGAGACCATGGAA & qPCR & 1044 \\
\hline Kin10 qPCR rev & CGATGGCTAACAGGTGAAGC & qPCR & 1045 \\
\hline Kin11 qPCR for & GCTCGTAACTTTTTCCAGCAGA & qPCR & 1046 \\
\hline Kin11 qPCR rev & TTCAGGTCTCTATGGACAACCA & qPCR & 1047 \\
\hline Lox1 qPCR for & ACCCTGCTAAACACTACACTACAGAC & qPCR & 912 \\
\hline Lox1 qPCR rev & GTCGCTGGTGTTTCATGTGGAAG & qPCR & 913 \\
\hline Asn1Promfor & CACGTGTACGGCTCTAAAGCA & ChIP & 387 \\
\hline Asn1Prom rev & GACCAGCTGTTTCCACGTGTT & ChIP & 388 \\
\hline ProDHProm for & CAAGTCCAGGTCCACATGTTG & ChIP & 381 \\
\hline ProDHProm rev & CAAGGCCCTGACCATAGGA & ChIP & 382 \\
\hline Actin7 for & CGTTTCGCTTTCCTTAGTGTTAGCT & ChIP & 618 \\
\hline Actin7 rev & AGCGAACGGATCTAGAGACTCACCTTG & ChIP & 619 \\
\hline Asn1 for & GTGGAATACTTGCCGTGTTAG & Northern & 343 \\
\hline Asn1 rev & CGAAATGCTCACAGTCATCG & Northern & 344 \\
\hline GDH2 for & GCTGCAACAAACAGAAACTTCC & Northern & 595 \\
\hline GDH2 rev & CCCTGAATCGATTTCCCGT & Northern & 596 \\
\hline ProDH for & ATGGCAACCCGTCTTCTCCG & Northern & 374 \\
\hline ProDH rev & TGGTCGGTCTTTGTCAGCAT & Northern & 375 \\
\hline PepCK for & ATGGCGGGAAACGGAAACGA & Northern & 752 \\
\hline PepCK rev & TCGTACAACTCGGCGGGAGA & Northern & 753 \\
\hline Asp3 for & CTTCCTCTTCTTCTTCCGATCG & Northern & 597 \\
\hline Asp3 rev & GTCGCTGGATCGTAGTATCGG & Northern & 598 \\
\hline GlnS for & CATCAACCTTAACCTCTCAGACTCCA & Northern & 624 \\
\hline GlnS rev & CTCGTAACCGCCTTCTTCCCTCATTG & Northern & 625 \\
\hline LBa1 & TGGTTCACGTAGTGGGCCATCG & $\begin{array}{l}\text { T-DNA } \\
\text { Insertion }\end{array}$ & 385 \\
\hline $\begin{array}{l}\text { Short bZIP1 } \\
\text { cDNA \#1 }\end{array}$ & ATGGCAAACGCAGAGAAGACAAGTTCA & $\begin{array}{l}\text { T-DNA } \\
\text { Insertion }\end{array}$ & 291 \\
\hline $\begin{array}{l}\text { Short bZIP1 } \\
\text { cDNA \#2 }\end{array}$ & TCATGTCTTAAAGGACGCCATTGGTTG & $\begin{array}{l}\text { T-DNA } \\
\text { Insertion }\end{array}$ & 292 \\
\hline bZIP10 for & TCTTCTCCATTGACGATTTCTC & $\begin{array}{l}\text { T-DNA } \\
\text { Insertion }\end{array}$ & 454 \\
\hline bZIP10 LP & TTGAGATGAGTTCTGGTGGTTA & $\begin{array}{l}\text { T-DNA } \\
\text { Insertion }\end{array}$ & 452 \\
\hline bZIP10 RP & GTCCACTTGATCTTCCGAGAA & $\begin{array}{l}\text { T-DNA } \\
\text { Insertion }\end{array}$ & 453 \\
\hline bZIP53 pGUS f & CTGCAGCTTAGGACAGCTCATCACCA & $\begin{array}{l}\text { T-DNA } \\
\text { Insertion }\end{array}$ & 205 \\
\hline bZIP53 pGUS r & GTCGACCTCGTTGACTTTTTGACTTC & $\begin{array}{l}\text { T-DNA } \\
\text { Insertion }\end{array}$ & 206 \\
\hline bZIP9 cDNA \#1 & ATGGATAATCACACAGCTAAAGA & $\begin{array}{l}\text { T-DNA } \\
\text { Insertion }\end{array}$ & 267 \\
\hline bZIP9 cDNA \#2 & AGAGTCATGGCCAGATGTCTGAG & $\begin{array}{l}\text { T-DNA } \\
\text { Insertion }\end{array}$ & 268 \\
\hline
\end{tabular}




\begin{tabular}{|c|c|c|c|}
\hline pbZIP63 f & CGTAGCTCGGTCATTGTGTCGG & $\begin{array}{l}\text { T-DNA } \\
\text { Insertion }\end{array}$ & 367 \\
\hline cbZIP63 rev2 & TCTCCGTCGTCTGCAGCGGC & $\begin{array}{l}\text { T-DNA } \\
\text { Insertion }\end{array}$ & 368 \\
\hline bZIP25 & ATGCACATCGTCTTCTCTGTCG & $\begin{array}{l}\text { T-DNA } \\
\text { Insertion }\end{array}$ & 670 \\
\hline bZIP25 & TGCCTTGTTTCTTTCTTCTCAG & $\begin{array}{l}\text { T-DNA } \\
\text { Insertion }\end{array}$ & 671 \\
\hline Oligo dT & ТTTTTTTTTTTTTTTTTTTT & $\begin{array}{l}\text { cDNA- } \\
\text { Synthese }\end{array}$ & - \\
\hline $\begin{array}{l}\text { Random } \\
\text { nonamer }\end{array}$ & NNNNNNNNN & $\begin{array}{l}\text { cDNA- } \\
\text { Synthese }\end{array}$ & - \\
\hline Uni24 & ACGACGTTGTAAAACGACGGCCAG & Sequenzierung & - \\
\hline Rev & TTCACACAGGAAACAGCTATGAC & Sequenzierung & - \\
\hline pE-HA LB & CGTCCCGGACTATGCAGATA & Sequenzierung & 842 \\
\hline pE-HA RB & CGTATGGATAACCCCCATCA & Sequenzierung & 843 \\
\hline SeqL1 & TCGCGTTAACGCTAGCATGGATCTC & Sequenzierung & 201 \\
\hline SeqL2 & GTAACATCAGAGATTTTGAGACAC & Sequenzierung & 202 \\
\hline pBT10 for & CAGCGAGTCAGTGAGCGAGGAA & Sequenzierung & 910 \\
\hline $\begin{array}{l}\text { Asn1PromXbaI } \\
\text { for }\end{array}$ & $\begin{array}{l}\text { AAAAAAAAAATCTAGACGTCTCAAGTAT } \\
\text { TGATAAAATAATAAT }\end{array}$ & $\begin{array}{l}\text { Klonierung } \\
\text { pBT10GUS } \\
\text { (1630bp) }\end{array}$ & - \\
\hline $\begin{array}{l}\text { Asn1Prom NcoI } \\
\text { rev }\end{array}$ & $\begin{array}{l}\text { AAAAAAAAAACCATGGGTTTTTTTTTTG } \\
\text { AAGAAAGTGAAAAAGATCACGAAGAA }\end{array}$ & $\begin{array}{l}\text { Klonierung } \\
\text { pBT10GUS } \\
\text { (1630bp) }\end{array}$ & - \\
\hline $\begin{array}{l}\text { ProDHProm PstI } \\
\text { for }\end{array}$ & $\begin{array}{l}\text { AAAAAAAAAACTGCAGACTTGCACTAA } \\
\text { AGACTAAACAGT }\end{array}$ & $\begin{array}{l}\text { Klonierung } \\
\text { pBT10GUS } \\
(1500 \mathrm{bp})\end{array}$ & - \\
\hline $\begin{array}{l}\text { ProDHProm } \\
\text { NcoI rev }\end{array}$ & $\begin{array}{l}\text { AAAAAAAAAACCATGGAAAATTCAAAG } \\
\text { ATTTTGTTTTTGAAAACGAAAACAAA }\end{array}$ & $\begin{array}{l}\text { Klonierung } \\
\text { pBT10GUS } \\
(1500 \mathrm{bp})\end{array}$ & - \\
\hline
\end{tabular}

Die Schmelztemperatur der Primer wird mit Hilfe folgender Formel (Bolton und McCarthy, 1962) berechnet:

$$
\operatorname{Tm}\left[{ }^{\circ} \mathrm{C}\right]=69,3+0,41 \times(\% \mathrm{GC})-650 / \mathrm{n}
$$

$\mathrm{Tm}=$ Schmelztemperatur,

$\mathrm{n}=$ Anzahl der Basen 


\subsubsection{Hybridisierungssonden}

\begin{tabular}{|l|l|l|}
\hline Sonde & Eigenschaften & Referenz \\
\hline ProDH & $\begin{array}{l}\text { Fragment aus PCR mit Primern ProDH for und } \\
\text { ProDH rev auf cDNA }\end{array}$ & Weltmeier, 2005 \\
\hline Asn1 & $\begin{array}{l}\text { Fragment aus PCR mit Primern Asn1 for und } \\
\text { Asn1 rev auf cDNA }\end{array}$ & Weltmeier, 2005 \\
\hline GDH2 & $\begin{array}{l}\text { Fragment aus PCR mit Primern GDH2 for und } \\
\text { GDH2 rev auf cDNA }\end{array}$ & Diese Arbeit \\
\hline GlnS & $\begin{array}{l}\text { Fragment aus PCR mit Primern GlnS for und } \\
\text { GlnS rev auf cDNA }\end{array}$ & Diese Arbeit \\
\hline Asp3 & $\begin{array}{l}\text { Fragment aus PCR mit Primern Asp3 for und } \\
\text { Asp3 rev auf cDNA }\end{array}$ & Diese Arbeit \\
\hline PepCK & $\begin{array}{l}\text { Fragment aus PCR mit Primern PepCK for und } \\
\text { PepCK rev auf cDNA }\end{array}$ & Weltmeier, 2005 \\
\hline Lox1 & $\begin{array}{l}\text { Fragment (ca. 1100 bp) aus PCR mit Primern } \\
\text { uni und rev auf Plasmid pGEM-T-Lox1 }\end{array}$ & Diese Arbeit \\
\hline Lox2 & $\begin{array}{l}\text { Fragment (ca. 1200 bp) aus PCR mit Primern } \\
\text { uni und rev auf Plasmid pGEM-T-Lox2 }\end{array}$ & Diese Arbeit \\
\hline
\end{tabular}

\subsection{Größenstandards}

\subsubsection{DNA-Größenstandard}

Als Fragmentlängenstandard wurden bei der Gelelektrophorese der Generuler DNA Ladder Mix von Fermentas als Größenmarker verwendet.

\subsubsection{Protein-Größenstandard}

Als Größenstandard bei SDS-Gelen wurde der Page Ruler-Prestained Protein Ladder von Fermentas verwendet.

\subsection{Antikörper}

\begin{tabular}{|l|l|l|l|l|}
\hline Bezeichnung & Spezifität & Eigenschaft & Verdünnung & Hersteller \\
\hline$\alpha$ HA IgG & $\begin{array}{l}\text { HA-Epitoptag } \\
\text { (YPYDVPDYA) }\end{array}$ & $\begin{array}{l}\text { polyklonal aus } \\
\text { Kaninchen }\end{array}$ & $1: 666$ & Santa Cruz \\
\hline $\begin{array}{l}\alpha \mathrm{HA} \mathrm{IgG} \\
\text { ChIPgrade }\end{array}$ & $\begin{array}{l}\text { HA-Epitoptag } \\
\text { (YPYDVPDYA) }\end{array}$ & $\begin{array}{l}\text { polyklonal aus } \\
\text { Kaninchen }\end{array}$ & $\begin{array}{l}1 \mu \mathrm{g} \text { für } 8-10 \mu \mathrm{g} \\
\text { Chromatin }\end{array}$ & abcam \\
\hline anti rabbit IgG & $\begin{array}{l}\text { Kaninchen- } \\
\text { Immunoglobulin }\end{array}$ & $\begin{array}{l}\text { polyklonal, } \\
\text { Peroxidase } \\
\text { gekoppelt }\end{array}$ & $1: 10000$ & Amersham \\
\hline
\end{tabular}




\subsection{Nährmedien und Zusätze}

\subsubsection{Bakterienmedien}

\begin{tabular}{|l|l|}
\hline DYT & $16 \mathrm{~g} / \mathrm{l}$ Trypton \\
& $10 \mathrm{~g} / \mathrm{l} \mathrm{Hefeextrakt}$ \\
& $5 \mathrm{~g} / \mathrm{l} \mathrm{NaCl}$ \\
& autoklavieren \\
\hline LB (Sambrook et al., 1989) & $10 \mathrm{~g} / \mathrm{l}$ Trypton \\
& $5 \mathrm{~g} / \mathrm{l} \mathrm{Hefeextrakt}$ \\
& $5 \mathrm{~g} / \mathrm{l} \mathrm{NaCl}$ \\
& $\mathrm{pH} 7,4$ mit $\mathrm{NaOH}$ \\
& autoklavieren \\
\hline YEB (Sambrook et al., 1989) & $10 \mathrm{~g} / \mathrm{l}$ Beefextrakt \\
& $2 \mathrm{~g} / 1$ Hefeextrakt \\
& $5 \mathrm{~g} / 1$ Pepton \\
& $5 \mathrm{~g} / 1$ Saccharose \\
& $2 \mathrm{mM}$ MgSO \\
& pH 7,0 mit NaOH einstellen \\
& autoklavieren \\
\hline
\end{tabular}

\subsubsection{Pflanzenmedien}

\begin{tabular}{|c|c|}
\hline 2 MS-Medium (Murashige und Skoog, 1962) & $\begin{array}{l}\text { 4,4 g/l Murashige und Skoog Medium } \\
20 \mathrm{~g} / \mathrm{l} \mathrm{Saccharose} \\
\text { pH 5,7 mit KOH } \\
\text { autoklavieren }\end{array}$ \\
\hline
\end{tabular}

\subsubsection{Medienzusätze}

\subsubsection{Antibiotika}

\begin{tabular}{|l|l|l|}
\hline Substanz & Endkonzentration & Stammlösung \\
\hline Ampicilin (Amp) & $100 \mu \mathrm{g} / \mathrm{ml}$ & $100 \mathrm{mg} / \mathrm{ml} \mathrm{in} \mathrm{H}_{2} \mathrm{O}$ \\
\hline Kanamycin (Kan) & $50 \mu \mathrm{g} / \mathrm{ml}$ & $50 \mathrm{mg} / \mathrm{ml} \mathrm{in} \mathrm{H}_{2} \mathrm{O}$ \\
\hline Gentamicin (Gent) & $10-25 \mu \mathrm{g} / \mathrm{ml}$ & $25 \mathrm{mg} / \mathrm{ml} \mathrm{in} \mathrm{H}_{2} \mathrm{O}$ \\
\hline Carbenicillin (Carb) & $100 \mu \mathrm{g} / \mathrm{ml}$ & $100 \mathrm{mg} / \mathrm{ml} \mathrm{in} \mathrm{H}_{2} \mathrm{O}$ \\
\hline Rifampicin (Rif) & $100 \mu \mathrm{g} / \mathrm{ml}$ & $20 \mathrm{mg} / \mathrm{ml}$ in Methanol \\
\hline
\end{tabular}




\subsubsection{Agar}

Festmedien für Bakterien enthalten zusätzlich $12 \mathrm{~g} / 1$ Kobe-Agar, Festmedien für Pflanzen 7,4 g/l Select-Agar. Der Agar wird nach dem Einstellen des pH-Wertes aber vor dem Autoklavieren zugegeben.

\subsubsection{Sonstige Zusätze}

\begin{tabular}{|l|l|l|}
\hline Substanz & Endkonzentration & Stammlösung \\
\hline X-Gal & $50 \mu$ pro Platte & $20 \mathrm{mg} / \mathrm{ml}$ in DMF \\
\hline IPTG & $50 \mu \mathrm{l}$ pro Platte & $100 \mathrm{mM} \mathrm{in} \mathrm{H}_{2} \mathrm{O}$ \\
\hline
\end{tabular}

\subsection{Lösungen und Puffer}

Soweit nicht anders beschrieben werden alle Lösungen und Puffer mit ultra pure $\mathrm{H}_{2} \mathrm{O}$ angesetzt und anschließend autoklaviert (15min, $\left.2 \mathrm{bar}, 121^{\circ} \mathrm{C}\right)$.

$35 \%$ Percoll (ChIP):

Church (Northern):

Crosslinkingpuffer (ChIP):

CTAB (DNA-Extraktion):

DEPC- $\mathrm{H}_{2} \mathrm{O}$ (RNA-Extraktion):

Elution Buffer (ChIP):
$35 \%$ Percoll

0,5 M Hexylenglycol

$50 \mathrm{mM}$ PIPES-KOH pH7,2

$10 \mathrm{mM} \mathrm{MgCl}_{2}$

$1 \%$ Triton X-100

Mit $\mathrm{H}_{2} \mathrm{O}$ auf $50 \mathrm{ml}$ auffüllen

Vor Gebrauch $5 \mathrm{mM} \beta$-Mercaptoethanol dazu

$7 \%$ SDS

$250 \mathrm{mM}$ NaPhosphat-Puffer (pH 7,0)

$1 \mathrm{mM}$ EDTA

50mM Kaliumphosphatpuffer $\mathrm{pH}$ 5,8

$1 \%$ Formaldehyd

$2 \% \mathrm{CTAB}$

$100 \mathrm{mM}$ Tris $\mathrm{HCl} \mathrm{pH} 8,0$

20 mM EDTA pH8,0

$1,4 \mathrm{M} \mathrm{NaCl}$

Vor Gebrauch $2 \%$ ß-Mercaptoethanol dazu

$11 \mathrm{H}_{2} \mathrm{O}$

$1 \mathrm{ml}$ DEPC

kräftig schütteln, ü.N. unterm Abzug ausdampfen

autoklavieren

0,1 M Glycin pH 2,5 mit $\mathrm{HCl}$

$500 \mathrm{mM} \mathrm{NaCl}$

$0,05 \%$ Tween 20 
Enzymlösung (Protos):

Estradiol (Estradiol-Induktion):

Extraktionspuffer (ChIP):

Fällungspuffer (RNA-Extraktion):

Färbelösung für Proteine

auf Nitrocellulosemembranen:

Glycinlösung (ChIP):

Gradientenpuffer (ChIP):

GUS-Extraktionspuffer mit B-Mercaptoethanol (Protos):

GUS-Stop-Puffer (Protos):

Harnstoffextraktionspuffer:

Laufpuffer 1x (SDS-PAGE):
$1,25 \%$ Cellulase R-10 $(0,625 \mathrm{~g}$ auf $50 \mathrm{ml})$ $0,3 \%$ Macerozyme R-10 $(0,15 \mathrm{~g}$ auf $50 \mathrm{ml})$

$0,4 \mathrm{M}$ Mannitol (26,6 $\mathrm{ml}$ von $0,75 \mathrm{M}$ auf $50 \mathrm{ml})$

$20 \mathrm{mM} \mathrm{KCl}(2 \mathrm{ml}$ von $0,5 \mathrm{M}$ auf $50 \mathrm{ml})$

$20 \mathrm{mM}$ MES ( $2 \mathrm{ml}$ von $0,5 \mathrm{M}$ auf $50 \mathrm{ml}$ )

$10 \mathrm{mM} \mathrm{CaCl}_{2}(0,5 \mathrm{ml}$ von $1 \mathrm{M}$ auf $50 \mathrm{ml})$ steril filtrieren und bei $4^{\circ} \mathrm{C}$ lagern

$10 \mathrm{mM}$ Estradiol $(0,027 \mathrm{~g} / 10 \mathrm{ml})$ in DMSO

$1 \mathrm{M}$ Hexylenglycol

$50 \mathrm{mM}$ PIPES-KOH pH 7,2

$10 \mathrm{mM} \mathrm{MgCl}_{2}$

Mit $\mathrm{H}_{2} \mathrm{O}$ auf $100 \mathrm{ml}$ auffüllen

Vor Gebrauch 5mM $\beta$-Mercaptoethanol dazu

$1,2 \mathrm{M} \mathrm{NaCl}$

$0,8 \mathrm{M}$ tri-Natrium-Citrat

$0,02 \%$ Ponceau S

$3 \%$ Trichloressigsäure

$50 \mathrm{mM}$ Kaliumphosphatpuffer

0,3 M Glycin

0,5 M Hexylenglycol

$50 \mathrm{mM}$ PIPES-KOH $\mathrm{pH} 7,2$

$10 \mathrm{mM} \mathrm{MgCl}_{2}$

$1 \%$ Triton $\mathrm{X}-100$

Mit $\mathrm{H}_{2} \mathrm{O}$ auf $50 \mathrm{ml}$ auffüllen

Vor Gebrauch $5 \mathrm{mM} \beta$-Mercaptoethanol dazu

$50 \mathrm{mM}$ Na-Phosphatpuffer

$10 \mathrm{mM}$ EDTA

$0,1 \%$ (v/v) Triton X100

$0,1 \%$ (v/v) Sarkosyl

$\mathrm{pH}$ einstellen auf 7,0; 7,2 oder 7,5

$0,05 \%$ (v/v) B-Mercaptoethanol (frisch zugeben)

$200 \mathrm{mM} \mathrm{Na}_{2} \mathrm{CO}_{3}(21,2 \mathrm{~g} / \mathrm{l})$

4M Harnstoff

$16,6 \%$ Glycerin $(100 \%)$

$5 \%$ B-Mercaptoethanol

$5 \%$ SDS

Ein paar Krümel Bromphenolblau

$25 \mathrm{mM}$ Tris

$190 \mathrm{mM}$ Glycin

$0,1 \%(w / v)$ SDS 
Ladepuffer für Agarosegele (OX): $\quad 10 \mathrm{ml} \mathrm{TBE}$

$10 \mathrm{ml} \mathrm{Glycerin}(87 \%)$

$0,2 \%$ Bromphenolblau

$0,2 \%$ Orange $\mathrm{G}$

$0,2 \%$ Xylencyanol

Lugol'sche Lösung

(Stärkenachweis):

MEN-Puffer 10x (RNA-Gel):

MMg (Protos):

MUG-Gebrauchslösung (Protos):

MUN-Gebrauchslösung (Protos):

NAN-Stop-Puffer (Protos):

PEG-Lösung (Protos):

RipaF (ChIP):

RipaF -SDS (ChIP):

RNA-Probenpuffer $(2,5 x)$ :
$2 \mathrm{~g} / \mathrm{l} \mathrm{I}_{2}$

$10 \mathrm{~g} / \mathrm{l} \mathrm{KI}$

$200 \mathrm{mM}$ MOPS

$50 \mathrm{mM}$ Natriumacetat

$10 \mathrm{mM}$ EDTA

pH 7,0 mit $\mathrm{NaOH}$

0,4 M Mannitol (26,6 $\mathrm{ml}$ von $0,75 \mathrm{M}$ auf $50 \mathrm{ml})$

$15 \mathrm{mM} \mathrm{MgCl}_{2}(1,5 \mathrm{ml}$ von $0,5 \mathrm{M}$ auf $50 \mathrm{ml})$

$4 \mathrm{mM}$ MES $(0,4 \mathrm{ml}$ von $0,5 \mathrm{M}$ auf $50 \mathrm{ml})$

steril filtrieren

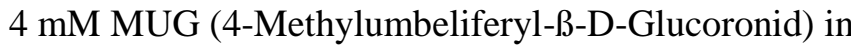
GUS-Extraktionspuffer $\mathrm{pH}$ 7,5 mit $\beta$-Mercaptoethanol

$1 \mathrm{mM}$ MUN (2'-(4-methylumbelliferyl)- $\alpha$-D- $N$-acetylneuraminic acid) in GUS-Extrakitonspuffer $\mathrm{pH}$ 7,0 mit B-Mercaptoethanol

$330 \mathrm{mM} \mathrm{Na} \mathrm{CO}_{3}(35 \mathrm{~g} / \mathrm{l})$

20 g PEG 4000

$14,16 \mathrm{ml} \mathrm{H}_{2} \mathrm{O}$

13,3 ml 0,75M Mannitol

$5 \mathrm{ml} 1 \mathrm{M} \mathrm{CaCl}_{2}$

steril filtrieren

$50 \mathrm{mM}$ Hepes/NaOH pH7,4

$140 \mathrm{mM} \mathrm{NaCl}$

$1 \mathrm{mM}$ EDTA

$1 \%$ Triton X-100

$0,1 \%$ DOC

$0,1 \%$ SDS

$50 \mathrm{mM}$ Hepes/NaOH pH7,4

1 mM EDTA

$1 \%$ Triton X-100

$0,1 \%$ DOC

$20 \%$ MEN

$8 \%$ Glycerin

$56,7 \%$ Formamid

$5 \%$ Formaldehyd

$0,001 \%$ Bromphenolblau

$0,1 \%$ Ethidiumbromid

4 mM EDTA pH 7,5 
Sammelgel (SDS-PAGE):

SonicBuffer-SDS (ChIP):

SonicBuffer 0,25\% SDS (ChIP):

SonicBuffer 0,5\%SDS (ChIP):

Stripp-Lösung (Northern):

SSC 20 x (Northern):

TAE 20 x (Northern):

TBS (Western):

TBST (Western):

Trenngel 12\% (SDS-PAGE):

Transferpuffer (Western):

Trizolpuffer (RNA-Extraktion):
$0,83 \mathrm{ml} 30 \%$ Acrylamid /BIS-Mix (19:1)

$0,63 \mathrm{ml} 1 \mathrm{M}$ Tris/ HCL pH 6,8

$0,05 \mathrm{ml} 10 \%$ SDS

$0,05 \mathrm{ml} 10 \%$ APS

$0,005 \mathrm{ml}$ TEMED

$3,4 \mathrm{ml} \mathrm{H}_{2} \mathrm{O}$

10 mM Tris/HCl pH 7,4

$10 \mathrm{mM}$ Tris/ $\mathrm{HCl} \mathrm{pH} 7,4$

$0,25 \%$ SDS

$10 \mathrm{mM}$ Tris/HCl pH 7,4

$0,5 \%$ SDS

$0,1 \%$ SDS

$2 \mathrm{M} \mathrm{NaCl}$

$0,3 \mathrm{M}$ Natriumcitrat $\mathrm{pH}$ 7,0 mit $\mathrm{HCl}$

$0,8 \mathrm{M}$ Tris

$2,3 \%(\mathrm{v} / \mathrm{v})$ Essigsäure

$20 \mathrm{mM}$ EDTA

$50 \mathrm{mM}$ Tris

$150 \mathrm{mM} \mathrm{NaCl}$

$\mathrm{pH}$ 7,6 mit $\mathrm{HCl}$

TBS

$0,1 \%$ Tween 20

$8 \mathrm{ml} 30 \%$ Acrylamid/ BIS-Mix (19:1)

$5 \mathrm{ml}$ 1,5M Tris/ HCL pH 8,8

$0,2 \mathrm{ml} 10 \%$ SDS

$0,2 \mathrm{ml} 10 \%$ APS

$0,008 \mathrm{ml}$ TEMED

$6,6 \mathrm{ml} \mathrm{H}_{2} \mathrm{O}$

192 mM Glycin

$25 \mathrm{mM}$ Tris

$20 \%(\mathrm{v} / \mathrm{v})$ Methanol

$0,01 \%(w / v)$ SDS

$380 \mathrm{ml} / 1$ Phenol mit 0,1 M Citrat-Puffer gesättigt $0,8 \mathrm{M}$ Guanidiniumthiocyanat

0,4 M Ammoniumthiocyanat

33,4 ml/l Na-Acetat (3 M pH 5,2 mit Essigsäure)

$5 \%$ Glycerin 
W5 (Protos):

WI (Protos):
$154 \mathrm{mM} \mathrm{NaCl}(4,5 \mathrm{~g} / 500 \mathrm{ml})$

$125 \mathrm{mM} \mathrm{CaCl}_{2}\left(2 \mathrm{H}_{2} \mathrm{O}\right)(9,19 \mathrm{~g} / 500 \mathrm{ml})$

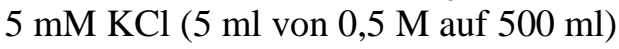

$2 \mathrm{mM}$ MES ( $2 \mathrm{ml}$ von $0,5 \mathrm{M}$ auf $500 \mathrm{ml}$ )

autoklavieren

0,5 M Mannitol (33,3 $\mathrm{ml}$ von $0,75 \mathrm{M}$ auf $50 \mathrm{ml})$

$4 \mathrm{mM}$ MES ( $2 \mathrm{ml}$ von $0,5 \mathrm{M}$ auf $50 \mathrm{ml})$

$20 \mathrm{mM} \mathrm{KCl}(0,4 \mathrm{ml}$ von $0,5 \mathrm{M}$ auf $50 \mathrm{ml})$

steril filtrieren

\subsection{Geräte}

\begin{tabular}{|l|l|l|}
\hline Gerät & Modell & Hersteller \\
\hline Autoklav & 3870 ELV & Tuttnauer \\
\hline Automatische Pipetten & $2,20,200,1000$ & Gilson \\
\hline Bioimager (Phosphoimager) & BAS-1000 & Fuji \\
\hline Digitalkamera & Coolpix & Nikon \\
\hline Digitalkamera & C4742-98 & Hamamatsu \\
\hline Eismaschine & AF-20 & Scotman \\
\hline Gefriertruhe -80 ${ }^{\circ}$ C & C54285 & New Brunswick Scientific \\
\hline Geldokumentationsanlage & & MWG Biotech \\
\hline $\begin{array}{l}\text { Gelelektrophoresekammer } \\
\text { (Agarose) }\end{array}$ & & $\begin{array}{l}\text { Werkstatt der Universität } \\
\text { Göttingen }\end{array}$ \\
\hline Heizblock & & Boekel Scientific \\
\hline Heizrührer & RCT basic & IKA Labortechnik \\
\hline Hybridisierungsofen & Hy-St-1 & Bachhofer \\
\hline Hybridisierungswasserbad & Belly Dancer & Sorvall \\
\hline Inkubationsschrank & & WTC Binder, Memmert \\
\hline Intelli-Mixer & RM-2L & ELMI \\
\hline Klimaschrank & & Percival Scientific \\
\hline Kühlschränke & & Liebherr \\
\hline Kühlzentrifuge & Sorvall RC 5B Plus & DuPont \\
\hline Multi-Well Plate Reader & CytoFluorII, Series4000 & Perspective Biosystems \\
\hline Netzgeräte & E 323 & Benedikt Heinemann \\
\hline Netzgeräte & EC 250-90 EC 105 & Apparatus Corporation \\
\hline PCR-Gerät, MiniCyclerTM & PTC-150 & MJ Research, USA \\
\hline pH-Meter & HI 9321 & Hanna Instruments \\
\hline Photometer & Unikon 720 LC & Kontron \\
\hline Polyacrylamid-Gelkammer & & AGS \\
\hline RealTime PCR & Mini Opticon & BioRad \\
\hline RNA-/ DNA-Calculator & GenQuant II & Pharmacia \\
\hline Scanner & & Epson \\
\hline Schüttler & 3005 & GFL \\
\hline Schwingmühlen & MM 301 & Retsch \\
\hline Semi-Dry-Blot-Apparatur & & Werkstatt der Universität \\
& Bielefeld \\
\hline Sequenziergerät & Microflow & Perkin-Elmer Corporation \\
\hline Sterilbank & & Nunc \\
\hline
\end{tabular}




\begin{tabular}{|l|l|l|}
\hline Szintillationsmessgerät & & Raytest Isootopenmessgeräte \\
\hline Tischzentrifuge & 5414 & Eppendorf \\
\hline Tischzentrifuge, gekühlt & 5403 & Eppendorf \\
\hline Ultrazentrifuge & Centrikon T-1065 & Kontron \\
\hline Rotoren f. Ultrazentrifuge & TFT 30.58; TFT 65.13 & Kontron \\
\hline Ultraschall & Labsonic M & Sartorius \\
\hline UV-Transilluminator & FLX-20 M & Vilber Lourmat \\
\hline Vortex & L46 & Labinco BV, Niederlande \\
\hline Waage, Feinwaage & SPO51, SAC62, & Scaltec Sartorius \\
\hline Wasseraufbereitungsanlage & Option 4, Maxima & ELGA \\
\hline Wasserbäder & 1086 & GFL \\
\hline Zentrifuge, Ausschwingrotor & Universal 16 A & Hettich \\
\hline
\end{tabular}

\subsection{Verbrauchsmittel}

\begin{tabular}{|l|l|}
\hline Produkt & Hersteller \\
\hline Alufolie & Roth \\
\hline Fließpapier & Whatman \\
\hline Gläser & Weck \\
\hline Glasmaterialien & Brand, Schott \\
\hline Haushaltsfolie & Tip \\
\hline Immobilon-P, PVDF-Transfer-Membranen & Millipore \\
\hline $\begin{array}{l}\text { Kunststoff-Einwegmaterial (Spitzen, Pipetten, } \\
\text { Reaktionsgefäße, Spritzen, Petrischalen usw.) }\end{array}$ & Eppendorf, Greiner, Sarstedt \\
\hline Microtiterplatten & Nunc, Roth \\
\hline Nylon-Membran Hybond ${ }^{\text {TM}}-\mathrm{N}$ & Amersham Life Science \\
\hline Parafilm N & American National Can \\
\hline Röntgenfilme & Kodak \\
\hline Stahl-Netz 0,063 mm (für Protoplasten-Trafo) & Pressel \\
\hline
\end{tabular}

\subsection{Chemikalien}

\begin{tabular}{|l|l|}
\hline Produkt & Hersteller \\
\hline Agar (Bacteriological) Kobe I & Roth \\
\hline Agar (für Pflanzen Anzucht) Select Agar & Invitrogen \\
\hline Agarose SeaKem LE & Biozym \\
\hline Ammoniumperoxodisulfat (APS) & Biometra \\
\hline Ampicillin & AGS \\
\hline Bromphenolblau-Natriumsalz & Roth \\
\hline Chloroform & Merck \\
\hline Dimethylsulfoxid (DMSO) & Sigma \\
\hline dNTPs & Roth, MBI Fermentas \\
\hline EDTA 25mM (für DNAseVerdau) & Fermentas \\
\hline EDTA & AppliChem \\
\hline Ethanol absolut & Merck \\
\hline
\end{tabular}




\begin{tabular}{|l|l|}
\hline Ethidiumbromidlösung 1\% & Roth \\
\hline Fluorescin (Fluorescin Calibration Dye) & BioRad \\
\hline Formaldehyd & Roth \\
\hline Formamid & Fluka \\
\hline Glycerin (87 \%) & Roth \\
\hline Harnstoff & Roth \\
\hline IPTG & BioTech Trade \\
\hline Magnesiumchlorid (MgCl ${ }_{2}$ ) & AppliChem \\
\hline Mannitol & Roth \\
\hline Milchpulver & Glücksklee \\
\hline MUG (4-methylumbelliferyl B-D-glucuronide ) & Sigma \\
\hline MUN (2'-(4-methylumbelliferyl)- $\alpha$-D-N-acetyl- & Biosynth \\
\hline neuraminic acid) & \\
\hline Murashige \& Skoog-Medium & Duchefa \\
\hline Natriumhypochlorid & Roth \\
\hline Natriumlaurylsulfat (SDS) & Roth \\
\hline Organische Lösungsmittel (Alkohole etc.) & Merck, Roth \\
\hline Pepton & Roth \\
\hline Percoll & Pharmacia \\
\hline Phenol & AppliChem \\
\hline PIPES & Roth \\
\hline Polyethylenglycol (PEG) 4000 & Fluka \\
\hline Ponceau rot & Sigma \\
\hline Protein A Sepharose beads (für ChIP-IP) & Sigma Aldrich \\
\hline Rifampicin & Duchefa \\
\hline Röntgenfilm Entwickler LX24 & Kodak \\
\hline Röntgenfilm Fixierer AL4 & Kodak \\
\hline Saccharose & Roth \\
\hline Salzsäure & Merck \\
\hline Select Agar & GIBCO \\
\hline Sephadex G-50 & Pharmacia \\
\hline Sodiumdodecylsulfat (SDS) & Roth \\
\hline Silwet L77 & Lehle Seeds \\
\hline Syber Green & früher Cambrex, jetzt Lonza \\
\hline TEMED (N,N,N',N'-Tetramethylethylen-diamidin) & Roth \\
\hline Trishydroxymethylaminomethan (Tris) & Roth \\
\hline Triton X-100 & Roth \\
\hline Tween & Sigma \\
\hline Verschiedene Salze & Roth \\
\hline X-Gal & BioTech Trade \\
\hline B-Mercaptoethanol & Roth \\
\hline & \\
\hline
\end{tabular}

Nicht aufgeführte Standardchemikalien wurden von den Firmen Merck, Roth, Boehringer, Fluka oder Sigma bezogen.

\subsection{Radiochemikalien}

Es wurde $\left[\alpha-{ }^{32} \mathrm{P}\right]-\mathrm{dATP}$ mit der spezifischen Aktivität von $800 \mathrm{Ci} / \mathrm{mmol}$ verwendet. 


\subsection{Enzyme}

\begin{tabular}{|l|l|}
\hline Enzym & Hersteller \\
\hline Advantage-Polymerase-Mix & BD Clontech \\
\hline Bio-Taq-DNA-Polymerase & BioLine \\
\hline Cellulase „Onozuka R-10“ & Serva \\
\hline DNaseI, RNase frei & Fermentas \\
\hline H Minus M-MulV Reverse Transkriptase & Fermentas \\
\hline Immolase-DNA-Polymerase & BioLine \\
\hline Klenow-DNA-Polymerase (exo-) & MBI Fermentas \\
\hline Macerocym R-10 & Sigma \\
\hline Proteinase K & Roth \\
\hline Restriktionsenzyme & MBI Fermentas \\
\hline RNase A (DNase-frei) & Sigma; Qiagen \\
\hline T4 DNA-Ligase & MBI Fermentas \\
\hline Taq DNA Polymerase & Haustaq, eigene Herstellung \\
\hline
\end{tabular}

\subsection{Kits}

\begin{tabular}{|c|c|}
\hline Kit & Hersteller \\
\hline $\begin{array}{l}\text { BigDye }^{\mathrm{TM}} \text { Terminator Cycle Sequencing Ready } \\
\text { Reaction Kit v3.1 }\end{array}$ & Perkin-Elmer \\
\hline Enhanced Chemiluminescence Plus Kit $\left(\mathrm{ECL}^{+}\right)$ & Amersham \\
\hline Megaprime DNA labeling system Kits & Amersham Pharmacia \\
\hline NucleoBond ${ }^{\circledR}$ MaxiKit & Macherey-Nagel \\
\hline Nucleospin ${ }^{\circledR}$ Extract & Macherey Nagel \\
\hline Nuleospin ${ }^{\circledR}$ Plasmid & Macherey Nagel \\
\hline pGEM $^{\circledR}-T$ Vector Systems & Promega \\
\hline StarchAssayKit & BioVision \\
\hline RNeasy ${ }^{\circledR}$ Plant Mini Kit & Quiagen \\
\hline
\end{tabular}




\section{Methoden}

\subsection{Bakterienanzucht, Lagerung und Transformation}

\subsubsection{Anzucht von Escherichia coli}

Die Anzucht von E. coli erfolgt entweder in LB- oder DYT-Flüssigmedium oder auf LB-Platten über Nacht bei $37^{\circ} \mathrm{C}$ mit einem geeigneten Antibiotikum zur Selektion (Sambrook et al., 1989).

\subsubsection{Anzucht von Agrobacterium tumefaciens}

Die Anzucht von Agrobacterium tumefaciens erfolgt entweder auf YEB-Festmedium oder in YEB-Flüssigmedium (Sambrook et al., 1989) im Schüttler bei $30^{\circ} \mathrm{C}$, mit geeigneten Antibiotika zur Selektion.

\subsubsection{Lagerung der Bakterien}

Die Bakterien können auf den Platten bei $4^{\circ} \mathrm{C}$ mittelfristig gelagert werden. Für längere Lagerung müssen Gefrierkulturen angelegt werden.

Anlage einer Gefrierkultur:

- $750 \mu 1$ einer frischen ü. N.-Kultur mit $750 \mu 187 \%$ Glycerin versetzen

- kräftig vortexen

- schockgefrieren in Flüssigstickstoff

- Lagerung bei $-80^{\circ} \mathrm{C}$

\subsubsection{Herstellung kompetenter Escherichia coli}

Für die Herstellung kompetenter Zellen nach einer modifizierten Methode von Inoue et al. (1990) werden Bakterien des E. coli-Stammes DH5a verwendet.

- $0,8 \mathrm{ml}$ einer Übernachtkultur in $40 \mathrm{ml}$ LB-Medium überimpfen

- Anzucht der Kultur bis zum Erreichen einer OD $_{600}$ von 0,5

- Je $10 \mathrm{ml}$ der Kultur in Greiner-Röhrchen überführen

- $5 \mathrm{Min} ., 6000 \mathrm{~g}, 4^{\circ} \mathrm{C}$ zentrifugieren

- Pellet in $5 \mathrm{ml} 50 \mathrm{mM} \mathrm{CaCl}_{2}\left(4^{\circ} \mathrm{C}\right)$ resuspendieren

- 30 Minuten auf Eis inkubieren 
- 5 Min., $6000 \mathrm{~g}, 4^{\circ} \mathrm{C}$ zentrifugieren

- Zellen in $2 \mathrm{ml} 50 \mathrm{mM} \mathrm{CaCl}_{2}\left(4^{\circ} \mathrm{C}\right)$ und $0,4 \mathrm{ml} 87 \%$ Glycerin aufnehmen

- Aliquotieren (je $200 \mu \mathrm{l}$ ) in Eppendorfgefäßen

- In flüssigem Stickstoff schockgefrieren

- Die Aufbewahrung erfolgt bis zur weiteren Verwendung bei $-80^{\circ} \mathrm{C}$.

\subsubsection{Transformation von Escherichia coli}

Kompetente E. coli-Zellen sind in der Lage, DNA aus dem Umgebungsmedium aufzunehmen. Mit Hilfe der nachfolgenden Methode werden E. coli-Zellen mit PlasmidDNA transformiert (Hanahan, 1983).

- Die kompetenten Zellen auf Eis auftauen

- Zugabe der Plasmid-DNA (200-300 ng)

- Inkubation für 30 Minuten bis mehrere Stunden auf Eis (Anheftung der DNA an die Zellen)

- Hitzeschock der Zellen für 2 Minuten bei $42^{\circ} \mathrm{C}$ (Aufnahme der DNA)

- Zugabe von 0,8 ml LB-Medium

- Regeneration der Zellen bei $37^{\circ} \mathrm{C}$ für 30 Minuten auf dem Schüttler

- Transformationsansatz auf LB-Selektionsmedium ausplattieren

\subsubsection{Herstellung kompetenter Agrobacterium tumefaciens}

Für die Herstellung kompetenter Zellen werden Agrobakterien des Stammes LBA 4404 verwendet.

- $5 \mathrm{ml}$ einer Agrobakterienflüssigkultur abzentrifugieren (5 min, 5000rpm, RT)

- Dreimal durch Resuspendieren und erneutes Abzentrifugieren in sterilem Wasser waschen

- Das Pellet in $500 \mu \mathrm{l}$ sterilem Wasser aufnehmen und in $100 \mu \mathrm{l}$ Aliquots einfrieren

\subsubsection{Transformation von Agrobacterium tumefaciens}

Durch Erzeugen kurzer Spannungspulse wird die Membran kompetenter Bakterienzellen permeabilisiert. Dadurch wird die Aufnahme von freier DNA aus dem Medium in die Zelle ermöglicht.

- Elektroporationsküvette mit $\mathrm{H}_{2} \mathrm{O}$ und $70 \% \mathrm{EtOH}$ waschen

- Küvette unter der Sterilbank trocknen

- Kompetente Agrobakterien auf Eis auftauen

- Zugabe der zu transformierenden DNA (50-100 ng) zu den kompetenten Zellen 
- Transformationsansatz in sterile Elektroporationsküvetten $(0,2 \mathrm{~mm})$ überführen

- Die Elektroporation erfolgt am GenePulser mit 2,5 kV, $25 \mu \mathrm{F}, 400 \mathrm{k} \Omega$

- Transformationsansatz in ein Eppendorfgefäß überführt und mit $2 \mathrm{ml} \mathrm{LB}$ - oder SOC-Medium auffüllen

- Regeneration der Agrobakterien erfolgt für 2 Stunden bei $28^{\circ} \mathrm{C}$

- danach den Ansatz auf YEB-Selektionsmedium mit entsprechenden Antibiotika ausplattieren

\subsection{Pflanzenanzucht und Transformation}

\subsubsection{Anzucht von Arabidopsis thaliana auf Erde}

Vor der Aussaat wird die Erde zweimal im Abstand von zwei Tagen für 30 Minuten bei $90^{\circ} \mathrm{C}$ autoklaviert, damit Pilze und Pilzsporen abgetötet werden. Die Samen werden nach dem Auslegen zwei bis vier Tage im Dunkeln bei $4^{\circ} \mathrm{C}$ stratifiziert, um eine gleichmäßigere und bessere Keimung zu erreichen. Die Kultivierung der Pflanzen findet in einer Klimakammer unter Langtagbedingungen (16 Stunden Licht, 8 Stunden Dunkel) statt.

\subsubsection{Oberflächensterilisation und sterile Anzucht von Arabidopsis thaliana auf MS-Platten}

Für eine sterile Anzucht der Arabidopsis Samen muss zuvor eine Oberflächensterilisation durchgeführt werden, um Kontaminationen auf den Platten zu vermeiden (Clough und Bent, 1998).

- Einige Samen in ein Eppendorfgefäß füllen (Schichtdicke bis höchstens $1 \mathrm{~cm}$ )

- Becherglas mit $100 \mathrm{ml}$ 12\%iger Natriumhypochloritlösung in einen Exsikkator stellen

- Eppendorfgefäße in einem Kunststoffständer auf das Becherglas stellen

- $\mathrm{ml} 37 \% \mathrm{HCl}$ zu der Hypochloritlösung gegeben und den Exsikkator schnell verschließen

- Nach 4 Stunden leichtem Vakuum den Exsikkator unter der Sterilbank öffnen

- Kurz ausdampfen lassen

- Die sterilisierten Samen auf den vorbereiteten MS-Platten verteilen

- Die Platten anschließend mit Parafilm abdichten und für zwei bis vier Tage bei $4^{\circ} \mathrm{C}$ stratifizieren 


\subsubsection{Dunkelinduzierte Seneszenz}

Je 8 bis 10 Pflanzen werden pro Topf auf Erde angezogen. Nach ca. 3 Wochen werden sie aus dem normalen Klimaschrank in einen abgedunkelten Klimaschrank überführt, der dann möglichst nicht mehr geöffnet wird. Proben werden zwischen 0 und 6 Tage nach Beginn der Dunkelheit genommen, indem die Rosetten oberhalb der Erde abgeschnitten und sofort in flüssigem Stickstoff weggefroren werden. Für TimecourseExperimente über mehrere Tage werden die Proben immer gegen 17.00 genommen. Für kurze Timecourse-Experimente werden die Proben über 2 Tage alle 4 Stunden, beginnend mit der Lichtphase morgens um 8.00 genommen.

\subsection{4 „Flower-dip“ Transformation}

Ein klassischer Weg zur Transformation von Pflanzen ist der Agrobakterien-vermittelte Gentransfer. Agrobacterium tumefaciens hat die Fähigkeit einen durch zwei BorderSequenzen definierten Abschnitt des so genannten Ti-Plasmids in eine Pflanzenzelle zu transportieren und dort an einer zufälligen Stelle eines Pflanzen-Chromosoms einzufügen (Herrera-Estrella et al., 1992).

Das Ti-Plasmid wurde speziell für die gezielte Integration von Genen in das pflanzliche Genom modifiziert. So werden z.B. die für den Transfer notwendigen Funktionen auf zwei Plasmide aufgeteilt. Die zu übertragenden DNA-Sequenzen lassen sich mit molekularbiologischen Methoden zwischen die Border-Sequenzen inserieren. Agrobacterium tumefaciens ist so zu einem hervorragenden Hilfsmittel geworden, um Pflanzen gezielt zu transformieren.

Für die Agrobakterien-vermittelte Transformation von Arabidopsis thaliana wurde eine sehr einfache Methode entwickelt (Clough und Bent, 1998). Pflanzen, die gerade begonnen haben zu blühen, werden in Medium mit den entsprechenden Agrobakterien und einem Benetzungsmittel getaucht. Dabei scheinen sich entwickelnde Eizellen das bevorzugte Ziel produktiver Transformationen zu sein (Bent, 2000). Aus diesen Zellen entstehen hemizygote Samen. Für die Transformation werden pro Topf $(6 \mathrm{~cm}$ Durchmesser) bis zu 20 Samen ausgesät. Gesunde und kräftige Pflanzen erhöhen die Transformationsrate. Durch das Abschneiden der ersten Blütenstände lässt sich die Bildung vieler sekundärer Blütenstände anregen, was die Ausbeute an transgenen Samen erhöhen kann.

- $25 \mathrm{ml}$ Vorkultur ansetzen mit YEB + entsprechende Antibiotika (10 $\mu 1$ Carbenicilin, $125 \mu \mathrm{l}$ Rifampecin, $15 \mu \mathrm{l}$ Gentamycin und $25 \mu \mathrm{l}$ Kanamycin), $28^{\circ} \mathrm{C}$

- $400 \mathrm{ml}$ YEB + entsprechende Antibiotika (160 $\mu \mathrm{l}$ Carbenicilin, $2 \mathrm{ml}$ Rifampecin, $240 \mu \mathrm{l}$ Gentamycin und $400 \mu$ l Kanamycin) am nächsten Tag mit der Vorkultur animpfen und bis zu einer OD600 von $\sim 2,0$ bei $28^{\circ} \mathrm{C}$ wachsen lassen

- Agrobakterien 10 Minuten bei $5000 \mathrm{rpm}$ abzentrifugieren

- Bakterien in einer frisch angesetzten 5\% igen Saccharoselösung mit 0,02\% Silwet resuspendieren, Bakteriendichte auf eine OD600 von $\sim 0,8$ einstellen 
- $500 \mathrm{ml}$ Bakteriensuspension in ein Becherglas geben und Pflanzen für einige Sekunden bis zur Rosette in die Agrobakterien-Lösung tauchen

- anschließend zurück in die Klimakammer stellen und 1-2 Tage mit einer Haube abdecken

Die Pflanzen werden bis zur Samenreife (2-3 Wochen) weiterkultiviert. Die Blütenstände lässt man trocknen. Die trockenen Pflanzen werden dann vorsichtig mit den Fingern zerrieben um die Schötchen aufzubrechen, und die Samen durch sieben grob von den übrigen Pflanzenteilen getrennt. Sie können anschließend trocken gelagert werden.

\subsubsection{Selektion auf Basta ${ }^{\circledR}$-Resistenz}

Die Samen werden zunächst wie gewohnt auf Erde ausgesät und kultiviert. Wenn die Pflanzen 2-4 vegetative Blätter gebildet haben werden sie mit $1 \mathrm{mM}$ Basta ${ }^{\circledR}$ besprüht (etwa $1 \mathrm{ml} /$ Topf). Basta ${ }^{\circledR}$ bzw. Phosphinothricin (auch Glufosinat = L-Homoanalin-4yl-(methyl)-phosphinsäure) wirkt als Strukturanalogon des L-Glutamat und inhibiert dadurch die Glutaminsynthetase. Die Pflanzen können bei Behandlung mit Basta ${ }^{\circledR}$ Glutamat nicht mehr in Glutamin umwandeln. Dadurch häuft sich Ammonium zu einer letalen Konzentration in der Pflanze an und führt zusammen mit dem Glutaminmangel zum raschen Absterben der behandelten Pflanzen. Pflanzen, die als Resistenzmarker das bar-Gen tragen, sind unempfindlich gegenüber Phosphinothricin (White et al., 1990). Nach 2-3 Tagen sind die nicht resistenten Pflanzen abgestorben. Um auszuschließen, dass nicht resistente Pflanzen überleben, werden die Pflanzen noch einmal nach 2-3 Tagen mit Basta $^{\circledR}$ besprüht.

\subsubsection{Selektion auf Hygromycin-Resistenz}

Transgene Samen, die das Hygromycin-Resistenzgen als Selektionsmarker enthalten, werden steril auf 2MS-Medium mit geeigneten Antibiotika angezogen.

- Samen nicht zu dicht auf die Platten streuen

- Die Platten für 2-3 Tage zum Stratifizieren bei $4^{\circ} \mathrm{C}$ im Dunkeln lassen

- 6 Stunden bei RT im Licht (Klimakammer)

- 2 Tage bei RT in Dunkelheit (in Alufolie eingewickelt in Klimakammer, die Keimlinge mit Hygromycin-Resistenz strecken sich jetzt)

- 2-3 Tage bei Dauerlicht und RT

Hygromycin-resistente Pflanzen lassen sich leicht von den nicht resistenten unterscheiden, da sie deutlich grüner sind und sich innerhalb der 2 Tage Dunkelheit stark strecken und so die anderen Keimlinge deutlich überragen. Diese positiven Pflanzen können in Erde umgetopft und weitergezogen werden. 


\subsubsection{Kreuzen von Arabidopsis thaliana Pflanzen}

Um multiple Mutanten z.B. der bZIP Transkriptionsfaktoren herzustellen werden Einzel- bzw. Doppelmutanten miteinander gekreuzt:

- Von der Mutterpflanze alle bereits bestehenden Schoten und alle Blüten bei denen schon die Blütenblätter zu sehen sind abschneiden (nur 1-2 ungeöffnete Blüten pro Pflanze bleiben)

- Von diesen die Kelch-, Blüten- und Staubblätter unter dem Binokular abpräparieren; der Fruchtknoten bleibt als einziges übrig

- Von der Vaterpflanze ein Staubblatt mit reifen Pollenkörnern abnehmen und damit den freipräparierten Fruchtknoten bestäuben

- Heranwachsende Schote enthält heterozygote Doppel-/Mehrfachmutanten

- Test der Doppel-/Mehrfachmutanten auf homozygote Pflanzen in der F2 Generation über PCR mit genspezifischen und T-DNA-spezifischen Primern

\subsubsection{Arabidopsis thaliana-Protoplasten-Transformation}

Arabidopsis Mesophyllprotoplasten sind ein sehr nützliches Werkzeug, um transiente Genexpressionsstudien durchführen zu können (Yoo et al. 2007). Auch verschiedenste Stressbedingungen wie z.B. Dunkelheit, DCMU oder Salz sowie der Einfluss verschiedener Hormone (z.B. ABA oder Auxin) auf die Genexpression unterschiedlicher Reportergene kann in diesem System einfach und schnell getestet werden.

\subsubsection{Arabidopsis thaliana-Protoplasten-Gewinnung}

- Von 3 bis 4 Wochen alten, auf Erde angezogenen Pflanzen ohne Blütenansätze werden Blätter entnommen und auf der Blattunterseite fein mit einem Skalpell eingeritzt

- Mit dieser Seite werden die Blätter auf $10 \mathrm{ml}$ Enzymlösung (enthält Cellulase und Macerozym) in eine Petrischale gelegt, ohne dass Blasen darunter sind

- Der Zellwandverdau erfolgt über Nacht im Klimaschrank

- Vorsichtiges Schwenken führt zum Ausfall der Protoplasten in die Lösung

- Ein vorher geformtes Metallnetz $(0,063 \mathrm{~mm})$ wird in ein frisches Greiner eingesetzt, mit W5-Puffer benetzt und anschließend vorsichtig die Protoplastensuspension hindurch gegossen

- 2 Minuten bei $100 \mathrm{~g}$ bei RT zentrifugieren; Beschleunigen und Abbremsen erfolgt langsam, damit die Protoplasten intakt bleiben

- Überstand mit abgeschnittener blauer Spitze entfernen

- Vorsichtig mit gekühlter W5-Lösung auf $10 \mathrm{ml}$ auffüllen 
- Durch leichtes Schwenken vorsichtig resuspendieren

- 1 Minute bei $100 \mathrm{~g}$ bei RT zentrifugieren; langsam beschleunigen und abbremsen

- Überstand mit abgeschnittener blauer Spitze entfernen

- Vorsichtig mit gekühlter W5-Lösung auf $10 \mathrm{ml}$ auffüllen

- Durch leichtes Schwenken vorsichtig resuspendieren

- Für 5 Stunden auf Eis stellen

\subsubsection{Arabidopsis thaliana-Protoplasten-PEG-Transformation}

- Überstand mit abgeschnittener blauer Spitze entfernen

- Protoplasten in MMg-Lösung durch leichtes Schwenken resuspendieren

- In $2 \mathrm{ml}$ Eppendorfgefäßen wird $20 \mu \mathrm{l}$ DNA $(20 \mu \mathrm{g})$ vorgelegt

- Eppendorfgefäß schräg halten und $200 \mu 1$ Protoplasten-Lösung mit abgeschnittener blauer Spitze hinzufügen

- Vorsichtig 3-4 mal invertieren

- $220 \mu 1$ PEG-Lösung hinzufügen

- 12-14 mal vorsichtig invertieren

- 25 min bei RT inkubieren

- $800 \mu \mathrm{l}$ W5-Lösung hinzugeben und schwenken

- 1 Minute bei 100g bei RT zentrifugieren (langsames Beschleunigen und Abbremsen)

- mit abgeschnittener blauer Spitze $1 \mathrm{ml}$ des Überstands entfernen

- 1 Minute bei $100 \mathrm{~g}$ bei RT zentrifugieren (langsamen Beschleunigen und Abbremsen)

- mit einer Insulin-Spritze den Rest vom Überstand abnehmen

- $250 \mu \mathrm{l}$ WI-Lösung zugeben und dadurch vorsichtig die Protoplasten resuspendieren

- Inkubation über Nacht unter geeigneten Bedingungen (z.B. im Klimaschrank mit $21^{\circ} \mathrm{C}$ bei Dauerlicht bzw. Dauerdunkel (in Alufolie eingewickelt) oder mit 20 $\mu \mathrm{M}$ DCMU im WI-Puffer)

\subsubsection{Arabidopsis thaliana-Protoplasten-Ernte}

- Überstand mit Insulin-Spritze entfernen

- Protoplasten in Eppendorfgefäß in Flüssigstickstoff schockgefrieren

Mit den Ansätzen kann sofort danach weiter gearbeitet werden. Sie können aber auch für einige Tage bei $-20^{\circ} \mathrm{C}$ gelagert werden. Je nach Ansatz würde sich jetzt ein GUSTest oder eine Western Analyse anschließen. 


\subsubsection{Messung der $\beta$-Glucuronidase (GUS)-Aktivität}

Die B-Glucuronidase (GUS) ist das Genprodukt des GUS-Reportergens. Das GUSEnzym ist in der Lage $\beta$-Glucuronide in D-Glucuronsäuren und einen aglyconischen Rest zu spalten. Setzt man das künstliche Substrat 4-Methylumbeliferyl-ß-D-Glucuronid (4-MUG) ein, so erhält man nach der Hydrolyse das fluoreszierende Molekül Methylumbeliferon (MU). Durch die Stärke der Fluoreszenz in den Ansätzen lässt sich die umgesetzte Menge an MUG quantifizieren und die Aktivität des GUS-Enzyms bestimmen. Die Anregung des fluoreszierenden Produktes MU erfolgt bei 360nm, die Emission bei 460nm.

- Gesamtzellextrakte in $70 \mu$ GUS-Extraktionspuffer mit ß-Mercaptoethanol aufnehmen

- Je 2 gleiche Protoplastenansätze in einem Reaktionsgefäß vereinigen (um die Varianz zwischen den einzelnen Protoplasten Transformationen zu verringern)

- $100 \mu \mathrm{l}$ der Protoplastensuspension in ein flaches Well der Mikrotiterplatte überführen

- $100 \mu \mathrm{l}$ MUG-Gebrauchslösung zugeben und mischen

- 10 min bei $37^{\circ} \mathrm{C}$ inkubieren

- $\quad 100 \mu \mathrm{l}$ des Reaktionsansatzes in ein neues Well überführen und die Reaktion mit $100 \mu \mathrm{l}$ GUS-Stopp-Puffer abstoppen $\left(\mathrm{t}_{0}\right)$

- restlichen Reaktionsansatz weitere $60 \mathrm{~min}$ bei $37^{\circ} \mathrm{C}$ inkubieren

- mit $100 \mu$ l GUS-Stopp-Puffer abstoppen $\left(\mathrm{t}_{60}\right)$

Die Quantifizierung der Fluoreszenz erfolgt im CytoFluor II Plate Reader. Die GUSAktivität wird nach folgender Formel berechnet:

Relative GUS-Aktivität $[\mathrm{pmol} / \mathrm{min}]=\frac{\Delta \mathrm{F} / 10}{\mathrm{t}}$

$\Delta \mathrm{F}=$ Differenz der Fluoreszenz $\mathrm{t}_{60}-\mathrm{t}_{0}$

10 Fluoreszenzeinheiten entsprechen 1 pmol MUG-Umsatz.

$\mathrm{t}=60 \mathrm{~min}$

\subsubsection{Messung der NAN-Aktivität und NAN-Abgleich}

Das $\mathrm{NAN}$-Gen ist das Kodon-optimierte Derivat des nanH-Gens. $\mathrm{NanH}$ ist ein Clostridium perfringens Gen, welches für die sog. „kleine“ zytoplasmatische Sialidase codiert. Eine Kodonoptimierung zur Anhebung des GC-Gehalts war nötig, damit eine Expression in Pflanzen möglich ist.

Sialidasen katalysieren die Abspaltung von terminalen N-Acylneuramin-Resten von Glycoproteinen, Glycolipiden und Polysacchariden. $\mathrm{Zu}$ den Substraten von NAN gehören u.a. 2'-(4-methylumbelliferyl)- $\alpha$-D- $N$-acetyl-neuraminic acid (MUN), 2-o-(pnitrophenyl)- $\alpha-\mathrm{D}-N$-acetylneuraminic acid (pNP-N) und 5-bromo-4-chloro-3-indolyl- $\alpha-$ 
D- $N$-acetylneuraminic acid (X-NeuNAc) (Kirby and Kavanagh, 2002). In der Regel wird MUN als Substrat verwendet, hierbei entsteht wie bei GUS als fluoreszierendes Produkt MU.

Die Anregung erfolgt wie beim GUS-Test bei 360nm, die Emission bei 460nm. Das $N A N$-Reportergen kann also unter genau den gleichen Bedingungen wie GUS verwendet werden. Diese Eigenschaft ermöglicht den Einsatz von $N A N$ als Abgleich-Reportergen für GUS.

- Eine geeignete Verdünnung der Protoplastensuspension mit GUSExtraktionspuffer herstellen (z.B. 1:2 oder 1:10)

- $10 \mu \mathrm{l}$ der verdünnten Protoplastensuspension in ein rundes Well (aufgrund des geringen Gesamtvolumens sammelt es ich so besser) einer Mikrotiterplatte überführen

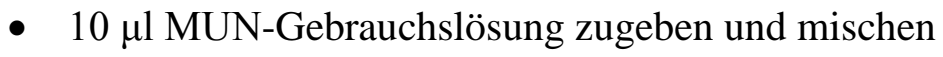

- 10 min bei $37^{\circ} \mathrm{C}$ inkubieren

- 3,3 $\mu \mathrm{l}$ des Reaktionsansatzes in ein neues Well (flacher Boden) überführen und mit $200 \mu 1$ NAN-Stopp-Puffer abstoppen $\left(\mathrm{t}_{0}\right)$

- den restlichen Reaktionsansatz weitere 60 min bei $37^{\circ} \mathrm{C}$ inkubieren

- 3,3 $\mu 1$ des Reaktionsansatzes in ein neues Well (flacher Boden) überführen und mit $200 \mu 1$ NAN-Stopp-Puffer abstoppen $\left(\mathrm{t}_{60}\right)$

Die Quantifizierung der Fluoreszenz erfolgt wie auch für den GUS-Test im CytoFluor II Plate Reader. Die NAN-Aktivität wurde nach folgender Formel berechnet:

NAN-Aktivität $[\mathrm{pmol} / \mathrm{min}]=\frac{\Delta \mathrm{F} / 10}{\mathrm{t}}$

$\Delta \mathrm{F}=$ Differenz der Fluoreszenz $\mathrm{t}_{60}-\mathrm{t}_{0}$

10 Fluoreszenzeinheiten entsprechen 1 pmol MUN-Umsatz.

$\mathrm{t}=60 \mathrm{~min}$

NAN-Abgleich:

Um Unterschiede in den Mengen des GUS-Reportergens, die während des Versuchsablaufs z.B. durch Pipettierungenauigkeiten entstehen, heraus rechnen zu können, wird die GUS-Aktivität mit der NAN-Aktivität abgeglichen.

Dazu teilt man einfach die berechneten GUS-Aktivitätswerte durch die NANAktivitätswerte.

\subsection{Extraktion genomischer DNA aus Arabidopsis thaliana}

Diese Methode ist relativ schnell und die extrahierte DNA nicht sehr sauber, aber ausreichend für eine PCR, die damit durchgeführt werden soll. Sie beruht ähnlich wie die RNA-Extraktion darauf, dass sich die DNA besser in der hydrophilen, wässrigen 
Phase löst, während Chlorophyll und andere Bestandteile besser in der hydrophoben Chloroform-Phase gelöst werden.

- Einige Blätter in ein $2 \mathrm{ml}$ Eppendorfgefäß füllen und in flüssigem $\mathrm{N}_{2}$ wegfrieren

- Pflanzenmaterial aufmörsern

- $200 \mu \mathrm{CTAB}$ dazugeben

- Inkubation für 15 Minuten bei $65^{\circ} \mathrm{C}$

- Gleiches Volumen Chloroform/Isoamylalkohol (24:1) dazu und gut mischen

- 10 Minuten bei RT und 13.000g abzentrifugieren

- Obere wässrige Phase in neues Eppendorfgefäß überführen

- Gleiches Volumen Isopropanol (eiskalt) dazu geben, mischen durch invertieren

- 2 Minuten bei Raumtemperatur inkubieren

- 10 Minuten bei RT und 10.000g abzentrifugieren

- Überstand vorsichtig verwerfen

- Pellet mit $300 \mu \mathrm{l} 70 \%$ Ethanol waschen

- Ethanol entfernen

- Pellet für 30 Sekunden bei $90^{\circ} \mathrm{C}$ trocknen

- Pellet in $50 \mu \mathrm{l}$ Wasser lösen

\subsection{Polymerase-Kettenreaktion}

Die Polymerase-Kettenreaktion (PCR = Polymerase Chain Reaction) ist eine Methode, um DNA-Fragmente in vitro zu amplifizieren. Die Technik wurde zuerst von (Mullis und Faloona, 1987) beschrieben. Grundlage ist die Fähigkeit der DNA-Polymerase, einzelsträngige DNA zu einem Doppelstrang aufzupolymerisieren, wenn ein kurzer doppelsträngiger Startbereich vorliegt. Deshalb sind zwei Oligonukleotid-Primer erforderlich, die komplementär zu Bereichen der zu amplifizierenden DNA sind, und die als Startpunkt für die Tochterstrang-Synthese dienen. Die beiden Primer begrenzen so auch das zu amplifizierende Fragment. Sie werden im Überschuss zugegeben. Zunächst wird die doppelsträngige DNA durch Erhitzen in Einzelstränge aufgetrennt. Beim anschließenden Abkühlen können sich die Primer an die DNA anlagern (Annealing). Es folgt dann die Aufpolymerisierung durch die DNA-Polymerase bei mittlerer Temperatur. Durch Verwendung der Taq-Polymerase bleibt die Aktivität des Enzyms über den Hitzeschritt erhalten. Die zyklische Wiederholung der Schritte führt zur Anreicherung des gewünschten Fragmentes.

Beispiel für einen Reaktionsansatz:

- 2,5 $\mu \mathrm{l}$ 10x PCR-Puffer $+\mathrm{MgCl}_{2}$ (MBI)

- $0,25 \mu \mathrm{l}$ dNTPs (je $10 \mathrm{mM}$ )

- $0,25 \mu \mathrm{l}$ Enhancer

- $1 \mu 1$ Primer $1(10 \mu \mathrm{M})$ 
- $1 \mu 1$ Primer $2(10 \mu \mathrm{M})$

- $0,5 \mu 1$ Taq DNA-Polymerase

- $2 \mu 1$ DNA-Template

- $17 \mu 1 \mathrm{H}_{2} \mathrm{O}$

Das verwendete PCR-Programm hängt von der Schmelztemperatur der Primer und dem verwendeten Template ab und muss für jede PCR individuell erstellt werden.

\subsubsection{Mutagenese-PCR}

Die Mutagenese-PCR ist eine spezielle Form der Polymerase-Kettenreaktion, bei der während der Amplifizierung Basen ausgetauscht werden. Im Unterschied zur klassischen PCR begrenzen hierbei die Primer nicht das gewünschte DNA-Fragment, sondern binden beide (Sense und Antisense Primer) an der Stelle, an der eine oder mehrere Basen ausgetauscht werden sollen. Die Basenabfolge der Primer entspricht dabei der gewünschten Mutation, ist also in diesen Bereichen nicht komplementär zur Matrize. Damit sie dennoch stabil und spezifisch an die DNA binden, sind sie entsprechend länger als Primer der klassischen PCR. Bei der Synthese des komplementären Strangs wird das Plasmid vollständig abgelesen und amplifiziert.

Die Mutagenese-PCR erfolgt nach der Anleitung des QuickChange ${ }^{\circledR}$ Site-Directed Mutagenesis Kit von Stratagene. Die Erstellung der Primer erfolgt über ein im Internet verfügbares Programm: http://www.stratagene.com/qcprimerdesign.

Beispiel für einen Reaktionsansatz:

- $5 \mu 1$ 10x Reaktionspuffer

- 50 ng dsDNA (Template)

- 125 ng Oligonukleotid-Primer 1 (sense)

- 125 ng Oligonukleotid-Primer 2 (antisense)

- $1 \mu 1 \mathrm{dNTP}-\mathrm{Mix}$

- mit $\mathrm{H}_{2} \mathrm{O}$ auf $50 \mu \mathrm{l}$ auffüllen

- zuletzt $1 \mu$ l Pfu-DNA-Polymerase (2.5U)

Im Thermocycler wird folgendes Programm benutzt:

- $95^{\circ} \mathrm{C} 30$ Sekunden initiale Denaturierung

- $95^{\circ} \mathrm{C} 30$ Sekunden Denaturierung

- $55^{\circ} \mathrm{C} 1$ Minute Annealing

- $68^{\circ} \mathrm{C} 1$ Minuten pro kb des Plasmids Elongation

- Schritte 2-4 17 mal wiederholen

- Lagerung bei $4^{\circ} \mathrm{C}$ 
Um mit dem PCR-Produkt weiter arbeiten zu können, muss zunächst die methylierte Template-DNA ohne Mutation mindestens $1 \mathrm{~h}$ bei $37^{\circ} \mathrm{C}$ durch $D p n I$ verdaut werden. DpnI greift dabei die Sequenz 5`-Gm ${ }^{6} \mathrm{ATC}-3^{`}$ an.

\subsection{Klonierung von amiRNA-Konstrukten}

Der artificial microRNA designer WMD2 (http://wmd.weigelworld.org/cgibin/mirnatools.pl) liefert vier Oligonukleotid Sequenzen (I bis IV), die benötigt werden, um die artificial microRNA in den miR319a Vorgänger durch Mutagenese hereinzubringen.

Als Ausgangsmaterial für die PCR wird das Plasmid pRS300 benötigt, das den miR319a Vorgänger im pBSK (kloniert über SmaI Schnittstelle) enthält.

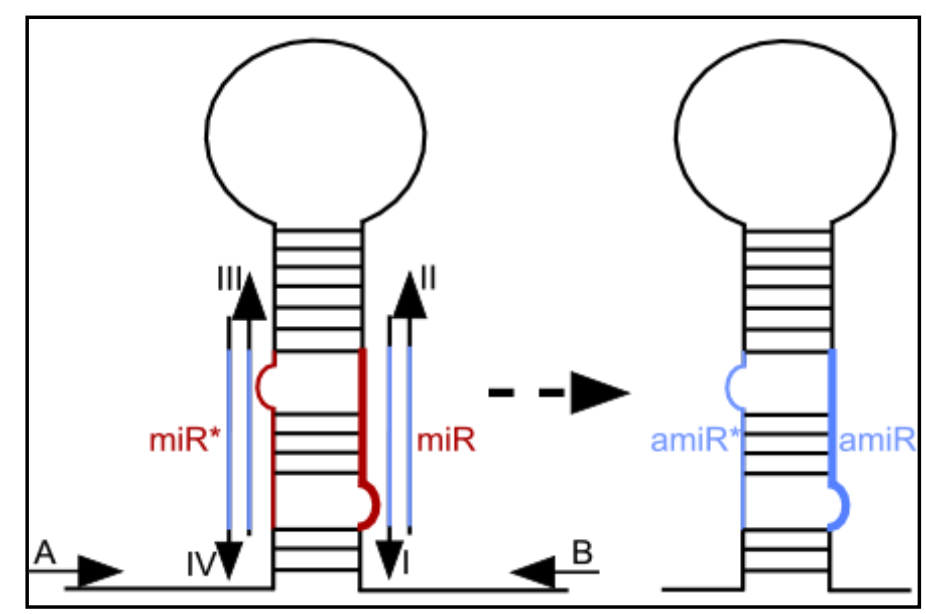

I: $\quad$ microRNA forward

II: microRNA reverse

III: $\quad$ microRNA* forward

IV: $\quad$ microRNA* reverse

Der Vorläufer, der die amiRNA enthält wird mit Hilfe von überlappender PCR generiert. In der ersten Runde werden die Fragmente (a), (b) und (c) amplifiziert (s. Tabelle unten), die dann anschließend in der Reaktion (d) verbunden werden.

\begin{tabular}{|l|l|l|l|}
\hline & forward Oligo & reverse Oligo & Template \\
\hline (a) & A & IV & pRS300 \\
\hline (b) & III & II & pRS300 \\
\hline (c) & I & B & pRS300 \\
\hline (d) & A & B & $(a)+(b)+(c)$ \\
\hline
\end{tabular}


Die Oligonukleotide A und B basieren auf der Sequenz des Ausgangsplasmids. Sie liegen außerhalb der multiple cloning site des pBSK um größere PCR Produkte zu bekommen. Um die amiRNA gateway-kompatible zu machen wurden zusätzlich noch links und rechts die gateway-sites angehängt.
amiRNA-GW Primer A :
5'-GGGGACAAGTTTGTACAAAAAAGCAGGCT
CTGCAAGGCGATTAAGTTGGGTAAC-3'
amiRNA-GW Primer B: 5'-GGGGACCACTTTGTACAAGAAAGCTGGGT

Für die PCR Reaktionen (a) - (c) wird folgender Mastermix angesetzt:

- $5 \mu \mathrm{l}$ 10xPCR Puffer (mit $\left.\mathrm{Mg}^{2+}\right)$

- $5 \mu \mathrm{ldNTPs}(2 \mathrm{mM})$

- $2 \mu 1$ jedes Primers $(10 \mu \mathrm{M})$

- $2 \mu 1$ Plasmid DNA (1:100)

- $0.5 \mu \mathrm{l}$ Pfu Polymerase

- $33.5 \mu 1$ Wasser

Das PCR-Programm:

- $95^{\circ} \mathrm{C} 2 \mathrm{Min}$

- $95^{\circ} \mathrm{C} 30 \mathrm{Sek}$

- $50^{\circ} \mathrm{C} 30 \mathrm{Sek}$ 32 Zyklen

- $72^{\circ} \mathrm{C} \quad 40 \mathrm{Sek}$

- $72^{\circ} \mathrm{C} 7 \mathrm{Min}$

Das PCR-Produkt wird auf einem 2\%igem Gel aufgetrennt, Banden werden ausgeschnitten, eine Gelextraktion durchgeführt (doppelte Menge NT-Puffer wegen der $2 \%$ igen Agarose) und in $25 \mu 1$ Wasser eluiert.

Für die PCR Reaktion (d) wird folgender Mastermix angesetzt:

- $5 \mu 1$ 10xPCR Puffer (mit $\mathrm{Mg}^{2+}$ )

- $5 \mu \mathrm{ldNTPs}(2 \mathrm{mM})$

- $2 \mu 1$ Primer A $(10 \mu \mathrm{M})$

- $2 \mu 1$ Primer B $(10 \mu \mathrm{M})$

- $1 \mu 1$ PCR (a) + 1 1 PCR (b) + $1 \mu 1$ PCR (c)

- $0.5 \mu \mathrm{lPu}$

- $33 \mu \mathrm{l}$ Wasser

Das PCR-Programm:

- $95^{\circ} \mathrm{C} 2 \mathrm{Min}$

- $95^{\circ} \mathrm{C} 3 \mathrm{Sek}$

- $50^{\circ} \mathrm{C} 3 \mathrm{Sek}$

32 Zyklen

- $72^{\circ} \mathrm{C}$ 1,5 Min

- $72^{\circ} \mathrm{C} 7 \mathrm{Min}$ 
Das PCR-Produkt wird auf 1\%igem Gel aufgetrennt, die Banden ausgeschnitten, eine Gelextraktion durchgeführt und in $25 \mu 1$ Wasser eluiert.

Das fertige amiRNA-Konstrukt aus Reaktion (d) kann mittels BP-Reaktion in beliebige Donor-Vektoren (z.B. pDON201) gebracht werden.

Da konstitutive Knock-Outs oder amiRNA-Ansätze für die Kinasen Kin10 und Kin11 letal sind, wurden die amiRNA-Konstrukte von diesen beiden Kinasen aus dem pDOND201 anschließend mittels LR-Reaktion in den Estradiol-induzierbaren Vektor pMDC7 gebracht und anschließend in Arabidopsis Pflanzen (Col-0) mittels FloralDip transformiert. Die Selektion erfolgt mit Hilfe von Hygromycin.

\subsubsection{Estradiol-Induktion}

Für die Estradiol-Induktion der induzierbaren amiRNA Pflanzen wurde jeweils ein großes Blatt pro Pflanze geerntet und für $24 \mathrm{~h}$ in einem $2 \mathrm{ml}$ Eppendorfgefäß mit 1,5 ml $5 \mu \mathrm{M}$ Estradiol in PBS pH 7,4 inkubiert. Die Estradiol-Stocklösung $(10 \mathrm{ml} 10 \mathrm{mM}$ Estradiol $(0,027 \mathrm{~g})$ in DMSO) sollte immer frisch angesetzt werden.

Anschließend wird die Flüssigkeit abgenommen, das Blatt abgetupft und in flüssigem Stickstoff weggefroren. Da Estradiol sehr giftig ist, den Flüssigabfall speziell entsorgen.

\subsection{Konzentrationsbestimmung von Nukleinsäuren}

Die Konzentrationsbestimmung von DNA und RNA erfolgte photometrisch am GeneQuant II (Pharmacia). Dabei wird die Absorption von Licht durch wässrige Lösungen von RNA und DNA bei $260 \mathrm{~nm}$ gemessen. Bei einer Schichtdicke von $1 \mathrm{~cm}$ entspricht eine $\mathrm{OD}_{260}$ von 1,0 einer Nukleinsäurekonzentration von $50 \mu \mathrm{g} / \mathrm{ml} \mathrm{dsDNA}$ bzw. $40 \mu \mathrm{g} / \mathrm{ml}$ RNA. Um den Reinheitsgrad der Nukleinsäuren zu ermitteln wird auch die Absorption von Proteinen bei $280 \mathrm{~nm}$ gemessen. Der Quotient der beiden Werte $\mathrm{OD}_{260} / \mathrm{OD}_{280}$ stellt ein $\mathrm{Ma} 3$ für den Reinheitsgrad dar. Der Reinheitsgrad sollte zwischen 1,7 und 2,0 liegen. Zur Konzentrationsbestimmung von DNA und RNA wurden 1:50 Verdünnungen gegen $\mathrm{H}_{2} \mathrm{O}$ gemessen.

Alternativ kann die DNA-Konzentration auch an einem anderen Gerät, dem Nanovue, gemessen werden. Hier werden $2 \mu$ der unverdünnten Probe auf die Detektionsfläche des Gerätes pipettiert und das Gerät gibt einem dann die Konzentration sowie die Reinheit der DNA- oder RNA-Probe aus.

Eine dritte Alternative ist das Abschätzen der DNA-Konzentration nach Auftrennung der Probe in einem Agarosegel und Anfärbung mit Ethidiumbromid im Vergleich zu DNA bekannter Konzentration (z.B. dem Marker). 


\subsection{Restriktionsspaltung von DNA}

Restriktionsendonukleasen (Desoxyribonukleasen) vom Typ II spalten PhosphodiesterBindungen doppelsträngiger DNA an spezifischen Basensequenzen (Smith und Wilcox, 1970). Es gibt eine große Anzahl verschiedener Restriktionsendonukleasen, die jeweils bestimmte Erkennungssequenzen haben (Roberts, 1985). Je nach Enzym entstehen glatte DNA-Enden (,,blunt ends“) oder 5'- bzw. 3'-überhängende Enden (,sticky ends“). Die zur Restriktionsspaltung eingesetzte DNA (ca. 0,5-2 $\mu$ g Plasmid-DNA) sollte frei von Kontaminationen wie hohen Salzkonzentrationen, EDTA oder organischen Lösungsmitteln sein, um die Enzymaktivität nicht zu mindern. Die Reaktionen finden für 2-16 Stunden bei den für jedes Enzym optimalen Temperatur- und Pufferbedingungen (Spaltungspuffer von MBI oder Boehringer) statt. Es werden Enzymmengen von mindestens 1 Unit (U) Restriktionsenzym pro $\mu \mathrm{g}$ DNA eingesetzt. Weil die Enzymlösungen Glycerin enthalten, wird nicht mehr Restriktionsenzym als höchstens $10 \%$ des Endvolumens zugesetzt, da Glycerinkonzentrationen von mehr als 5 $\%$ die Spezifität herabsetzen. Die meisten Restriktionsenzyme können durch eine Hitzebehandlung für 10 Minuten bei $65^{\circ} \mathrm{C}$ inaktiviert werden. Die Kontrolle der Spaltung erfolgt durch Agarosegelelektrophorese mit einem Aliquot des Ansatzes. Restriktionsspaltungen können zur Klonanalyse eingesetzt werden. Außerdem sind sie die Grundlage der Klonierungen (Cohen et al., 1973).

\subsection{Agarosegelelektrophorese von DNA-Molekülen}

Mit Hilfe der Agarosegelelektrophorese werden DNA-Moleküle nach ihrer Größe aufgetrennt (McDonell et al., 1977; Southern, 1979). DNA ist aufgrund des ZuckerPhosphat-Rückgrats negativ geladen. Im elektrischen Feld wandert sie somit zur Anode. Die Wanderungsgeschwindigkeit ist umso größer, je kleiner die DNA-Moleküle sind. Als Gelmatrix dient Agarose, ein gelierfähiges Polysaccharid, welches aus sich abwechselnden Einheiten von $\beta$-1,3-verknüpfter D-Galaktopyranose und $\alpha$-1,4verknüpfter 3,6-Anhydro-L-Galaktopyranose besteht. Der Trennbereich ist abhängig von der Agarosekonzentration, da sie die Porengröße beeinflusst. Je höher die Agarosekonzentration, desto kleiner die Poren, desto besser werden kleine Moleküle aufgetrennt. Zur Auftrennung großer Fragmente wird ein 0,7\%iges Gel benutzt. Kleine Fragmente, wie PCR-Produkte, werden in Gelen aufgetrennt, die 1\% Agarose enthalten. Ethidiumbromid (3,8-Diamino-6-ethyl-5-phenylphenantridiumbromid) dient zum Anfärben der DNA. Es bindet an die DNA, indem es zwischen die Basenpaare interkaliert. Der Komplex aus DNA und Ethidiumbromid fluoresziert unter UV-Licht und wird damit auf dem Transilluminator sichtbar. 


\subsection{DNA-Elution aus Agarosegelen}

Für die Isolierung von DNA-Fragmenten aus Agarosegelen wird das Nucleospin ${ }^{\circledR}$ Extract Kit von Macherey-Nagel verwendet. Die Aufreinigung erfolgte nach dem Protokoll des Herstellers.

\subsection{Ligation}

Ligation bezeichnet den Vorgang, bei dem zwei DNA-Stränge mit glatten Enden oder komplementären überhängenden Enden über Bildung von Phosphodiesterbindungen zwischen den $3^{6}-\mathrm{OH}-\mathrm{Gruppen}$ und den $5^{6}$-Phosphatgruppen an den jeweiligen Enden verbunden werden. Dieser Vorgang wird durch die T4-DNA-Ligase katalysiert. In Anwesenheit von ATP wird das Enzym durch Adenylierung aktiviert, wobei Pyrophosphat abgespalten wird. Das AMP wird auf das 5'-Ende eines DNA-Strangs übertragen. Durch die daraus resultierende Aktivierung des 5'-Phosphoratoms wird an diesem ein nucleophiler Angriff durch die 3'-OH-Gruppe des anderen DNA-Strangs möglich. Die Stränge werden geschlossen und AMP freigesetzt.

Da die Taq-Polymerase keine Fragmente mit glatten Enden produziert, sondern einen Überhang von einer Base schafft, wobei es sich in den meisten Fällen um ein Adenosin handelt (Clark, 1988), lassen sich Taq-amplifizierte PCR-Produkte gut in Vektoren mit Thymin-Überhang klonieren. Ein solcher Vektor ist pGEM $^{\circledR}$-T von Promega oder auch der hauseigen hergestellte psk-T Vektor.

Mit Hilfe entsprechender Schnittstellen und Restriktionsenzyme lassen sich aber auch alle Fragmente mit anderen Überhängen oder glatten Enden in beliebige andere Vektoren bringen.

- Vektor (ca. $50 \mathrm{ng}$ ) und Fragment (>50 ng) mit 1 $\mu 1$ T4-DNA-Ligasepuffer und 1 $\mu 1$ T4-DNA Ligase in Gesamtvolumen von $10 \mu$ in Eppendorfgefäß pipettieren

- Über Nacht bei $4^{\circ} \mathrm{C}$ ligieren

- Die Reaktion durch 15 minütige Inkubation bei $60^{\circ} \mathrm{C}$ abstoppen

\subsection{Blau-Weiß-Selektion}

Für die Blau-Weiß-Selektion muss die Klonierungsstelle im Vektor innerhalb des lacZGens liegen. LacZ codiert für die ersten 146 aminoterminalen Aminosäuren ( $\alpha$-Peptid) der $\beta$-Galaktosidase. Sie können zusammen mit einem inaktiven Enzym, dem die Aminosäuren 11-41 fehlen, eine funktionierende $\beta$-Galaktosidase bilden $(\alpha$ Komplementation). Das aktive Enzym hydrolysiert das Substrat X-Gal, das daraufhin durch Luftoxidation eine blaue Färbung zeigt. Bakterienstämme mit dem inaktiven Enzym können durch Aufnahme eines Plasmids, das das lacZ-Gen trägt, nach Induktion mit IPTG X-Gal umsetzen. Wird die Sequenz des lacZ-Gens jedoch durch den Einbau von fremder DNA in das Plasmid unterbrochen, so bleibt die Bakterienkolonie weiß. 
Dieses Verfahren erleichtert die Selektion der Kolonien mit rekombinanten Plasmiden. Die Platten, auf denen eine Blau-Weiß-Selektion durchgeführt wird, werden mit $50 \mu 1$ X-Gal-Lösung $(20 \mathrm{mg} / \mathrm{ml})$ und $50 \mu \mathrm{l}$ IPTG-Lösung $(0,1 \mathrm{M})$ beschichtet. Animpfen und Inkubation finden wie gewohnt statt.

\subsection{Gateway-Rekombination}

Bei Gateway-Klonierungen werden DNA-Segmente über ortsspezifische Rekombination zwischen verschiedenen Plasmiden transferiert (Gateway ${ }^{\circledR}$ Technology - The Gateway Manual). Das System basiert auf der ortsspezifischen Integration des Phagen Lambda in das Genom von E.coli. Um für die Rekombination verfügbar zu sein, müssen Erkennungssequenzen an das gewünschte DNA-Segment angefügt werden. Dies geschieht, indem man das gewünschte DNA-Stück mit Primern amplifiziert, die an den 5'-Enden die Erkennungssequenzen enthalten. Bei Gateway-Klonierungen werden zwei Reaktionen verwendet. Das DNA-Segment kann aus dem PCR-Produkt in der BPReaktion in einen Eingangs-Vektor rekombiniert werden. Von dort aus kann es in der LR-Reaktion in verschiedene Ziel- Vektoren transferiert werden. Außerdem besteht die Möglichkeit, das DNA-Segment aus dem Ziel-Vektor in einer weiteren BP-Reaktion in einen anderen Eingangs-Vektor zu transferieren.

\subsubsection{BP-Reaktion}

Die BP-Reaktion dient dazu, den DNA-Abschnitt zwischen den attB-sites in einen Donor-Vektor mit attP-sites zu transferieren. Dabei entsteht ein Eingangsplasmid mit attL-sites.

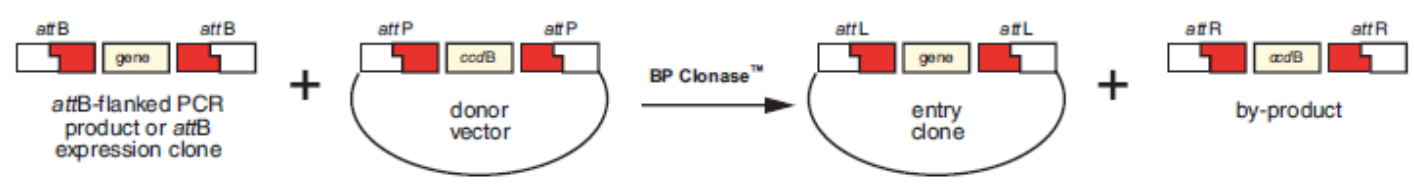

- 50-150 ng attB-PCR-Produkt (oder linearisierter Ziel-Vektor) in ein 1,5 ml

- Eppendorfgefäß geben

- 150 ng Eingangs-Vektor (z.B. pDON201) zugeben

- Mit $\mathrm{H}_{2} \mathrm{O}$ auf $8 \mu \mathrm{l}$ auffüllen

- $2 \mu \mathrm{BP}$ Clonase Enzym Mix (enthält bereits den Puffer) zugeben

- ü.N. bei $25^{\circ} \mathrm{C}$ inkubieren

- $1 \mu 1$ Proteinase $\mathrm{K}$ zugeben und 10 Minuten bei $37^{\circ} \mathrm{C}$ inkubieren

- $5 \mu \mathrm{l}$ des Ansatzes in $100 \mu \mathrm{l}$ chemisch kompetente DH5 $\alpha$-E.coli Zellen transformieren 


\subsubsection{LR-Reaktion}

Die LR-Reaktion dient dazu, die DNA zwischen den attL-sites eines Eingangsplasmids in einen Ziel-Vektor mit attR-sites zu transferieren. Sie läuft am effizientesten ab, wenn beide Vektoren linearisiert werden.

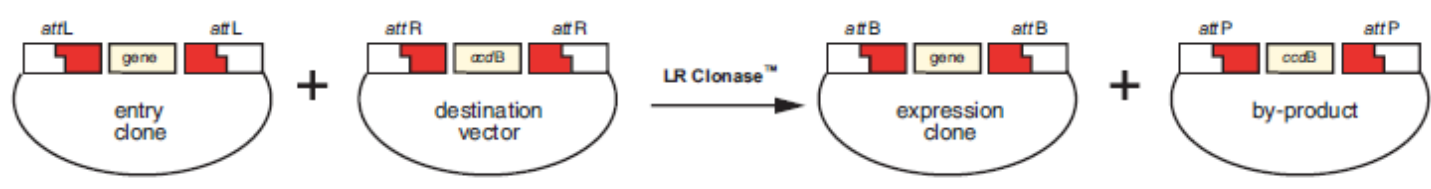

- 300 ng Eingangs-Vektor in ein 1,5 ml Eppendorfgefäß geben

- 300 ng Ziel-Vektor zugeben

- Mit $\mathrm{H}_{2} \mathrm{O}$ auf $8 \mu \mathrm{l}$ auffüllen

- $2 \mu \mathrm{LR}$ Clonase Enzym Mix (enthält bereits den Puffer) zugeben

- ü.N. bei $25^{\circ} \mathrm{C}$ inkubieren

- $1 \mu 1$ Proteinase $\mathrm{K}$ zugeben und 10 Minuten bei $37^{\circ} \mathrm{C}$ inkubieren

- $5 \mu \mathrm{l}$ des Ansatzes in $100 \mu \mathrm{l}$ chemisch kompetente DH5 $\alpha$-E.coli Zellen transformieren

\subsection{Colony-Screen mittels PCR}

Um potenziell positive Klone aus der Blau-Weiß Selektion (weiße Kolonien) noch in einer PCR zu verifizieren oder auch Kolonien von Platten ohne Blau-Weiß Selektion zu testen, können die Plasmide mit Hilfe einer Schnelllyse mittels Kochen isoliert werden.

- $10 \mu \mathrm{l} \mathrm{H}{ }_{2} \mathrm{O}$ in ein PCR-Gefäß geben

- Kolonie mit sterilem Zahnstocher picken und auf eine Masterplatte überimpfen

- Den restlichen Teil der am Zahnstocher befindlichen Zellen in den $10 \mu \mathrm{H}_{2} \mathrm{O}$ resuspendieren

- 10 Minuten bei $95^{\circ} \mathrm{C}$ (Zellen lysieren, DNasen denaturieren), dann auf Eis

- Entsprechenden Mastermix für PCR zugeben

- PCR Programm starten (auf Primer abstimmen)

\subsection{Plasmid-Präparation mit Hilfe von Kits}

Mit Hilfe des Nucleospin ${ }^{\circledR}$ Plasmid-Kits ist es möglich, sehr schnell kleinere Mengen Plasmid-DNA aus E.coli Zellen (5 ml Kulturen) zu gewinnen. Die Extraktion erfolgt nach dem Protokoll des Herstellers Macherey-Nagel. 
Größere DNA-Mengen z.B. für die Protoplasten-Transformation wurden mit Hilfe des NucleoBond $^{\circledR}$ MaxiKits von Macherey-Nagel aus $300 \mathrm{ml}$ E.coli Kulturen gewonnen, die mit einer $5 \mathrm{ml}$ Übertagkultur angeimpft wurden. Die Extraktion erfolgte hier nach dem modifizierten Protokoll des Herstellers, indem die Säulen zweimal nacheinander zur Bindung und Elution desselben Plasmids benutzt werden.

\subsection{Plasmid-Präparation durch alkalische Lyse}

Eine weitere Möglichkeit sehr schnell kleinere Mengen Plasmid-DNA aus E.coli Zellen zu gewinnen ist eine modifizierte alkalische Lyse der Bakterien (Le Gouill et al., 1994). Die hieraus gewonnene DNA ist allerdings sehr viel unsauberer als die DNA, die mittels des Nucleospin ${ }^{\circledR}$ Plasmid-Kits gewonnen wurde und wird deshalb nur verwendet, wenn viele verschiedene Klone durch Restriktionsspaltungen getestet werden sollen.

- $\quad$ 1,5 ml einer $E$. coli-ü.N.-Kultur pelletieren (3 Minuten, $5000 \mathrm{rpm}$ )

- Überstand verwerfen

- Die Zellen in $100 \mu 1$ S1 (DNA-Maxi-Kit-Puffer) resuspendieren

- Die Lyse der Bakterien erfolgt durch Zugabe von $150 \mu 1$ S2

- 7-9 mal invertieren, max. 5 Minuten stehen lassen

- Zur Neutralisation $150 \mu \mathrm{l} \mathrm{S3}$ zugegeben und invertieren

- Zentrifugation (10 Minuten, $13000 \mathrm{rpm}$ )

- Überstand verwerfen

- Die pelletierte DNA wird mit $70 \%$ Ethanol waschen und kurz trocknen

- Pellet in $40 \mu \mathrm{l} \mathrm{H}_{2} \mathrm{O}$ lösen und so zur Restriktionsanalyse einsetzen

\subsection{DNA-Sequenzierung}

Zum Sequenzieren der DNA wird ein Verfahren benutzt, das auf der kontrollierten Unterbrechung der DNA-Synthese beruht. Diese Methode wurde von (Sanger et al., 1977) entwickelt. Einzelsträngige DNA dient als Template für die Synthese eines neuen Stranges. Es wird ein Primer zugegeben, der mit der DNA hybridisieren kann. Die DNA-Polymerase I benötigt für ihre Syntheseaktivität einen kurzen Abschnitt doppelsträngiger DNA. Zusätzlich $\mathrm{zu}$ den Desoxyribonukleotiden werden auch Didesoxyribonukleotide (ddNTPs) in den Reaktionsansatz gegeben. Diesen fehlt die Hydroxylgruppe am 3'-C-Atom des Zuckers. Werden die ddNTPs in den neuen DNAStrang eingebaut, so stoppt das Kettenwachstum, da keine weitere Phosphodiesterbindung gebildet werden kann. Über die unterschiedliche Länge der neu entstandenen DNA-Stränge lässt sich die Basenabfolge nach einer gelelektrophoretischen Auftrennung ermitteln. Längenunterschiede von einem Basenpaar können aufgelöst werden. Die ddNTPs sind unterschiedlich Fluoreszenzmarkiert, so dass nach einer Kapillar-Gelelektrophorese jeder DNA-Strang mit einer 
Laserapparatur detektiert wird. Bei dem Cycle Sequencing wird durch zyklisches Denaturieren und anschließende Neusynthese die Menge an $\mathrm{zu}$ analysierender DNA erhöht. Cycle Sequencing und Aufreinigung der DNA erfolgen mit dem ABI PRISM BigDye Terminator Cycle Sequencing Ready Reaction Kit.

In ein PCR-Gefäß werden pipettiert:

- 1,5 $\mu 1$ 5x T-Puffer (BDT1)

- $1 \mu 1$ Terminator Ready Reaction Mix

- 3-5 pmol Primer

- 100-200 ng DNA/kb (z.B 400-800 ng für einen 4 kb Vektor)

- Mit $\mathrm{H}_{2} \mathrm{O}$ auf $10 \mu \mathrm{l}$ auffüllen

Im Thermocycler wird folgendes Programm benutzt:

- $95^{\circ} \mathrm{C} 1$ Minute initiale Denaturierung

- $95^{\circ} \mathrm{C} 10$ Sekunden Denaturierung

- $50^{\circ} \mathrm{C} 5$ Sekunden Annealing (auf Primer abstimmen)

- $60^{\circ} \mathrm{C} 3$ Minuten Elongation

- Schritte 2-4; 29 mal wiederholen

- Lagerung bei $4^{\circ} \mathrm{C}$

Damit die DNA sequenziert werden kann, muss sie gereinigt werden. Alle Verunreinigungen, vor allem aber ungebundene Terminatoren, stören die Sequenzierung.

- Die $10 \mu \mathrm{l}$ Sequenzieransatz in 1,5 ml Eppendorfgefäße geben

- $40 \mu 170 \%$ Ethanol (unvergällt) zugeben

- Gut mischen

- Inkubation für 1 Stunde bei Raumtemperatur

- 20 Minuten bei RT/ 13.000 rpm zentrifugieren

- Überstand vollständig abnehmen

- Pellet mit $125 \mu 170 \%$ Ethanol (unvergällt) waschen

- 10 Minuten bei RT/ 13.000 rpm zentrifugieren

- Überstand vollständig abnehmen

- Pellet 1 Minuten bei $95^{\circ} \mathrm{C}$ mit offenem Deckel trocknen

- Pellet in $10 \mu \mathrm{l}$ HiDi aufnehmen; kann so direkt im Sequencer verwendet werden 


\subsection{RNA Extraktion mit Trizol}

Die Methode basiert auf einer Phenol/Chloroform Extraktion. Da RNA sich besser in der hydrophilen, wässrigen Phase löst, während Chlorophyll und andere Bestandteile besser in der hydrophoben Chloroform-Phase gelöst werden, können sie so voneinander getrennt werden.

Die beiden Thiocyanat-Salze im Extraktionspuffer inhibieren RNasen und verhindern so eine Degradation der RNA (Chomczynski, 1993; Chomczynski und Sacchi, 1987).

- $0,2 \mathrm{~g}$ Blattmaterial in $\mathrm{N}_{2}$ aufmörsern und in ein $2 \mathrm{ml}$ Eppendorfgefäß überführen

- 1,5 ml Trizolpuffer hinzugeben

- Gefäß auf dem Vortexer fixieren und 5 Minuten schütteln

- $300 \mu \mathrm{l}$ Chloroform hinzugeben

- Erneut 5 Minuten schütteln

- 30 Minuten bei $4^{\circ} \mathrm{C} / 12.000 \mathrm{~g}$ zentrifugieren

- Überstand (ca. 1,2 ml) in ein neues Gefäß überführen

- $420 \mu \mathrm{l}$ Fällungspuffer und $420 \mu \mathrm{l}$ Isopropanol zugegeben

- Invertieren und 10 Minuten bei RT inkubieren

- 15 Minuten bei $4^{\circ} \mathrm{C} / 12.000 \mathrm{~g}$ abzentrifugieren

- Überstand abnehmen

- Pellet in $250 \mu \mathrm{l} 70 \% \mathrm{EtOH}$ resuspendieren

- 10 Minuten bei $4^{\circ} \mathrm{C} / 12.000 \mathrm{~g}$ abzentrifugieren

- Einige Minuten lufttrocknen

- In $50 \mu \mathrm{l} \mathrm{H} \mathrm{H}_{2} \mathrm{O}$ lösen (Inkubation 20 min. bei RT auf dem Schüttler)

\subsection{Northern Blot Analyse}

Im Northern Blot Verfahren (Alwine et al., 1977; Thomas, 1980) wird die zu analysierende RNA durch eine denaturierende Agarosegelelektrophorese zunächst aufgetrennt und nach Kontrolle des Gellaufs auf dem Transilluminator durch einen Kapillarblot auf eine Nylonmembran übertragen. Durch Hybridisierung des Filters mit radioaktiv markierten einzelsträngigen DNA-Sonden ist es möglich, diejenigen RNATranskripte durch Autoradiographie sichtbar zu machen, die komplementär zu der eingesetzten Sonde sind.

\subsubsection{Auftrennung von RNA in denaturierenden Agarosegelen}

Um die elektrophoretische Größenauftrennung von RNA-Molekülen zu ermöglichen, muss die Elektrophorese unter denaturierenden Bedingungen stattfinden, da sonst die 
Sekundärstrukturen das Laufverhalten beeinflussen würden. Die Elektrophorese findet deshalb in einem Formaldehyd-haltigen Agarosegel statt:

- 1,5 g Agarose in 112,5 $\mathrm{ml} \mathrm{H}_{2} \mathrm{O}$ aufkochen

- Unter Rühren auf ca. $60^{\circ} \mathrm{C}$ abkühlen lassen

- $15 \mathrm{ml}$ 10x MEN-Puffer und 22,5 ml 37 \% Formaldehyd dazu geben

Als Laufpuffer dient 1x MEN-Puffer. Die je $10 \mu \mathrm{g}$ der RNA-Proben werden mit Wasser auf das gleiche Volumen abgeglichen und mit je $10 \mu \mathrm{l}$ RNA-Probenpuffer $(2,5 \mathrm{x})$ versetzt. Die Denaturierung der Proben erfolgt bei $65^{\circ} \mathrm{C}$ für $10 \mathrm{~min}$. Bis zum Auftragen der Proben werden diese auf Eis gehalten.

\subsubsection{Kapillar Blot}

Durch den Kapillar Blot wird die aufgetrennte RNA auf eine Nylonmembran übertragen.

- Zwei Lagen Fließpapier mit 10x SSC äquilibrieren und so auf einer ebenen Platte legen, dass die Enden in ein 10x SSC-Pufferreservoir tauchen

- Das RNA-Gel luftblasenfrei mit der Oberseite nach unten auf das Fließpapier legen

- Die Nylonmembran luftblasenfrei auf das Gel auflegen

- Drei Lagen Fließpapier und Papiertïchern oben drauf

- Mit einem Gewicht (ca. 500 g) gleichmäßig beschweren

- Über Nacht blotten

- RNA durch zweistündige Inkubation bei $80^{\circ} \mathrm{C}$ auf der Filteroberfläche fixieren

\subsubsection{Herstellen einer radioaktiv markierten DNA-Sonde}

Für die Herstellung radioaktiv markierter Hybridisierungssonden wird ein DNAFragment nach Restriktionsspaltung oder ein PCR-Produkt aus einem Agarosegel eluiert. Die Markierungsreaktion erfolgt nach der Random-Prime-Labeling-Methode (Feinberg und Vogelstein, 1983; Feinberg und Vogelstein, 1984), bei der Hexanukleotide zufälliger Sequenz an die Matrizen-DNA binden. Die gebundenen Hexanukleotide dienen dann als Primer für die Neusynthese eines komplementären Stranges durch die Klenow-Polymerase unter Einbau von radioaktiven Nukleotiden. Die verwendete Klenow-Polymerase ist modifiziert, so dass sie keine Exonucleaseaktivität (exo-) mehr besitzt.

Die Markierungsreaktion wird mit Hilfe des Megaprime-DNA-labeling-system Kits von Amersham Pharmacia vorgenommen. Die Durchführung erfolgt nach dem Protokoll des Herstellers, wobei jeweils $5 \mu \mathrm{l}\left[{ }_{32} \mathrm{P}\right]$ dATP zugefügt werden. Nach zweistündiger Inkubation bei $37^{\circ} \mathrm{C}$ wird die Reaktion durch Zugabe von $60 \mu 1 \mathrm{H}_{2} \mathrm{O}$ gestoppt. Nicht 
eingebaute Nukleotide und Primer werden durch Gelfiltration über eine Sephadex G50Säule abgetrennt. Als Säule dient eine $1 \mathrm{ml}$ Einwegspitze, die mit einem Fließpapierkügelchen verschlossen und dann mit dem Säulenmaterial beladen wird. Das Packen der Säule sowie die Elution der Sonde erfolgt jeweils durch Zentrifugation bei 1500 rpm für 5 min in der Hettichzentrifuge mit Ausschwingrotor. Die gereinigte Sonde wird in einem verschraubbaren Eppendorfgefäß aufgefangen.

\subsubsection{Hybridisierung der Northern Blot Membran}

Durch Hybridisierung der Membran mit radioaktiv markierten, einzelsträngigen DNASonden lassen sich komplementäre RNA-Transkripte auf der Membran lokalisieren. Die Spezifität, mit der die Sonde an die RNA bindet, ist abhängig von der Salzkonzentration und der Temperatur. Bei hoher Salzkonzentration und niedriger Temperatur ist die Stabilität unspezifischer DNA-RNA-Hybride größer als in Lösungen niedriger Salzkonzentration und höherer Temperatur. Durch die Absenkung der Salzkonzentration in den Waschlösungen erhöht man die Stringenz. Die Methode ist modifiziert nach (Church und Gilbert, 1984).

- Die zu analysierende Membran 30 Minuten bei $65^{\circ} \mathrm{C}$ in einer Hybridisierungsröhre mit 15 ml Hybridisierungslösung (Church) inkubieren

- Die Sonden-DNA 10 Minuten bei $95^{\circ} \mathrm{C}$ denaturieren

- Zugabe der Sonden-DNA zu ca. $15 \mathrm{ml}$ Hybridisierungslösung in die Hybridisierungsröhre

- Hybridisierung bei $65^{\circ} \mathrm{C}$ über Nacht im Roller

- Zur Abtrennung unspezifisch gebundener Sonden-DNA die Membran zweimal 5 Minuten mit 2x SSC / 0,1\% SDS in der Röhre waschen

- Weitere 10 Minuten im Bellydancer mit 1x SSC / 0,1\% SDS waschen

- Optional für weitere 15 - 30 Minuten mit 0,5x SSC / 0,1\% SDS waschen

Für den Nachweis der Radioaktivität wird die Membran in Folie eingeschweißt und mit einem IP-Screen exponiert. Die Dauer der Exposition hängt von der Menge der nachweisbaren Radioaktivität ab. Sie beträgt für diese Arbeit in der Regel ein bis zwei Tage. Die Auswertung erfolgt mit Hilfe des Bioimagers (BAS-1000 von Fuji). Zur Quantifizierung werden die Programme PCBAS ${ }^{\circledR} 2.09$ und TINA ${ }^{\circledR} 2.0$ der Firma Raytest verwendet. Die Normalisierung der detektierten Signale wird über den Vergleich mit der dokumentierten Ethidiumbromid-Färbung der RNA erreicht.

\subsubsection{Rehybridisierung}

Die auf der Filteroberfläche fixierte RNA kann nacheinander mit mehreren verschiedenen Sonden hybridisiert werden. Dazu müssen die auf dem Filter befindlichen radioaktiven Sonden aus der vorhergehenden Hybridisierung durch Denaturierung der RNA-DNA-Hybride in Waschlösungen mit geringer 
Salzkonzentration bei hoher Temperatur abgelöst werden. Die Membran wird durch Zugabe kochendheißer 0,1\%iger SDS-Lösung für 1 Stunde bei $65^{\circ} \mathrm{C}$ gewaschen. Danach ist der Filter für eine erneute Hybridisierung einsetzbar.

\subsection{RT-PCR mit quantitativer Real-Time-PCR}

Eine Alternative zum RNA-Gel und anschließendem Northern Blot, mit der ebenfalls die Menge eines bestimmten Transkripts in einer Probe bestimmt werden kann, ist die RT-PCR mit anschließender quantitativer Real-Time-PCR. Dabei wird die vorhandene mRNA einer Probe zunächst in komplementäre DNA (cDNA) umgeschrieben, die dann in der anschließenden PCR amplifiziert wird.

\subsubsection{RT-PCR}

Für die Reverse-Transkriptase-PCR (RT-PCR) nutzt man die Fähigkeit der Reversen Transkriptase, an die RNA gebundene Primer in 3'-Richtung zu verlängern. In diesem Fall werden ein Oligo-dT-Primer und ein Random-Nonamer-Primer verwendet. Der Oligo-dT-Primer lagert sich spezifisch an den poly-A-Schwanz der mRNAs an, während der Random-Nonamer Primer je nach Sequenz an verschiedensten Stellen der mRNA bindet. So werden in dieser Reaktion alle mRNAs in cDNA umgeschrieben. Um Verunreinigungen durch genomische DNA vorzubeugen wird vor der cDNA-Synthese noch ein DNAse-Verdau durchgeführt.

- $1 \mu \mathrm{g}$ RNA in ein PCR-Gefäß geben

- $1 \mu 1$ 10x Reaktionspuffer und $1 \mu 1$ DNAseI dazu geben und mit DEPC- $\mathrm{H}_{2} \mathrm{O}$ auf $10 \mu 1$ auffüllen

- 30 Minuten bei $37^{\circ} \mathrm{C}$

- $1 \mu 125$ mM EDTA dazu

- 10 Minuten bei $65^{\circ} \mathrm{C}$

- $\quad$,2 $\mu$ l Oligo-dT- und $1 \mu 1$ Random-Nonamer-Primer dazu geben

- Bei $70^{\circ} \mathrm{C}$ für 10 Minuten im Thermocycler inkubieren

- Auf Eis zwischenlagern

- Mastermix für alle Proben vorbereiten, pro Probe:

- $2 \mu \mathrm{ldNTPs}$

○ $4 \mu$ RT-Puffer

○ $0,25 \mu 1$ Reverse Transkriptase

- 6,25 $\mu \mathrm{l}$ des Mastermixes zu jeder Probe geben und mischen

- 70 Minuten bei $42^{\circ} \mathrm{C}$ im Thermocycler inkubieren

- 10 Minuten bei $70^{\circ} \mathrm{C}$ im Thermocycler (stoppt die Reaktion)

- Lagerung bei $4^{\circ} \mathrm{C}$ 
Die cDNA wird anschließend 1:10 mit Wasser verdünnt und so als Template für die qPCR eingesetzt.

\subsubsection{Quantitative Real-Time-PCR}

Die quantitative Real-Time-PCR ist eine sehr sensitive Methode, die die Amplifikation und Quantifizierung auch kleinerer DNA-Mengen in Echtzeit ermöglicht.

Während der Real-Time-PCR wird die Fluoreszenz nach jedem Zyklus gemessen. Als Fluorophor dient hier Sybr Green. Sybr Green ist ein Farbstoff, der an doppelsträngige, nicht aber an einzelsträngige DNA bindet und dann fluoresziert. Die Zunahme der Fluoreszenz während der Reaktion repräsentiert also die zunehmende Menge an amplifizierter DNA. Je mehr Template zu Beginn der Reaktion vorhanden ist, desto weniger Zyklen werden benötigt, um ein signifikant über dem Hintergrund liegendes Fluoreszenz-Signal zu erhalten (Gibson et al., 1996). Dieser Punkt wird als C(t)-Wert definiert und liegt immer in der exponentiellen Phase der Amplifikation.

Als interner Abgleich wird der Fluoreszenzfarbstoff Fluorescin zu jeder Reaktion dazugegeben.

- Master Mix ansetzen (pro Reaktion):

○ $18,45 \mu \mathrm{l} \mathrm{H} \mathrm{H}_{2}$

○ $2,5 \mu$ l 10x PCR-Puffer

○ $1 \mu \mathrm{l} \mathrm{MgCl}_{2}$

○ $0,25 \mu l \mathrm{dNTPs}$

○ $0,625 \mu 1$ Primer for $(10 \mu \mathrm{M})$

○ $0,625 \mu$ l Primer rev $(10 \mu \mathrm{M})$

○ $0,05 \mu \mathrm{l}$ DNA Polymerase (z.B. BioTaq, Advantage Taq für ChIP)

$\circ \quad 0,25 \mu \mathrm{l}$ Sybr Green

○ $0,25 \mu 1$ Fluorescin

- $24 \mu \mathrm{l}$ Master Mix in jedes PCR-Gefäß

- $1 \mu \mathrm{l}$ cDNA (1:10 verdünnt) zum Master Mix geben

- Gut mischen, kurz zentrifugieren

- PCR-Programm (Primer- und Polymerase-abhängig) starten

Da Sybr Green nicht zwischen unterschiedlichen doppelsträngigen DNA-Abschnitten unterscheidet, ist es wichtig als Qualitätskontrolle eine Schmelzkurve zu erstellen. Dafür wird am Ende der PCR die Temperatur langsam in $0,5^{\circ} \mathrm{C}$-Schritten erhöht. Am Schmelzpunkt trennen sich die Doppelstränge auf und die Fluoreszenz sinkt rapide. Alle PCR-Produkte eines spezifischen Primerpaares sollten die gleiche Schmelztemperatur haben. Sind in der Schmelzkurve mehrere Maxima zu erkennen, kann das verschiedene Gründe wie z. B. unspezifische Bindung, Primerdimere oder Kontamination haben.

Ist tatsächlich nur ein Maximum zu erkennen, kann das Ergebnis ausgewertet werden. Dazu werden die $\mathrm{C}(\mathrm{t})$-Werte der Proben miteinander verglichen. Die Menge des zu amplifizierenden Fragmentes sollte in jedem Zyklus verdoppelt werden. Ein 
Unterschied von 3,3 Zyklen im C(t)-Wert bedeutet deshalb etwa eine 10 fache Menge an DNA in der Ausgangs-Probe.

Für die Normalisierung der Messwerte wurde zusätzlich zu jeder Probe eine Amplifikation mit Primern für das Ubiquitin 5 (Ubi5) Gen durchgeführt. Dieses sollte in jeder Zelle gleichmäßig expremiert werden. Die gemessenen $C(t)$ Werte der anderen Primer Kombinationen werden deshalb mit den $C(t)$ Werten des Ubi5 verrechnet $(\Delta C(t)$ $=\mathrm{C}(\mathrm{t})$ Primer $\mathrm{x}-\mathrm{C}(\mathrm{t})$ Ubq5).

Der besseren Darstellung wegen werden alle Werte als Vielfaches der WT Probe (0h) dargestellt.

\subsection{Chromatin-Immunopräzipitation (ChIP)}

Die Chromatin-Immunopräzipitation ist eine Methode, mit der die in vivo Bindung von Proteinen an DNA gezeigt werden kann (Hecht et al., 1996; Johnson et al., 2001).

\subsubsection{Kreuzvernetzung der DNA-Protein Komplexe}

Die Kreuzvernetzung der DNA-Proteinkomplexe (Solomon et al., 1988; Solomon und Varshavsky, 1985) erfolgt mit Hilfe eines formaldehydhaltigen Crosslinkingpuffers.

- Je 5 g Blattmaterial pro Linie ernten und in Nylonstrümpfe packen

- In ein Einmachglas überführen und mit Crosslinkingpuffer (+ $1 \%$ Formaldehyd) überschichten

- Vakuum anlegen bis die Blätter mit dem Puffer getränkt sind (2 x 5 Minuten)

- 20 Minuten bei Raumtemperatur ohne Vakuum inkubieren

- Puffer entfernen und durch Glycinlösung ersetzen

- 5 Minuten Vakuum

- 5 Minuten bei Raumtemperatur ohne Vakuum inkubieren

- Blätter mit eiskaltem bidestilliertem Wasser waschen

- Blätter trocken tupfen

- In flüssigem Stickstoff einfrieren und lagern

\subsubsection{Isolation der Kerne}

In diesem Schritt werden die Kerne von den restlichen Zellorganellen und Zelltrümmern getrennt. Die Durchführung erfolgt im Kühlraum bei $4^{\circ} \mathrm{C}$.

- Blattmaterial in Stickstoff aufmörsern

- In $20 \mathrm{ml}$ Extraktionspuffer aufnehmen 
- Mit einem Homogenisator (Miccra) auf Stufe B für etwa 4 Minuten weiter homogenisieren und anschließend durch 2 Lagen Miracloth filtrieren

- Das Volumen mit Extraktionspuffer auf $24 \mathrm{ml}$ bringen

- Unter langsamen Rühren langsam $1 \mathrm{ml} 25 \%$ Triton tropfen

- 15 Minuten weiter rühren

- $6 \mathrm{ml} 35 \%$ Percoll mit den $25 \mathrm{ml}$ Kernen überschichten

- Bei $2000 \mathrm{~g}$ (3500 rpm), soft stopp, $4^{\circ} \mathrm{C}, 30$ Minuten abzentrifugieren

- Extraktionspuffer und $35 \%$ Percoll abnehmen

- Pellet in $20 \mathrm{ml}$ Gradientenpuffer resuspendieren

- Auf ein neues $6 \mathrm{ml} 35 \%$ Percollkissen geben

- Bei $2000 \mathrm{~g}$ (3500 rpm), soft stopp, $4^{\circ} \mathrm{C}, 10$ Minuten abzentrifugieren

- Überstand abnehmen und die Kerne in 0,5 ml SonicBuffer (0,5 \% SDS) aufnehmen

- 20 Minuten unter leichter Bewegung bei $4^{\circ} \mathrm{C}$ inkubieren

- $0,5 \mathrm{ml}$ SonicBuffer ohne SDS dazugeben, um endgültige Konzentration von $0,25 \%$ SDS zu erreichen

\subsubsection{Fragmentierung des Chromatins}

Die Ultraschallbehandlung zur Fragmentierung des Chromatins findet bei Cycle 1 und Amplitude 80\% für 1,5 Minuten pro Probe auf Eis statt. Anschließend wird 15 Minuten bei $13.000 \mathrm{rpm}$ und $4^{\circ} \mathrm{C}$ abzentrifugiert. Der Überstand, der das fixierte Chromatin enthält, wird in Aliquots von $200 \mu 1$ bei $-80^{\circ} \mathrm{C}$ weggefroren.

$50 \mu 1$ werden aufgehoben, um die DNA-Konzentration zu bestimmen:

- Zugabe von $5 \mu 1$ Proteinase K und $1 \mu$ l RNAse

- 1 Stunde Inkubation bei $42^{\circ} \mathrm{C}$

- Über Nacht Inkubation bei $65^{\circ} \mathrm{C}$ (Quervernetzung wird rückgängig gemacht)

Quantifizierung der DNA:

- $200 \mu 1$ Phenol:Chloroform:Isoamylalkohol (25:24:1) zum Aliquot dazugeben

- 30 Sekunden mischen

- 10 Minuten bei RT und 13.000 rpm abzentrifugieren

- Obere wässrige Phase in neues Eppendorfgefäß

- $200 \mu$ l Chloroform:Isoamylalkohol (24:1) dazu

- 30 Sekunden mischen

- 10 Minuten bei RT und 13.000 rpm abzentrifugieren

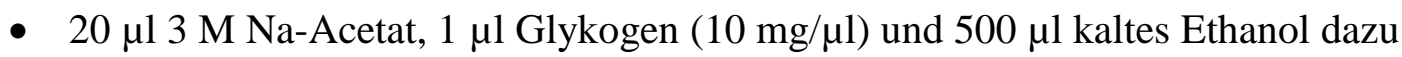


- Gut mischen

- 4 Stunden bei $-80^{\circ} \mathrm{C}$

- 45 Minuten bei $4^{\circ} \mathrm{C}$ und $13.000 \mathrm{rpm}$ zentrifugieren

- Pellet mit $900 \mu 170 \%$ Ethanol waschen

- 20 Minuten bei $4^{\circ} \mathrm{C}$ und $13.000 \mathrm{rpm}$ zentrifugieren

- Pellet bei $37^{\circ} \mathrm{C}$ trocknen

- Pellet in $100 \mu \mathrm{l} \mathrm{H}_{2} \mathrm{O}$ lösen

- Konzentrationsbestimmung in 1:20 Verdünnung am GeneQuant

- Kontrolle der Fragmentgröße auf 1\%igem Agarosegel

\subsubsection{Immunopräzipitation}

Die aliquotierten Chromatin-Proteinkomplexe werden nun für die Immunopräzipitation verwendet:

- Proben auf Eis auftauen

- 10 Minuten bei 13.000 rpm zentrifugieren

- Mit Hilfe der zuvor bestimmten DNA-Konzentrationen die gleiche Menge DNA $(12 \mu \mathrm{g})$ in neues Eppendorfgefäß überführen

- Mit SonicBuffer + 0,25\% SDS auf $200 \mu$ l auffüllen

- $300 \mu 1$ RIPAF-SDS dazu

- 1 Stunde mit $5 \mu 1$ Preimmunserum unter Bewegung im Intellimixer bei $4^{\circ} \mathrm{C}$ inkubieren

- In der Zwischenzeit 0,125 g Protein A Sepharose beads mit $1 \mathrm{ml}$ RipaF aktivieren, 15 Minuten aufquellen lassen, abzentrifugieren für 3 Minuten bei $5.000 \mathrm{rpm}$, Puffer mit Insulinnadel abziehen, erneut waschen und anschließend in $500 \mu 1$ RipaF aufnehmen, um eine 50 \%ige Lösung zu bekommen

- Je $50 \mu \mathrm{l}$ gewaschene Protein A beads zu de $500 \mu$ l Proben hinzugeben

- 1 Stunde bei $4^{\circ} \mathrm{C}$ im Intellimixer inkubieren

- 2 Minuten bei $13.000 \mathrm{rpm}$ zentrifugieren

- Überstand mit $1 \mu \mathrm{l}$ HA-Antikörper (ChIP grade HA-AK von abcam) mindestens $2 \mathrm{~h}$ bei $4^{\circ} \mathrm{C}$ inkubieren (vorher $50 \mu \mathrm{l}$ als Input-Kontrolle aufbewahren)

- $50 \mu \mathrm{l}$ gewaschene Protein A beads zugeben

- $2 \mathrm{~h}$ bei $4^{\circ} \mathrm{C}$ im Intellimixer inkubieren

- 5 Minuten $5.000 \mathrm{rpm}$ zentrifugieren

- Überstand mit Insulinnadel abnehmen (aufheben für Western-Kontrolle)

- Protein A beads (mit gebundenem Antikörper und Proteinen) 4 mal mit $1 \mathrm{ml}$ RIPAF waschen 
- mit 2 × $200 \mu 1$ Glycin elution buffer eluieren (Puffer auf Protein A beads geben, vortexen, 1 Minute abzentrifugieren bei $13.000 \mathrm{rpm}$ ), jeweils $50 \mu \mathrm{l}$ davon aufheben für Western Kontrolle

- restliche $150 \mu \mathrm{l}$ Überstand direkt in $150 \mu \mathrm{l} 1 \mathrm{M}$ Tris- $\mathrm{HCl} \mathrm{pH}$ 9,7 geben (zum Neutralisieren)

- $400 \mu \mathrm{l}$ Sonic Buffer mit 0,25\% SDS zur Input-Kontrolle geben und von da an genauso wie die Probe behandeln

Der Erfolg der IP wird anschließend im Western überprüft. Dafür werden je $100 \mu \mathrm{l}$ Überstand und Eluat mit $400 \mu \mathrm{l}$ Aceton über Nacht gefällt und anschließend in Harnstoffextraktionspuffer aufgenommen und auf das SDS-Gel aufgetragen. $10 \mu 1$ Ausgangschromatin werden ebenfalls mit Harnstoffextraktionspuffer versetzt und mit aufgetragen.

Nachdem die durch die Immunopräzipitation gewonnene DNA (auch die der InputKontrollen) mit einer Phenol-Chloroformfällung aufgereinigt wurde (s. Fragmentierung des Chromatins), bei der die DNA am Ende in $35 \mu 1 \mathrm{H}_{2} \mathrm{O}$ (bzw. $450 \mu \mathrm{l}$ für die InputKontrolle) aufgenommen wird, kann sie in einer Real-Time-PCR getestet werden.

Für die Normalisierung werden neben den Primern für das potenzielle Zielgen auch Primer verwendet, die einen Teil des Actin 7 Promotors amplifizieren. Da dieser keine bekannten Motive enthält, an die bZIP Transkriptionsfaktoren binden dient er als Negativ-Kontrolle und sollte in WT und bZIP-Überexpressionspflanzen gleich stark amplifiziert werden. Die Anreicherung des Promotorfragments in den Überexpremierern wird als ein Vielfaches des Wildtyps angegeben.

\subsection{Herstellung von Proteinextrakten aus Pflanzen}

Proteinextrakte können aus Blattmaterial mittels einer Extraktion mit Harnstoffextraktionspuffer gewonnen werden.

- Blattgewebe unter flüssigem Stickstoff aufmörsern

- 50-200 mg des Pulvers im gefrorenen Zustand in ein Eppendorfgefäß einwiegen

- $150 \mu$ Harnstoffextraktionspuffer dazugeben und gut mischen

- Bei $80^{\circ} \mathrm{C}$ für 10 Minuten im Thermomixer inkubieren

- 10 Minuten bei RT und 13.000 rpm zentrifugieren, um Zelltrümmer und DNA abzutrennen

- Überstand in ein neues Eppendorfgefäß überführen

- Die Proteinextrakte bis zur weiteren Verwendung bei $-20^{\circ} \mathrm{C}$ lagern

- Vor Auftragung in der SDS-PAGE 5 Minuten bei $65^{\circ} \mathrm{C}$ inkubieren

- Die Proben können direkt auf das Gel aufgetragen werden 


\subsection{Western Blot Analyse}

\subsubsection{SDS-Polyacrylamidgelelektrophorese}

Die SDS-Polyacrylamidgelelektrophorese (SDS-PAGE, Laemmli, 1970) dient der Auftrennung von Proteinen nach ihrer Molekularmasse. Die Polyacrylamidmatrix wird durch Polymerisation von Acrylamid mit dem Quervernetzer N,N'Methylenbisacrylamid (BIS) hergestellt. Die Porengröße im Gel kann durch die Wahl der Acrylamidkonzentration sowie des Verhältnisses Acrylamid/BIS verändert werden. Die Polymerisation wird durch Zugabe von Ammoniumpersulfat (APS) durch Erzeugung freier Radikale gestartet. Als Katalysator wird N,N,N',N'Tetramethylethylendiamin (TEMED) zugefügt. Nach Beladen der Taschen des Gels mit je $20 \mu \mathrm{l}$ Proteinextrakt aus denaturierten Harnstoffextrakten und Bedecken der Taschen mit Laufpuffer erfolgt der Gellauf bei $140 \mathrm{~V}$ für etwa 2 Stunden.

\subsubsection{Proteintransfer auf PVDF-Membranen}

Der Transfer der im SDS-Gel aufgetrennten Proteine auf eine PVDF-Membran erfolgt mittels der „Semi-Dry-Blotting“"-Methode (Kyhse-Anderson, 1984).

- Drei Lagen Fließpapier in Transferpuffer anfeuchten und auf die Blottingapparatur auflegen

- Die PVDF-Membran in Methanol aktivieren, mit Transferpuffer äquilibrieren und luftblasenfrei auf die Schicht Fließpapier legen

- Das Gel auf dem Filter positionieren

- Mit drei Lagen in Transferpuffer äquilibriertem Fließpapier bedecken

Der Elektrotransfer läuft für eine Stunde bei $1 \mathrm{~mA} / \mathrm{cm}^{2}$ Filterfläche $(=125 \mathrm{~mA}$ bei einem großen Gel). Nach dem Transfer wird der Filter kurz in TBS gewaschen und zwischen zwei Lagen Fließpapier getrocknet. Die Membran wird vor der Weiterbehandlung wieder mit Methanol aktiviert.

\subsubsection{Immunodetektion mit dem ECL+System}

Bei der hier angewendeten indirekten Nachweismethode werden die auf der Membran immobilisierten Proteine zuerst mit einem Primärantikörper immunodetektiert. Dieser Antikörper ist spezifisch gegen ein Epitop des nachzuweisenden Proteins gerichtet. Unter Verwendung eines Peroxidase-gekoppelten zweiten Antikörpers wird der Primärantikörper erkannt. Der Nachweis erfolgt mit Hilfe des $\mathrm{ECL}^{+}$Kits der Firma Amersham. Nach Inkubation des Filters mit einem Substrat-Mix kann die bei der Peroxidase-katalysierten Oxidation des Substrates Luminol entstehende Chemilumineszenz durch Exposition eines Röntgenfilms nachgewiesen werden. 
- 1 Stunde Inkubation mit $5 \%$ Milchpulver in TBST (Absättigen freier Stellen auf der Membran = Blocken )

- 2 Stunden oder länger mit $1 \%$ Milchpulver in TBST und Primärantikörper inkubieren

- Die Membran dreimal 5 Minuten in 1x TBST mit $1 \%$ Milchpulver waschen (zum Entfernen von nicht gebundenem Antikörper)

- 2 Stunden oder länger in TBST mit $1 \%$ Milchpulver mit dem Sekundärantikörper inkubieren

- 5 x 5 Minuten Waschen mit 1x TBST (entfernt nichtgebundenen zweiten Antikörper)

- Das ECL-Substratmix frisch aus Lösung A und Lösung B herstellen (für eine große Membran von 17,5 x 7,5 cm 4ml Lösung A und $100 \mu \mathrm{l}$ Lösung B)

- Die Membran mit der Proteinseite nach oben auf eine Klarsichtfolie legen und mit dem Substratmix 5 Minuten inkubieren

- Überschüssiges Substratmix entfernen

- Eine zweite Klarsichtfolie obendrauf legen

Die Detektion der Chemilumineszenzsignale erfolgt durch Exposition eines Röntgenfilms, je nach Signalstärke für wenige Sekunden bis zu einer Stunde, der dann für 1-5 Minuten entwickelt, kurz gewässert und 3 Minuten fixiert wird.

\subsection{Messung des Chlorophyllgehalts}

Die Messung des Gesamtchlorophyllgehalts ist eine photometrische Methode. Da Landpflanzen und damit auch Arabidopsis zwei verschiedene Chlorophylle besitzen, die auch ein leicht unterschiedliches Absorptionsmaximum haben (Chlorophyll a bei 665 $\mathrm{nm}$ und Chlorophyll b bei $650 \mathrm{~nm}$ ), wird die Extinktion der hergestellten RohextraktLösung bei beiden Wellenlänge gemessen und anschließend verrechnet.

- Pflanzenmaterial in flüssigem Stickstoff aufmörsern und je $100 \mathrm{mg}$ in gefrorenem Zustand in 1,5 ml Eppendorfgefäße überführen

- $1 \mathrm{ml}$ Methanol dazugeben

- 30 Minuten bei $60^{\circ} \mathrm{C}$ inkubieren

- 10 Minuten bei RT und $13.000 \mathrm{rpm}$ zentrifugieren

- Überstand in neues Eppendorfgefäß überführen

- Messung einer 1:20 Verdünnung am Photometer bei 650 und $665 \mathrm{~nm}$ (Extinktion muss $<0,5$ sein)

Berechnung des Chlorophyllgehalts mit folgender Formel (Holden, 1965):

$\mathrm{E}(650) * 0,025+\mathrm{E}(665) * 0,005=\mathrm{mg}$ Gesamtchlorophyll pro ml Meßlösung 


\subsection{Stärkenachweis in Arabidopsis}

\subsubsection{Stärkefärbung von Arabidopsis Pflanzen}

Zur Färbung von Stärke in Blättern von Arabidopsis Pflanzen wird die sogenannte Iodstärkereaktion benutzt. Stärke besteht im Wesentlichen aus Amylose (unverzweigte Glukoseketten) und Amylopektin (verzweigte Glukoseketten). Die unverzweigte Amylose bildet mit Iod einen blaufarbigen Komplex. Dieser kommt dadurch zustande, dass sich Polyiodidketten $\left(\mathrm{I}_{3-}, \mathrm{I}_{5-}, \mathrm{I}_{7-}, \mathrm{I}_{9-}\right)$ in den kanalartigen Hohlraum der AmyloseHelix einlagern. Die Polyiodidketten entstehen, indem sich $\mathrm{I}_{2}$-Moleküle an ein in der Lösung vorhandenes Iod-Ion anlagern. In diesen Ketten sind alle sieben Valenzelektronen der Iod-Atome delokalisiert. Dadurch wird die Anregungsenergie der Valenzelektronen herabgesetzt, sodass sie im langwelligeren Bereich Licht absorbieren und blau erscheinen.

- Ganze Arabidopsis Rosetten werden geerntet und in Falcon-Röhrchen mit $80 \%$ Ethanol überführt

- 30 Minuten bei $75^{\circ} \mathrm{C}$ inkubieren und damit entfärben

- Überstand verwerfen

- Nochmal $80 \%$ igen Ethanol draufgeben und weitere 30 Minuten bei $75^{\circ} \mathrm{C}$ entfärben

- Lugol'sche Lösung (2 g/l $\mathrm{I}_{2}$ und $\left.10 \mathrm{~g} / \mathrm{l} \mathrm{KI}\right)$ draufgeben

- 20 Minuten bei Raumtemperatur inkubieren

- Überstand verwerfen und zweimal mit $\mathrm{H}_{2} \mathrm{O}$ spülen

\subsubsection{Quantitative Messung des Stärkegehalts}

Für die quantitative Bestimmung des Stärkegehalts wurde das StarchAssay Kit von Biovision verwendet. In diesem Assaysystem wird Stärke zu Glukose hydrolysiert und anschließend oxidiert. Dabei entsteht Fluoreszenz $(E x / E m=535 / 587 \mathrm{~nm})$, die detektiert werden kann. Für die Bestimmung wurden $50 \mathrm{mg}$ aufgemörsertes Pflanzenmaterial pro Probe verwendet und die lösliche Stärke nach dem Protokoll des Herstellers extrahiert. Gemessen wurden je zwei Replikate mit dem CytoFluor II Plate Reader.

\subsection{Bestimmung des Aminosäuregehalts mittels HPLC}

Die Bestimmung des Aminosäuregehalts erfolgt in einer Kooperation mit Klaus Harter und Bettina Stadelhofer (Universität Tübingen). Dafür wurde das aufgemörserte, in flüssigem Stickstoff eingefrorene, Pflanzenmaterial gefriergetrocknet (mit der Gefriertrocknung in der Abteilung Tischner, bei $-80^{\circ} \mathrm{C}$ ü.N.) und anschließend verschickt. 
In Tübingen wurden dann die Aminosäuren folgendermaßen extrahiert:

- 5-10 mg gefriergetrocknetes Material nehmen

- $500 \mu 180 \%$ iges Methanol zufügen

- 3 Minuten im Wasserbad kochen

- 3 Minuten bei maximaler Geschwindigkeit zentrifugieren

- Überstand auf Eis

- Pellet mit $500 \mu 1$ 20\%igem Methanol waschen

- 3 Minuten im Wasserbad kochen

- 3 Minuten bei maximaler Geschwindigkeit zentrifugieren

- Überstände vereinigen

- In der speedvac ca. $3 \mathrm{~h}$ „trocknen“

- In $138 \mu \mathrm{l}$ Verdünnungspuffer $(0,7 \%$ Lithiumacetat und $0,6 \% \mathrm{LiCl})+12 \mu \mathrm{l} 2,5$ $\mathrm{mM}$ Norleucin aufnehmen

- 3 Minuten bei maximaler Geschwindigkeit zentrifugieren

- durch 0,2 $\mu \mathrm{m}$ Minisart RC15 filtrieren (500 $\mu$ 1 Eppendorfgefäße verwenden)

Die Messung erfolgte danach mittels eines HPLC-Verfahrens auf einer KationenAustausch-Säule mit Lithiumpuffer als Eluat (wie in Pilot et al. 2004).

\subsection{Massenspektrometrische Bestimmung der Metabolitgehalte}

Die Bestimmung der Metabolitgehalte erfolgte in einer Kooperation mit Wolfram Weckwerth (Universität Wien) mit Hilfe eines GC-MS Verfahrens (zur Übersicht: Halket et al., 2005; Goodacre et al., 2004; Weckwerth, 2003). Dafür wurden 100mg des aufgemörserten in flüssigem Stickstoff eingefrorenen Pflanzenmaterials abgewogen und auf Trockeneis nach Wien gebracht. Dort erfolgte die Extraktion der Metabolite:

- Zugabe von $1 \mathrm{ml}$ Extraktionsgemisch (Methanol, Chlorophorm, Wasser) zu allen Proben (auch der Leerprobe)

- Extrakt ca. 10 sek vortexen, 8 min auf Eis inkubieren und zwischendurch ab und zu nochmal vortexen

- Abzentrifugieren für $4 \mathrm{~min}$. bei $14.000 \mathrm{~g}$ und $4^{\circ} \mathrm{C}$

- Überstand in ein frisches Eppi überführen (Pellet enthält Zellreste und Proteine, Überstand Metabolite)

- Zugabe von $500 \mu 1$ Millipore Wasser zur Trennung der polaren und unpolaren Phase

- Proben noch einmal vortexen

- Abzentrifugieren für $2 \mathrm{~min}$. bei $14.000 \mathrm{~g}$ und $4^{\circ} \mathrm{C}$ 
- Obere polare Phase auf zwei frische Eppendorfgefäße aufteilen (2 Aliquots)

- Internen Standard zufügen $(25 \mu 1$ Ribitol 0,02 g/l)

- In der SpeedVac ü.N. einrotieren und Eppendorfgefäße mit getrockneten Pellets bei $-80^{\circ} \mathrm{C}$ lagern

Die extrahierten Metabolite werden anschließend in zwei Schritten derivatisiert. Im ersten Schritt findet eine Methoximierung statt. Durch diese wird die Komplexität der Zuckerisomere reduziert.

- $20 \mu \mathrm{l}$ eines Methoximierungsgemisches (40 mg Methoxyaminhydrochlorid in 1 ml Pyridin) zur Probe gegeben (unterm Abzug arbeiten!)

- $90 \mathrm{~min}$ bei $30^{\circ} \mathrm{C}$ im Thermomixer inkubieren

Im zweiten Schritt der Derivatisierung findet eine Silylierung statt. Dabei werden Trimethylsilylgruppen (TMS Gruppen) an die Moleküle gehängt, damit diese thermisch stabiler und flüchtiger werden, was wichtig für die spätere Auftrennung in der GC-MS ist.

- $80 \mu 1$ Silylierungsgemisch (1 ml MSTFA mit $30 \mu 1$ Alkanmix) zugeben

- Mindestens 30 min bei $37^{\circ} \mathrm{C}$ auf Thermoschüttler inkubieren

- Abzentrifugieren für 2 min bei $14.000 \mathrm{~g}$ und RT

- $50 \mu 1$ des Überstandes in GC-Vials mit Microeinsätzen überführen

Für die Bestimmung der Metabolite in den Proben wird ein „fullscan“ mit Hilfe der Gaschromatographie (GC) mit anschließender Massenspektrometrie (MS) in einem Triple Quadrupole MS durchgeführt.

Die Auswertung der Daten erfolgte mit Hilfe der Programme AMDIS und XCALIBUR.

\subsection{Verwendete Computerprogramme}

- MicrosoftOffice 2003; GraphPadPrism5 - Datenauswertung und -präsentation

- Genevestigator (Hruz et al., 2008) - vergleichende Expressionsanalyse von Genen in öffentlichen Transkriptomdatensätzen

- PCBAS 2.09 und TINA 2.0 (Raytest) - Bearbeitung von Northern Blots

- MyIQ (BioRad) - qPCR Auswertung

- AMDIS (NIST) und XCALIBUR (Thermo Scientific) - Auswertung der massenspektrometrischen Metabolitdaten

- VectorNTI 10.1.1 (Invitrogen) - Bearbeitung von DNA- und Proteinsequenzen

- Chromas 1.55 (Technelysium, 1998) - Analyse von Sequenzierdaten

- Blast (Altschul et al., 1997; Schäffer et al., 2001) - Programme zur Suche von ähnlichen DNA- oder Proteinsequenzen 


\section{Ergebnisse}

\subsection{Eine verlängerte Dunkelphase als experimentelles Modell- system für Studien der Energieverarmung in Pflanzen}

Um Energie zu gewinnen, sind Pflanzen darauf angewiesen Photosynthese zu betreiben. Einen Teil ihrer Photosyntheseprodukte lagern sie während des Tages in Form von Stärke in den Chloroplasten ein. Während eines normalen Tag/Nacht-Zyklus erreicht die Stärkeeinlagerung ihr Maximum am Ende der Lichtphase (Abb. 5.1). Während der folgenden Nacht werden die angelegten Speicherreserven dann wieder verbraucht. Das pflanzliche System ist dabei so gut an den gegebenen Tag-/Nachtrhythmus angepasst, dass gegen Ende der Nacht die gesamten Stärkevorräte aufgebraucht sind (Abb. 5.1; Usadel et al., 2008). Verlängert man nun die Dunkelphase, so führt dies unmittelbar zu einem starken Energiemangel. Dieser synchrone Entzug der Nährstoffe während der verlängerten Nacht ist deshalb eine einfache Methode, um die Auswirkungen von Energiemangelbedingungen auf den pflanzlichen Metabolismus zu untersuchen (Lin und $\mathrm{Wu}, 2004)$.

Energieverarmung während der verlängerten Nacht führt letztendlich zur Ausprägung einer dunkelinduzierten Seneszenz. Während dieser kommt es zu schwerwiegenden

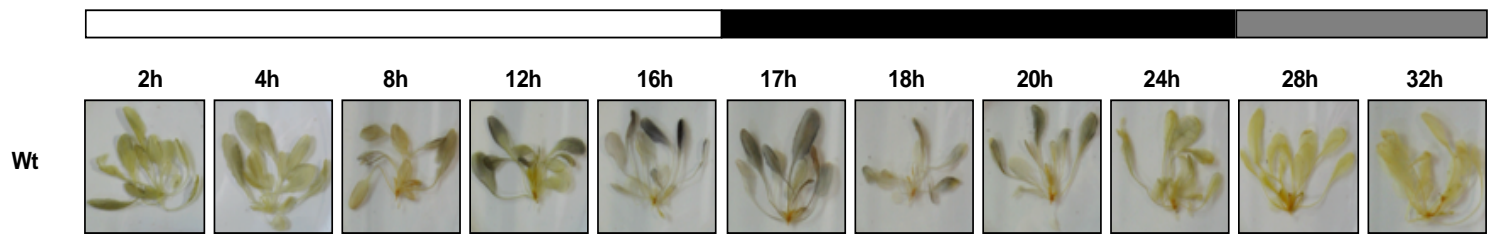

Abb. 5.1: Stärkefärbung von Arabidopsis Pflanzen während Tag, Nacht und verlängerter Dunkelphase Wildtyp Pflanzen wurden 3-4 Wochen im Langtag angezogen. Für die Stärkefärbung wurde zu den angegebenen Zeitpunkten eine Rosette oberhalb der Erde abgeschnitten. Die Pflanzen wurden anschließend mit Ethanol entfärbt und die Stärke mit Iod-Iodkalium-Lösung sichtbar gemacht. weißer Balken: normale Lichtphase (16h), schwarzer Balken: normale Nacht $(8 \mathrm{~h})$, grauer Balken: verlängerte Nacht 
Änderungen des Primärmetabolismus, unter anderem dem Abbau von Proteinen, Aminosäuren, Nukleinsäuren, der Hydrolyse von Polysacchariden und Oxidation von Fettsäuren (Smart, 1994).

Um die Versuchsbedingungen zu charakterisieren, wurden durch Seneszenz induzierte Markergene $($ SAG $=$ SENESCENCE ASSOCIATED GENE) mit Hilfe von quantitativer Real-Time PCR (qPCR) untersucht. Unterschiedliche Formen der Seneszenz, wie die natürliche Seneszenz oder dunkelinduzierte Seneszenz, führen dabei zur Expression unterschiedlicher, aber überlappender Sets dieser SAGs. Während der dunkelinduzierte Seneszenz wird z.B. SAG103 transkriptionell aktiviert (Van der Graaff et al., 2006).
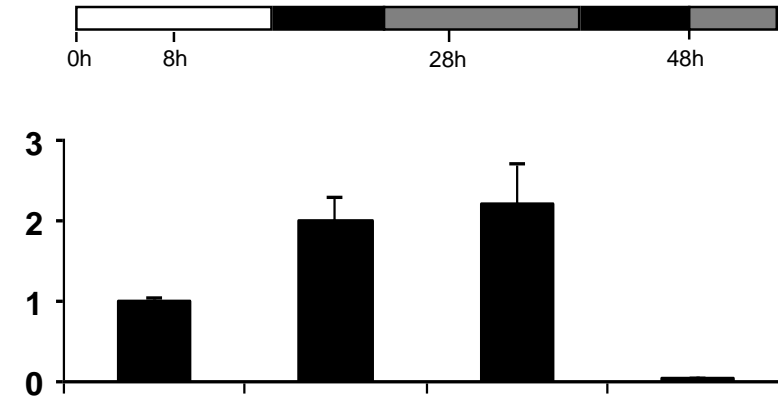

$C A B$
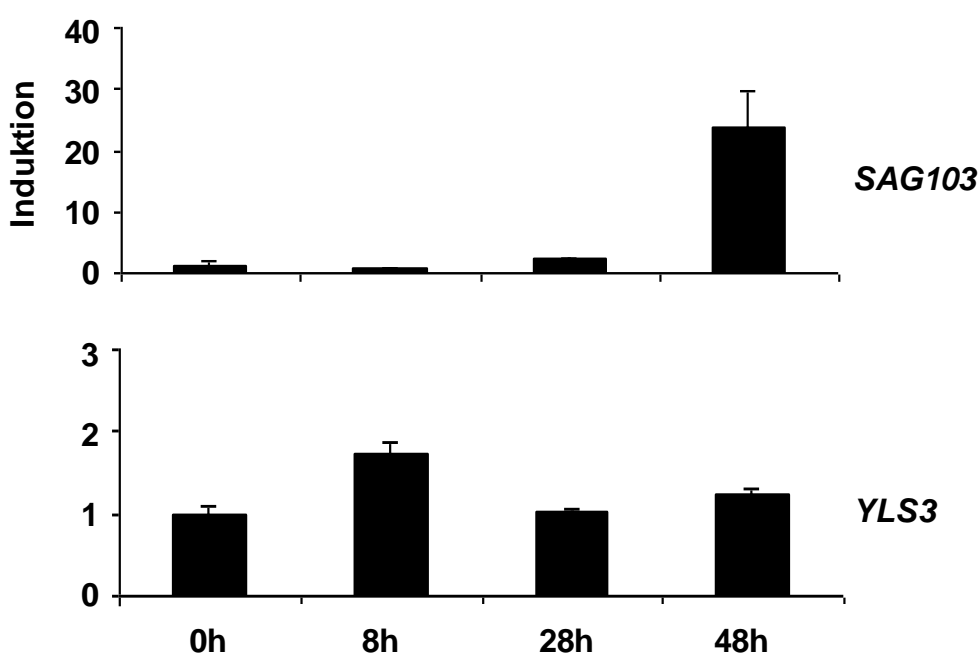

\footnotetext{
Abb. 5.2: Expression typischer Markergene für licht-/dunkelheitsabhängige Prozesse und natürliche Seneszenz, während der verlängerten Nacht

Wildtyp Pflanzen wurden 3-4 Wochen im Langtag angezogen. Zu den angegebenen Zeitpunkten wurden jeweils 8-10 Pflanzen geerntet und zusammen aufgearbeitet. Mit Hilfe der quantitativer Real-Time PCR (qPCR) wurden die oben angegebenen Gene untersucht. Dargestellt sind die relativen Werte im Vergleich zur Expression nach 0 Stunden Dunkelheit von je zwei Replikaten nach Abgleich mit dem Haushaltsgen Ubiquitin. Weißer Balken: normale Lichtphase (16h), schwarzer Balken: normale Nacht $(8 \mathrm{~h})$, grauer Balken: verlängerte Nacht
} 
Bereits nach 4 Stunden der verlängerten Nacht kommt es unter unseren Versuchsbedingungen $\mathrm{zu}$ einer leichten Induktion von SAG103, nach weiteren 12 Stunden in Dunkelheit ist die Induktion im Vergleich zum 0h-Wert bereits auf das 25fache gestiegen (Abb. 5.2). Natürliche Seneszenz induziert dieses Gen dagegen nicht. YLS3 (YELLOW LEAF SPECIFIC 3), ein Markergen für die natürliche Seneszenz, wird dagegen unter den hier gewählten Versuchsbedingungen der verlängerten Dunkelphase nicht induziert. Die Transkription des lichtinduzierten Markergens CAB (CHLOROPHYLL A/B BINDING PROTEIN) wird nach 16 Stunden verlängerter Nacht stark reprimiert.

Dass innerhalb der ersten 16 Stunden der Dunkelinduktion bereits typische dunkelinduzierte Gene wie SAG103 transkriptionell angeschaltet und typische lichtinduzierte Gene wie $C A B$ transkriptionell herunter reguliert werden, zeigt, dass der Zeitraum zwischen 4 und 16 Stunden der verlängerten Nacht bereits zu weitreichenden Änderungen des Metabolismus führt.

\subsection{Viele bZIP Transkriptionsfaktoren werden während der verlängerten Nacht transkriptionell induziert}

Die Inkubation der Pflanzen in der verlängerten Nacht führt zu einer starken Veränderung der Genexpression, die dann letztendlich zu der Anpassung des pflanzlichen Metabolismus und zur Aktivierung typischer Prozesse der dunkelinduzierten Seneszenz, wie z.B. dem Abbau von Proteinen, Aminosäuren, Nukleinsäuren, der Hydrolyse von Polysacchariden und Oxidation von Fettsäuren führt. Einen großen Anteil daran haben die Transkriptionsfaktoren. Sie führen zu einer Aktivierung oder Reprimierung ihrer Zielgene und tragen dadurch dazu bei, dass die Pflanze schnell auf diese Energiemangelbedingungen reagieren kann. Eine Gruppe von Transkriptionsfaktoren sind die basischen Leucinzipper (bZIPs). Viele von ihnen werden unter Energiemangelbedingungen während der verlängerten Nacht transkriptionell aktiviert, wie Analysen mit öffentlichen Datenbanken wie Genevestigator (Hruz et al., 2008) ergaben (Abb. 5.3). 

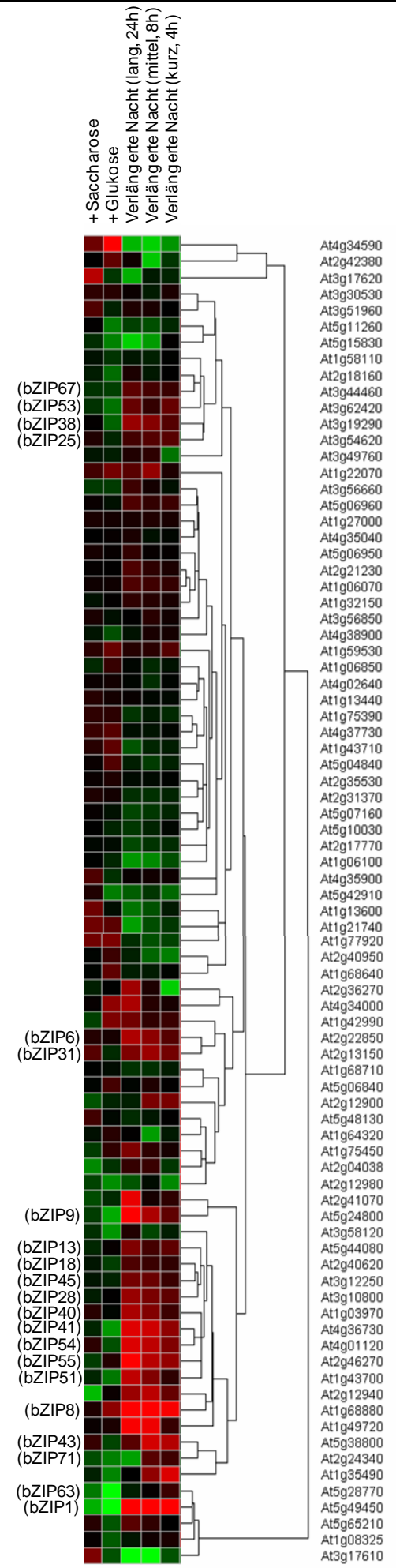

Abb. 5.3: Genevestigator Analyse (Hruz et al., 2008) der Expression aller bZIP Transkriptionsfaktoren während der verlängerten Nacht

Behandlung mit Glukose oder Saccharose sowie eine verlängerte Nacht führen zur Aktivierung (rot) bzw. Reprimierung (grün) der Transkription einer Reihe von bZIP TF. Dargestellt sind die relativen Expressionswerte unter den angegebenen Bedingungen im Vergleich zur Kontrolle, sowie die At-Nummern aller bZIP TF. Für einige ausgewählte TF wird auch der Name in der bZIP Nomenklatur (nach Jakoby et al., 2001) angegeben. 
Viele der durch Dunkelheit transkriptionell aktivierten bZIPs werden durch Zugabe von Zuckern reprimiert. Dies zeigt, dass die Energiemangelbedingungen während der verlängerten Nacht zur Aktivierung dieser Gene führen und Zucker diesen Prozess wieder reprimieren kann.

\subsection{AtbZIP1 und AtbZIP53 werden während der verlängerten Nacht transkriptionell aktiviert}

Einer der während der verlängerten Nacht am stärksten aktivierten bZIP Transkriptionsfaktoren ist AtbZIP1 (At5g49450, Abb. 5.3), ein Mitglied der Gruppe S1 der bZIP Transkriptionsfaktoren (Ehlert et al., 2006). Die Expression von AtbZIP1 wird auch sehr stark durch Zucker reprimiert. Eine qPCR Analyse der Transkription dieser Untergruppe der bZIPs während mehrerer Tage in Dunkelheit bestätigte die Genevestigator Analyse. Hier zeigt AtbZIP1 eine sehr starke 30fache Aktivierung während der Dunkelinduktion (Abb. 5.4). Der nächste Verwandte von AtbZIP1,

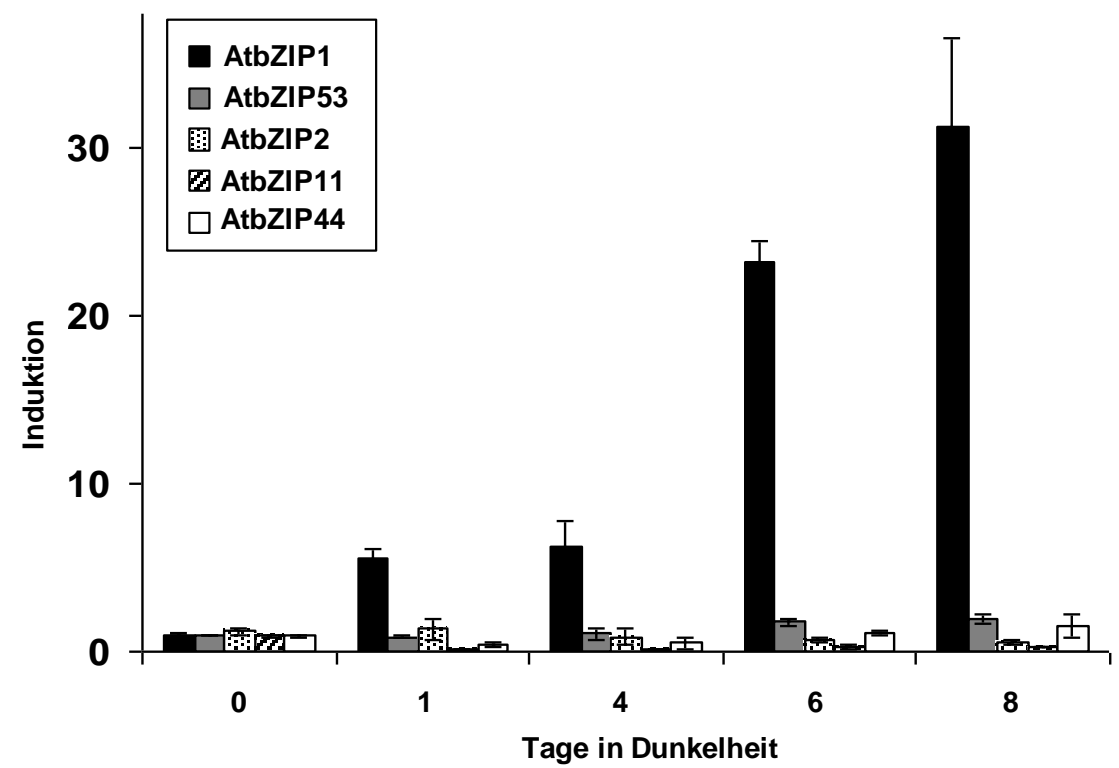

Abb. 5.4: Analyse der Expression der Gruppe S1 bZIP Transkriptionsfaktoren während der verlängerten Nacht

Wildtyp Pflanzen wurden 3-4 Wochen im Langtag angezogen. Zu den angegebenen Zeitpunkten wurden jeweils 8-10 Pflanzen geerntet und zusammen aufgearbeitet. Mit Hilfe der qPCR wurden die oben angegebenen Gene untersucht. Angegeben sind die relativen Werte im Vergleich zur Expression nach 0 Tagen Dunkelheit von je zwei Replikaten nach Abgleich mit dem Haushaltsgen Ubiquitin. Der Versuch wurde mehrmals mit ähnlichem Ergebnis wiederholt. 
AtbZIP53, zeigt ebenfalls eine Induktion, die allerdings sehr viel schwächer ist als die von AtbZIP1. AtbZIP2, AtbZIP11 und AtbZIP44 bilden innerhalb der S1 Transkriptionsfaktoren eine eigene Untergruppe. Im Gegensatz zu AtbZIP1 und AtbZIP53 werden sie durch Energiemangel nicht transkriptionell aktiviert. Die Transkription von AtbZIP2 wird kaum reguliert, AtbZIP44 zeigt nur eine sehr schwache Induktion. Die Transkription von AtbZIP11 wird durch Energiemangel nach Dunkelheit sogar reprimiert (Abb. 5.4). Aufgrund dieser Ergebnisse wurden AtbZIP1 und AtbZIP53 als mögliche Kandidaten für die transkriptionelle Regulation der Prozesse während der Energieverarmung in der verlängerten Nacht ausgewählt.

Um die Rolle von AtbZIP1 und AtbZIP53 während der verlängerten Nacht nun näher zu untersuchen wurde die Expression der beiden Gene in einem detaillierteren Experiment untersucht. Dabei wird deutlich, dass die Expression von AtbZIPl bereits nach 4 Stunden der verlängerten Nacht (Abb. 5.5; 28h Zeitpunkt des Gesamt-Experiments)

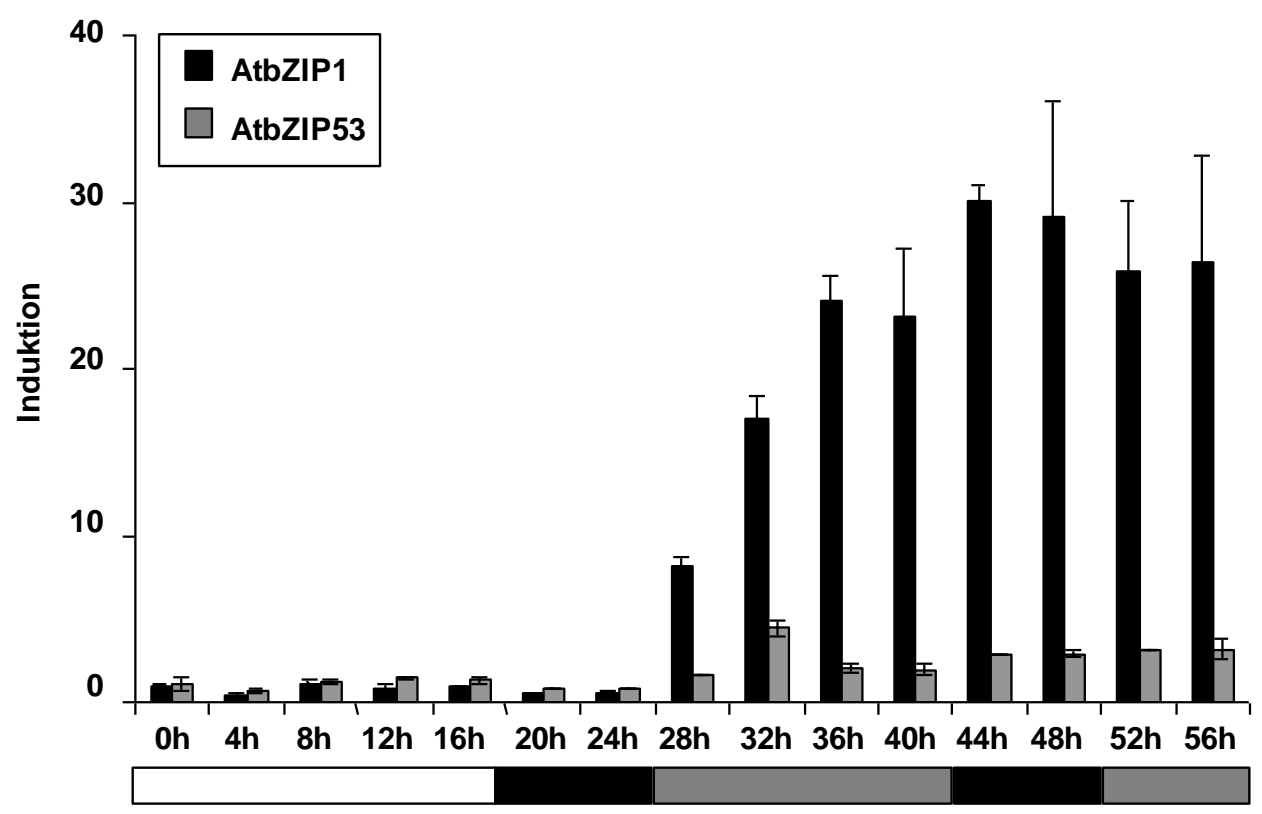

Abb. 5.5: qPCR-Analyse der Expression von AtbZIP1 und AtbZIP53 während der verlängerten Nacht Wildtyp Pflanzen wurden 3-4 Wochen im Langtag angezogen. Zu den angegebenen Zeitpunkten wurden jeweils 8-10 Pflanzen geerntet und zusammen aufgearbeitet. Mit Hilfe der qPCR wurden die oben angegebenen Gene untersucht. Angegeben sind die relativen Werte im Vergleich zur Expression nach 0 Tagen Dunkelheit von je zwei Replikaten nach Abgleich mit dem Haushaltsgen Ubiquitin. Der Versuch wurde mehrmals mit ähnlichem Ergebnis wiederholt. weißer Balken: normale Lichtphase (16h), schwarzer Balken: normale Nacht $(8 \mathrm{~h})$, grauer Balken: verlängerte Nacht 
stark angeschaltet wird und ihr Maximum nach etwa 20 Stunden (44h Zeitpunkt) mit einer 30fachen Induktion findet. AtbZIP53 zeigt wie im letzten Experiment eine deutlich schwächere aber reproduzierbare 3-4 fache Induktion.

Auch die Repression der Transkription von AtbZIP1 durch Zucker, die in der Genevestigator Analyse gezeigt wurde, konnte mit Hilfe einer Northern Analyse reproduziert werden (Abb. 5.6; Weltmeier 2005). Nach einem Tag in Dunkelheit sieht man bereits die starke Akkumulation des AtbZIPl Transkripts (0h). Lässt man die in Hydroponik gewachsenen Pflanzen weitere 2 Tage in Dunkelheit und gibt zusätzlich Glukose oder Saccharose in das Medium, so lässt sich die dunkelinduzierte AtbZIP1 Expression reprimieren. Zusätzliche Gabe von Orthomethyl-Glukose (3-OMG), die von der Pflanze zwar aufgenommen, aber nicht metabolisiert werden kann, führt dagegen zu keiner Repression der AtbZIP1 Transkription. Die Expression von AtbZIP53 unter diesen Bedingungen folgt dem gleichen Muster, ist aber etwas weniger stark ausgeprägt (Daten hier nicht gezeigt, siehe Weltmeier 2005). Dieses Experiment zeigt, dass nicht die Abwesenheit des Lichts, sondern der unter den Bedingungen der verlängerten Nacht fehlende Zucker zur transkriptionellen Aktivierung von AtbZIPl führt. Die zusätzliche Gabe von Zuckern kann dagegen den Effekt der Dunkelheit auf die Expression von AtbZIPl aufheben.

\begin{tabular}{|c|c|c|c|c|c|}
\hline Oh & 1d & \multicolumn{3}{|c|}{$1 d+2 h$} & Dunkelheit \\
\hline $\mathbf{L}$ & D & OMG & G & $\mathbf{S}$ & \\
\hline & 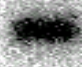 & ext & arest & (n) & AtbZIP1 \\
\hline & & $=$ & I & 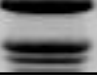 & EtBr \\
\hline
\end{tabular}

Abb. 5.6: Die dunkelinduzierte Transkription von AtbZIP1 wird durch Zucker reprimiert Die Pflanzen wurden auf Netzen in hydroponischer Kultur (ohne Zucker) im Kurztag angezogen. Drei Stunden nach Beginn der Lichtphase wurde die erste Probe (L) geerntet, danach wurden die Pflanzen für 24 Stunden dunkel gestellt. Nach dem Ernten einer weiteren Probe (D, 0h) wurden die Pflanzen mit Netz in Gefäße mit Hydroponikmedium mit 167mM 3-Orthomethyl-Glukose (OMG), Glukose (G) oder Saccharose (S) transferiert und dabei weiter im Dunkeln gehalten. Nach 2 Stunden wurden die Pflanzen mit Wurzeln geerntet und die RNA mit Hilfe einer Northern Analyse untersucht. Der Versuch wurde von Fridtjof Weltmeier durchgeführt. EtBr: EthidiumbromidFärbung der verwendeten RNA-Gele zum Nachweis der gleichmäßigen Beladung. 


\subsection{Die Überexpression von AtbZIP1 bzw. AtbZIP53 führt zu einem verfrühten Eintritt in die dunkelinduzierte Seneszenz}

Um die Funktion von AtbZIP1 und AtbZIP53 in der dunkelinduzierten Energieverarmung während der verlängerten Nacht weiter untersuchen zu können, wurden verschiedene Überexpressions- und T-DNA-Insertions-Linien der beiden Transkriptionsfaktoren hergestellt (Weltmeier, 2005).

Während Pro35S:AtbZIP1 Überexpremierer unter normalen Lichtbedingungen keinen sichtbaren Phänotyp haben, zeigen Pro35S:AtbZIP53 Überexpremierer einen starken Zwergwuchs (Alonso et al., 2009). Stellt man allerdings die Überexpremierer für einige

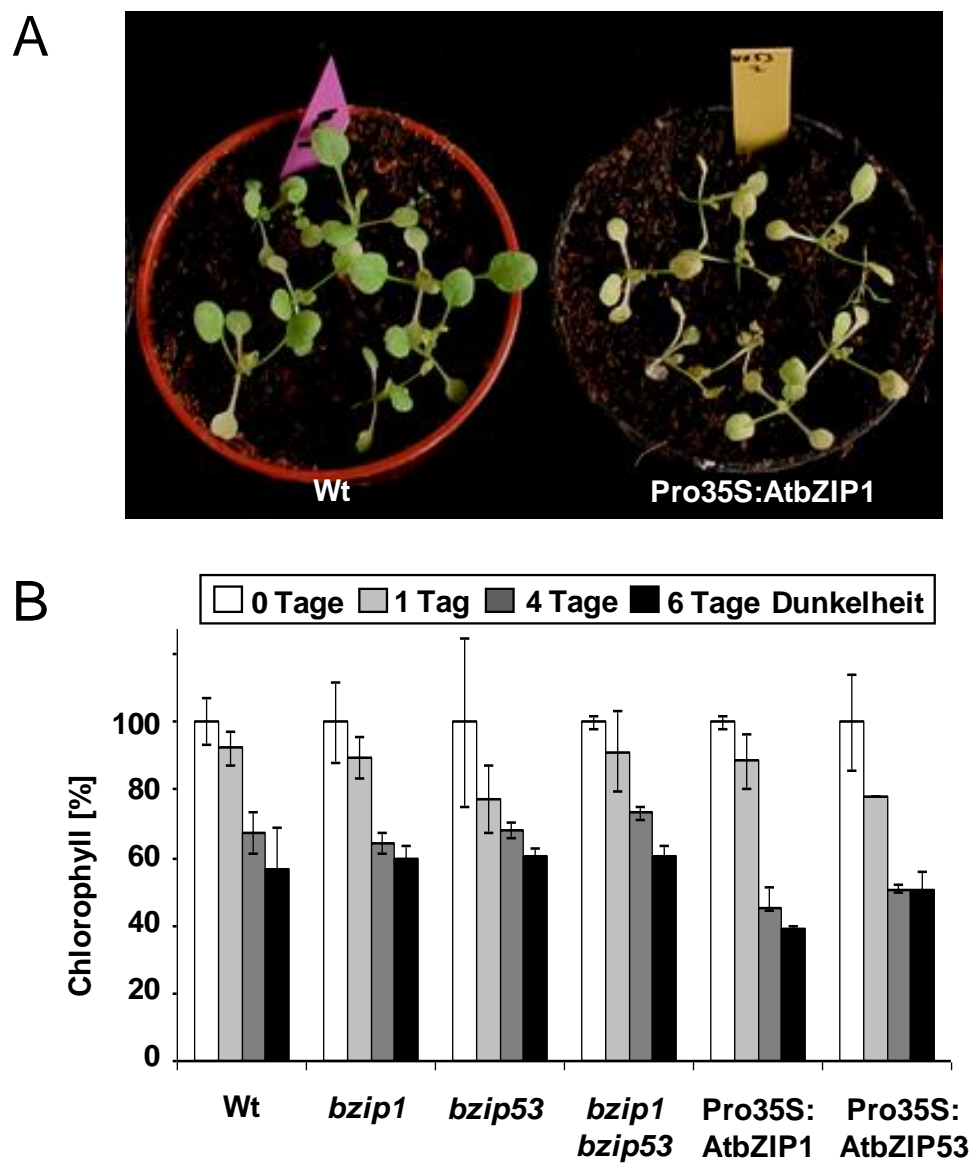

Abb. 5.7: Pro35S:AtbZIP1 und Pro35S:AtbZIP53 Pflanzen zeigen einen verfrühten Eintritt in die dunkelinduzierte Seneszenz

Pflanzen wurden 2-3 Wochen im Langtag angezogen und anschließend für 6 Tage dunkel gestellt. A: Phänotyp der Pro35S:AtbZIP1 Pflanzen im Vergleich zum WT nach 6 Tagen Dunkelheit. B: Quantifizierung des Chlorophyllgehalts der Überexpremierer und Mutanten im Vergleich zum Wt nach 0, 1, 4 und 6 Tagen Dunkelinduktion. Der Null-Tage-Wert jeder Linie wurde auf 100\% gesetzt. Dargestellt sind Mittelwerte und Standardabweichungen von zwei unabhängigen Messungen. Der Versuch wurde mehrmals mit vergleichbarem Ergebnis wiederholt. 
Tage ins Dunkel, so zeigen beide einen verfrühten Seneszenzphänotyp, der sich durch ein schnelles Gelbfärben der Blätter bemerkbar macht. Besonders ausgeprägt ist dieser Phänotyp bei den Pro35S:AtbZIP1 Überexpremierern (Abb. 5.7 A).

Zur Quantifizierung des Phänotyps wurde der Chlorophyllgehalt in diesen Pflanzen im Vergleich zum Wildtyp und auch zu den Mutanten von AtbZIP1 und AtbZIP53 nach null bis sechs Tagen in Dunkelheit gemessen (Abb. 5.7 B). Während weder in den Einzelmutanten atbzip1 und atbzip53 noch in der Doppelmutante atbzipl atbzip53 ein Unterschied zum Wildtyp zu erkennen ist, zeigen beide Überexpremierer einen im Vergleich zum Wildtyp um ca. 20 Prozent reduzierten Chlorophyllgehalt nach vier und sechs Tagen Dunkelheit. Diese Daten sprechen dafür, dass die Überexpression von AtbZIP1 und AtbZIP53 zu einer Aktivierung physiologischer Prozesse führt, die im Zusammenhang mit der dunkelinduzierten Energieverarmung während der verlängerten Nacht stehen.

\subsection{Die Überexpression von AtbZIP1 bzw. AtbZIP53 führt zu einer verstärkten Expression von Genen des Primärstoffwechsels}

Um herauszufinden, welche physiologischen Prozesse durch AtbZIP1 und AtbZIP53 beeinflusst werden und so möglicherweise $\mathrm{zu}$ einem verfrühten Eintritt der Überexpremierer in die dunkelinduzierte Seneszenz führen, können die vorhandenen Mutanten und Überexpressionslinien genutzt werden, um mögliche Zielgene mit Hilfe von genomweiten Transkriptomanalysen (Micro-Arrays) zu finden. In einem ersten Ansatz wurde die Expression von Pro35S:AtbZIP53 Pflanzen mit dem Wildtyp verglichen, in einem zweiten Ansatz dann die Expression von Pro35S:AtbZIP1 Pflanzen mit der atbzipl atbzip53 Doppelmutante und dem Wildtyp nach zwei Tagen in Dunkelheit (Weltmeier 2005). Viele der regulierten Gene spielen eine wichtige Rolle in einem primären Stoffwechselweg (eine Auswahl der Gene findet sich in Tabelle 5.1). So finden sich z.B. Gene aus dem Aminosäurestoffwechsel, dem Lipid- und auch dem Kohlenhydratmetabolismus, die in den Überexpressionspflanzen verstärkt expremiert werden. In der Doppelmutante wird die Expression der entsprechenden Gene dagegen meist herunter reguliert. 
Tabelle 5.1: In den Überexpremierern und der Doppelmutante regulierte Gene aus Lipid-, Kohlenhydrat- und Aminosäuremetabolismus

Gegeben ist die logarithmische Signalstärke (log Ratio) aus den Quotienten von Überexpremierern bzw. Mutante und Wildtyp für ausgewählte Gene der Transkriptomanalysen (Weltmeier, 2005). Der Schwellenwert liegt bei einem p-Wert von 0,05 und einer log Ratio von mindestens 1,3 für die Überexpremierer. Die Unterschiede in der Mutante sind meist geringer. Positive Zahlen: verstärkte Expression im Vergleich zum Wt, negative Zahlen: Gene sind im Vergleich zum Wt herunter reguliert, freie Felder: Gene wurden im Vergleich zum Wt nicht signifikant unterschiedlich reguliert.

\begin{tabular}{|c|c|c|c|c|}
\hline Gen & AGI code & $\begin{array}{l}\text { log Ratio } \\
\text { Pro35S: } \\
\text { AtbZIP53 } \\
\text { /WT }\end{array}$ & $\begin{array}{l}\text { log Ratio } \\
\text { Pro35S: } \\
\text { AtbZIP1 } \\
\text { /WT }\end{array}$ & $\begin{array}{l}\text { log Ratio } \\
\text { atbziplatbzip53 } \\
\text { /WT }\end{array}$ \\
\hline \multicolumn{5}{|l|}{ Lipidmetabolismus } \\
\hline Lipoxygenase 1 (LOX1) & At1g55020 & 1,56 & 3,3 & $-0,7$ \\
\hline Lipoxygenase 2 (LOX2) & At3g45140 & - & 2,0 & $-1,1$ \\
\hline Lipase EXL6 & At1g73610 & - & 2,2 & $-0,1$ \\
\hline Esterase/Lipase/Thioesterase & At3g26840 & - & 2,1 & $-0,8$ \\
\hline Lipase & At5g24200 & 1,75 & - & - \\
\hline Caleosin related & At1g70670 & - & 2,7 & $-0,5$ \\
\hline Oleosin & At3g01570 & 1,7 & - & - \\
\hline \multicolumn{5}{|l|}{ Kohlenhydratmetabolismus } \\
\hline B-Amylase 5 (BAM5) & At4g15210 & - & 4,4 & 2,5 \\
\hline $\begin{array}{l}\text { Trehalose-6-Phosphat-Phosphatase } \\
\text { (TPPG) }\end{array}$ & At4g22590 & 2,69 & 2,7 & $-1,0$ \\
\hline $\begin{array}{l}\text { Trehalose-6-Phosphat-Phosphatase } \\
\text { (TPPD) }\end{array}$ & At1g35910 & 1,82 & - & - \\
\hline \multicolumn{5}{|l|}{ Aminosäurestoffwechsel } \\
\hline Prolin Dehydrogenase (PRODH) & At3g30775 & 2,28 & - & - \\
\hline Prolin Dehydrogenase2 (PRODH2) & At5g38710 & 1,37 & - & - \\
\hline $\begin{array}{l}\text { Branched Chain Aminoacid } \\
\text { Transaminase (BCAT2) }\end{array}$ & At1g10070 & 1,63 & - & - \\
\hline Asparagin Synthetase (ASN1) & At3g47340 & 2,14 & - & - \\
\hline Glutamat Dehydrogenase (GDH2) & At5g07440 & - & 1,6 & $-0,36$ \\
\hline Aspartat Aminotransferase (ASP3) & At5g11520 & - & 2,3 & $-0,19$ \\
\hline Glutamin Synthase (GLNS) & At5g37600 & - & 2,3 & $-0,8$ \\
\hline Asparaginase (ANS) & At3g16150 & - & 2,7 & $-0,8$ \\
\hline
\end{tabular}




\subsubsection{Gene des Lipidstoffwechsels werden durch AtbZIP1 und AtbZIP53 reguliert}

Unter den Genen des Lipidstoffwechsels, die in den Pro35S:AtbZIP1 und Pro35S:AtbZIP53 Pflanzen verstärkt expremiert werden, finden sich eine Reihe von Lipasen. Lipasen sind Enzyme, die von Lipiden die freien Fettsäuren abspalten. Dieser Degradationsprozess findet in der natürlichen Blattseneszenz im Zuge der Mobilisierung von Nährstoffen und deren Recycling für noch wachsende Pflanzenteile statt (Nooden et al., 1997; Buchanan-Wollaston, 1997; Quirino et al., 2000). Die verstärkte Expression dieser Gene in den Überexpremierern von AtbZIP1 und 53 passt also gut zu dem verfrühten Einsetzten der dunkelinduzierten Seneszenz in diesen Pflanzen. Ob die verstärkte Expression der Lipasen aber die Ursache des Phänotyps ist, oder ob das verfrühte Einsetzten der Seneszenz zur verfrühten und damit zum Zeitpunkt der Probennahme stärkeren Expression der Lipasen führt ist noch zu klären.

Die durch die Lipaseaktivität frei werdenden Fettsäuren wie z.B. Linolsäure können als Ausgangsmaterial für die Synthese von Jasmonsäure (JA) durch sogenannte 13Lipoxygenasen genutzt werden (Abb. 5.8; Creelman und Mullet, 1997). In Arabidopsis existieren 6 verschiedene Lipoxygenasen (Feussner und Wasternack, 2002; Stenzel et al., 2003). Vier von ihnen, darunter auch die in den Arrays der Pro35S:AtbZIP1 Pflanzen verstärkt expremierte $L O X 2$, gehören zu diesen 13-Lipoxygenasen und können damit den ersten Schritt zur Biosynthese von JA katalysieren.

Die Rolle der beiden 9-Lipoxygenasen, zu denen die LOXI gehört, die sowohl in den Arrays der Pro35S:AtbZIP1 als auch der Pro35S:AtbZIP53 Pflanzen stark expremiert wird, ist wesentlich weniger gut untersucht. Metabolite dieser Lipoxygenasen spielen möglicherweise eine Rolle in Wurzelentwicklung, Pathogen-Abwehr und Zelltod (Abb. 5.8; Melan et al., 1993; Velosillo et al., 2007).

Die verstärkte Expression der beiden Lipoxygenasen LOX1 und LOX2 in den Pro35S:AtbZIP1 Pflanzen, die in den Array Analysen entdeckt wurde, konnte mittels Northern Analyse reproduziert werden (Abb. 5.9). 


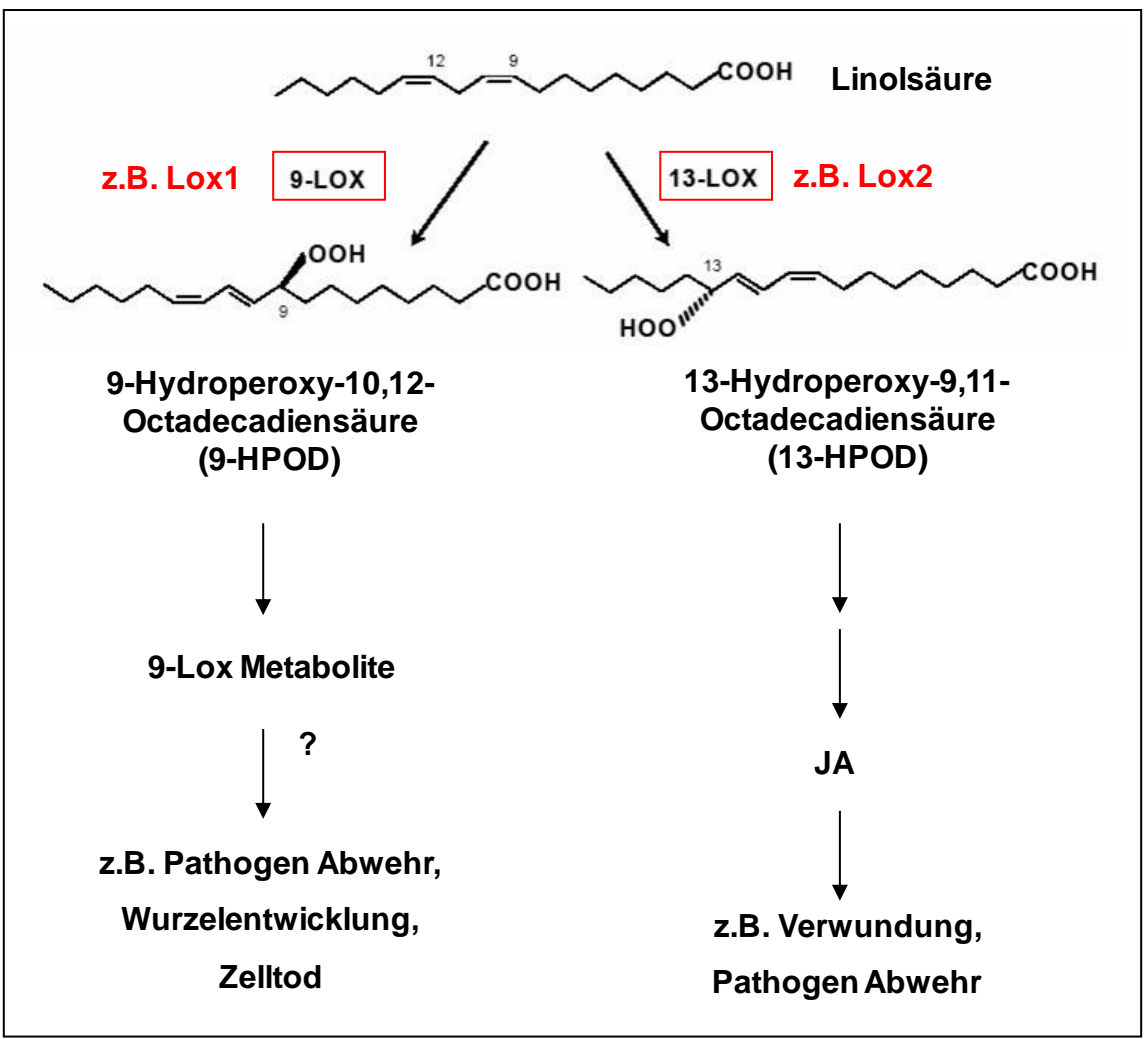

Abb. 5.8: Schema des Abbaus der Linolsäure durch 9- und 13-Lipoxygenasen Linolsäure wird durch 9-Lipoxygenasen wie die LOX1 zu 9-HPOD abgebaut. Die daraus entstehenden Metabolite haben eine mögliche Funktion in Pathogen Abwehr, Wurzelentwicklung und Zelltod (Melan et al., 1993, Velosillo et al., 2007). Der Abbau der Linolsäure durch 13Lipoxygenasen wie der LOX2 führt zur Bildung von 13-HPOD, das weiter zu Jasmonsäure (JA) umgewandelt werden kann. Dieses spielt u.a. eine Rolle in Pathogen Abwehr und Verwundung (Hildebrand et al., 1998; Schaller, 2001).

Die beiden Lipoxygenasen zeigen hierbei gegenläufige Expressionsmuster während der dunkelinduzierten Seneszenz. Während die LOXI im Wildtyp erst nach mehreren Tagen Dunkelheit deutlich transkriptionell aktiviert wird, wird die LOX2 bereits unter normalen Langtagbedingungen expremiert und bei beginnender Dunkelheit herunter reguliert. In der atbzipl Mutante konnten keine signifikanten Änderungen der Expressionsstärke im Vergleich zum Wildtyp festgestellt werden.

Eine lox1 Mutante wurde von E. Hornung und I. Feussner (Uni Göttingen, Abt. Biochemie der Pflanze) zur Verfügung gestellt. In dieser Mutante ist die dunkelinduzierte LOXI Induktion deutlich unterdrückt (Abb. 5.9). 


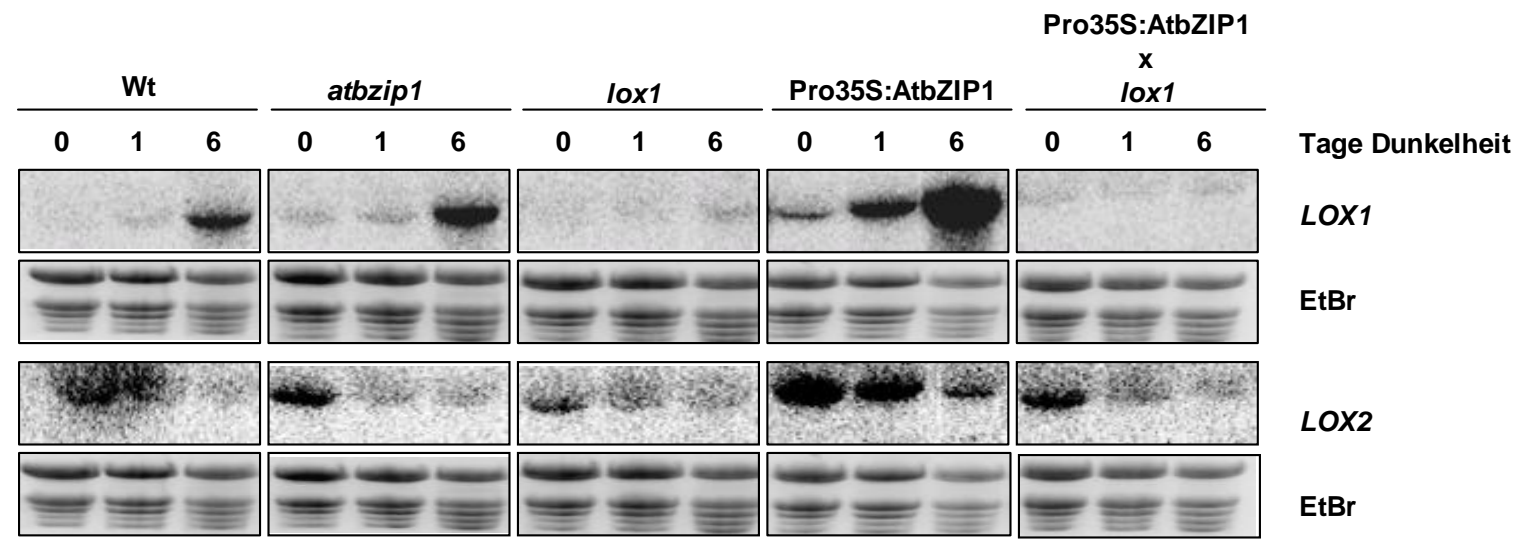

Abb. 5.9: Die Überexpression von AtbZIP1 führt zu einer verstärkten Expression von LOX1 und 2 Pflanzen wurden 3-4 Wochen im Langtag angezogen. Anschließend wurden die Pflanzen dunkel gestellt. Zu den angegebenen Zeitpunkten wurden jeweils 8-10 Pflanzen pro Linie geerntet und zusammen aufgearbeitet. Daraus wurde RNA gewonnen und im Northern mit Sonden für die oben angegebenen Gene untersucht. EtBr: Ethidiumbromid-Färbung der verwendeten RNA-Gele zum Nachweis der gleichmäßigen Beladung.

Auch in der Kreuzung aus Pro35S:AtbZIP1 Linie und loxl Mutante ist keinerlei LOX1Expression mehr zu erkennen. Interessanterweise ist in diesen Pflanzen im Vergleich zu den Pro35S:AtbZIP1 Pflanzen auch die Expression der LOX2 reduziert, obwohl die Expression der LOX2 durch den Knock-Out der LOX1 eigentlich nicht beeinträchtig werden sollte. Möglicherweise existieren hier bisher nicht bekannte Regulationsmechanismen zwischen diesen beiden Lipoxygenasen.

Die anderen vier Lipoxygenasen aus Arabidopsis werden insgesamt sehr viel schwächer expremiert als $L O X 1$ und $L O X 2$. Während $L O X 3$ und $L O X 4$ im Northern gar kein Signal lieferten, zeigte die LOX5 ein ähnliches, wenn auch sehr viel schwächeres Expressionsmuster wie die LOX1, während die LOX6 während der Dunkelinduktion ähnlich wie die LOX2 reguliert wird (Anhang Abb. 8.1).

Phänotypisch zeigt die loxl Mutante keine sichtbaren Unterschiede zum Wildtyp. Auch während der verlängerten Nacht verhält sie sich wie der Wildtyp. Bemerkenswert ist allerdings der Phänotyp der Kreuzung aus AtbZIP1 Überexpremierer und loxl Mutante. Wenn die Pro35S:AtbZIP1 Pflanzen nach 6 Tagen Dunkelheit bereits eine deutliche Gelbfärbung der Blätter zeigen, sind die Pro35S:AtbZIP1 x lox1 Pflanzen noch genauso grün wie Wildtyp oder loxl Mutante (Abb. 5.10). 


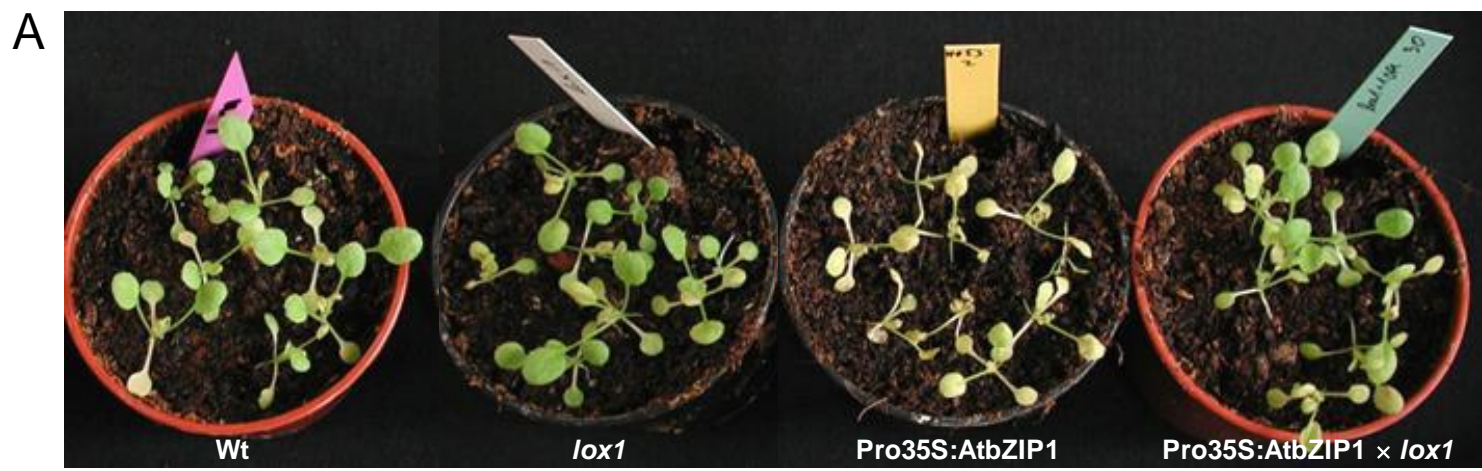

B

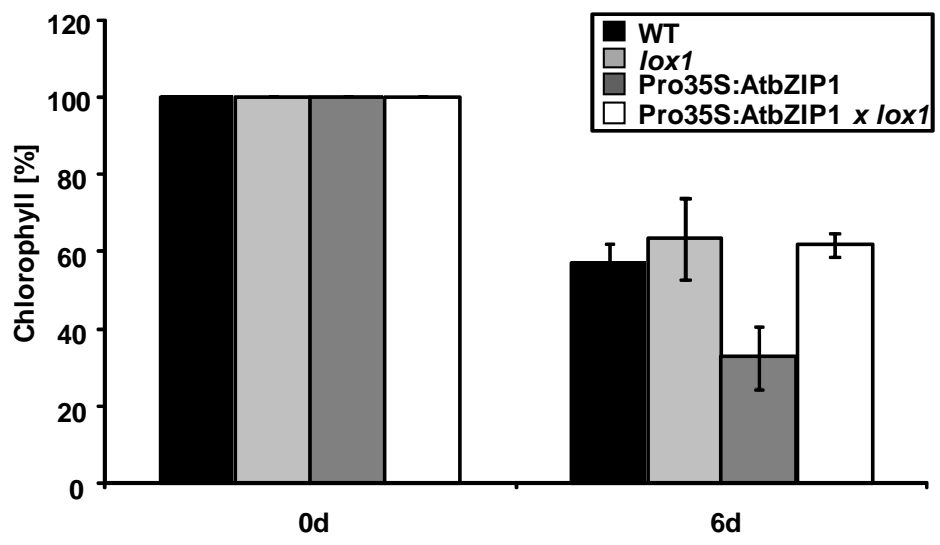

Abb. 5.10: Der dunkelinduzierte Seneszenz-Phänotyp der Pro35S:AtbZIP1 Überexpressionspflanzen ist abhängig von der Expression der LOX1

Pflanzen wurden 2-3 Wochen im Langtag angezogen und anschließend für 6 Tage dunkel gestellt. A: Phänotyp der Pro35S:AtbZIP1 Pflanzen im Vergleich zu Wildtyp, lox1 Mutante und Pro35S:AtbZIP1 x lox1 nach 6 Tagen Dunkelheit

B: Quantifizierung des Chlorophyllgehalts der Überexpremierer und Mutanten im Vergleich zum Wt nach 0 und 6 Tagen Dunkelinduktion. Der Null-Tage-Wert jeder Linie wurde auf $100 \%$ gesetzt. Dargestellt sind Mittelwerte und Standardabweichungen von zwei unabhängigen Messungen. Der Versuch wurde mehrmals mit vergleichbarem Ergebnis wiederholt.

Diese Beobachtung konnte auch mit Hilfe einer Chlorophyllmessung quantifiziert werden. Während die AtbZIP1 Überexpremierer nach 6 Tagen Dunkelheit nur noch $30 \%$ ihres anfänglichen Chlorophyllgehalts aufweisen, liegen Wildtyp, loxl und die Kreuzung aus Pro35S:AtbZIP1 und lox1 noch bei etwa $60 \%$ des ursprünglichen Chlorophylls. 


\subsubsection{Der Kohlenhydratmetabolismus wird durch AtbZIP1 und AtbZIP53 beeinflusst}

Nicht nur der Lipidstoffwechsel, auch Gene des Kohlenhydrathaushalts der Pflanze werden durch die Überexpression von AtbZIP1 und/oder AtbZIP53 beeinflusst. Zucker liefern der Zelle Kohlenstoff und Energie und werden während der Lichtphase durch die Photosynthese gebildet. Teile der so gewonnenen Energie werden als Reserve für die Nacht unter anderem in Form von Stärke in den Chloroplasten gespeichert. Mit Hilfe einer Iod-Iodkalium-Färbung kann man diese Stärke sichtbar machen (Abb. 5.11). Eine große Stärkemenge korreliert dabei mit einer intensiven Blaufärbung. Parallel Zur IodIodkalium-Färbung wurde auch ein quantitativer Stärketest mit Hilfe des Biovision StarchAssay Kits durchgeführt, in dem die Menge der löslichen Stärke enzymatisch bestimmt wurde (Abb. 5.12).

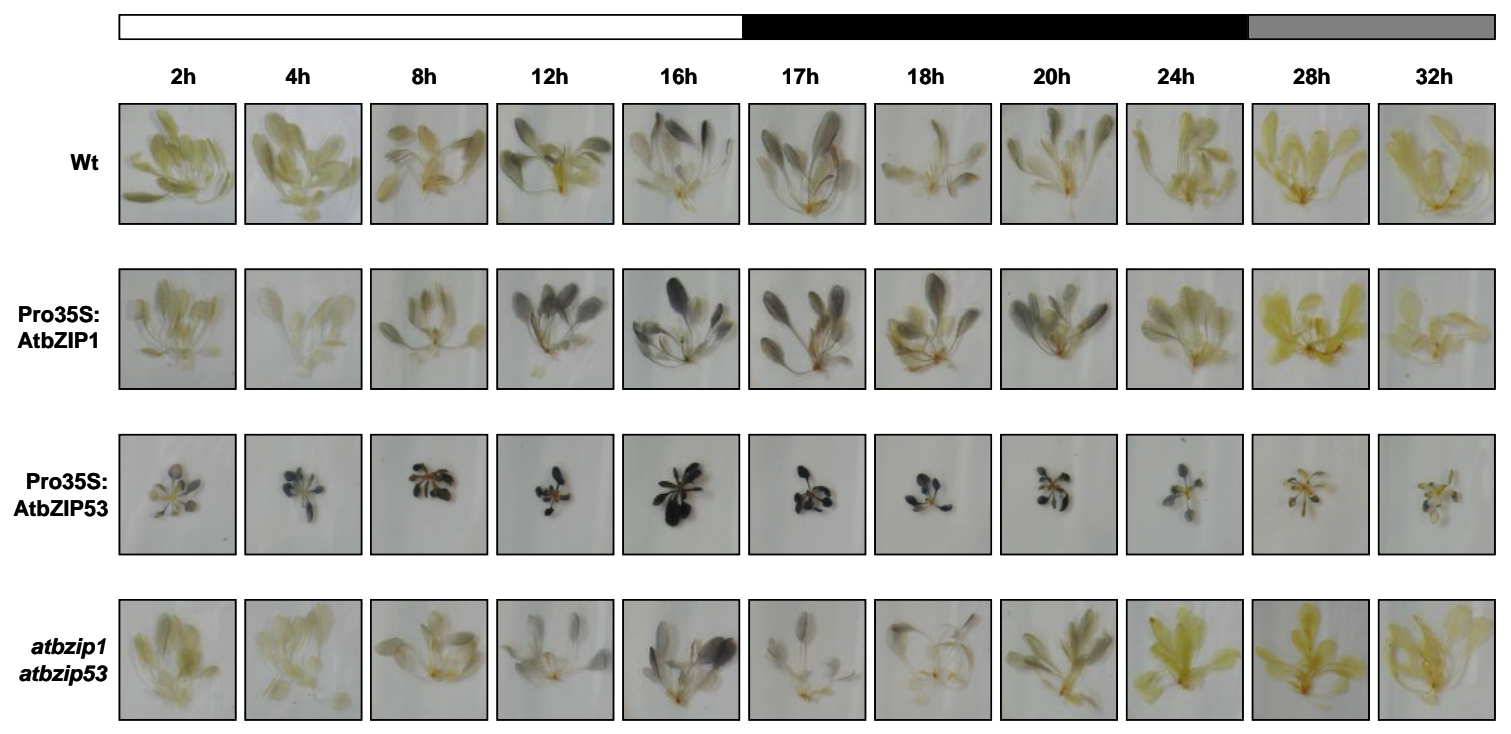

Abb. 5.11: AtbZIP53 Überexpremierer akkumulieren große Mengen Stärke

Pflanzen wurden 3-4 Wochen im Langtag angezogen. Für die Stärkefärbung wurde zu den angegebenen Zeitpunkten eine Rosette oberhalb der Erde abgeschnitten. Die Pflanzen wurden anschließend mit Ethanol entfärbt und die Stärke mit Iod-Iodkalium-Lösung sichtbar gemacht. weißer Balken: normale Lichtphase (16h), schwarzer Balken: normale Nacht (8h), grauer Balken: verlängerte Nacht 

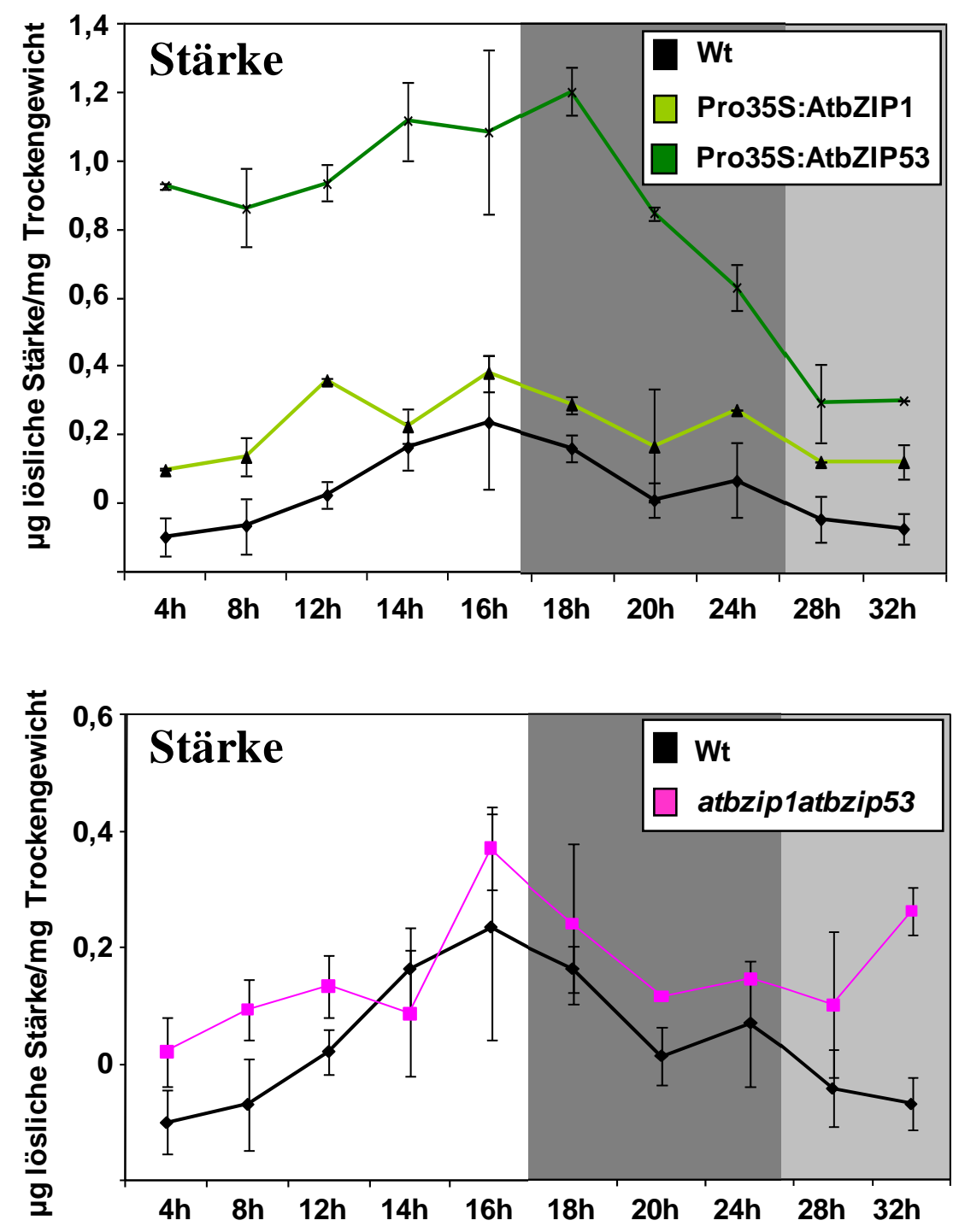

Abb. 5.12: Quantifizierung des Stärkegehaltes von AtbZIP1 und AtbZIP53 Überexpremierern sowie der atbzip1 atbzip53 Doppelmutante

Die Pflanzen wurden 3-4 Wochen im Langtag angezogen. Für die Quantifizierung des Stärkegehaltes wurde alle 2-4 Stunden Proben genommen, indem von 8-10 Pflanzen die Rosette oberhalb der Erde abgeschnitten wurde. Die Pflanzen wurden anschließend aufgearbeitet und mit Hilfe des Biovision StarchAssay Kits der Gehalt der löslichen Stärke in den Pflanzen bestimmt. Gemessen wurden zwei biologische Replikate. weiß: normale Lichtphase (16h), dunkelgrau: normale Nacht $(8 \mathrm{~h})$, hellgrau: verlängerte Nacht

In beiden Versuchen ist im Wildtyp die meiste Stärke am Ende der Lichtphase (im Langtag nach 16h Licht) zu beobachten (Abb. 5.11), die dann während der folgenden Nacht (im Langtag 8h Dunkelphase) langsam wieder abgebaut wird. Pro35S:AtbZIP1 Pflanzen zeigen im Vergleich zum Wildtyp einen etwas höherer Stärkegehalt sowohl in der Iod-Iodkalium-Färbung als auch in der quantitativen Bestimmung der Stärke. Noch 
deutlicher ist dies bei den Pro35S:AtbZIP53 Pflanzen ausgeprägt. Bei ihnen ist so viel Stärke eingelagert, dass sogar während der verlängerten Nacht (28h und 32h Zeitpunkt) noch Stärke übrig ist. Zu diesen Zeitpunkten ist bei allen anderen Pflanzen keine Stärke mehr messbar. Die Doppelmutante atbzipl atbzip53 zeigt zu den meisten Zeitpunkten sowohl in der Iod-Iodkalium-Färbung als auch in der quantitativen Bestimmung nur geringe Unterschiede zum Wildtyp, die meist nicht signifikant sind. Nur der $32 \mathrm{~h}$ Zeitpunkt fällt in der quantitativen Bestimmung heraus, da hier eine recht hohe Stärkemenge in der Mutante vorliegt, obwohl zu diesem Zeitpunkt in der Stärkefärbung alle Stärke verbraucht war.

Was ist für diesen dramatischen Stärkephänotyp der Pro35S:AtbZIP53 Pflanzen verantwortlich? Eine mögliche Erklärung wäre, dass der Stärkeabbau in diesen Pflanzen nicht mehr funktioniert. Das würde möglicherweise auch erklären, warum diese Pflanzen zwergwüchsig sind. Ihnen würde während der Nacht nicht genug Energie in Form von frei werdenden Zuckern aus dem Stärkeabbau zur Verfügung stehen.

Eine Gruppe von Enzymen, die für den Stärkeabbau verantwortlich ist, ist die Familie der B-Amylasen. Sie besteht aus 9 Mitgliedern, die bisher unterschiedlich gut untersucht worden sind. Während eine erste Real-Time Analyse bei 8 der $9 \beta$-Amylasen nur wenige Unterschiede in der Expression während des Tag-Nacht-Rhythmus zwischen Wildtyp und Pro35S:AtbZIP53 ergab (Anhang Abb. 8.2), zeigt die $\beta$-AMYLASE 5 (BAM5) einen deutlichen Unterschied (Abb. 5.13). Sie wird im Wildtyp noch während der Lichtphase hochreguliert und zeigt ihr Expressionsmaximum nach $12 \mathrm{~h}$ Licht. Anschließend sinkt die Expression wieder und während der Nacht findet nur noch eine geringe Expression statt. Dies ist ein Expressionsmuster, das für stärkeabbauende Enzyme typisch ist (Smith et al., 2004; Zeeman et al., 2007). So wird sichergestellt, dass zu Beginn der Nacht bereits genug Protein bereitgestellt wird, damit die Stärke direkt abgebaut werden kann und keine Versorgungslücke entsteht. In den Überexpressionspflanzen von AtbZIP53 wird die BAM5 fast gar nicht expremiert (Abb. 5.13). Die Überexpression von AtbZIP1 hat dagegen keinen Einfluss auf die Expression der BAM5 (Daten nicht gezeigt). 


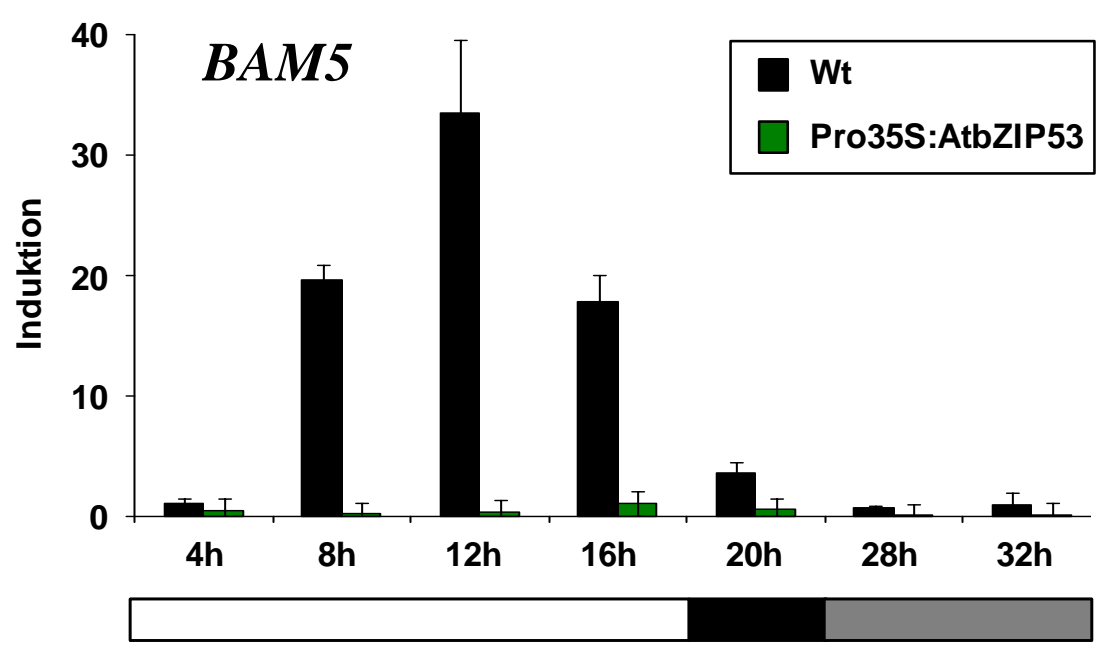

Abb. 5.13: Die $\beta$-Amylase 5 (BAM5) wird in den Pro35S:AtbZIP53 Pflanzen nicht expremiert Wildtyp und Pro35S:AtbZIP53 Pflanzen wurden 3-4 Wochen im Langtag angezogen und danach dunkel gestellt. Zu den angegebenen Zeitpunkten wurden jeweils 8-10 Pflanzen geerntet und zusammen aufgearbeitet. Mit Hilfe der qPCR wurde die Expression der BAM5 untersucht. Angegeben sind die relativen Werte im Vergleich zur Expression nach 4 Stunden von je zwei Replikaten nach Abgleich mit dem Haushaltsgen Ubiquitin. Der Versuch wurde mit vergleichbarem Ergebnis wiederholt. weißer Balken: normale Lichtphase (16h), schwarzer Balken: normale Nacht (8h), grauer Balken: verlängerte Nacht

Wenn der Zwergwuchs der Pro35S:AtbZIP53 Pflanzen tatsächlich auf mangelnde Energievorsorge durch ein Defizit im Stärkeabbau während der Nacht zurückzuführen wäre, dann sollten diese Pflanzen besser wachsen können, wenn sie im Dauerlicht angezogen werden. Vergleicht man nun die AtbZIP53 Überexpressionspflanzen unter normalen Langtagsbedingungen mit Pflanzen, die im Dauerlicht angezogen wurden, so erkennt man keine großen Unterschiede. Auch die im Dauerlicht angezogenen Pflanzen zeigen immer noch einen starken Zwergwuchs (Abb. 5.14). Möglicherweise sind der Zwergwuchs und der erhöhte Stärkegehalt also nicht allein auf den verminderten Abbau der Stärke zurückzuführen, sondern auch auf eine verstärkte Stärkesynthese. Diese würde dann zu einem ständigen Mangel an frei verfügbaren Zuckern und damit zu einem Energiemangel führen, der unabhängig vom Tag-/Nachtrhythmus ist. 

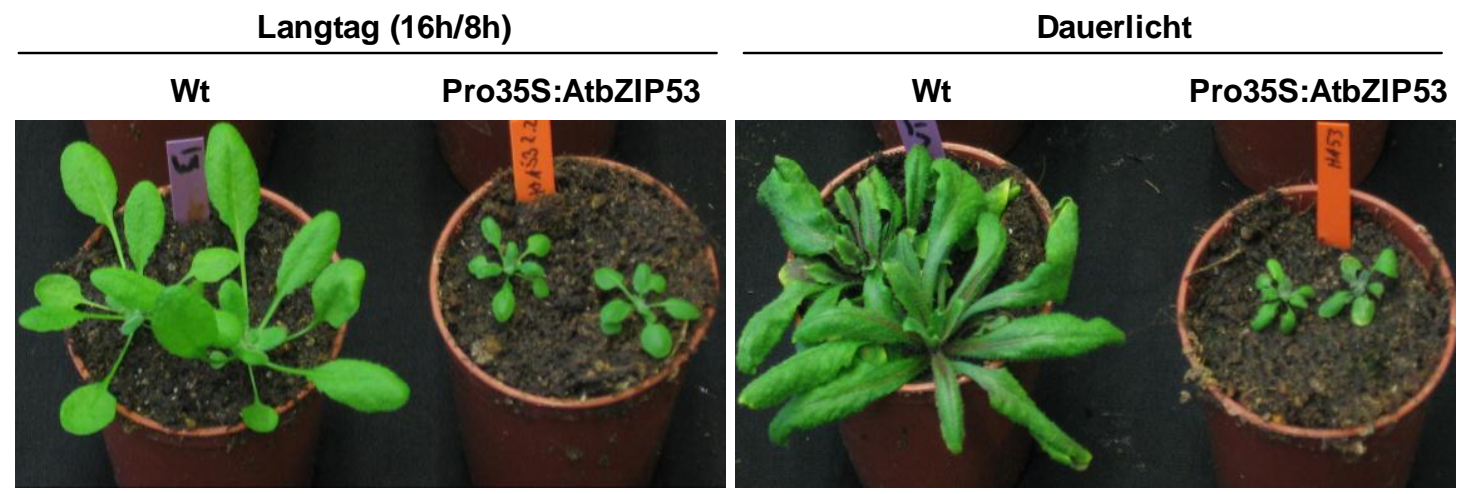

Abb. 5.14: Auch im Dauerlicht zeigen AtbZIP53 Überexpremierer einen Zwergwuchs Wildtyp und Pro35S:AtbZIP53 Pflanzen wurden 3-4 Wochen im Langtag (16h Licht / 8h Dunkel) bzw. im Dauerlicht angezogen und anschließend phänotypisch untersucht.

Eine Messung der Metabolite in Wildtyp, Überexpressionspflanzen und Doppelmutante in Kooperation mit W. Weckwerth (Universität Wien) mit Hilfe eines GC-MSVerfahrens ergab allerdings, dass die Pro35S:AtbZIP53 Pflanzen hohe Mengen an freien Hexosen wie Glukose und Fruktose während des Tages und auch während der verlängerten Nacht aufweisen. Auch die Saccharosemengen sind in diesen Pflanzen stark erhöht. Lediglich Pentosen wie die Ribose sind in diesen Überexpremierern im Vergleich zum Wildtyp stark reduziert (Abb. 5.15 A). Im Wildtyp erkennt man dagegen gut den Unterschied zwischen der Lichtphase, in der viel Glukose, Fruktose und Saccharose vorhanden ist, und der verlängerten Nacht, in der die Zuckerreserven fast vollständig aufgebraucht werden. Nur die Ribose zeigt im Wildtyp kaum Schwankungen in Tag/Nachrhythmus. Ribose ist allerdings ein wichtiger Bestandteil des RNA-Rückrats und z.B. auch Teil des Energieträgers ATP und sollte deshalb möglichst immer verfügbar sein.

Die Doppelmutante zeigt wie schon bei der Stärkemessung keine signifikanten Unterschiede zum Wildtyp. Interessant sind aber die Pro35S:AtbZIP1 Pflanzen. Im Gegensatz zu den Pro35S:AtbZIP53 Pflanzen zeigen sie im Vergleich zum Wildtyp während des Tages reduzierte Glukose- und Fruktosemengen. Der Saccharosegehalt ist dagegen tagsüber vergleichbar mit dem im Wildtyp, nach einem Tag Dunkelheit ist sogar noch etwas mehr Saccharose vorhanden.

Der Abbau von Glukose, Fruktose und Saccharose zur Energiegewinnung erfolgt normalerweise über die Glykolyse und den anschließenden Citratzyklus. Obwohl sich 

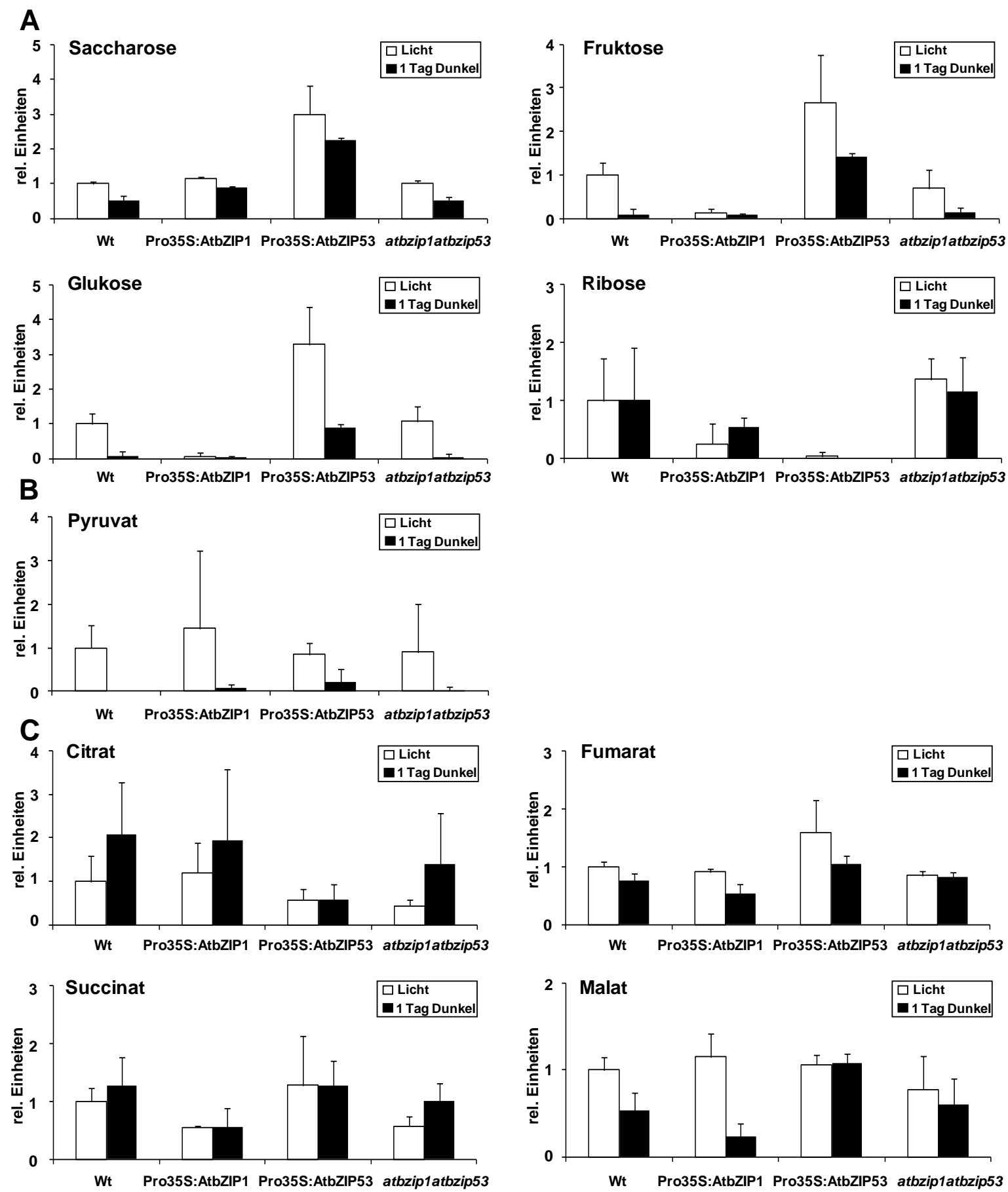

Abb. 5.15: Pro35S:AtbZIP53 Pflanzen akkumulieren große Mengen an Glukose, Fruktose und Saccharose, während Pro35S:AtbZIP1 Pflanzen weniger Glukose und Fruktose als der Wildtyp haben Die Pflanzen wurden 3-4 Wochen im Langtag angezogen und entweder in der Mitte der Lichtphase gegen 17 Uhr geerntet (weiße Balken) oder am nächsten Tag um 17 Uhr nach einer ca. 8 Stunden verlängerten Nacht (schwarze Balken). Zu den angegebenen Zeitpunkten wurden jeweils 8-10 Pflanzen jeder Linie geerntet und zusammen aufgearbeitet. $100 \mathrm{mg}$ dieses Materials wurden abgewogen und die Metabolitmengen in Kooperation mit W. Weckwerth (Universität Wien) mit Hilfe einer GC-MS bestimmt. Dargestellt sind die Mittelwerte von drei biologischen Replikaten. 
die Menge der Zucker in den AtbZIP53 Überexpremierern stark von der im Wildtyp und der Doppelmutante unterscheidet, bleibt die Menge an Pyruvat (Abb. 5.15 B), dem Endprodukt der Glykolyse, und von Komponenten des Citratzyklus wie Citrat, Succinat, Fumarat und Malat (Abb. 5.15 C) erstaunlich konstant. Es existieren zwar leichte Unterschiede, z.B. ist in den Pro35S:AtbZIP53 Pflanzen im Dunkeln etwas weniger Citrat, dafür etwas mehr Malat zu finden, und in Pro35S:AtbZIP1 Pflanzen im Dunkeln etwas weniger Succinat als im Wildtyp, die meisten Schwankungen sind aber nicht signifikant.

\subsubsection{Die Überexpression von AtbZIP1 und AtbZIP53 führt zu einer veränderten Expression von Genen aus Aminosäureabbau und -Biosynthese}

In den letzten beiden Kapiteln zeigte sich, dass es unter Energiemangelbedingungen während langanhaltender Dunkelheit zu einem Abbau von Makromolekülen wie z.B. Stärke und Lipiden kommt. Diese dienen der Pflanze als Reserve während sie keine Photosynthese betreiben kann. Aber auch Proteine und Aminosäuren dienen während dieser Zeit als Quelle für Kohlenstoff und Stickstoff, die von der Pflanze dringend benötigt werden.

Durch den Abbau der Proteine nimmt der Gehalt an freien Aminosäuren während der verlängerten Nacht stetig zu (Abb. 5.16). Der Abbau dieser freien Aminosäuren erfolgt zunächst über eine Transaminierung zu Glutamat, das durch das Enzym GLUTAMAT DEHYDROGENASE wieder in $\alpha$-Ketoglutarat und Ammoniak gespalten wird. Aus diesem Grund steigt während der Dunkelinduktion auch stetig der Ammoniakgehalt in den Pflanzen an (Abb. 5.16).

In den Überexpressionspflanzen von AtbZIP1 und AtbZIP53, die einen verfrühten Eintritt in die dunkelinduzierte Seneszenz zeigen, werden typische Gene für den Abbau von Aminosäuren verstärkt expremiert (Tabelle 5.1). Dazu gehören z.B. die PROLIN DEHYDROGENASE (ProDH) und die BRANCHED CHAIN AMINO ACID TRANSAMINASE2 (BCAT2). Es finden sich aber auch eine Reihe von Genen, die für den Aufbau der Aminosäure Asparagin verantwortlich sind. 

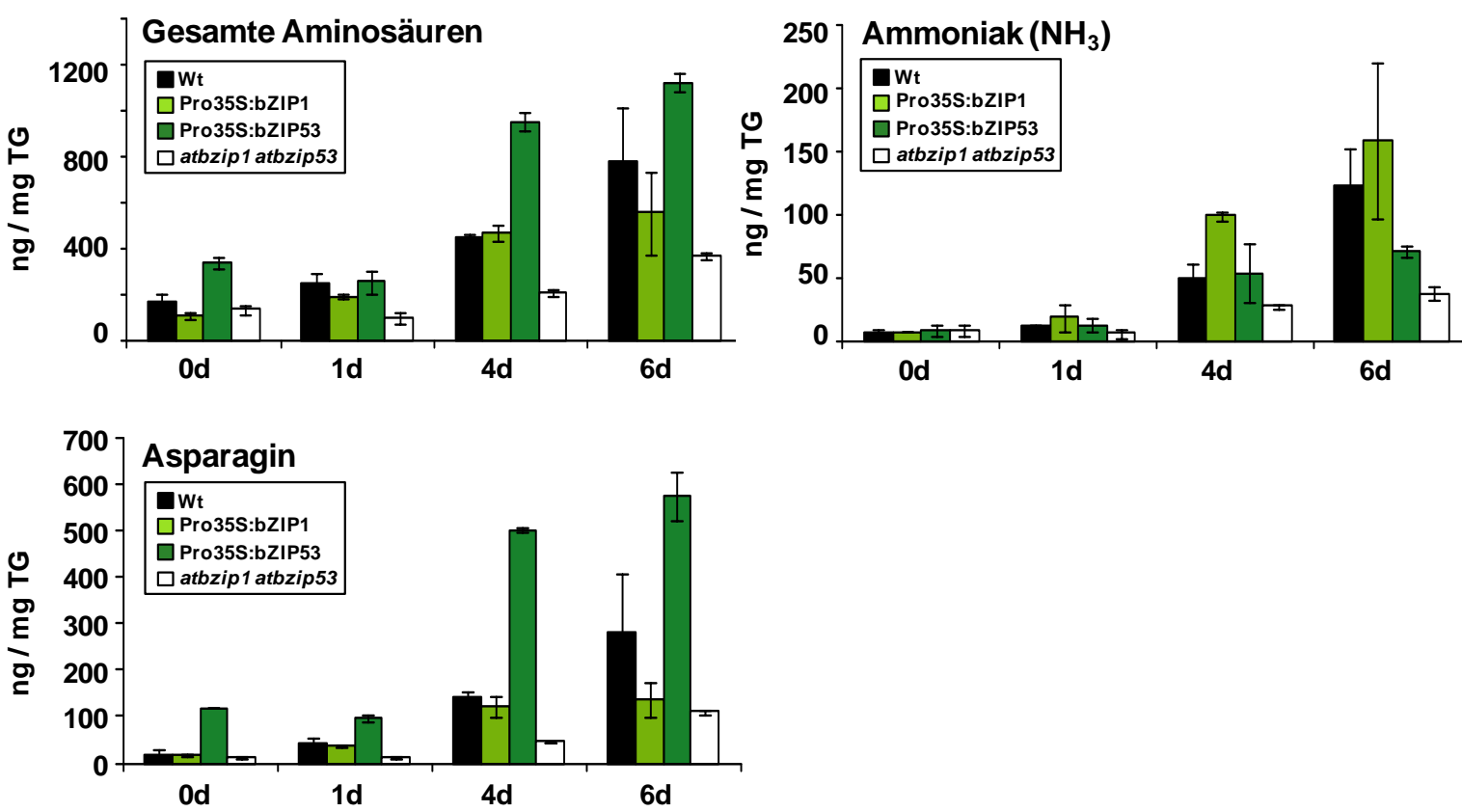

Abb. 5.16: Die Gesamtmenge an freien Aminosäuren und Ammoniak nimmt während der verlängerten Nacht zu

Die Pflanzen wurden 3-4 Wochen im Langtag angezogen und anschließend für bis zu 6 Tage dunkel gestellt. $\mathrm{Zu}$ den angegebenen Zeitpunkten wurden jeweils 8-10 Pflanzen jeder Linie geerntet und zusammen aufgearbeitet. $100 \mathrm{mg}$ dieses Materials wurden gefriergetrocknet und die Aminosäuremengen in Kooperation mit K. Harter und B. Stadelhofer (Universität Tübingen) bestimmt. Dargestellt sind die Mittelwerte von zwei biologischen Replikaten. Der Versuch wurde ein weiteres Mal mit vergleichbaren Werten wiederholt.

Dies mag im ersten Moment verwundern, aber Asparagin dient in der Pflanze während der Dunkelheit als Transportform für Stickstoff und Kohlenstoff, und wird deshalb besonders unter diesen Bedingungen der verlängerten Nacht gebildet. Asparagin macht deshalb auch einen Großteil der gesamten freien Aminosäuren aus (Abb. 5.16; Tabelle mit Originaldaten im Anhang 8.2). Die Unterschiede in der Menge der freien Aminosäuren zwischen Überexpremierern, Doppelmutante und Wildtyp lassen sich hauptsächlich auf die unterschiedlichen Asparaginmengen in diesen Pflanzen zurückführen. Die folgenden Kapitel behandeln die Regulation dieser Gene aus Aminosäureabbau und -biosynthese. 


\subsubsection{Die verstärkte Expression der ProDH in den Überexpremierern führt zu einem reduzierten Prolingehalt dieser Pflanzen während der verlängerten Nacht}

Die ProDH katalysiert den ersten Schritt des Abbaus der Aminosäure Prolin zu Glutamat (Abb. 5.17). Während der dunkelinduzierten Seneszenz kommt es zu einer Induktion der ProDH (Abb. 5.18). Unter diesen Bedingungen dient der Abbau von Prolin wie der Abbau anderer Aminosäuren auch als Quelle für Kohlenstoff und Stickstoff, die unter diesen Energiemangelbedingungen dringend benötigt werden (Blum und Ebercon, 1976; Ahmad und Hellebust, 1988).

Die Überexpression von AtbZIP1 und AtbZIP53 führt zu einem signifikanten Anstieg der ProDH-Expression während der gesamten sechs Tage Dunkelinduktion. Während Pro35S:AtbZIP53 Pflanzen eine konstitutive Missexpression im Licht wie auch in Dunkelheit zeigen, führt die Überexpression von AtbZIPl erst nach einem oder mehreren Tagen Dunkelheit zu einer verstärkten Expression der ProDH (Abb. 5.18). Die Doppelmutante atbzipl atbzip53 zeigt eine leichte Reduktion der ProDH Expression, allerdings ist auch bei ihr noch eine deutliche Induktion der ProDH durch Dunkelheit zu erkennen.

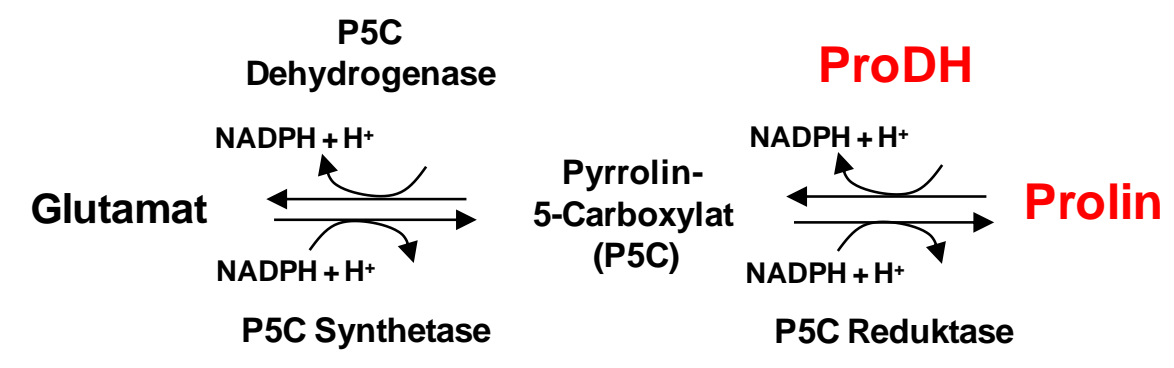

Abb. 5.17: Schema des Abbaus von Prolin zu Glutamat durch die ProDH und weitere Enzyme über das Zwischenprodukt Pyrrolin-5-Carboxylat (P5C)nach (Hellmann et al., 2000). 


\begin{tabular}{|c|c|c|c|c|c|c|c|c|c|c|c|c|c|c|c|}
\hline \multicolumn{5}{|c|}{ Wt } & \multicolumn{5}{|c|}{ Pro35S:AtbZIP1 } & \multicolumn{5}{|c|}{ Pro35S:AtbZIP53 } & \multirow[b]{2}{*}{ Tage Dunkelheit } \\
\hline 0 & 1 & 4 & 6 & 8 & 0 & 1 & 4 & 6 & 8 & 0 & 1 & 4 & 6 & 8 & \\
\hline & thes & & & & & & & & & & & & & & ProDH \\
\hline$=$ & & & 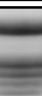 & $=$ & E & & & & $=$ & 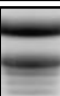 & & 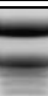 & $=$ & $=$ & $\mathrm{EtBr}$ \\
\hline
\end{tabular}

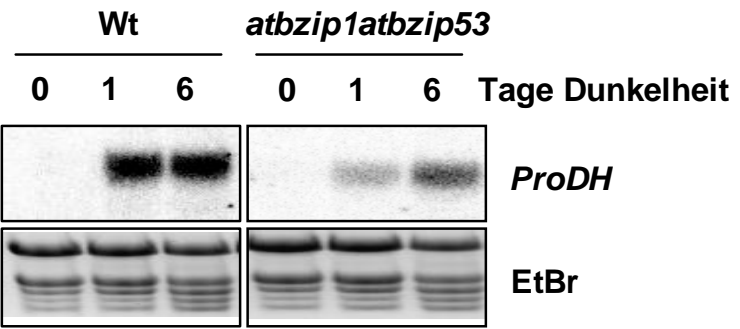

Abb. 5.18: AtbZIP1 und AtbZIP53 haben einen starken Einfluss auf die Expression der ProDH Wildtyp, Überexpremierer und Doppelmutante wurden 3-4 Wochen im Langtag angezogen. Anschließend wurden die Pflanzen dunkel gestellt. Zu den angegebenen Zeitpunkten wurden jeweils 8-10 Pflanzen pro Linie geerntet und zusammen aufgearbeitet. Daraus wurde RNA gewonnen und mit Hilfe einer Northern Analyse untersucht. Der Versuch wurde mehrfach mit vergleichbarem Ergebnis durchgeführt. EtBr: Ethidiumbromid-Färbung der verwendeten RNAGele zum Nachweis der gleichmäßiger Beladung.

Um diese Ergebnisse aus den Northern Analysen noch einmal zu reproduzieren und auch eine bessere Auflösung insbesondere der physiologisch relevanten frühen Zeitpunkte der verlängerten Nacht zu bekommen, wurde der Versuch noch einmal mit kürzeren Dunkelinduktionen durchgeführt und dieses Mal mit Hilfe der qPCR die Transkriptmenge der ProDH bestimmt (Abb. 5.19). In dieser Analyse bestätigen sich die schon aus dem vorherigen Versuch gewonnenen Ergebnisse. Im Wildtyp sieht man, wie die ProDH Expression mit Einbruch der Dunkelheit stetig steigt. Die Pro35S:AtbZIP53 Pflanzen zeigen eine starke konstitutive Expression der ProDH im Licht, die während der Nacht stärker wird und auch während der verlängerten Nacht noch etwas gesteigert werden kann. Die AtbZIP1 Überexpremierer zeigen dagegen während der Lichtphase nur eine geringfügig stärkere ProDH-Expression als der Wildtyp, dies ändert sich aber mit dem Eintreten in die verlängerte Dunkelphase. Hier steigt die Transkription der ProDH in den Pro35S:AtbZIP1 Pflanzen deutlich stärker an. Die atbzipl atbzip53 Doppelmutante zeigt dagegen wie schon im Northern nur eine leichte Reduktion der ProDH-Expression. 


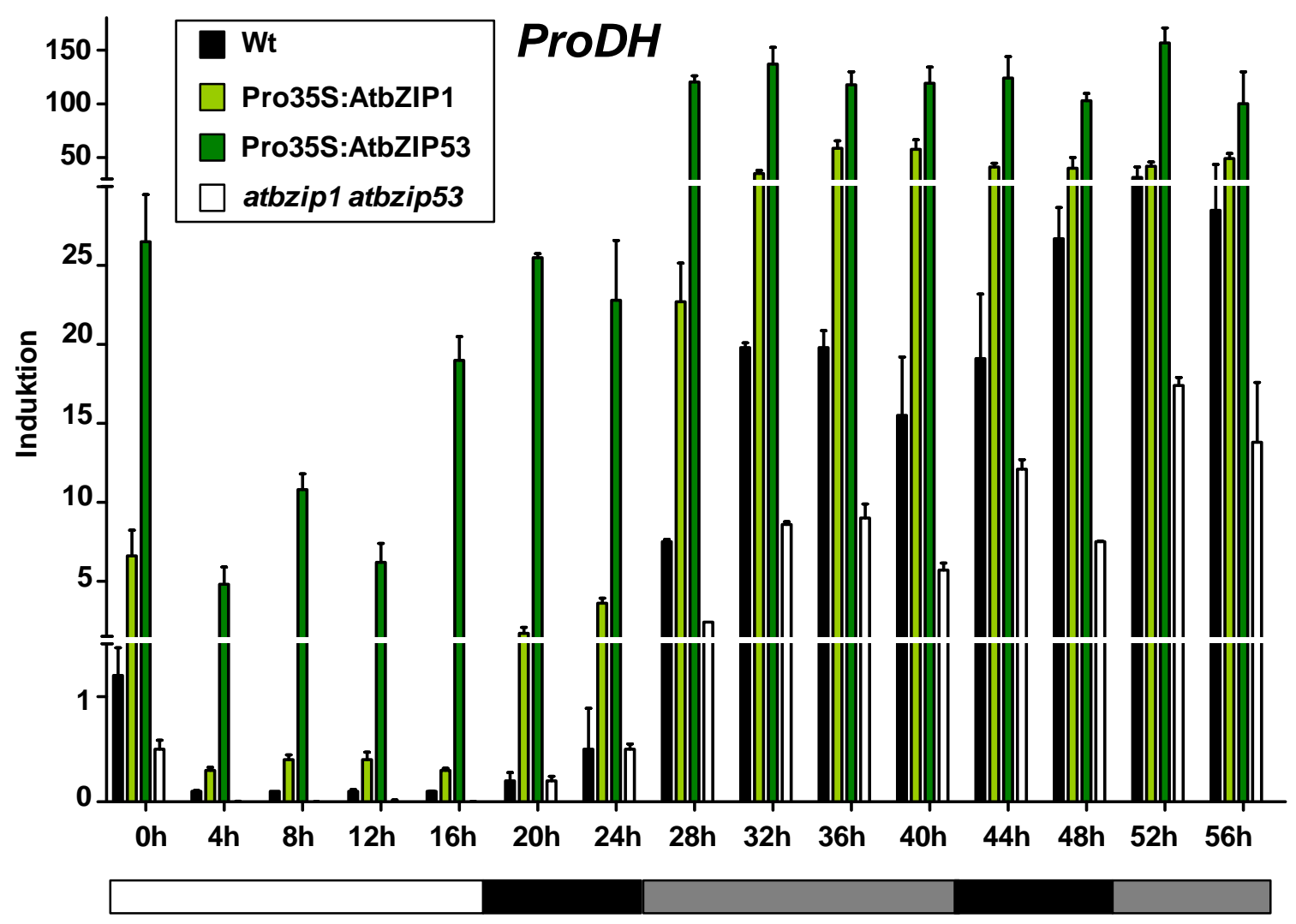

Abb. 5.19: Detaillierte qPCR-Analyse der Expression der ProDH während der verlängerten Nacht Die Pflanzen wurden 3-4 Wochen im Langtag angezogen und danach dunkel gestellt. Zu den angegebenen Zeitpunkten wurden jeweils 8-10 Pflanzen geerntet und zusammen aufgearbeitet. Die Expression der ProDH wurde mit Hilfe der qPCR untersucht. Angegeben sind die relativen Werte im Vergleich zur Expression zu Beginn des Versuchs von je zwei Replikaten nach Abgleich mit dem Haushaltsgen Ubiquitin. Zur besseren Übersicht ist die y-Achse zweimal unterbrochen (bei 2 facher und 30facher Induktion). weißer Balken: normale Lichtphase (16h), schwarzer Balken: normale Nacht (8h), grauer Balken: verlängerte Nacht.

Um zu testen ob sich die transkriptionelle Regulation der ProDH auch auf die Menge der Aminosäure Prolin in der Pflanze auswirkt, wurden der Aminosäuregehalt während der verlängerten Nacht bestimmt. Die deutliche Aktivierung der ProDH im Wildtyp während der Dunkelinduktion, die in qPCR und Northern Analyse gezeigt werden konnte, führt dazu, dass die Prolinmenge während der Dunkelinduktion deutlich ab nimmt (Abb. 5.20). 


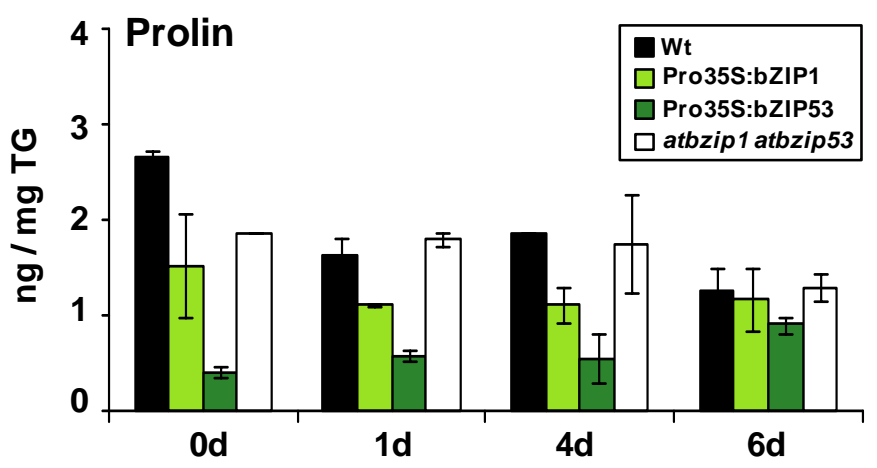

Abb. 5.20: Die Prolinmenge ist in den Überexpremierern von AtbZIP1 und 53 deutlich reduziert Die Pflanzen wurden 3-4 Wochen im Langtag angezogen und anschließend für bis zu 6 Tage dunkel gestellt. Zu den angegebenen Zeitpunkten wurden jeweils 8-10 Pflanzen jeder Linie geerntet und zusammen aufgearbeitet. $100 \mathrm{mg}$ dieses Materials wurden gefriergetrocknet und die Aminosäuremengen in Kooperation mit K. Harter und B. Stadelhofer (Universität Tübingen) bestimmt. Dargestellt sind die Mittelwerte von zwei biologischen Replikaten. Der Versuch wurde ein weiteres Mal mit vergleichbaren Werten wiederholt.

Die starke Expression der ProDH in den Überexpremierern von AtbZIP1 und AtbZIP53 führt zu einem verstärkten Abbau von Prolin durch die ProDH und damit auch zu einem stark reduzierten Gehalt an Prolin in diesen Pflanzen während der gesamten verlängerten Nacht. Besonders ausgeprägt ist dies bei den Pro35S:AtbZIP53 Pflanzen, die auch die stärkste ProDH Expression zeigten. Die leichte Reduktion der ProDHExpression in der atbziplatbzip53 Doppelmutante führt dagegen nicht $\mathrm{zu}$ einem erhöhten Prolingehalt. Hier sind kaum Unterschiede zum Wildtyp zu erkennen.

Die Überexpremierer von AtbZIP1 und AtbZIP53 zeigen aber eine deutliche Veränderung der ProDH-Expression, die auch zu einer deutlichen Änderung des Aminosäuregehalts führt. Die Frage ist, ob AtbZIP1 und AtbZIP53 direkt an den Promotor der ProDH binden, oder ob die beobachteten Veränderungen der Expression durch indirekte Effekte hervorgerufen werden.

Kürzlich wurde für die ProDH mit Hilfe von ChIP Analysen gezeigt, dass sie ein direktes Zielgen von AtbZIP53 während der Anpassung der Pflanze an hypoosmotische Stressbedingungen ist (Weltmeier et al., 2006). Der Promotor der ProDH enthält mehrere cis-Elemente, die als Bindestellen für bZIP Transkriptionsfaktoren in Frage kommen. So gibt es z.B. zwei ACTCAT-Motive (Satoh et al., 2004; Weltmeier et al., 2006) und eine C-Box (GACGTC). Für die folgende ChIP-Analyse wurden die Primer 
so gewählt, dass sie einen 190 bp großen Promotorbereich amplifizieren, der beide ACTCAT-Motive enthält (Abb. 5.21 A).

Tatsächlich konnte gezeigt werden, dass dieses Promotorfragment nach der Immunopräzipitation in den Pro35S:HA-AtbZIP1 Pflanzen etwa 5fach angereichert ist (Abb. 5.21 B), was eine Bindung von AtbZIP1 an der ProDH Promotor belegt. Diese Bindung von AtbZIP1 an den Promotor der ProDH ist dabei zumindest unter den gewählten Versuchsbedingungen unabhängig von Licht oder Dunkelheit. Der Vergleich von Chromatin aus Pflanzen nach 4 Tagen Inkubation in Dunkelheit mit Pflanzen aus normalen Langtagsbedingungen zeigt keinerlei Unterschiede. Der gleichmäßige Einsatz des Chromatins wurde in einer Western Analyse kontrolliert (Abb. 5.21 C).

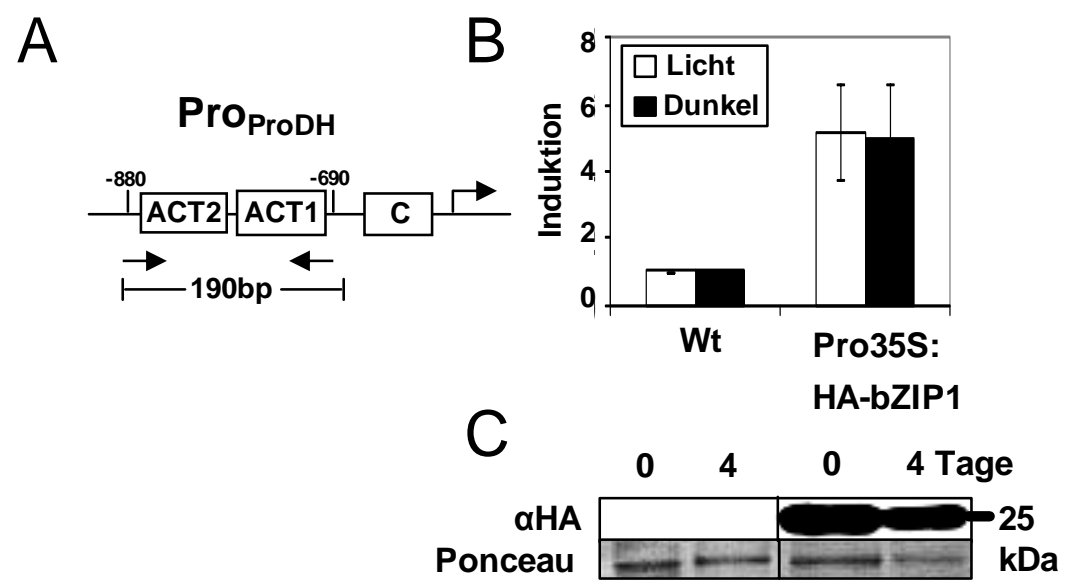

\footnotetext{
Abb. 5.21: AtbZIP1 bindet direkt an den Promotor der ProDH

A: Schema des ProDH Promotors mit zwei benachbarten ACTCAT Elementen und einer C-Box. Pfeile geben die Position der Primer für die Amplifikation des 190 bp großen PCR Fragmentes an B: Pflanzen für die Immunopräzipitation wurden 3-4 Wochen im Langtag angezogen und anschließend direkt geerntet bzw. vorher für weitere 4 Tage dunkel gestellt. Nach der Immunopräzipitation mit einem ChIPgrade HA-Antikörper wurde eine qPCR der aufgereinigten DNA mit Primern durchgeführt, die das Stück des ProDH Promotors mit den 2 ACTCAT Elementen umfassen. Dargestellt ist die Anreicherung dieses Fragments im Vergleich zum Wildtyp nach Abgleich mit Inputkontrolle und einem unspezifischen Actin-Gen (siehe Material und Methoden). Gezeigt wird Mittelwert und Standardabweichung von drei unabhängigen Experimenten.

C: Zur Kontrolle der gleichmäßigen Beladung der Chromatins aus Licht und Dunkelheit wurden die Input-Kontrollen vor der Immunopräzipitation in einem Western analysiert.
} 


\subsubsection{Die BCAT2 wird in den Überexpremierern von AtbZIP1 und AtbZIP53} verstärkt expremiert und führt zu einer Reduktion der verzweigten Aminosäuren

Die BCAT2 ist ein weiteres Gen des Aminosäurestoffwechsels, das in den Transkriptomanalysen der Pro35S:AtbZIP53 Pflanzen verstärkt expremiert wurde. Sie gehört zu einer Familie von sieben Enzymen, von denen sechs in Arabidopsis transkribiert werden (BCAT1-6). Die Mitglieder dieser Familie katalysieren den letzten Schritt der Synthese der verzweigtkettigen Aminosäuren Leucin, Isoleucin und Valin, aber auch den ersten Schritt ihrer Degradation (Abb. 5.22).

Die Bestimmung der Aminosäuregehalte ergab, dass die Mengen der verzweigtkettigen Aminosäuren Leucin, Isoleucin und Valin im Wildtyp kontinuierlich während der verlängerten Nacht ansteigt (Abb. 5.23). Da unter diesen Bedingungen besonders Kohlenstoff knapp ist, wird dieser starke Anstieg wahrscheinlich nicht auf eine Neusynthese dieser Aminosäuren zurückzuführen sein, sondern vielmehr auf einen Abbau von Proteinen, und damit eine Freisetzung auch dieser drei Aminosäuren. Dafür spricht auch die zunehmende Gesamtmenge an freien Aminosäuren (Abb. 5.16).

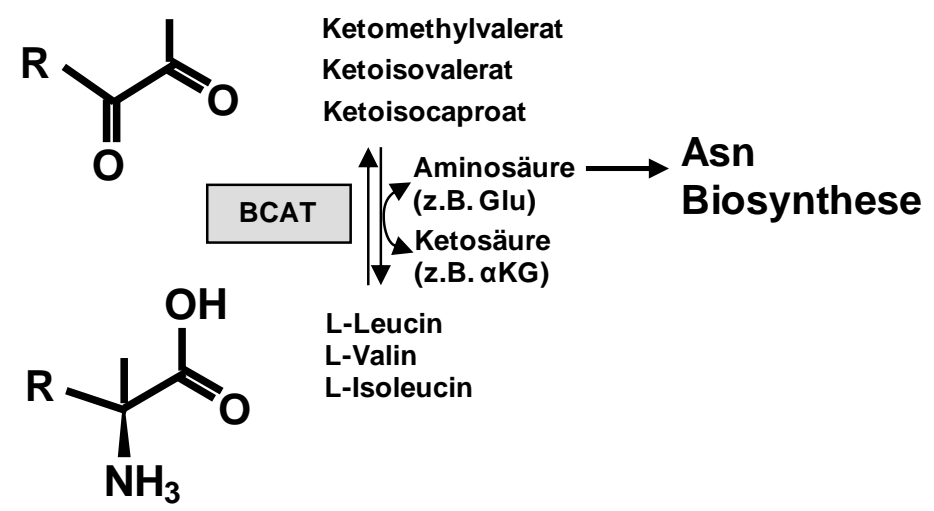

Abb. 5.22: Schema des durch die Mitglieder der BCAT-Familie katalysierten Abbaus /Aufbaus der verzweigtkettigen Aminosäuren Leucin, Valin und Isoleucin (nach Binder et al., 2007)

Durch den Abbau von Leucin, Isoleucin oder Valin frei werdende Aminosäuren können zur Synthese von Asparagin (Asn) genutzt werden. Glu = Glutaminsäure; $\alpha K G=\alpha$ Ketoglutarat 

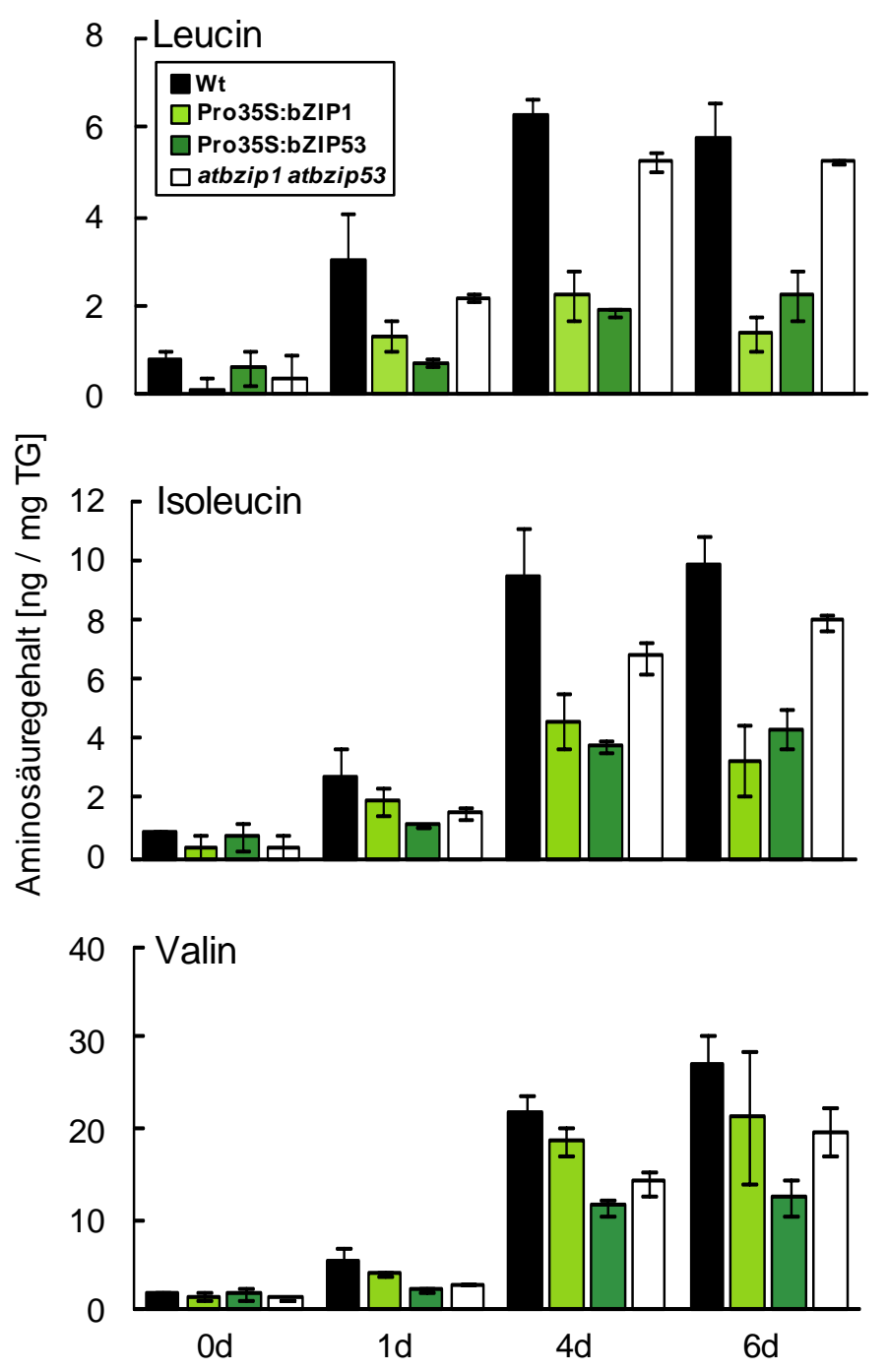

Abb. 5.23: Die Menge der verzweigtkettigen Aminosäuren Leucin, Isoleucin und Valin ist in den Überexpremierern von AtbZIP1 und AtbZIP53 deutlich reduziert

Die Pflanzen wurden 3-4 Wochen im Langtag angezogen und anschließend für bis zu 6 Tage dunkel gestellt. Zu den angegebenen Zeitpunkten wurden jeweils 8-10 Pflanzen jeder Linie geerntet und zusammen aufgearbeitet. $100 \mathrm{mg}$ dieses Materials wurden gefriergetrocknet und die Aminosäuremengen in Kooperation mit K. Harter und B. Stadelhofer (Universität Tübingen) bestimmt. Dargestellt sind die Mittelwerte von zwei biologischen Replikaten. Der Versuch wurde ein weiteres Mal mit vergleichbaren Werten wiederholt.

Während die Doppelmutante atbzipl atbzip53 keinen großer Unterschied zum Wildtyp zeigt, finden sich in beiden Überexpremierer viel geringere Mengen der drei verzweigtkettigen Aminosäuren Leucin, Isoleucin und Valin während der gesamten Phase der Dunkelinduktion (Abb. 5.23). In diesen Pflanzen scheint also der Abbau dieser drei Aminosäuren verstärkt abzulaufen. 
In der Literatur wird die BCAT1 als zentrales Enzym beschrieben, dass in den Mitochondrien für den Abbau der verzweigtkettigen Aminosäuren zuständig ist (Schuster und Binder, 2005). Eine Analyse der Expression der 6 BCAT-Gene mit der Genevestigator Software (Hruz et al., 2008) ergab, dass Dunkelheit die BCAT1 zwar leicht induziert, die $B C A T 2$ wird unter diesen Bedingungen aber noch viel stärker induziert (Abb. 5.24). Sie zeigt außerdem auch eine starke Repression durch Zucker und ähnelt damit in ihrer Expression sehr stark der Expression von AtbZIP1 (Abb. 5.3).

Eine Analyse von Wildtyppflanzen in der qPCR bestätigt die starke Aktivierung der BCAT2 Expression während der verlängerten Nacht (Abb. 5.25). Die atbzipl atbzip53 Mutante unterscheidet sich nicht vom Wildtyp. Dies spiegelt die gemessenen Aminosäuremengen wieder, die sich in der Doppelmutante auch nicht vom Wildtyp unterscheiden. Bei den Überexpremierern zeigen besonders die Pro35S:AtbZIP1 Pflanzen eine starke Expression der BCAT2, die weit über der des Wildtyps liegt.

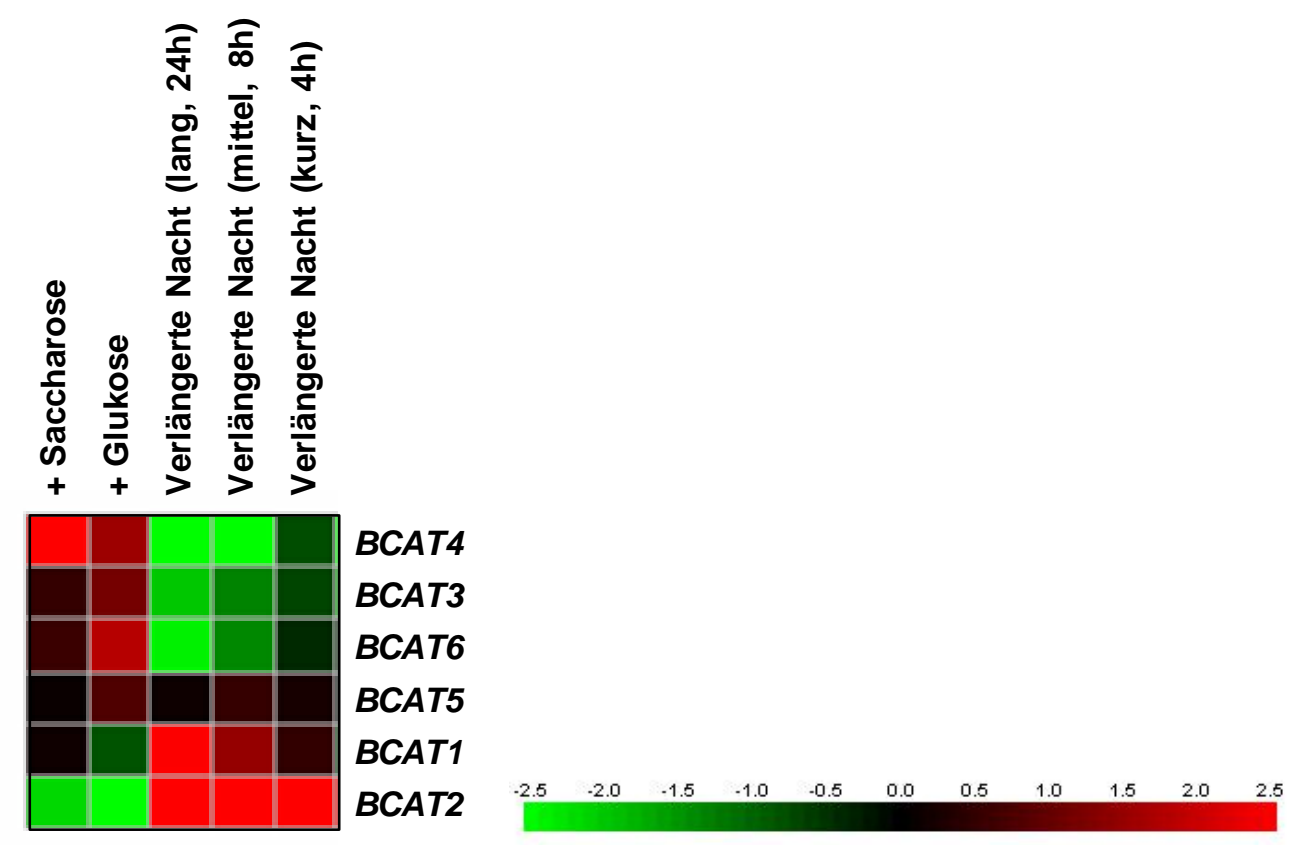

Abb. 5.24: Genevestigator Analyse (Hruz et al., 2008) der Expression der 6 BCAT Gene während der verlängerten Nacht

Behandlung mit Glukose oder Saccharose führt zu einer Reprimierung (grün), eine verlängerte Nacht führt dagegen zur Aktivierung (rot) der Transkription von BCAT1 und BCAT2. Dargestellt sind relative Expressionswerte unter den angegebenen Bedingungen im Vergleich zur Kontrolle. 


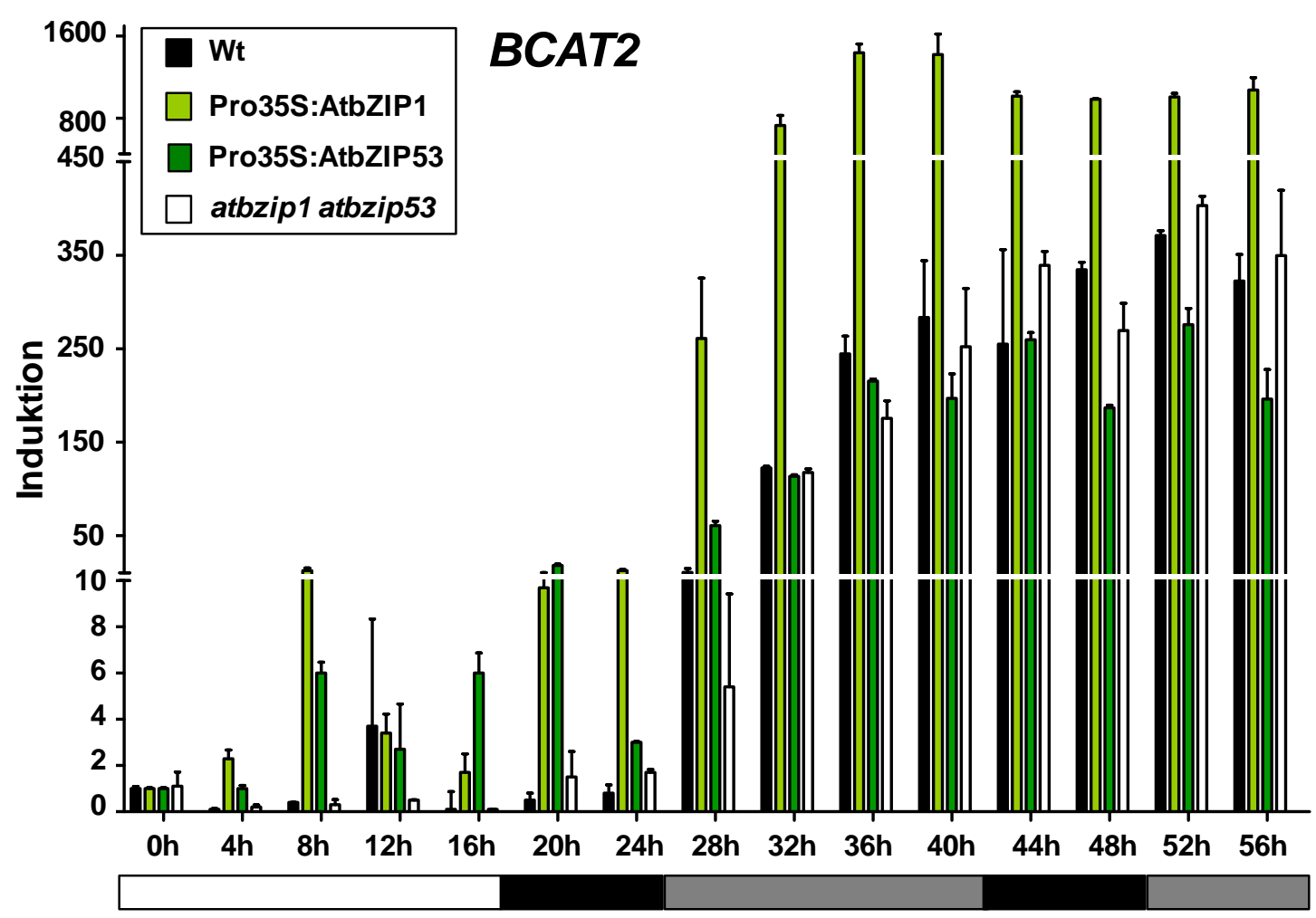

Abb. 5.25: Detaillierte qPCR-Analyse der Expression der BCAT2 während der verlängerten Nacht Die Pflanzen wurden 3-4 Wochen im Langtag angezogen und danach dunkel gestellt. $\mathrm{Zu}$ den angegebenen Zeitpunkten wurden jeweils 8-10 Pflanzen geerntet und zusammen aufgearbeitet. Die Expression der BCAT2 wurde mit Hilfe der qPCR untersucht. Angegeben sind die relativen Werte im Vergleich zur Expression zu Beginn des Versuchs von je zwei Replikaten nach Abgleich mit dem Haushaltsgen Ubiquitin. Zur besseren Übersicht ist die y-Achse zweimal unterbrochen (bei 10facher und 450facher Induktion). weißer Balken: normale Lichtphase (16h), schwarzer Balken: normale Nacht $(8 \mathrm{~h})$, grauer Balken: verlängerte Nacht

In den Pro35S:AtbZIP53 Pflanzen wird die BCAT2 vor allem während des normalen Tag-/Nacht-Rhythmus und der beginnenden verlängerten Nacht verstärkt expremiert, während der späteren Dunkelinduktion ist die Expression etwa mit der des Wildtyps vergleichbar.

Diese starke Expression der BCAT2 in den Überexpremierern führt möglicherweise zum starken Abbau der verzweigtkettigen Aminosäuren in diesen Pflanzen und führt dazu, dass die Menge dieser Aminosäuren in beiden Überexpremierern weit unter der Menge des Wildtyps liegt. 


\subsubsection{Die Überexpression von AtbZIP1 und AtbZIP53 führt zu einer verstärkten Expression der Gene der Asparagin Biosynthese während der verlängerten Nacht}

Die starke Expression von ProDH und BCAT2 in den Überexpremierern von AtbZIP1 und AtbZIP53 führte zu einem erhöhten Abbau der jeweiligen Aminosäuren. In den Transkriptomanalysen der beiden Überexpressionspflanzen (Weltmeier, 2005) fällt auf, dass auch ein Aminosäurebiosyntheseweg stark durch die Überexpression der beiden bZIP Transkriptionsfaktoren beeinflusst wird. Dieser führt zur Synthese der Aminosäure Asparagin (Lin und $\mathrm{Wu}, 2004)$. Beinahe alle Gene dieses Stoffwechselweges werden durch einen oder beide bZIP Transkriptionsfaktoren reguliert (Abb. 5.26 A, Tabelle $5.1)$.
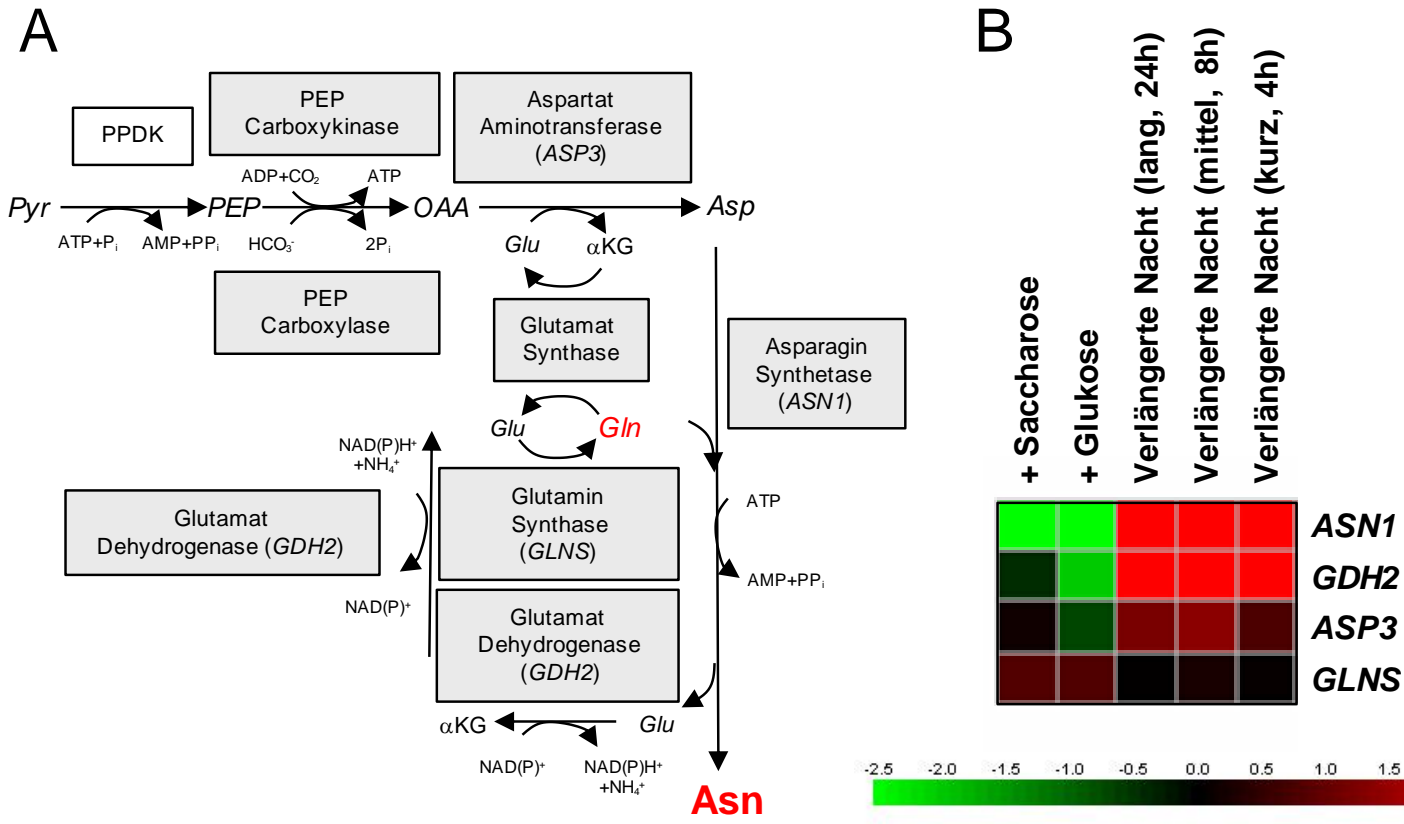

Abb. 5.26: A: Schema des Biosyntheseweges der Aminosäure Asparagin (nach Lin und Wu, 2004) und B: Genevestigator (Hruz et al., 2008) Daten der Expression der beteiligten Gene während der verlängerten Nacht

Behandlung mit Glukose oder Saccharose führt zu einer Reprimierung (grün), eine verlängerte Nacht dagegen zur Aktivierung (rot) der Transkription der meisten beteiligten Gene. Dargestellt sind relative Expressionswerte unter den angegebenen Bedingungen im Vergleich zur Kontrolle. 
Untersucht man die Expression dieser Gene während der verlängerten Nacht und bei Behandlung mit Zuckern mit Hilfe der Genevestigator Software (Hruz et al., 2008), so ergibt sich ein ähnliches Bild wie für die Expression von AtbZIP1 und AtbZIP53 (Abb. 5.3, Abb. 5.26 B). Die Expression von drei Genen der Asparagin-Biosynthese, nämlich der ASPARAGIN SYNTHETASE (ASN1), ASPARTAT AMINOTRANSFERASE (ASP3) und GLUTAMAT DEHYDROGENASE (GDH2) wird stark während der verlängerten Nacht induziert und durch Zucker reprimiert. Die Expression der PEP CARBOXYKINASE (PEPCK), die den ersten Schritt des Asparagin Biosyntheseweges katalysiert, konnte mit Hilfe der Software leider nicht untersucht werden, da das Gen nicht auf den Arrays enthalten war. Die GLUTAMIN SYNTHASE (GLNS) zeigt dagegen ein umgekehrtes Expressionsmuster. Ihre Expression wird durch Dunkelheit reprimiert und durch Zucker aktiviert. Diese Expressionsmuster führen dazu, dass Asparagin während der Nacht als bevorzugte Transportform für Stickstoff und Kohlenstoff dient, während tagsüber vor allem Glutamin diese Aufgabe übernimmt (Lam et al., 1994). Dies liegt an dem Verhältnis von Kohlenstoff zu Stickstoff in den beiden Aminosäuren. Während Glutamin 5 Kohlenstoffatome auf 2 Stickstoffatomen enthält, benötigt Asparagin bei gleicher Anzahl Stickstoff ein Kohlenstoffatom weniger, was besonders unter Bedingungen wichtig ist, unter denen Kohlenstoff limitierend ist, wie z.B. in der Dunkelheit, wenn die Pflanze keine Photosynthese betreiben kann.

Zur Reproduktion der Daten aus der Genevestigator Analysen wurden Northern Experimente gemacht, in denen die Expression der Gene der Asparagin- und Glutaminbiosynthese während der verlängerten Nacht untersucht wurde (Abb. 5.27). Die Expression von $A S N 1, G D H 2$ und ASP3 während der Induktion durch Dunkelheit im Wildtyp stimmt mit der Expressionsanalyse aus öffentlichen Transkriptomdatensätzen (Abb. 5.26) überein und auch die Reprimierung der GLNS während der verlängerten Nacht konnte hier reproduziert werden. Lediglich die Expression der PEPCK, zu der es auch in den öffentlichen Transkriptomdatensätzen keine Daten gibt, liegt in der Northern Analyse unter der Nachweisgrenze.

Die Pro35S:AtbZIP1 Überexpremierer zeigen unter den gleichen Bedingungen eine frühere und teilweise auch stärkere Induktion der Gene. Ausnahme ist hier wieder die $P E P C K$, die auch in den AtbZIP1 Überexpressionspflanzen nicht induziert wird. 


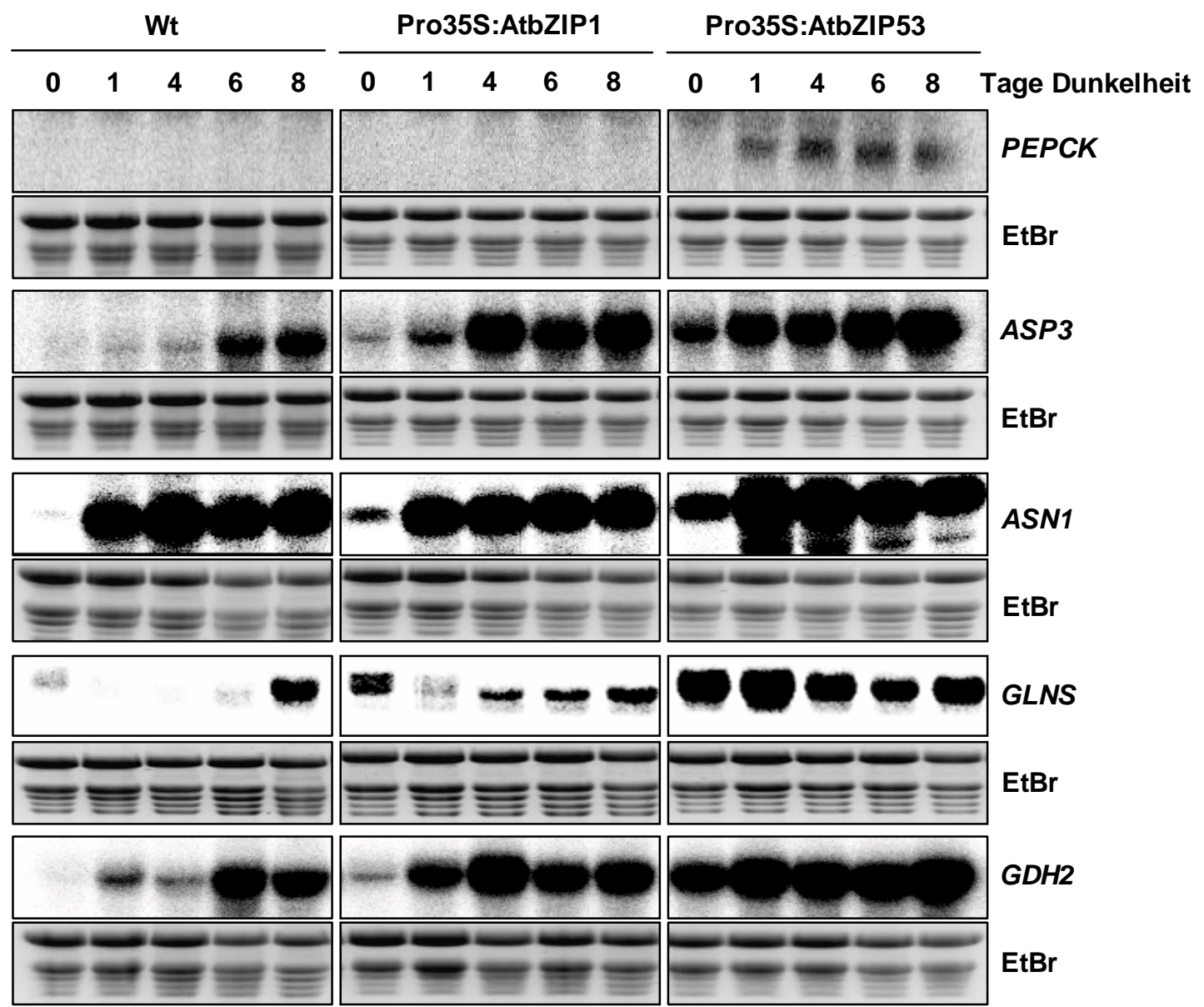

Abb. 5.27: AtbZIP1 und AtbZIP53 haben einen starken Einfluss auf die Expression der Gene, die zur Biosynthese von Asparagin führen

Wildtyp und Überexpressionspflanzen wurden 3-4 Wochen im Langtag angezogen. Anschließend wurden die Pflanzen dunkel gestellt. $\mathrm{Zu}$ den angegebenen Zeitpunkten wurden jeweils 8-10 Pflanzen pro Linie geerntet und zusammen aufgearbeitet. Daraus wurde RNA gewonnen und im Northern mit Sonden für die oben angegebenen Gene untersucht. EtBr: Ethidiumbromid-Färbung der verwendeten RNA-Gele zum Nachweis der gleichmäßigen Beladung.

Die Pro35S:AtbZIP53 Überexpremierer zeigen dagegen eine starke konstitutive Expression fast aller getesteten Gene aus Asparagin- und Glutamin-Biosynthese während des Tages und während der verlängerten Nacht. Nur die PEPCK wird nicht konstitutiv expremiert, sondern erst nach Induktion durch Dunkelheit.

Da für die späteren Zeitpunkte zwischen vier und acht Tagen Dunkelheit für die Expression der ASN1, dem zentralen Gen des Asparagin Biosyntheseweges, keine großen Unterschiede zwischen Wildtyp und Überexpremierern mehr zu erkennen sind, wurde noch einmal ein detaillierterer Versuch durchgeführt, um insbesondere auch die 
früheren Zeitpunkte der Dunkelinduktion, die physiologisch interessanter sind, näher zu untersuchen. In diesem detaillierteren Experiment (Abb. 5.28) ist zu erkennen, dass die ASN1 im Wildtyp im Licht nicht expremiert wird, aber schon nach 4 Stunden der verlängerten Nacht (28h Zeitpunkt des Experiments) hat sich die Transkriptmenge verzwanzigfacht. Ihr Maximum erreicht sie schließlich nach 28 Stunden der verlängerten Nacht mit einer fast 120fachen Transkriptmenge verglichen mit dem Beginn des Tages. Dies spiegelt die Ergebnisse aus der Northern Analyse wieder. Die Expression der ASN1 in den Pro35S:AtbZIP1 Überexpremierern ist während des normales Tag-/Nachtrhythmus nur unwesentlich stärker als im Wildtyp, steigt dann aber während der verlängerten Nacht deutlich stärker an.

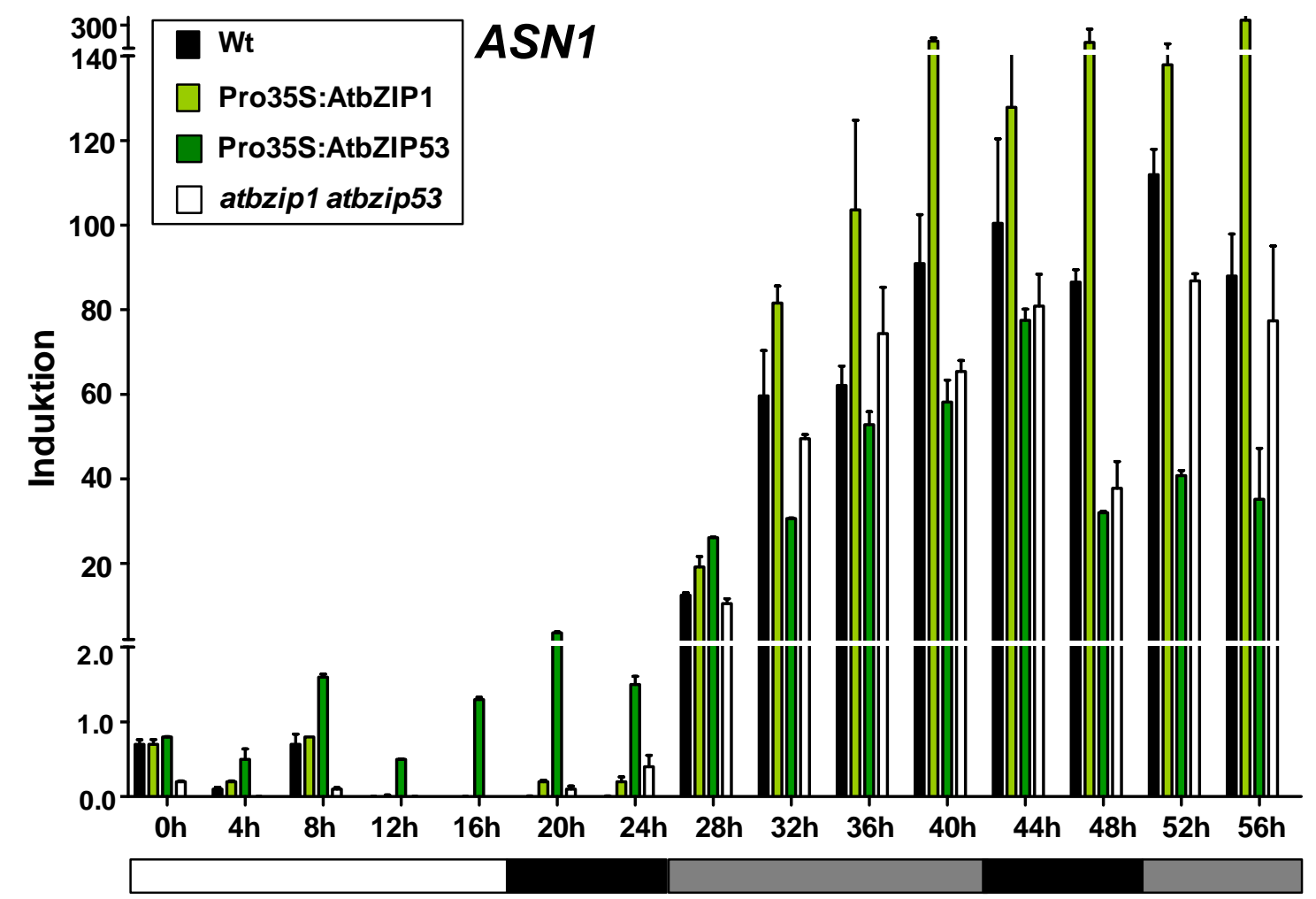

Abb. 5.28: Detaillierte qPCR-Analyse der Expression der ASN1 während der verlängerten Nacht Die Pflanzen wurden 3-4 Wochen im Langtag angezogen und danach dunkel gestellt. Zu den angegebenen Zeitpunkten wurden jeweils 8-10 Pflanzen geerntet und zusammen aufgearbeitet. Die Expression der ASN1 wurde mit Hilfe der qPCR untersucht. Angegeben sind die relativen Werte im Vergleich zur Expression zu Beginn des Versuchs von je zwei Replikaten nach Abgleich mit dem Haushaltsgen Ubiquitin. Zur besseren Übersicht ist die y-Achse zweimal unterbrochen (bei 2 facher und 140facher Induktion). weißer Balken: normale Lichtphase (16h), schwarzer Balken: normale Nacht (8h), grauer Balken: verlängerte Nacht 
Die AtbZIP53 Überexpremierer zeigen wie schon in der Northern Analyse eine konstitutiv stärkere Expression der ASNl während des normalen Tag-/Nachtwechsels, während der verlängerten Nacht ist die Expression im Gegensatz zur Northern Analyse aber eher etwas schwächer als im Wildtyp. Die Unterschiede sind allerdings nicht so groß, so dass sie möglicherweise in der wesentlich weniger sensitiveren Northern Analyse nicht zu sehen waren.

Die Doppelmutante atbzipl atbzip53, die in diesem Experiment ebenfalls getestet wurde zeigte weder im Licht noch im Dunkeln große Unterschiede zum Wildtyp. Dies deutet daraufhin, dass AtbZIP1 und AtbZIP53 nicht die einzigen Faktoren sind, die an der Regulation der ASN1 beteiligt sind.

Um zu testen, welche Auswirkung auf den Asparagingehalt die verstärkte Expression der Biosynthesegene dieser Aminosäure in den Überexpressionspflanzen hat, haben wir die Aminosäuremengen von Wildtyp, Überexpremierern und der Doppelmutante während der verlängerten Nacht quantifiziert (Abb. 5.29). Es zeigt sich, dass der Asparagingehalt im Wildtyp während der verlängerten Nacht stark ansteigt. Dies lässt sich auf die transkriptionelle Aktivierung der Asparagin-Biosynthesegene während der Dunkelinduktion zurückführen.

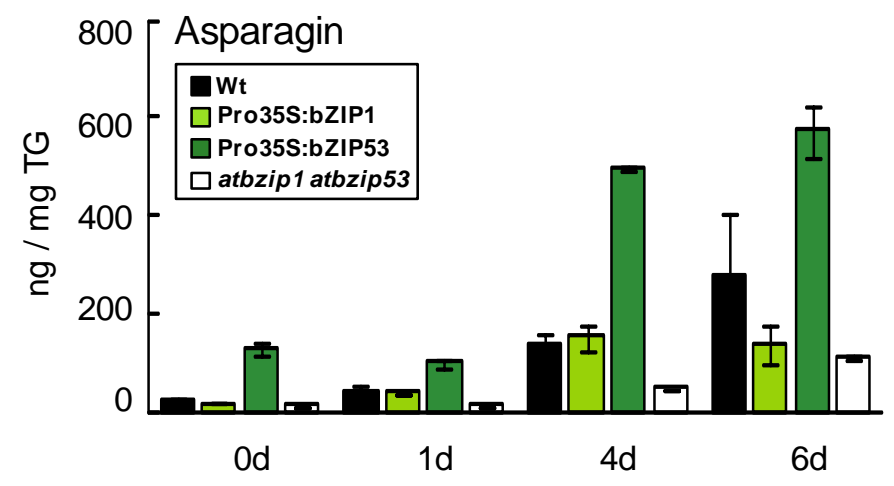

Abb. 5.29: Die Asparaginmenge ist in den Überexpremierern von AtbZIP53, nicht aber von AtbZIPI deutlich erhöht

Die Pflanzen wurden 3-4 Wochen im Langtag angezogen und anschließend für bis zu 6 Tage dunkel gestellt. Zu den angegebenen Zeitpunkten wurden jeweils 8-10 Pflanzen jeder Linie geerntet und zusammen aufgearbeitet. $100 \mathrm{mg}$ dieses Materials wurden gefriergetrocknet und die Aminosäuremengen in Kooperation mit K. Harter und B. Stadelhofer (Universität Tübingen) bestimmt. Dargestellt sind die Mittelwerte von zwei biologischen Replikaten. Der Versuch wurde ein weiteres Mal mit vergleichbaren Werten wiederholt. 
In der atbzipl atbzip53 Doppelmutante zeigt sich im Vergleich zum Wildtyp eine leichte Reduktion der Asparaginmenge, obwohl die ASN1 Expression in der Doppelmutante nicht sehr stark beeinträchtigt war. Für die Überexpremierer wurde eine deutliche Erhöhung des Asparagingehalts erwartet, da in diesen Pflanzen die Gene der Asparagin Biosynthese stark aktiviert werden. Dies trifft allerdings nur für die Pro35S:AtbZIP53 Pflanzen zu. Sie zeigen tatsächlich eine verstärkte Akkumulation von Asparagin während der Dunkelinduktion. Die Menge an Asparagin in den Pro35S:AtbZIP1 Pflanzen unterscheidet sich dagegen zu den meisten Zeitpunkten nicht von der im Wildtyp. Nach sechs Tagen liegt sie sogar deutlich unter der Menge des Wildtyps.

Eine mögliche Erklärung dafür, dass die Gene für die Asparagin Biosynthese in den Pro35S:AtbZIP1 Pflanzen zwar verstärkt expremiert werden, dies aber nicht zu einer Akkumulation von Asparagin in den Pflanzen führt ist, dass in diesen Pflanzen auch noch ein anderes Protein vermehrt gebildet wird, das den Abbau von Asparagin zu Aspartat katalysiert.

Bei diesem Gen könnte es sich um eine ASPARAGINASE (ANS) handeln (Bruneau et al., 2006). Die Transkription der ANS wird spezifisch in den Pro35S:AtbZIP1 Überexpremierern, nicht aber in den AtbZIP53 überexpremierenden Pflanzen nach Dunkelheit aktiviert (Abb. 5.30). Bereits nach 4 Stunden in der verlängerten Nacht ist bei ihnen eine 10fache Induktion der ANS zu messen, die sich im Laufe der Zeit noch auf eine fast 300fache Induktion steigert, während in Wildtyp, Doppelmutante und Pro35S:AtbZIP53 Pflanzen keinerlei Steigerung der Transkription während der verlängerten Nacht zu erkennen ist.

Die Expressionsdaten und Aminosäuremessungen der Überexpressionspflanzen sprechen dafür, dass AtbZIP1 und AtbZIP53 einen Einfluss auf die Regulation des Asparagin Biosyntheseweges haben. Ist dieser Effekt aber nun direkt, d.h. können AtbZIP1 und AtbZIP53 direkt an den Promotor der ASN1 binden und diese so aktivieren, oder handelt es sich hier um einen indirekten Effekt? 


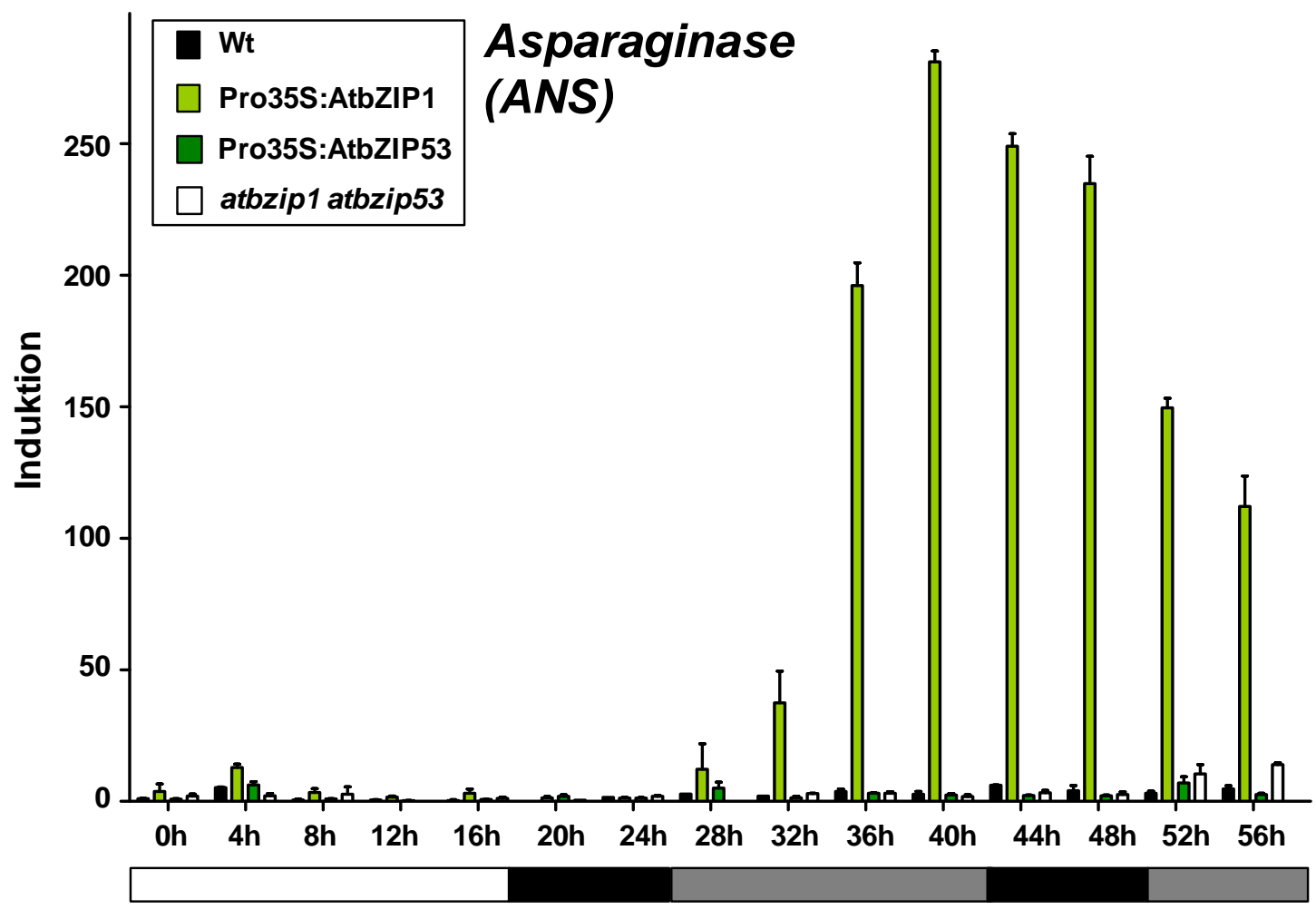

Abb. 5.30: Die Pro35S:AtbZIP1 Pflanzen zeigen eine deutlich erhöhte Expression der Asparaginase Die Pflanzen wurden 3-4 Wochen im Langtag angezogen und danach dunkel gestellt. $\mathrm{Zu}$ den angegebenen Zeitpunkten wurden jeweils 8-10 Pflanzen geerntet und zusammen aufgearbeitet. Die Expression der ANS wurde mit Hilfe der qPCR untersucht. Angegeben sind die relativen Werte im Vergleich zur Expression zu Beginn des Versuchs von je zwei Replikaten nach Abgleich mit dem Haushaltsgen Ubiquitin. weißer Balken: normale Lichtphase (16h), schwarzer Balken: normale Nacht (8h), grauer Balken: verlängerte Nacht

Mögliche Bindestellen für bZIP Transkriptionsfaktoren gibt es viele im ASN1 Promotor. In den ersten 1000bp finden sich alleine 5 ACGT Motive (Anhang Tabelle 8.1). Zwei der ACGT-Motive sind G-Boxen (CACTGG), an die eine Bindung von bZIP Faktoren bereits gezeigt werden konnte (Abb. 5.31 A; Schindler et al., 1992; Izawa et al., 1993). Um die Frage beantworten zu können, ob AtbZIP1 oder AtbZIP53 direkt an eines dieser Elemente aus dem ASN1 Promotor binden, wurden ChIP Analysen durchgeführt. Für AtbZIP53 konnte bereits demonstriert werden, dass eine direkte Bindung existiert (Weltmeier 2005). Für AtbZIP1 soll dies in dieser Arbeit gezeigt werden. Die Primer wurden so gewählt, dass sie ein 222 bp großes Fragment amplifizieren, das beide GBoxen des ASN1-Promotors enthält. 
A

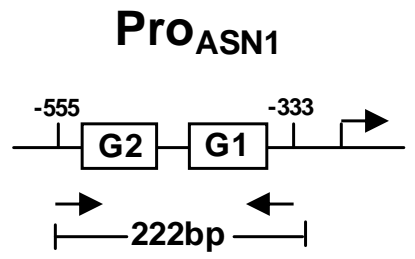

B

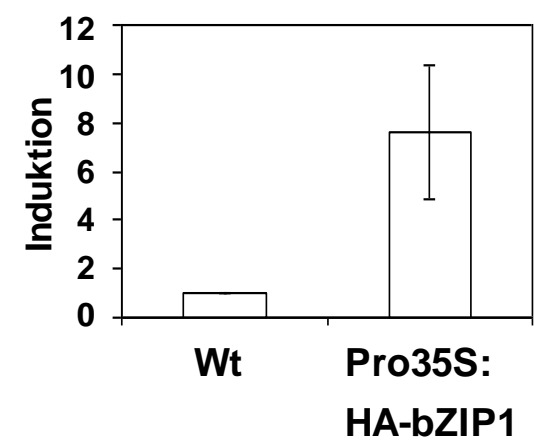

Abb. 5.31: AtbZIP1 bindet direkt an den Promotor der ASN1

A: Schema des ASN1 Promotors mit zwei benachbarten G-Boxen. Pfeile geben die Position der Primer für die Amplifikation des 222 bp großen PCR Fragments an.

B: Pflanzen für die Immunopräzipitation wurden 3-4 Wochen im Langtag angezogen und anschließend direkt geerntet. Nach der Immunopräzipitation mit einem ChIPgrade HA-Antikörper wurde eine qPCR der aufgereinigten DNA mit Primern durchgeführt, die das Fragment des ASN1 Promotors mit den 2 G-Boxen umfassen. Dargestellt ist die Anreicherung dieses Fragments im Vergleich zum Wildtyp nach Abgleich mit Inputkontrolle und einem unspezifischen Actin-Gen (Wildtyp=1). Gezeigt wird Mittelwert und Standardabweichung von drei unabhängigen Experimenten.

Tatsächlich konnte gezeigt werden, dass dieses Fragment nach der Immunopräzipitation in den Pro35S:AtbZIP1 Pflanzen etwa 8fach angereichert ist, was eine deutliche Bindung von AtbZIP1 an den Promotor der ASN1 belegt (Abb. 5.31 B).

Diese Ergebnisse zeigen, dass sowohl AtbZIP1, als auch AtbZIP53 direkt an den Promotor der ASNl binden und zu einer transkriptionellen Aktivierung der ASN1 führen, was sich letztendlich auch auf die Asparaginmengen in den Pflanzen auswirkt.

\subsection{ASN1 und ProDH werden auch im Protoplasten-System durch dunkelinduzierte Energieverarmung aktiviert}

Das Protoplastensystem eignet sich gut, um schnell den Einfluss vieler unterschiedlicher

Faktoren wie z.B. verschiedene Transkriptionsfaktoren oder verschiedene

Stressbedingungen auf die Expression einzelner Gene in vivo zu testen.

Um herauszufinden, ob das System auch geeignet ist, um den Prozess der Energieverarmung während der verlängerten Nacht $\mathrm{zu}$ untersuchen wurden 
Promotor:GUS Konstrukte der ProDH und der ASN1 transient in Arabidopsis Mesophyllprotoplasten transformiert und die GUS-Expression nach Inkubation in konstantem Licht und konstantem Dunkel verglichen. Wie man in Abb. 5.32 sehen kann führt die Inkubation über Nacht im Dunkeln zu einer deutlich (3-4fachen) Aktivierung der GUS-Aktivität beider Promotor:GUS Konstrukte. Die Induktion von ProDH und ASN1 durch dunkelinduzierte Energieverarmung kann also auch im Protoplastensystem reproduziert werden.

Energieverarmung kann auch andere Ursachen haben. So führt die Gabe des Photosynthese Inhibitors DCMU (3-(3,4-Dichlorphenyl)-1,1-Dimethyl-Harnstoff) ebenfalls zu einem Mangel an Energie, da die Pflanze nicht mehr in der Lage ist Photosynthese zu betreiben. Diese Behandlung führt wie schon die Dunkelinduktion zu einer Aktivierung der beiden Promotor:GUS Konstrukte (Abb. 5.32). Um zu zeigen, dass diese Induktion durch Energieverarmung im Protoplastensystem spezifisch für ProDH und ASN1 ist, wurde ein drittes Konstrukt als Kontrolle verwendet.
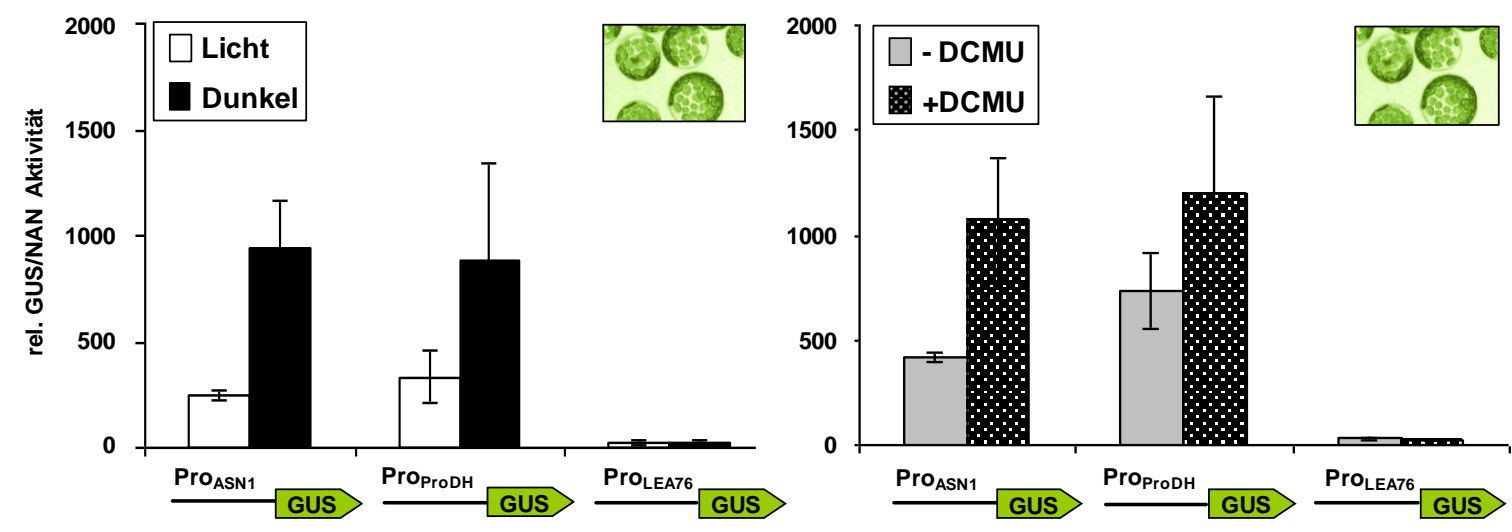

Abb. 5.32: ASN1 und ProDH werden auch im Protoplastensystem durch dunkelinduzierte Energieverarmung aktiviert

Die Protoplasten wurden nach der Transformation über Nacht für $16 \mathrm{~h}$ in Dauerlicht (weiße Balken) oder Dauerdunkel (schwarze Balken) bzw. ohne DCMU (graue Balken) oder mit DCMU (gepunktete Balken) im WI Puffer inkubiert. Die Ansätze wurden mit je 5 $\mu$ g Reporterplasmid,

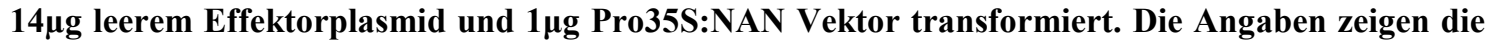
Mittelwerte von vier unabhängigen Transformationsansätzen. Das Experiment wurde mehrmals mit vergleichbarem Ergebnis wiederholt. 
Hierbei handelt es sich um den Promotor des LEA76 (LATE EMBRYOGENESIS ABUNDANT 76) Gens, das wie ProDH und ASN1 ein Zielgen von AtbZIP53 ist, aber keine Rolle in der dunkelinduzierten Seneszenz sondern in der Samenentwicklung und Antwort auf Salzstress in der Wurzel spielt (Alonso et al., 2009). Wie erwartet zeigt dieses ProLea76:GUS Konstrukt keine Aktivierung nach Induktion durch Dunkelheit oder DCMU.

In stabil transformierten Pflanzen führt die Überexpression von AtbZIP1 bzw. AtbZIP53 zu einer verstärkten Expression von ProDH und $A S N 1$ während der verlängerten Nacht. Diese verstärkte Expression von sowohl ProDH als auch ASN1 durch Überexpression von AtbZIP53 lässt sich auch im Protoplastensystem reproduzieren. Sowohl im Licht, als auch im Dunkeln sowie nach Gabe von DCMU zeigte die Überexpression von AtbZIP53 hier eine konstitutiv stärkere Aktivierung beider Promotor:GUS Konstrukte (Abb. 5.33 A,B). Die Überexpression von AtbZIPl zeigt dagegen im Protoplastensystem kaum Auswirkung auf die Aktivierung der beiden Konstrukte. Die GUS Aktivität ist hier nur geringfügig stärker als in der Kontrolle.

Um sicherzugehen, dass diese Unterschiede in der Aktivierung der Promotor:GUS Konstrukte in Protoplasten nicht auf die unterschiedlich starke Expression von AtbZIP1 und AtbZIP53 zurückzuführen ist, wurde eine Western Analyse durchgeführt, in der die Proteinmenge der beiden Transkriptionsfaktoren unter den getesteten Bedingungen verglichen wurde (Abb. 5.33 C). Die Proteinmenge von AtbZIP1 ist im Vergleich zu der von AtbZIP53 eher etwas größer. Dies kann also nicht die Unterschiede in der Aktivierung von ProDH und ASN1 erklären. Da AtbZIP1 auch in transgenen Pflanzen die Expression der beiden Gene erst während der verlängerten Nacht stark aktiviert hat, ist es möglich, dass in Protoplasten die Länge der Dunkelinduktion nicht ausreichend ist (nur über Nacht), oder andere wichtige Stimuli fehlen, die in der ganzen Pflanze vorhanden sind. 
A
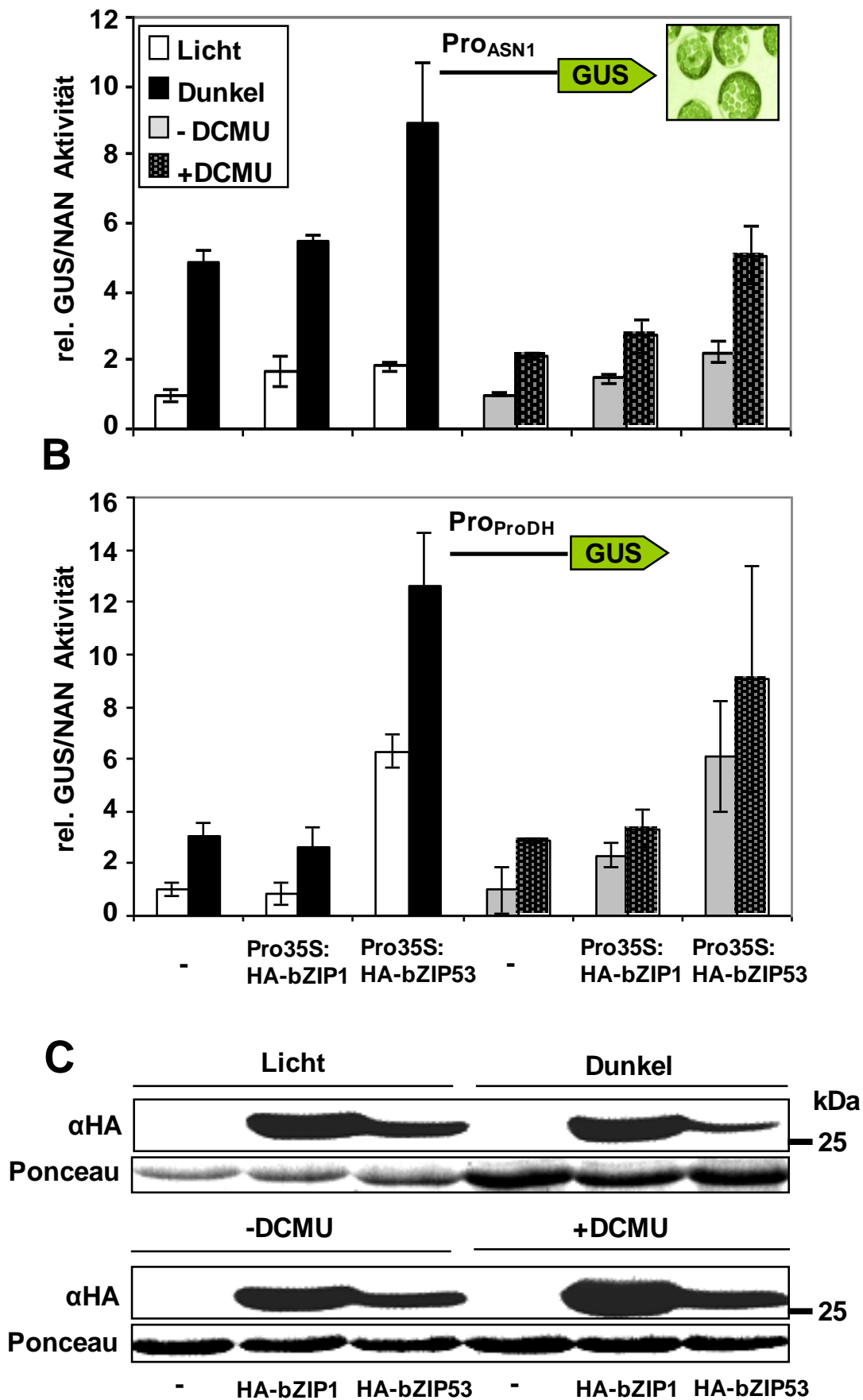

Abb. 5.33: AtbZIP53 aktiviert auch im Protoplastensystem ASN1 und ProDH, AtbZIP1 dagegen kaum Die Protoplasten wurden nach der Transformation über Nacht für 16 h in A: Dauerlicht (weiße Balken) oder Dauerdunkel (schwarze Balken) bzw. B: ohne DCMU (graue Balken) oder mit DCMU (gepunktete Balken) im WI Puffer inkubiert. Die Ansätze wurden mit je $5 \mu$ g Reporterplasmid, 14 $\mu$ g Effektorplasmid und $1 \mu \mathrm{g}$ Pro35S:NAN Vektor transformiert. Die Angaben zeigen die Mittelwerte von vier unabhängigen Transformationsansätzen. Das Experiment wurde mehrmals mit vergleichbarem Ergebnis wiederholt.

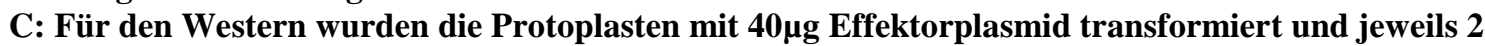
Transformationsansätze nach der Inkubation über Nacht in Harnstoffextraktionspuffer aufgenommen und vereinigt. 


\subsubsection{Auch andere bZIP Transkriptionsfaktoren können im Protoplastensystem ProDH und $A S N 1$ aktivieren}

Die Ergebnisse der Expression von ProDH und ASN1 nach Dunkelinduktion, die wir aus den qPCR Analysen gewonnen haben lassen sich mit dem Protoplastensystem einfach nachstellen. Jetzt kann dieses System angewendet werden, um mögliche weiter Faktoren zu finden, die einen Einfluss auf die Expression dieser Gene haben.

Kandidaten finden sich in den bZIP Transkriptionsfaktoren der Gruppen S1 und C. Die drei bZIP Faktoren AtbZIP2, AtbZIP11 und AtbZIP44 gehören wie AtbZIP1 und AtbZIP53 zur Gruppe S1 und sind eng miteinander verwandt. Von der Gruppe C ist bekannt, dass ihre vier Mitglieder AtbZIP9, AtbZIP10, AtbZIP25 und AtbZIP63 mit den fünf Transkriptionsfaktoren der Gruppe S1 Heterodimere bilden können und so möglicherweise gemeinsam die Expression ihrer Zielgene regulieren (Ehlert et al., 2006).

Im Protoplastensystem kann man nun einfach testen, ob eine transiente Überexpression dieser neun bZIP Transkriptionsfaktoren der Gruppen S1 und C zu einer Aktivierung des ProProDH:GUS und des ProASN1:GUS Konstrukts führt. Wie bereits in dem Vorexperiment gezeigt führt auch in diesem Experiment die Inkubation im Dunkeln zu einer deutlichen Steigerung der GUS-Aktivität (Abb. 5.34 A, B).

Die zusätzliche transiente Überexpression der einzelnen bZIP Faktoren hat dagegen sehr unterschiedlichen Einfluss auf die Aktivität der beiden Konstrukte. Während AtbZIP2, 11, 44 und $53 \mathrm{zu}$ einer deutlichen Aktivierung der ProDH und einer schwächeren Aktivierung der ASN1 sowohl im Licht wie auch im Dunkeln führen, hat die Überexpression von AtbZIP1, 9, 10, 25 und 63 nur relativ geringe Auswirkungen auf die Expression der beiden Gene. Für die ProDH führt von diesen fünf zuletzt genannten Faktoren lediglich die Expression von AtbZIP10 zu einer etwas höheren GUS-Aktivität im Dunkeln und AtbZIP63 hat eine etwas höhere Grundaktivität im Licht. Für die ASN1 zeigt die Expression von AtbZIP63 zumindest eine leichte Induktion im Vergleich zur Kontrolle, während AtbZIP9, AtbZIP10 und AtbZIP25 eher einen leicht negativen Effekt auf die Expression der ASN1 im Protoplastensystem haben. 

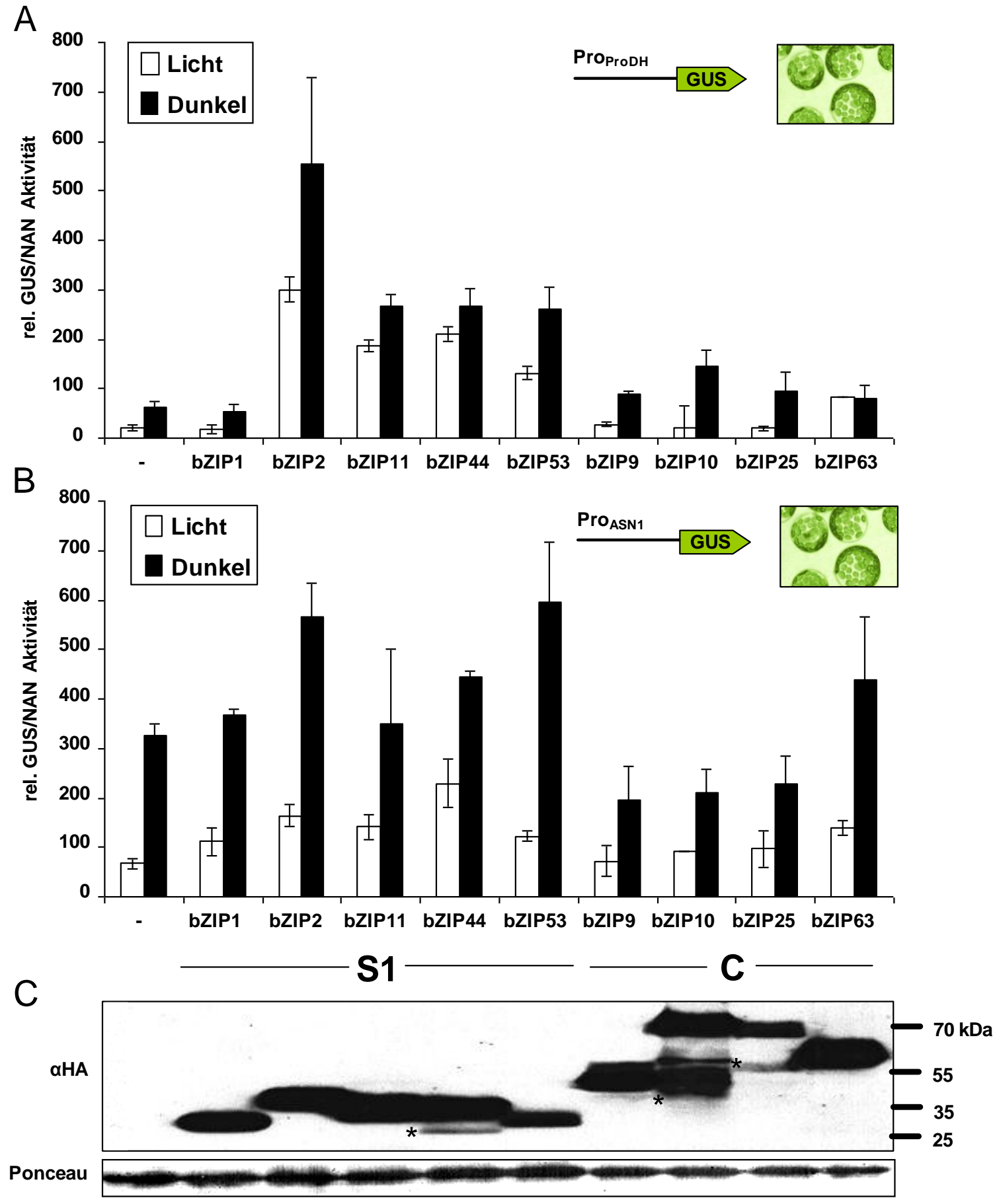

Abb. 5.34: bZIPs regulieren die Aktivität von ProDH und ASN1 im Protoplastensystem Die Protoplasten wurden nach der Transformation über Nacht für $16 \mathrm{~h}$ in Dauerlicht (weiße Balken) oder Dauerdunkel (schwarze Balken) inkubiert. Die Ansätze wurden mit je $5 \mu \mathrm{g}$

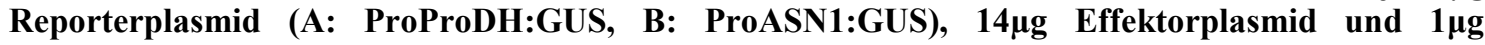
Pro35S:NAN Vektor transformiert. Die Angaben zeigen die Mittelwerte von vier unabhängigen Transformationsansätzen. Das Experiment wurde mehrmals mit vergleichbarem Ergebnis wiederholt.

C: Für den Western wurden die Protoplasten mit 40 $\mu \mathrm{g}$ Effektorplasmid transformiert und jeweils 2 Transformationsansätze nach der Inkubation über Nacht in Harnstoffextraktionspuffer aufgenommen und vereinigt. * kennzeichnet Abbauprodukte 
Die gleichmäßige Expression der neun bZIP Transkriptionsfaktoren in Protoplasten wurde in einer Western Analyse überprüft (Abb. $5.34 \mathrm{C}$ ). Alle neun werden stark expremiert, und auch wenn für AtbZIP44 und AtbZIP25 eine leichte und für AtbZIP10 sogar mehrere sehr starke Abbauprodukte $\mathrm{zu}$ sehen sind, ist dennoch noch eine vergleichbare Überexpression dieser drei bZIP Faktoren gegeben.

Durch diese Protoplastenexperimente hat sich gezeigt, dass nicht nur AtbZIP53 im Protoplastensystem die Expression von ProDH und ASN1 regulieren kann, sondern dass auch noch andere Faktoren dazu in der Lage sind. In wie weit dies auch Relevanz in der ganzen Pflanze während der verlängerten Nacht hat ist noch nicht geklärt. AtbZIP11 z.B. ist zwar ein starker Aktivator der ProDH im Protoplastensystem, seine Expression wird aber während der verlängerten Nacht herunter reguliert.

\subsubsection{Eine G-Box im ASN1 Promotor sowie zwei ACTCAT Motive und eine C- Box im ProDH Promotor sind notwendig für die Aktivierung der beiden Gene durch Dunkelheit}

Das Protoplastensystem ist nicht nur geeignet, um den Einfluss verschiedener Stressbedingungen (wie z.B. Dunkelheit und DCMU) und Transkriptionsfaktoren (z.B. die neun bZIP Faktoren der Gruppe S1 und C) auf die Expression verschiedener Gene wie ProDH und ASN1 zu testen, sondern ermöglicht auch eine genaue Analyse der Promotoren dieser Gene. Einzelne Elemente der zu untersuchenden Promotoren können hierfür mutiert werden, und die GUS-Aktivität dieser mutierten Promotor:GUS Konstrukte mit der der intakten Konstrukte verglichen werden.

Die ChIP-Experimente in Kapitel 5.5.3.3 haben gezeigt, dass in den Pro35S:AtbZIP1 Pflanzen ein 222 bp großes Fragment des ASN1 Promotors angereichert wird. Dieses Fragment enthält zwei G-Boxen (CACGTG), für die bereits in der Literatur eine Bindung von bZIP Transkriptionsfaktoren gezeigt werden konnte (Baena-Gonzalez et al., 2007; Hanson et al., 2008).

Mutiert man die erste der beiden G-Boxen und transformiert dieses mutierte ProASN1:GUS Konstrukt in Protoplasten, so bekommt man keinerlei Dunkelinduktion 
mehr und auch die Co-Transformation mit AtbZIP1 oder AtbZIP53 führt zu keiner Aktivierung des Promotors (Abb. 5.35).

Mutiert man aber die zweite G-Box im ASN1 Promotor, so führt dies zu keiner Änderung im Vergleich zum wildtypischen ASN1 Promotor. Dieses Konstrukt zeigt eine normale Dunkelinduktion und auch eine zusätzliche Aktivierung durch CoTransformation mit AtbZIP53. Obwohl beide G-Box-Elemente exakt die gleiche Sequenz (CACGTG) haben führt ihre Mutation doch zu völlig unterschiedlichen Ergebnissen. Dies zeigt, dass nicht nur die Sequenzinformation allein wichtig für die Funktion ist, sondern anscheinend auch der Kontext des Promotors. Aus diesem Experiment und den zuvor durchgeführten ChIP-Experimenten kann man schließen, dass die bZIP Faktoren an die G1-Box des ASN1 Promotors binden und so zu einer Aktivierung der Transkription der ASN1 führen.

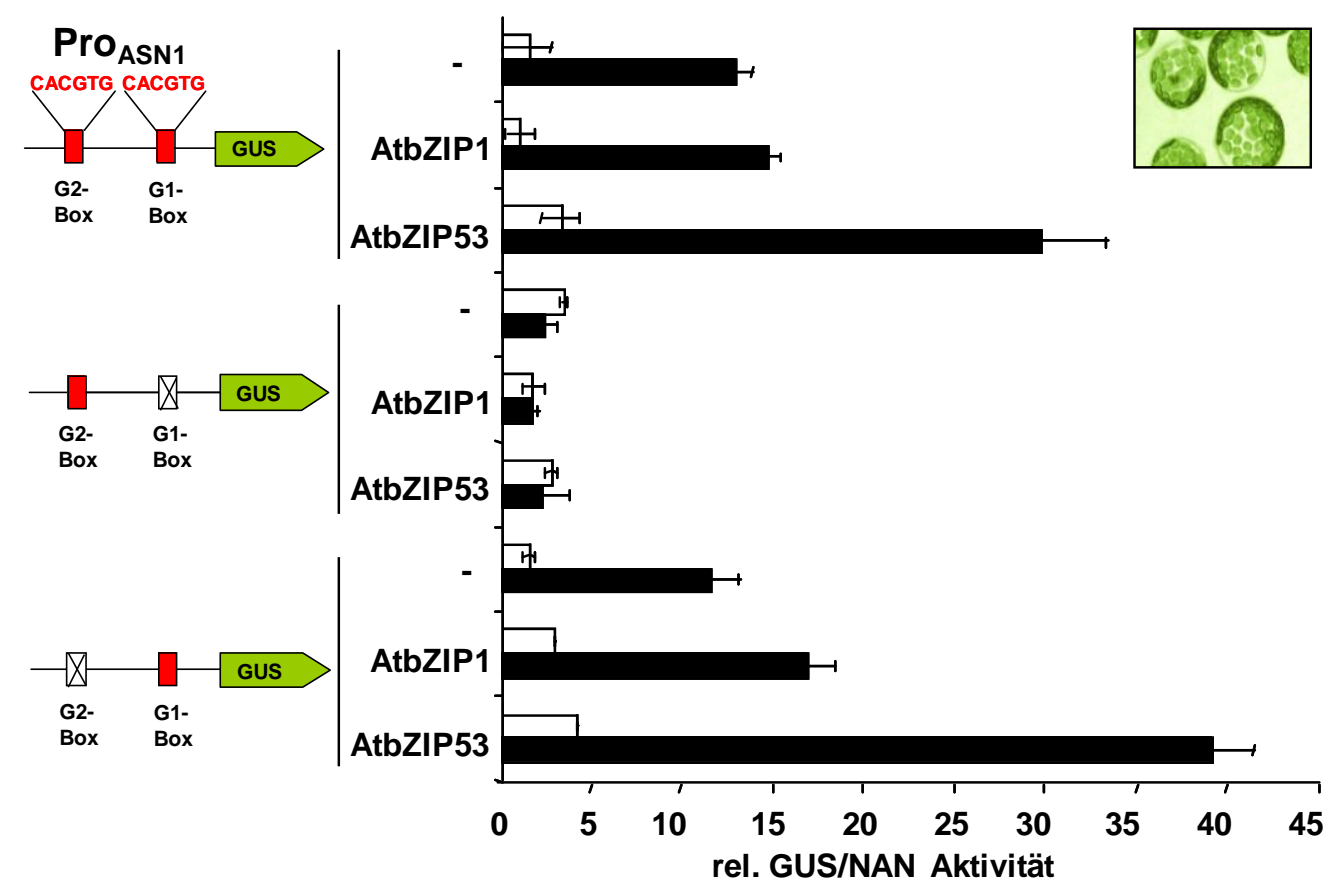

Abb. 5.35: Die dunkelinduzierte Aktivierung der ASN1 hängt von der G1-Box ab

Die Protoplasten wurden nach der Transformation über Nacht für 16 h in Dauerlicht (weiße Balken) oder Dauerdunkel (schwarze Balken) inkubiert. Die Ansätze wurden mit je $5 \mu \mathrm{g}$ Reporterplasmid, 14 $\mu$ g Effektorplasmid und 1 $\mu$ g Pro35S:NAN Vektor transformiert. Die Angaben zeigen die Mittelwerte von vier unabhängigen Transformationsansätzen. Das Experiment wurde mehrmals mit vergleichbarem Ergebnis wiederholt. Rote Kästchen zeigen G-Boxen im Promotor, mutierte Boxen werden durch eine weiße Box mit Kreuz dargestellt. Dieser Versuch wurde von Andrea Ehlert durchgeführt. 
Für die ProDH wurden ebenfalls ChIP Experimente durchgeführt (beschrieben in Kapitel 5.5.3.1). In diesen Experimenten konnte gezeigt werden, dass ein 190 bp großes Fragment des ProDH Promotors in den Überexpressionspflanzen von AtbZIP1 nach der Immunopräzipitation angereichert wurde. Dieses Fragment enthält zwei ACTCAT Motive als mögliche Bindestellen für die bZIP Transkriptionsfaktoren.

Untersucht man ProProDH:GUS Konstrukte in Protoplasten, in denen jeweils nur eines dieser beiden Motive mutiert ist, so ist die GUS-Aktivität im Vergleich zum WildtypPromotor nur leicht reduziert. Es ist aber immer noch eine deutliche Induktion durch Dunkelheit oder durch Co-Transformation mit AtbZIP1 oder AtbZIP53 zu erkennen (Abb. 5.36). Mutiert man aber beide ACTCAT Motive gleichzeitig, so zeigt dieses neue Konstrukt keinerlei Induktion durch Dunkelheit oder durch Co-Transformation mit den beiden bZIP Transkriptionsfaktoren mehr.

Anders als beim ASN1 Promotor hängt die Induktion des ProDH Promotor also nicht von einem einzigen Motiv ab, an das die bZIP Faktoren binden können, sondern beide ACTCAT Motive sind für die Expression der ProDH wichtig.

Schaut man sich den ProDH Promotor genauer an, so findet man außer den beiden ACTCAT Motiven auch noch eine C-Box als mögliche Bindestelle für bZIP Transkriptionsfaktoren (Anhang Tabelle 8.1). Mutiert man diese C-Box, so führt das wie schon die Mutation der einzelnen ACTCAT Motive lediglich zu einer leichten Reduktion der GUS-Aktivität. Mutiert man zusätzlich zur C-Box aber noch das ACT1oder das ACT2-Motiv, wird die GUS-Aktivität wesentlich stärker reduziert. Diese Konstrukte zeigen zwar noch eine leichte Induktion durch Dunkelheit, die Gesamtaktivität ist aber sehr gering. 

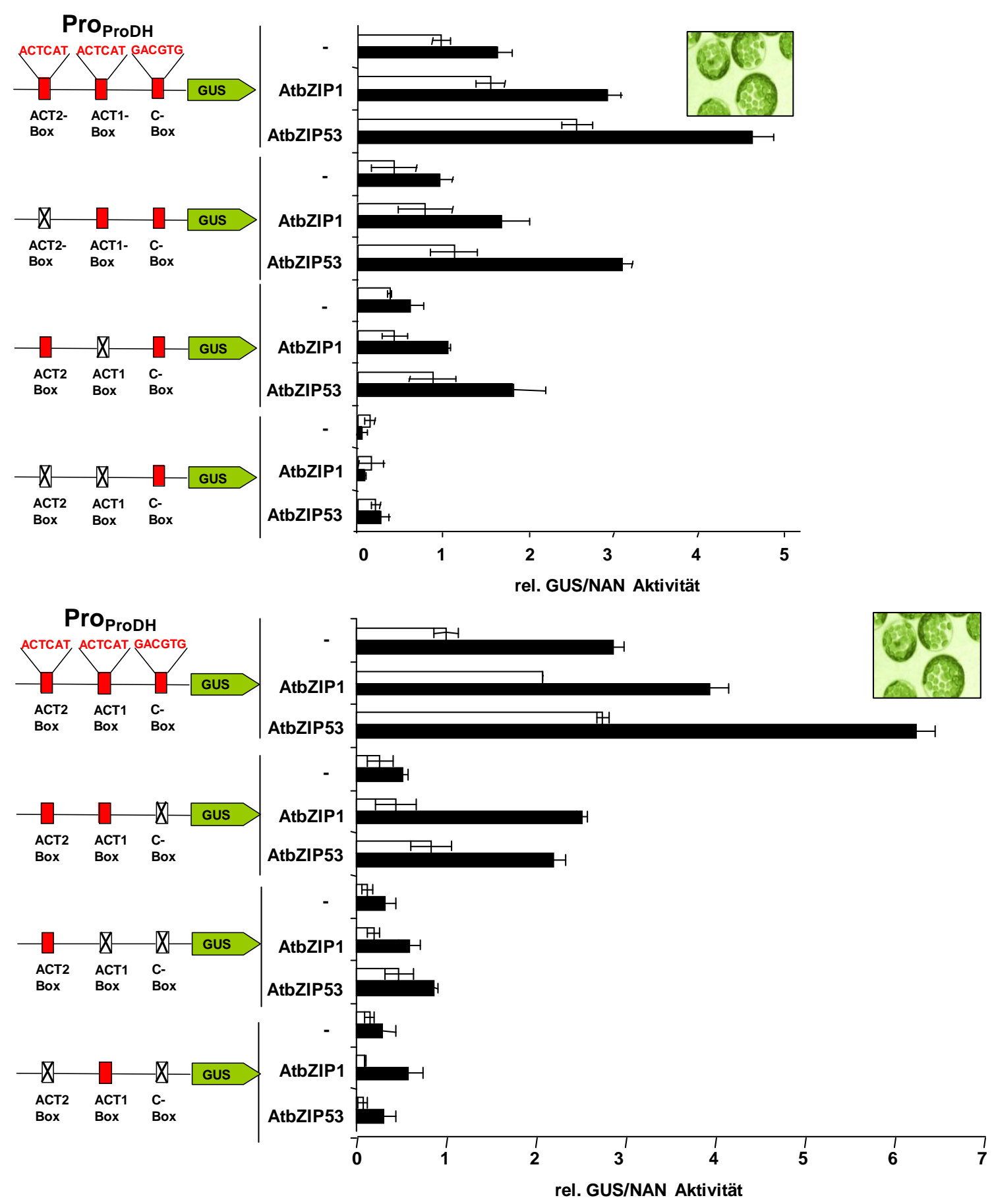

Abb. 5.36: Die Aktivierung der ProDH durch Dunkelheit hängt von zwei ACTCAT Elementen und einer C-Box ab

Die Protoplasten wurden nach der Transformation über Nacht für 16 h in Dauerlicht (weiße Balken) oder Dauerdunkel (schwarze Balken) inkubiert. Die Ansätze wurden mit je $5 \mu \mathrm{g}$ Reporterplasmid, 14 $\mu$ g Effektorplasmid und 1 $\mu$ g Pro35S:NAN Vektor transformiert. Die Angaben zeigen die Mittelwerte von vier unabhängigen Transformationsansätzen. Das Experiment wurde mehrmals mit vergleichbarem Ergebnis wiederholt. Rote Kästchen zeigen cis-Elemente im Promotor, mutierte Elemente werden durch eine weiß Box mit Kreuz dargestellt. Dieser Versuch wurde durchgeführt von Andrea Ehlert. 


\subsection{Verschiedene „loss-of-function“ Ansätze führen zu einer Reduktion der bZIP vermittelten Expression der Zielgene des Aminosäuremetabolismus}

In allen bisher durchgeführten Versuchen erkennen wir deutlich, dass die Überexpression von AtbZIP1 und AtbZIP53 einen großen Einfluss auf verschiedene Stoffwechselwege des Primärmetabolismus hat. Die Einzelmutanten atbzipl und atbzip53 sowie die Doppelmutante atbzip1 atbzip53 zeigten aber bisher keine oder nur leichte Unterschiede im Vergleich zum Wildtyp.

Schaut man sich die Abbildung der Genevestigator Analyse der bZIP Transkriptionsfaktoren während der verlängerten Nacht noch einmal an (Abb. 5.3), so kann man sehen, dass sehr viele der bZIP Faktoren unter den Bedingungen der verlängerten Nacht transkriptionell aktiviert werden.

All diese bZIP Transkriptionsfaktoren könnten möglicherweise redundante Funktionen in der Anpassung des Metabolismus während der verlängerten Nacht übernehmen, so dass ein Mutation von nur ein oder zwei dieser Faktoren, wie in der atbzipl atbzip53 Doppelmutante, von anderen Faktoren ausgeglichen werden kann.

\subsubsection{Die Expression einer Fusion aus AtbZIP1 bzw. AtbZIP53 mit der EAR- Repressor-Domäne kann die dunkelinduzierte Aktivierung der ProDH verhindern}

Um diese mögliche Redundanz der bZIP Transkriptionsfaktoren zu umgehen, wurden AtbZIP1 und AtbZIP53 mit einer EAR-Domäne (Hiratsu et al., 2003) fusioniert und transient in Protoplasten expremiert. Durch die EAR-Domäne werden die sonst als transkriptionelle Aktivatoren wirkenden bZIP Faktoren zu Repressoren und blockieren durch ihre massive Überexpression in den Protoplasten gleichzeitig die bZIPBindestellen des Promotors für andere endogene Transkriptionsfaktoren (Abb. 5.37 A). Die Expression von EAR-AtbZIP1 in Protoplasten führt zu einer stark reduzierten Grundaktivität des Promotors im Licht und Dunkelheit (Abb. 5.37 B). Und auch die transiente Überexpression von EAR-AtbZIP53 führte sowohl im Licht, als auch nach 
Dunkelinduktion $\mathrm{zu}$ einer starken Reduktion der AtbZIP53 vermittelten ProDH Expression.

Die Expression der Fusionsproteine aus EAR-Domäne und bZIP Faktor wurde in einer Western Analyse kontrolliert (Abb. 5.37 C). Beide wurden sowohl im Licht als auch im Dunkeln expremiert. Der direkte Vergleich der Expression mit der Expression der bZIP Proteine ohne EAR-Domäne ist nicht möglich, da die EAR-Konstrukte aus technischen Gründen nur zwei Wiederholungen des HA-Tags statt den normalen drei Wiederholungen haben. Dies führt zu einem schwächeren Signal im Western.
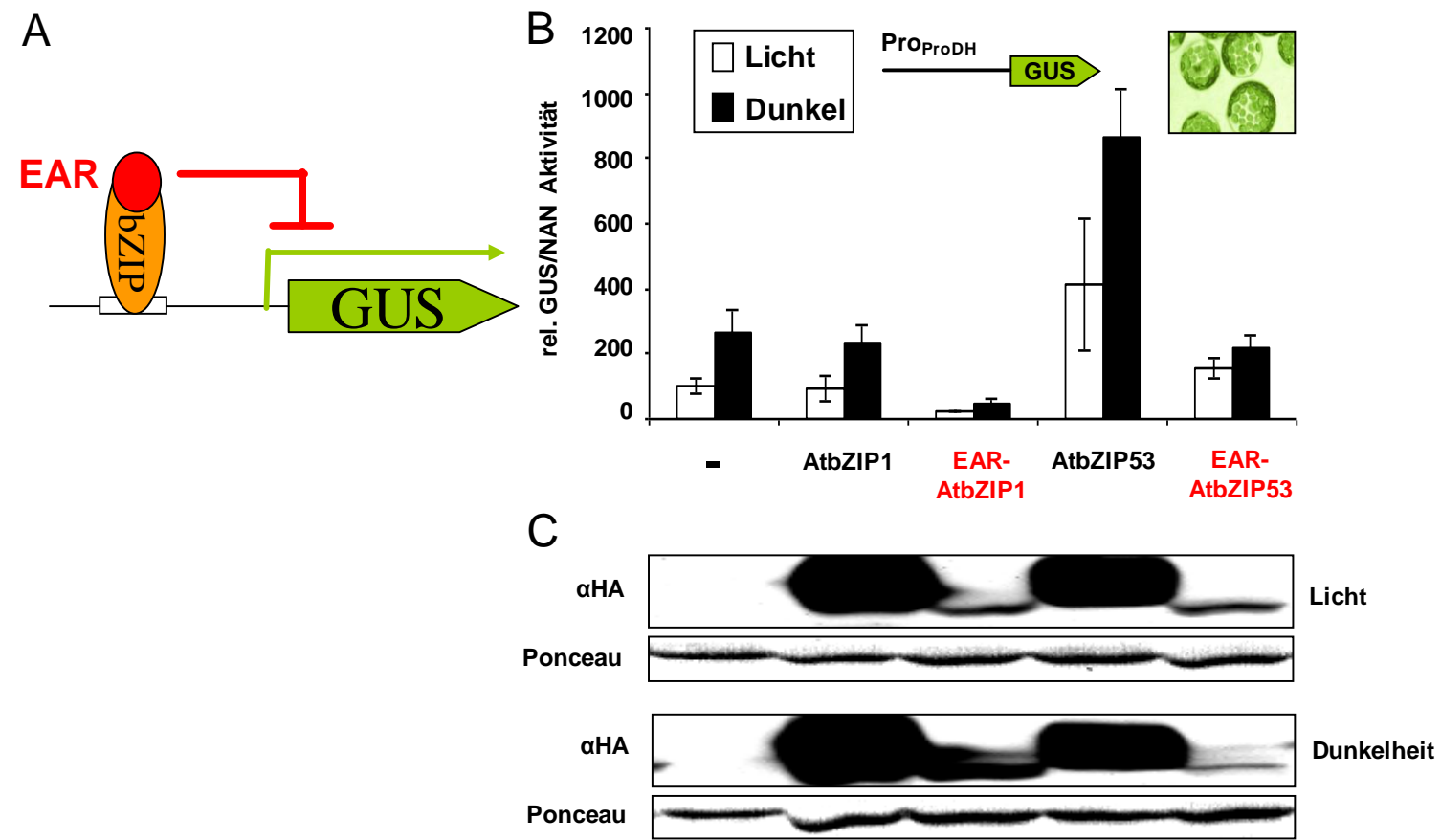

Abb. 5.37: Die Fusion von AtbZIP1 und AtbZIP53 mit der EAR-Domäne kann die Aktivierung der ProDH durch Dunkelheit inhibieren

A: Schema des EAR-Fusion Ansatzes. B: Die Protoplasten wurden nach der Transformation über Nacht für 16 h in Dauerlicht (weiß) oder Dauerdunkel (schwarz) inkubiert. Die Ansätze wurden mit je 5 $\mu$ g Reporterplasmid, $14 \mu \mathrm{g}$ Effektorplasmid und $1 \mu \mathrm{g}$ Pro35S:NAN Vektor transformiert. Die Angaben zeigen die Mittelwerte von vier unabhängigen Transformationsansätzen. Das Experiment wurde mehrmals mit vergleichbarem Ergebnis wiederholt. C: Für die Western Analyse wurden die Protoplasten mit $40 \mu \mathrm{g}$ Effektorplasmid transformiert und jeweils zwei Transformationsansätze nach der Inkubation über Nacht in Harnstoffextraktionspuffer aufgenommen und vereinigt. Da die bZIPs mit EAR-Domäne in einem anderen Ausgangsvektor mit einem zweifachen statt eines dreifachen HA-tags vorliegen, kann das Signal in der Westernanalyse nicht direkt mit dem Signal der unfusionierten bZIPs verglichen werden. 
Das Ergebnis der EAR-Domänen-Fusion zeigt, dass AtbZIP1 und AtbZIP53 an cisElemente des ProDH Promotors binden. Da die Doppelmutante atbzipl atbzip53 noch eine Induktion der ProDH zeigt, können möglicherweise andere redundante Faktoren die Funktion dieser beiden bZIP Transkriptionsfaktoren in der Mutante übernehmen, die im EAR-Domänen-Ansatz ihre Funktion nicht ausüben, da sie nicht an den Promotor binden können.

\subsubsection{Vierfachmutanten von AtbZIP1, AtbZIP53 und Mitgliedern der Gruppe C der bZIP Transkriptionsfaktoren führen zu einer deutlichen Reduktion der Expression von ProDH, BCAT2 und ASN1}

Parallel zum EAR-Domänen-Ansatz wurden Mehrfachmutanten von möglichst vielen der redundanten bZIP Transkriptionsfaktoren hergestellt. Gute zusätzliche Kandidaten zu AtbZIP1 und AtbZIP53 sind die vier Mitglieder der Gruppe C, von denen bekannt ist, dass sie mit den Mitgliedern der Gruppe S1, zu denen auch AtbZIP1 und AtbZIP53 gehören, heterodimerisieren.

Die Doppelmutante atbzip1 atbzip53 wurde deshalb mit den Doppelmutanten atbzip9 atbzip63 bzw. atbzip10 atbzip25 (beide ebenfalls während dieser Dissertation hergestellt) gekreuzt. Die Vierfachmutanten (Anhang Kapitel 8.1.8) wurden mittels 3Primer-PCR auf die Insertion der T-DNA untersucht und die homozygoten Linien für die weitere Analyse ausgewählt.

Um zu zeigen, dass die T-DNA-Insertion auch tatsächlich zu einer Reduktion des Transkripts führt, wurden mit Hilfe der qPCR die Transkriptmengen der einzelnen bZIP Faktoren in diesen Vierfachmutanten während der Dunkelinduktion bestimmt (Abb. 5.38). Deutlich ist hier wieder die transkriptionelle Aktivierung von AtbZIP1 und AtbZIP53 im Wildtyp während der verlängerten Nacht zu erkennen.

Während es sich bei der atbzipl Mutante um einen Knock-Out handelt, in dem keinerlei Transkript mehr zu detektieren ist, handelt es sich bei der atbzip53 Mutante lediglich um einen Knock-Down. Die Insertion der T-DNA im Promotorbereich (Anhang Kapitel 8.1.8) führt nur zu einer Reduktion der Transkriptmenge von AtbZIP53 auf etwa die Hälfte des Wildtyps (Abb. 5.38). 

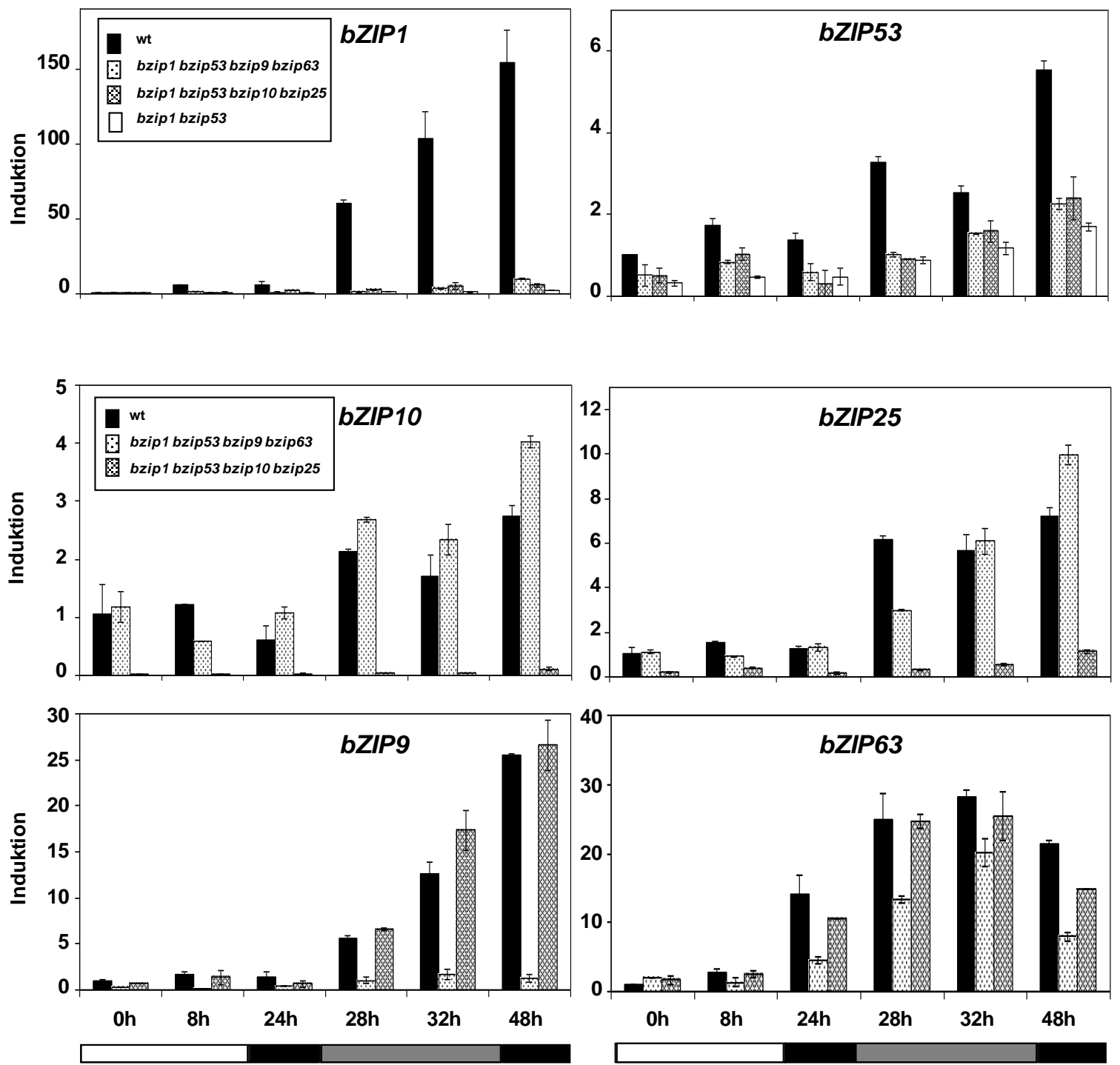

Abb. 5.38: Die Expression der bZIP Faktoren ist in den Doppel- und Vierfachmutanten deutlich reduziert

Die Pflanzen wurden 3-4 Wochen im Langtag angezogen und danach dunkel gestellt. $\mathrm{Zu}$ den angegebenen Zeitpunkten wurden jeweils 8-10 Pflanzen geerntet und zusammen aufgearbeitet. Die Expression der oben genannten bZIP Faktoren wurde mit Hilfe der qPCR untersucht. Angegeben sind die relativen Werte im Vergleich zur Expression nach 0 Stunden Dunkelheit von je zwei Replikaten nach Abgleich mit dem Haushaltsgen Ubiquitin. Weißer Balken: normale Lichtphase (16h), schwarzer Balken: normale Nacht $(8 \mathrm{~h})$, grauer Balken: verlängerte Nacht

AtbZIP10 wird in der atbzip1 atbzip53 atbzip10 atbzip25 Vierfachmutante nicht mehr expremiert und auch die T-DNA-Insertion in das AtbZIP25 Gen führt zu einer sehr starken Reduktion der Expression. AtbZIP9 wird in der atbzipl atbzip53 atbzip9 atbzip63 Vierfachmutante ebenfalls nicht mehr expremiert, AtbZIP63 ist allerdings wie AtbZIP53 nur ein Knock-Down, d.h. hier findet während der verlängerten Nacht noch 
eine Induktion des Transkripts durch Dunkelheit statt, auch wenn die Menge im Vergleich zum Wildtyp signifikant reduziert ist (Abb. 5.38).

Phänotypisch zeigen beide Vierfachmutanten unter Standardwuchsbedingungen im Langtag keine Auffälligkeiten im Vergleich zum Wildtyp (hier exemplarisch für die atbzip1 atbzip53 atbzip9 atbzip63 Mutante gezeigt, Abb. 5.39).

Ein Versuch eine Mutante herzustellen, in der AtbZIP1, AtbZIP53 und die gesamte Gruppe C ausgeschaltet sind, scheiterte aber schon nach der ersten Generation. Bereits die Fünfachmutante, in der AtbZIP1, AtbZIP53, AtbZIP9, und AtbZIP63 homozygot mutiert sind und lediglich atbzip10 heterozygot ist, zeigte einen starken Zwergwuchs (Abb. 5.39). Eine vollständig homozygote Fünfachmutante konnte bisher trotz vieler Versuche nicht identifiziert werden.

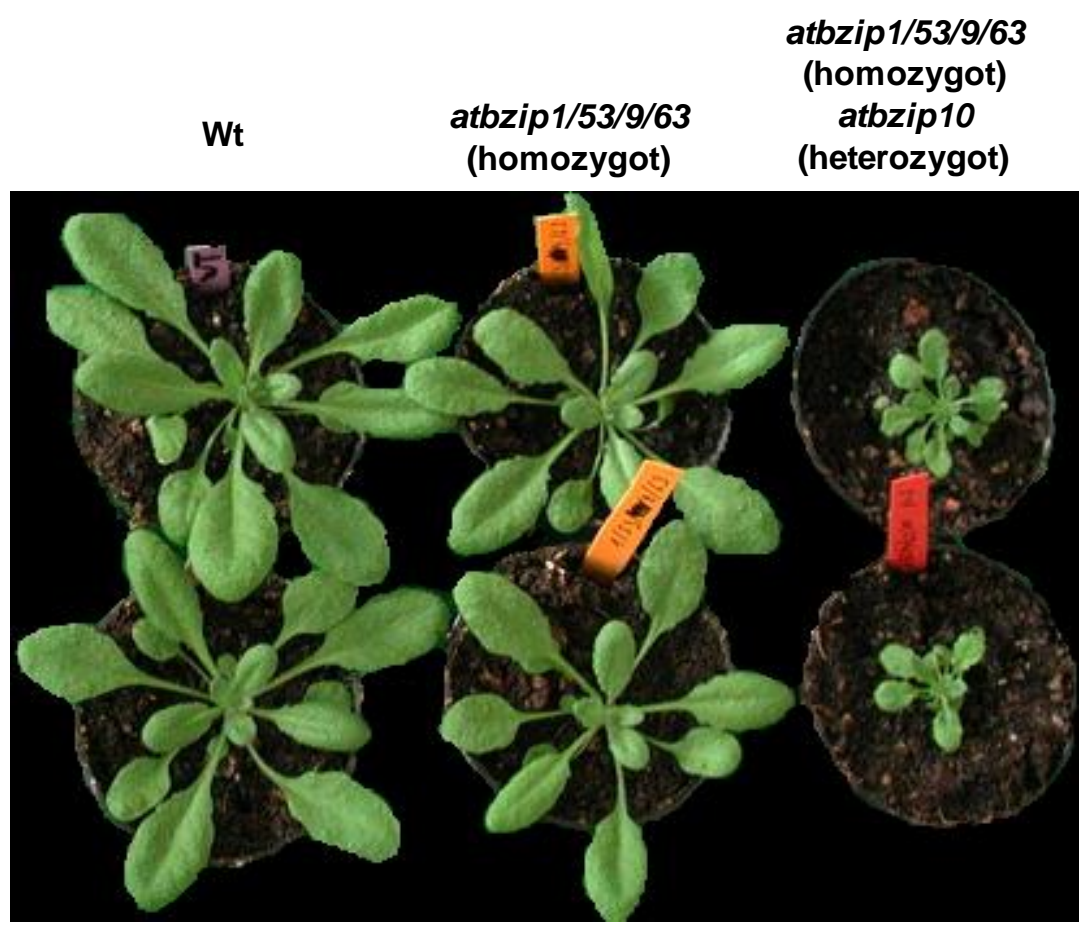

Abb. 5.39: Phänotyp von Vierfach- und Fünffachmutanten des C/S1-bZIP Netzwerkes Die Pflanzen wurden 3-4 Wochen im Langtag angezogen und anschließend phänotypisch begutachtet und fotografiert. Gezeigt sind Wildtyp (Wt), homozygote atbzip1 atbzip53 atbzip9 atbzip63 Vierfachmutante und die Fünfachmutante, in der atbzip1 atbzip53 atbip9 und atbzip63 homozygot sind und atbzip10 heterozygot ist. 

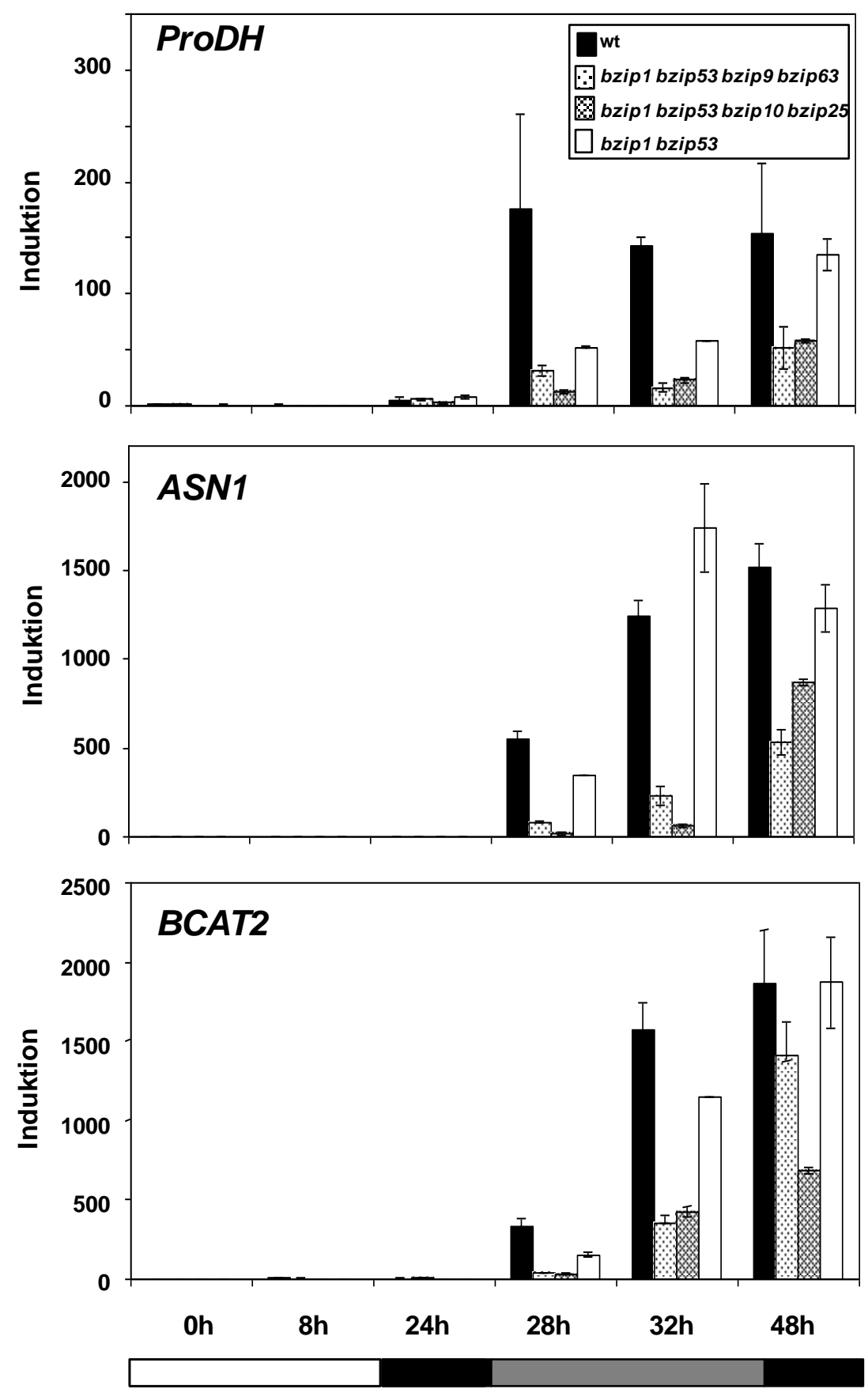

Abb. 5.40: Die Expression von ProDH, ASN1 und BCAT2 ist in beiden Vierfachmutanten des C/S1 bZIP Netzwerkes deutlich reduziert

Die Pflanzen wurden 3-4 Wochen im Langtag angezogen und danach dunkel gestellt. Zu den angegebenen Zeitpunkten wurden jeweils 8-10 Pflanzen geerntet und zusammen aufgearbeitet. Die oben angegebenen Gene wurde mit Hilfe der qPCR untersucht. Angegeben sind die relativen Werte im Vergleich zur Expression nach 0 Stunden Dunkelheit von je zwei Replikaten nach Abgleich mit dem Haushaltsgen Ubiquitin. Weißer Balken: normale Lichtphase (16h), schwarzer Balken: normale Nacht $(8 \mathrm{~h})$, grauer Balken: verlängerte Nacht 
Eine Expressionsanalyse der drei Gene ProDH, ASN1 und BCAT2 während der verlängerten Nacht mittels qPCR zeigte deutlich, dass beide Vierfachmutanten in der Expression dieser Gene stark beeinträchtigt sind (Abb. 5.40). Für alle drei Gene sieht man die deutlich dunkelabhängige Induktion während der verlängerten Nacht. Wie bereits in den vorherigen Experimenten zeigt die Doppelmutante keinen Unterschied in der Expression der ASN1 und der BCAT2 im Vergleich zum Wildtyp und auch die ProDH Expression ist in der Doppelmutante nur geringfügig schwächer. In beiden Vierfachmutanten haben alle drei Gene besonders während der frühen Zeitpunkte der verlängerten Nacht (vier und acht Stunden) eine sehr deutlich reduzierte Expression. Nach länger anhaltender Dunkelheit (12 Stunden verlängerte Nacht) steigen aber auch in den Vierfachmutanten die Transkriptmengen von ProDH, ASN1 und BCAT2 deutlich an, auch wenn sie noch nicht an die Expressionsstärke im Wildtyp herankommen.

\subsection{Bedeutung der beiden SnRK1-Kinasen KIN10 und KIN11 als mögliche Regulatoren der bZIP Transkriptionsfaktoren in der Anpassung an Energieverarmung}

Obwohl sowohl AtbZIP1, als auch AtbZIP53 die Expression von ASN1, ProDH und BCAT2 während der verlängerten Nacht regulieren können, zeigen sich in allen Experimenten doch auch deutliche Unterschiede zwischen den beiden Transkriptionsfaktoren. Während AtbZIP53 während der verlängerten Nacht nur geringfügig transkriptionell aktiviert wird, führen schon geringe Steigerungen der Proteinmenge zu einer konstitutiven Aktivierung seiner Zielgene. Die Transkription von AtbZIP1 dagegen wird sehr stark nach Dunkelheit hochreguliert. Eine Überexpression allein führt aber noch nicht zu einer konstitutiven Expression der Zielgene. Die Expression von ProDH, ASN1 und BCAT2 in den Überexpremierern von AtbZIP1 unterscheidet sich erst während der verlängerten Nacht wesentlich von der im Wildtyp. AtbZIP1 braucht also anscheinend eine posttranslationale Modifizierung um seine regulatorische Funktion ausüben zu können. 
Erst kürzlich wurden die zwei Kinasen KIN10 und KIN11 als zentrale Regulatoren der Anpassung des pflanzlichen Metabolismus auf Energieverarmung nach Dunkelheit beschrieben (Baena-Gonzalez et al., 2007). In diesem Artikel wurde auch die ASN1 als ein Ziel dieser KIN10/KIN11 vermittelten Anpassung an Energiemangelbedingungen gefunden. Es ist daher naheliegend $\mathrm{zu}$ spekulieren, dass diese beiden Kinasen möglicherweise eine regulatorische Funktion auf die bZIP Transkriptionsfaktoren ausüben, die dann wiederrum ihre Zielgene wie z.B. die ASN1 oder auch die ProDH direkt regulieren.

\subsubsection{Die Expression von KIN10 bzw. KIN11 führt zu einer Aktivierung von ProDH und ASN1 im Protoplastensystem}

Um den Effekt der Kinasen auf die Expression der beiden Gene ASN1 und ProDH näher zu untersuchen, wurde das Protoplastensystem verwendet.

Die transiente Überexpression von KIN10 und KIN11 führt hier zu einer sehr starken Steigerung der GUS-Aktivität beider Promotor:GUS Konstrukte, sowohl im konstanten Licht, als auch in konstanter Dunkelheit (Abb. 5.41 A). Durch die Überexpression der Kinasen braucht man also keinen zusätzlichen Stimulus z.B. durch Dunkelheit mehr, um ProDH und ASN1 zu aktivieren.

Zur Kontrolle wurde auch das ProLea76:GUS Konstrukt getestet. Wie schon zuvor wird auch in diesem Versuch das Konstrukt nicht durch Dunkelheit aktiviert. Auch die Überexpression der beiden Kinasen zeigt keine Steigerung der GUS-Aktivität, obwohl sowohl KIN10 als auch KIN11 gut expremiert werden, wie der Western in der Abbildung zeigt (Abb. 5.41 B). Die Induktion der beiden Gene ASN1 und ProDH durch die Kinasen ist also spezifisch. 


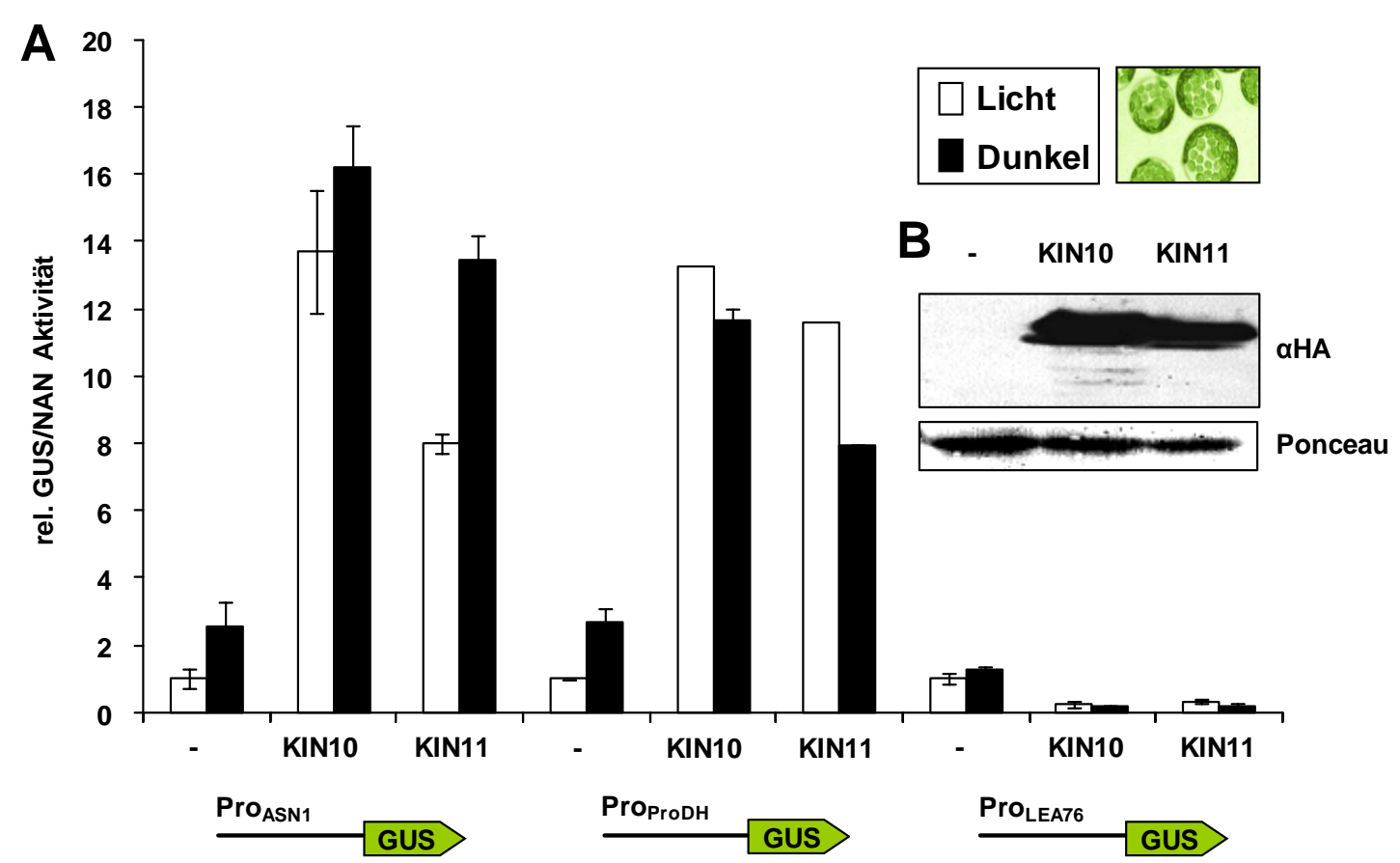

Abb. 5.41: KIN10 und KIN11 regulieren die Aktivität von ProDH und ASN1 im Protoplastensystem A: Die Protoplasten wurden nach der Transformation über Nacht für $16 \mathrm{~h}$ in Dauerlicht (weiße

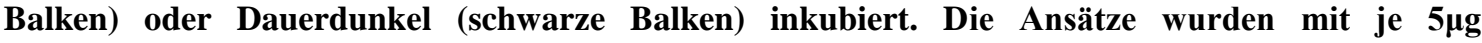
Reporterplasmid, 14 $\mu$ g Effektorplasmid und 1 $\mu$ g Pro35S:NAN Vektor transformiert. Die Angaben zeigen die Mittelwerte von vier unabhängigen Transformationsansätzen. Das Experiment wurde mehrmals mit vergleichbarem Ergebnis wiederholt. B: Für die Western Analyse wurden die

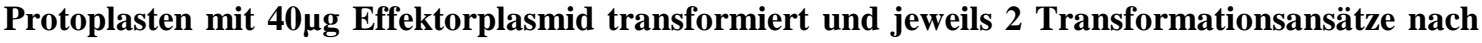
der Inkubation über Nacht in Harnstoffextraktionspuffer aufgenommen und vereinigt.

\subsubsection{KIN10 und KIN11 regulieren nicht die Transkription von AtbZIP1 und AtbZIP53}

Die nächste Frage ist jetzt, ob und wie KIN10 und KIN11 die Aktivität von AtbZIP1 und 53 beeinflussen können. Die erste Möglichkeit ist, dass KIN10 und KIN11 die Transkription von AtbZIP1 und AtbZIP53 aktivieren. Um dies zu testen wurde ein Experiment durchgeführt, in dem KIN10 und KIN11 transient in Protoplasten überexpremiert wurden. Von diesen Protoplasten wurde RNA extrahiert, in cDNA umgeschrieben und anschließend in der qPCR analysiert.

Es ist deutlich zu erkennen, dass die Transformation der Protoplasten mit KIN10 und KIN11 zu einer massiven Überexpression der beiden Kinasen führt (Abb. 5.42). 


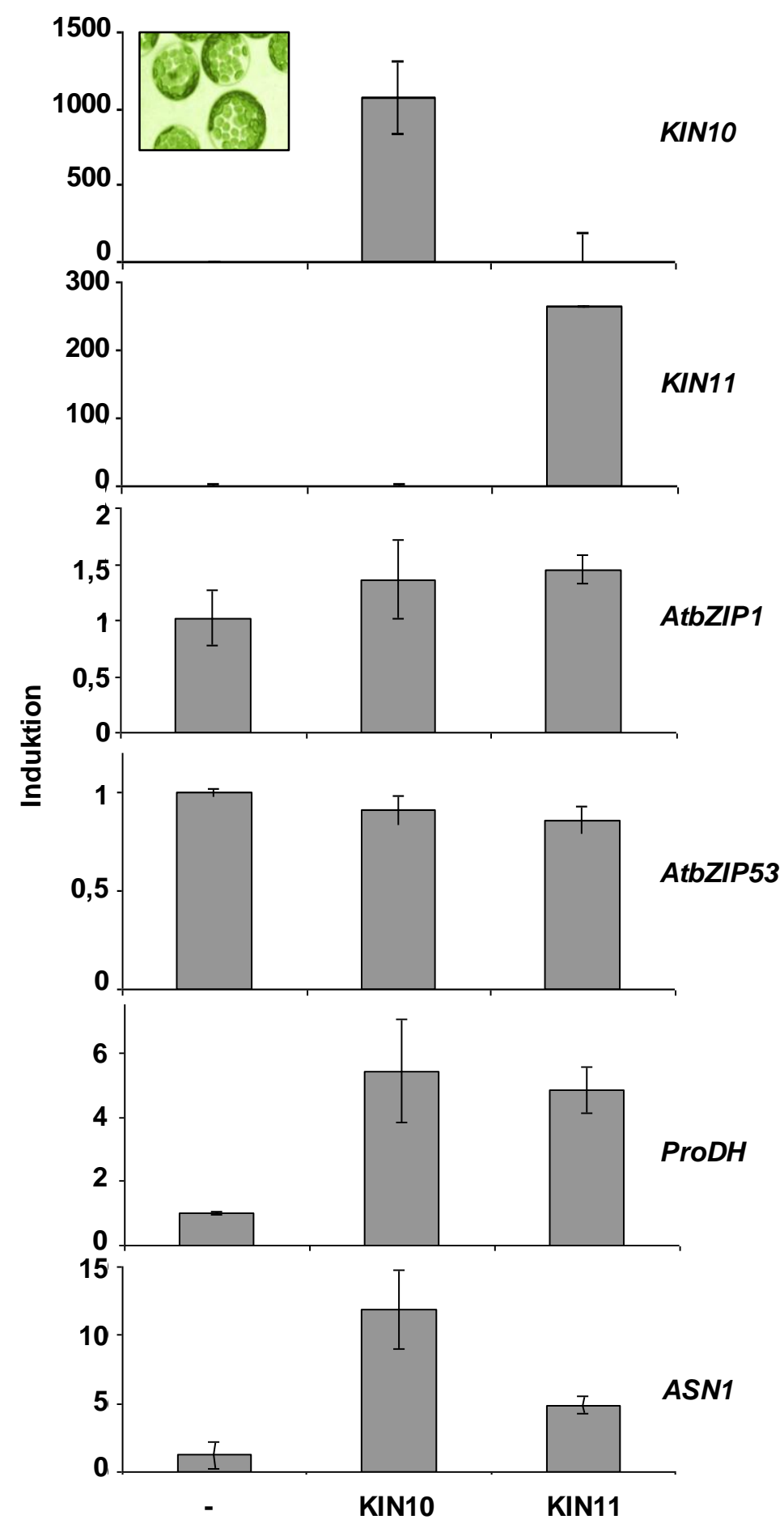

Abb. 5.42: KIN10 und KIN11 regulieren die Transkription von ProDH und ASN1 nicht aber die Transkription von AtbZIP1 und AtbZIP53

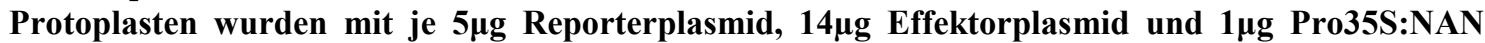
Vektor transformiert und über Nacht für $16 \mathrm{~h}$ in WI Puffer inkubiert. Anschließend wurden je vier Ansätze vereinigt und für die RNA Extraktion und cDNA Synthese verwendet. Die oben angegebenen Gene wurden anschließend mit Hilfe der qPCR analysiert. Die Angaben zeigen die Mittelwerte von zwei Experimenten. Angegeben sind die relativen Werte im Vergleich zur Expression in der Negativ-Kontrolle (-) nach Abgleich mit dem Haushaltsgen Ubiquitin. 
Die Transkription von AtbZIP1 und AtbZIP53 wird durch diese Überexpression aber nicht beeinflusst. Dagegen ist sowohl durch die Überexpression von KIN10 als auch durch die Überexpression von KIN11 eine Induktion der Zielgene ProDH und ASN1 zu erkennen, was das Ergebnis aus dem vorherigen Protoplastenexperiment bestätigt, dass KIN10 und KIN11 einen großen Einfluss auf die Expression der beiden Gene haben. Dies geschieht allerdings nicht über eine transkriptionelle Aktivierung der beiden bZIP Transkriptionsfaktoren.

\subsubsection{Die Mutation putativer SnRK-Phosphorylierungsstellen in AtbZIP1 bzw. AtbZIP53 hat keinen Einfluss auf die Aktivierung der ProDH}

Eine weitere Möglichkeit ist, dass KIN10 und KIN11 die beiden bZIP Faktoren posttranslational modifizieren, indem sie sie phosphorylieren. In Huang und Huber (2001) werden typische Phosphorylierungsmotive von Kinasen der SnRK Familie, zu denen auch KIN10 und KIN11 gehören, beschrieben. Sie zeichnen sich durch ein oder zwei Serine/Threonine aus, die von hydrophoben und basischen Aminosäuren an definierten Positionen umgeben sind (Abb. 5.43 A).

In der Aminosäuresequenz von AtbZIP1 und AtbZIP53 finden sich viele Serine und Threonine (Anhang Kapitel 8.1.4 und 8.1.5). Untersucht man die umliegenden Aminosäuren um diese Serine/Threonine, so findet sich bei beiden Transkriptionsfaktoren am C-terminalen Ende ein Bereich, der relativ gut mit einer der vorhergesagten Aminosäuresequenzen aus der Veröffentlichung von Huang und Huber (2001) übereinstimmt (Abb. 5.43 B).

Sollten die Kinasen während der Dunkelheit tatsächlich die beiden bZIP Transkriptionsfaktoren an diesen Serinen phosphorylieren und damit ihre Aktivität beeinflussen, so sollte eine Mutation dieser Serine dazu führen, dass die bZIP Faktoren ihre regulatorische Funktion auf die Expression ihrer Zielgene nicht mehr ausüben können. Um dies zu testen wurden die beiden in Abb. 5.43 B dargestellten Serine aus AtbZIP1 und AtbZIP53 in Zusammenarbeit mit Johanna Lendner gegen Alanin ausgetauscht (Lendner, 2009). Diese Mutation sollte eine etwaige Phosphorylierung durch KIN10 und/oder KIN11 an dieser Stelle verhindern. 
A

$$
B a-H y-P-B a-X-X-\underline{S}-X-X-X-H y-X-B a
$$

$$
H y-\mathrm{X}-\mathrm{Ba}-\mathrm{X}-\mathrm{X}-\underline{\mathbf{T}} / \mathbf{S}-H y-\mathrm{X}-\mathrm{Ba}-H y-\mathrm{X}-\underline{\mathbf{S}}-\mathrm{X}-\mathrm{X}-\mathrm{X}-H y
$$

B
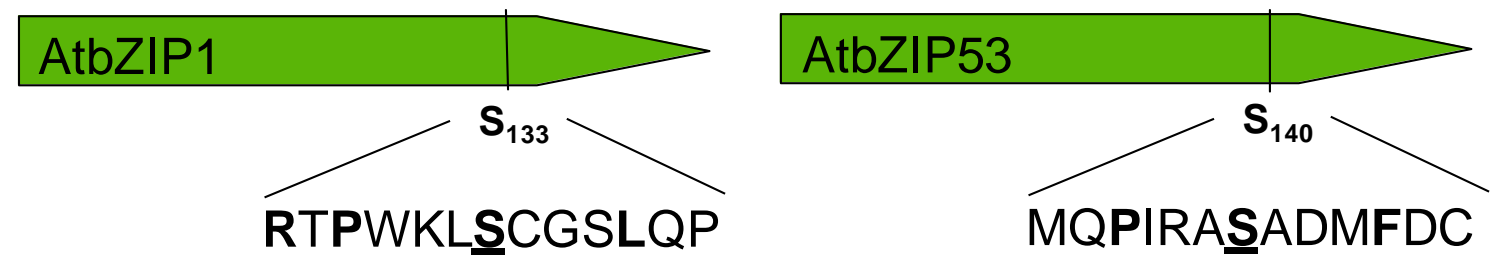

Abb. 5.43 AtbZIP1 und AtbZIP53 haben putative SnRK-Phosphorylierungsmotive in ihrer Aminosäuresequenz

A: Zwei typische Phosphorylierungsmotive der SnRK Kinasen (aus Huang und Huber, 2001); $\mathbf{S}=$ Serin, $\mathbf{T}=$ Threonin, $\mathbf{P}=$ Prolin, $\mathbf{B a}=$ basische Aminosäure, $\mathbf{H y}=$ hydrophobe Aminosäure, $X=$ beliebige Aminosäure.

B: Putative SnRK-Phosphorylierungsmotive in AtbZIP1 und AtbZIP53. Das unterstrichene Serin kennzeichnet die mögliche Phosphorylierungsstelle. Fettgedruckte Aminosäuren stimmen mit den vorhergesagten Aminosäuren aus der Sequenz von Huang und Huber (2001) überein.

Zusätzlich wurden Konstrukte hergestellt, in denen die entsprechenden Serine durch Aspartat ausgetauscht wurden. Dieses sollte eine konstitutive Phosphorylierung nachahmen (Furihata et al., 2006). Es ist allerdings bekannt, dass dieser Ansatz nicht immer $\mathrm{zu}$ einer konstitutiven Aktivierung führt. Alle unsere Aspartat-Mutanten verhielten sich in den folgenden Versuchen so wie die Alanin-Mutanten, so dass die Ergebnisse für die Aspartat-Mutanten hier nicht extra aufgeführt werden.

In Protoplasten wurde dann getestet, ob die mutierten bZIP Transkriptionsfaktoren trotz des durch Alanin ausgetauschten Serins immer noch die gleichen Aktivierungseigenschaften für ihr Zielgen die ProDH besitzen. Da KIN10 während der vorherigen Versuche immer die stärkeren Effekte gezeigt hat, wurde in diesem Versuch nur diese Kinase verwendet, um den Effekt auf die bZIP vermittelte ProDH Expression zu untersuchen. Die Inkubation der Protoplasten fand über Nacht im Dauerlicht statt, da die Überexpression der Kinase in Protoplasten die Induktion durch Dunkelheit überflüssig macht. Zusätzliche Dunkelinduktion führte in vorherigen Experimenten 
kaum noch zu einer Steigerung der ProDH Aktivität (Abb. 5.41). Wie in vorherigen Protoplastenexperimenten auch, führt die Überexpression von AtbZIP1 (Abb. 5.44 A) lediglich zu einer geringen Aktivierung der ProDH, während AtbZIP53 (Abb. 5.44 B) und natürlich auch KIN10 zu einer starken Steigerung der ProDH Aktivität führen. Die Expression von AtbZIP1 zusammen mit der Kinase KIN10 führt aber ebenso wie die Co-Expression von AtbZIP53 und KIN10 zu einer deutlich stärkeren Aktivität als KIN10 allein. AtbZIP1 und AtbZIP53 können also die KIN10 vermittelte Expression der ProDH verstärken.

A

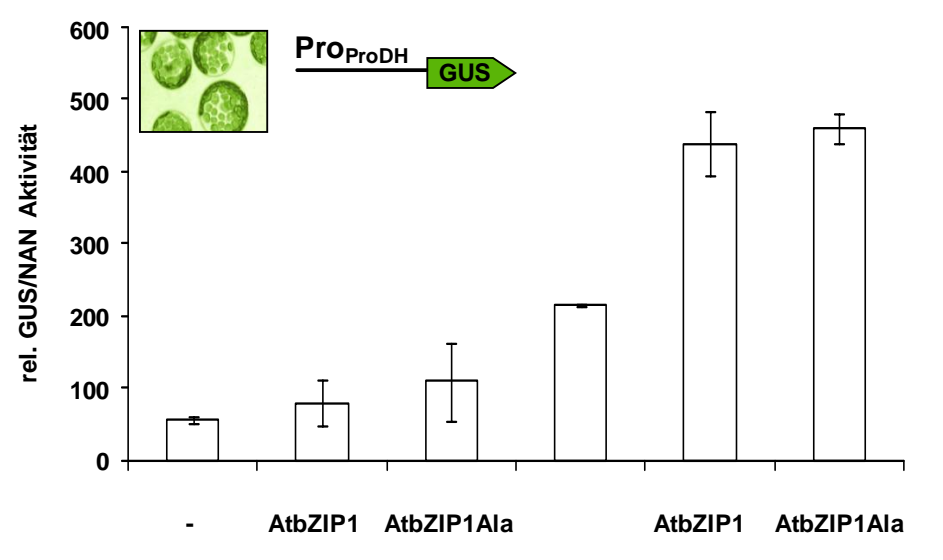

B

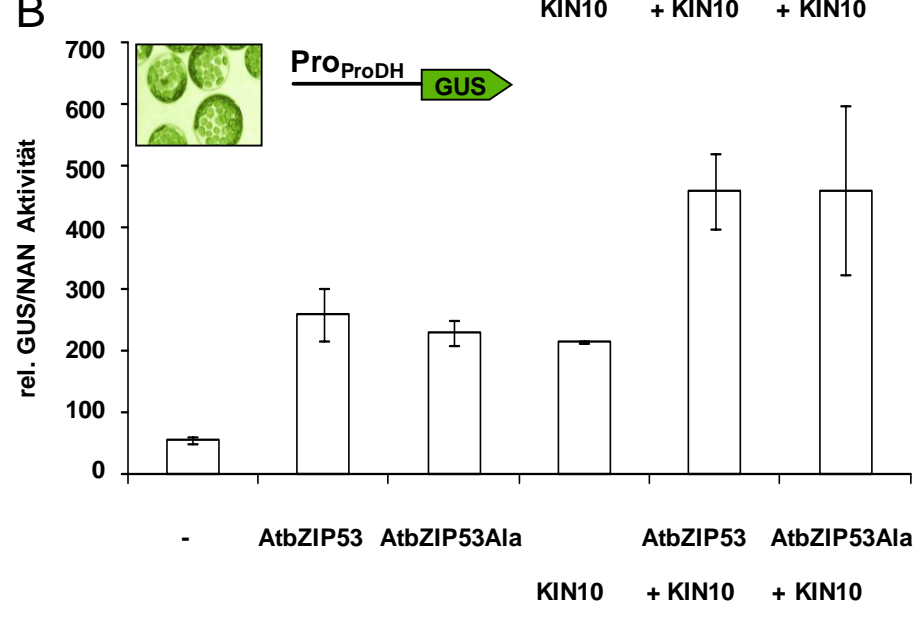

C

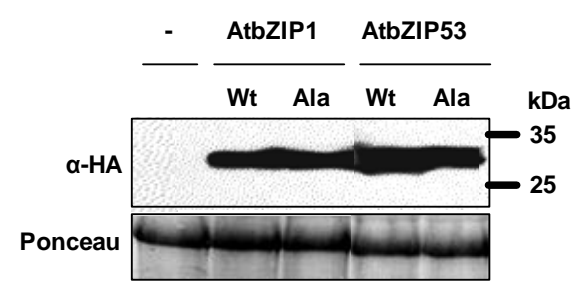

Abb. 5.44: Die Mutation der putativen SnRK-Phosphorylierungsstellen in AtbZIP1 und AtbZIP53 hat keinen Einfluss auf die bZIP vermittelte Aktivierung der ProDH

A/B: Protoplasten wurden nach der Transformation über Nacht für $16 \mathrm{~h}$ in Dauerlicht inkubiert. Die Ansätze wurden mit je $5 \mu \mathrm{g}$ Reporterplasmid, $14 \mu \mathrm{g}$ Effektorplasmid $(7 \mu \mathrm{g}$ pro Effektor, wenn nur ein Effektorplasmid zugegeben wurde, wurde mit $7 \mu \mathrm{g}$ leerem Effektorplasmid aufgefüllt) und $1 \mu g$ Pro35S:NAN Vektor transformiert. Die Angaben zeigen die Mittelwerte von vier unabhängigen Transformationsansätzen. Das Experiment wurde mehrmals mit vergleichbarem Ergebnis

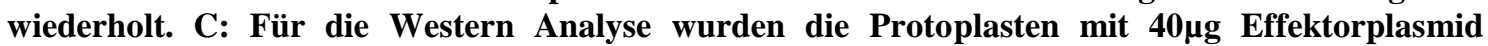
transformiert und jeweils zwei Transformationsansätze nach der Inkubation über Nacht in Harnstoffextraktionspuffer aufgenommen und vereinigt. 
Allerdings ist diese Expression der ProDH unabhängig von einer Phosphorylierung der Serine 133 in AtbZIP1 und 140 in AtbZIP53. Die Alanin-Mutanten von AtbZIP1 und AtbZIP53 weisen die gleichen Aktivierungsschaften wie die unmutierten bZIP Transkriptionsfaktoren auf.

Wildtypprotein und Alanin-Mutante von AtbZIP1 und AtbZIP53 werden aber beide expremiert und zeigen etwa gleich starke Proteinbanden in der Western Analyse (Abb. $5.44 \mathrm{C})$.

Ob möglicherweise andere Serine in AtbZIP1 und/oder AtbZIP53 existieren, die nicht den von Huang und Huber (2001) beschriebenen Phosphorylierungsmotiven entsprechen, aber ebenfalls durch KIN10 phosphoryliert werden können, kann zu diesem Zeitpunkt nicht ausgeschlossen werden (Anhang Kapitel 8.1.4 und 8.1.5).

\subsubsection{Die Mutation putativer SnRK-Phosphorylierungsstellen in AtbZIP63 führt zu einer Reduktion der ProDH Expression}

Eine weitere Möglichkeit ist, dass die Kinasen KIN10 und KIN11 gar nicht direkt AtbZIP1 und AtbZIP53 phosphorylieren, sondern andere Signalkomponenten wie z.B. mögliche Heterodimerisierungspartner der beiden Transkriptionsfaktoren.

Ein guter Kandidat hierfür ist AtbZIP63. Im Labor unseres Kooperationspartners M. Teige (Universität Wien) konnte bereits gezeigt werden, dass die Kinasen KIN10 und KIN11 mit AtbZIP63 interagieren. Eine genauere Analyse konnte bisher vier Serine in der Aminosäuresequenz von AtbZIP63 identifizieren, die in vivo phosphoryliert werden. Dies sind Serin 29, 59, 261 und 300 (persönliche Mitteilung, Anhang Kapitel 8.1.6). Alle vier Serine umgeben Aminosäuren, die gut zu den SnRK-PhosphorylierungsMotiven aus Huang und Huber (2001) passen. Besonders das Motiv um Serin 300 erfüllt perfekt diese Aminosäureabfolge (Abb. 5.45; Abb. 5.43 A).

Während die Mutation der Serine in AtbZIP1 und AtbZIP53 keinen Einfluss auf die Aktivierung des ProProDH:GUS Konstrukts hat, kann man mit der Mutante von 


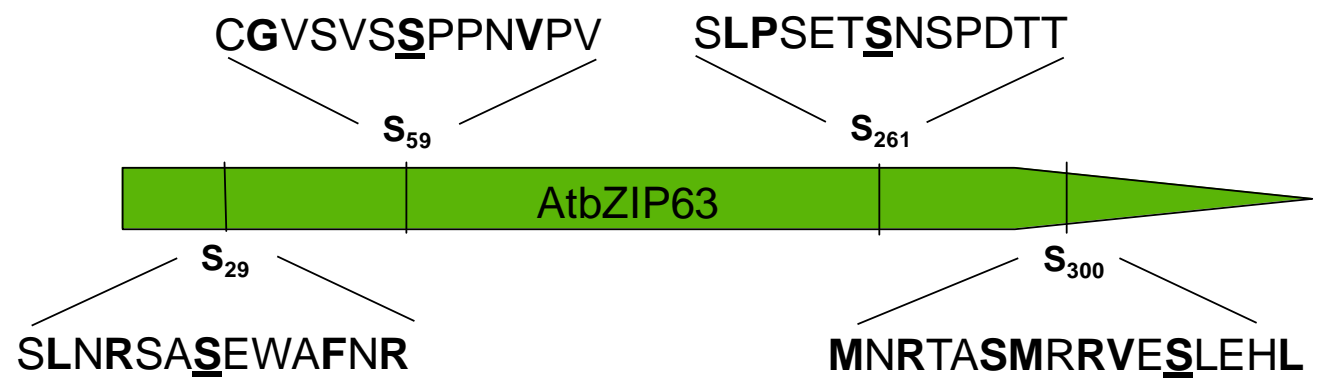

Abb. 5.45: in vivo-Phosphorylierungsmotive in AtbZIP63

Das unterstrichene Serin kennzeichnet die jeweilige Phosphorylierungsstelle. Fettgedruckte Aminosäuren stimmen mit den vorhergesagten Aminosäuren aus der Sequenz von Huang und Huber (2001) überein.

AtbZIP63, in der alle 4 in vivo phosphorylierten Serine durch Alanin ausgetauscht sind, sehr wohl einen Effekt sehen (Abb. 5.46). Die Mutation von S300 wurde bereits während der Diplomarbeit von Johanna Lendner angefertigt, die anderen drei Mutationen wurden von Christina Chaban (Universität Tübingen) durch zusätzliche Mutagenese eingefügt.

Die KIN10 vermittelte Steigerung der ProDH-Aktivität kann durch Co-Expression mit AtbZIP63 fast verdoppelt werden. Eine Co-Expression mit der Alanin-Mutante zeigt dagegen nur eine schwache Steigerung. Hier ist die ProDH-Aktivität nur fast genauso stark wie durch Expression der Kinase allein. Die vier Serine von AtbZIP63 und möglicherweise auch deren Phosphorylierungen haben also eine wichtige regulatorische Funktion für die Kinase-vermittelte Aktivierung der ProDH.

Um zu zeigen, dass dieser Unterschied in der GUS-Aktivität des ProProDH:GUS Konstrukts nicht auf eine unterschiedlich starke Expression der verschiedenen bZIPProteine zurückzuführen ist, wurde eine Western Analyse durchgeführt.

Die Expression der Mutationen von AtbZIP63 war dabei vergleichbar mit der Expression der wildtypischen Proteine (Abb. 5.46 B). Die Bande des mutierten AtbZIP63 Proteins ist aber etwas mobiler und läuft deshalb im Gel etwas schneller als die Wildtyp AtbZIP63 Bande. Möglicherweise ist dies auf die fehlenden vier Phosphorylierungen in der Alanin-Mutante zurückzuführen. 
A

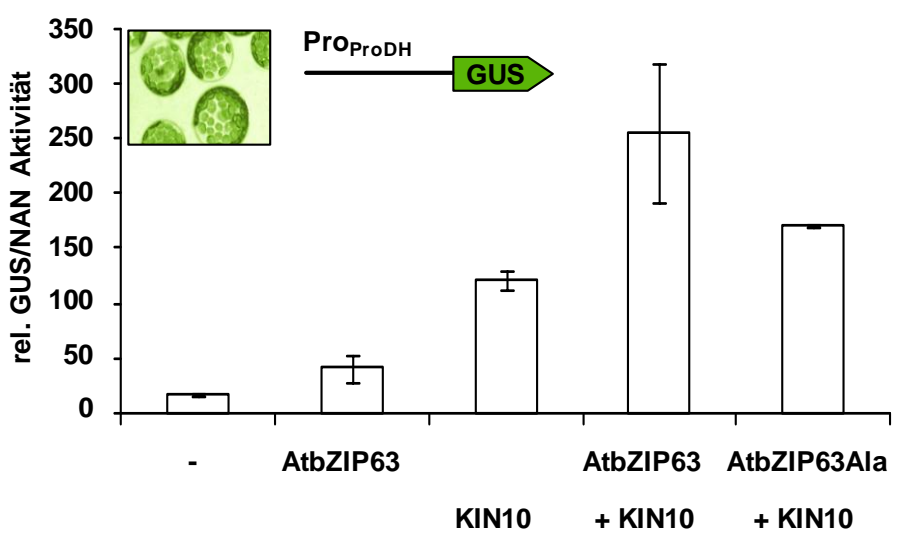

B

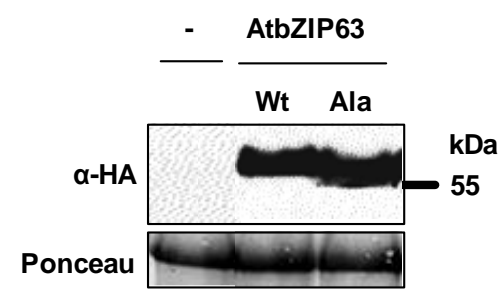

Abb. 5.46: Mutation von S29, S59, S261 und S300 in AtbZIP63 führt zu einer Reduktion der ProDH Aktivierung durch diesen Transkriptionsfaktor

A: Protoplasten wurden nach der Transformation über Nacht für $16 \mathrm{~h}$ in Dauerlicht inkubiert. Die

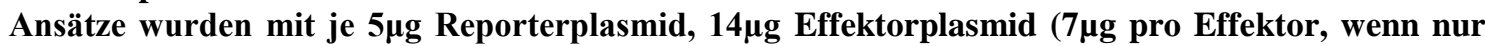
ein Effektorplasmid zugegeben wurde, wurde mit $7 \mu \mathrm{g}$ leerem Effektorplasmid aufgefüllt) und $1 \mu \mathrm{g}$ Pro35S:NAN Vektor transformiert. Die Angaben zeigen die Mittelwerte von vier unabhängigen Transformationsansätzen. Das Experiment wurde mehrmals mit vergleichbarem Ergebnis

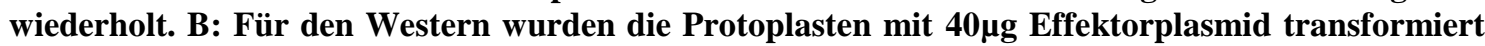
und jeweils zwei Transformationsansätze nach der Inkubation über Nacht in Harnstoffextraktionspuffer aufgenommen und vereinigt.

Die bisherigen Ergebnisse deuten darauf hin, dass die beiden Kinasen nicht direkt AtbZIP1 und AtbZIP53 sondern ihren Heterodimerisierungspartner AtbZIP63 phosphorylieren. Diese Phosphorylierung scheint auch dafür wichtig zu sein, dass AtbZIP63 zusammen mit KIN10 die ProDH aktivieren kann (Abb. 5.46). Können die Serine von AtbZIP63 wie im Fall der Alanin-Mutante nicht durch KIN10 phosphoryliert werden, so hat die Expression von AtbZIP63 keinen zusätzlichen Einfluss auf die KIN10-vermittelte ProDH Expression. 


\section{Diskussion}

\subsection{Protoplasten und transgene Pflanzen: Vor- und Nachteile zweier Modellsysteme zur Untersuchung von Energiemangel in Pflanzen}

Eine Beteiligung der Gruppe S1 bZIP Transkriptionsfaktoren an der KIN10/KIN11 vermittelten dunkelinduzierten Aktivierung der ASN1 konnte durch transiente Überexpressionen der bZIP Faktoren und Kinasen im Protoplastensystem demonstriert werden (Baena-Gonzales et al., 2007). Versuche zur Energieverarmung im Protoplastensystem wurden auch in der vorliegenden Arbeit erfolgreich durchgeführt. Die Aktivierung von ProDH und ASN1 durch Dunkelheit und den Photosynthese Inhibitor DCMU konnte mit diesem System gezeigt werden. Die Überexpression von AtbZIP53 führt in Protoplasten ebenso wie in transgenen Pflanzen zu einer konstitutiven Aktivierung von ProDH und ASNI in Licht und Dunkelheit. Die Überexpression von AtbZIP1 hat in Protoplasten dagegen nur geringe Auswirkungen auf die Expression dieser beiden Gene. Transgene Pro35S:AtbZIP1 Pflanzen zeigten zwar während der Lichtphase ebenfalls keine deutlichen Unterschiede zum Wildtyp, während der verlängerten Nacht kam es aber zu einer verstärkten Induktion der ProDH und ASN1 im Vergleich zum Wildtyp. Möglicherweise fehlen in Protoplasten weitere Faktoren, die zu einer Aktivierung von AtbZIP1 benötigt werden, oder aber die Dunkelinduktion über Nacht (ca. 16h) reicht nicht aus, um die Zielgene zu aktivieren. Auch in transgenen Pflanzen konnte erst nach einigen Stunden der verlängerten Nacht eine verstärke Expression von ProDH und ASN1 beobachtet werden. Die Stärke der Genaktivierung hängt dabei ganz entscheidend von den untersuchten Zeitpunkten ab.

Hier werden die Limitierungen des Protoplastensystems deutlich. Trotz aller Vorteile die es bietet (kostengünstiges, schnelles System zur transienten Transformation, Möglichkeit viele Faktoren auf einmal zu testen, Auswirkungen unterschiedlichster Bedingungen wie Energiemangel, Salzstress, Hormonbehandlungen etc.), gibt es doch auch deutliche Nachteile. Es handelt sich um ein artifizielles System, in dem die Expression unabhängig von ihrer natürlichen Gewebe oder Kompartiment untersucht 
wird. Durch die Protoplastierung werden die Zellen gestresst und in einem Puffer inkubiert, der ebenfalls einen Einfluss auf die Induktion der untersuchten Gene haben kann. Zudem kann lediglich eine Überexpression der Proteine durchgeführt werden. „Loss-of-function“ Ansätze sind dagegen nicht möglich. Das Protoplastensystem kann also nur erste Hinweise liefern, die anschließend in transgenen Pflanzen reproduziert werden müssen. Das Beispiel von AtbZIP1 zeigt, dass sich die Ergebnisse dort von den Ergebnissen in Protoplasten deutlich unterscheiden können.

Transgene Pflanzen bieten außerdem die Möglichkeit Wuchsphänotypen zu beobachten, die auch auf die physiologische Bedeutung der untersuchten Proteine hinweisen können. Pflanzen, die die bZIP Transkriptionsfaktor AtbZIP1 oder AtbZIP53 überexpremieren, zeigen z.B. einen deutlich verfrühten Eintritt in die dunkelinduzierte Seneszenz. Ein ähnlicher Phänotyp der Überexpressionspflanzen wurde während der natürlichen, entwicklungsbedingten Seneszenz dagegen nicht beobachtet. Parallelen zwischen dem Transkriptom dunkelinduzierter Pflanzen und dem Transkriptom einer durch Zuckerverarmung in die Seneszenz getriebenen Zellkultur weisen darauf hin, dass die dunkelinduzierte Seneszenz auf einen Zuckermangel zurückzuführen ist (Swidzinski et al., 2002). Zuckermangel, wie er während langer Inkubation in Dunkelheit auftritt, induziert die Expression von AtbZIP1 und AtbZIP53 und auch Gruppe C bZIP Transkriptionsfaktoren wie AtbZIP63 werden stark unter diesen Bedingungen aktiviert. Während der natürlichen Seneszenz kommt es dagegen zu keiner Induktion dieser Faktoren. Die Expression von AtbZIP63 wird während der natürlichen Seneszenz sogar reprimiert (Weltmeier, 2005).

Diese Daten sprechen dafür, dass die Überexpression von AtbZIP1 und 53 zu einer Aktivierung physiologischer Prozesse führt, die eine wichtige Rolle in der Anpassung an eine dunkelinduzierten Energieverarmung spielen. Für die Ausprägung der natürlichen Seneszenz scheinen sie dagegen keine Bedeutung zu haben. 


\subsection{Die beiden Transkriptionsfaktoren AtbZIP1 und AtbZIP53 werden transkriptionell und posttranskriptionell durch Energieverarmung aktiviert}

Bedingungen wie langanhaltende Dunkelheit führen zur Aktivierung einer ganzen Reihe von bZIP Transkriptionsfaktoren. Die stärkste transkriptionelle Aktivierung aller 75 bZIP Faktoren zeigte dabei AtbZIP1. Schon nach 4 Stunden der verlängerten Nacht wird die Expression von AtbZIP1 deutlich induziert. Zu diesem Zeitpunkt ist die gespeicherte Stärke vollständig verbraucht und ein deutlicher Energiemangel spürbar (Usadel et al., 2008). Die Transkription seines nächsten Verwandten, AtbZIP53, wird ebenfalls, wenn auch deutlich schwächer, durch Dunkelheit aktiviert. Andere Mitglieder der Gruppe S1 zeigen dagegen nur geringe Änderungen ihrer Transkription oder wurden während der verlängerten Nacht sogar reprimiert. Aus diesem Grund wurden AtbZIP1 und AtbZIP53 als mögliche transkriptionelle Regulatoren unter Energiemangelbedingungen für die weiteren Analysen ausgewählt.

Um zu testen, ob die transkriptionelle Aktivierung von AtbZIP1 und AtbZIP53 durch Dunkelheit oder durch die daraus resultierende Zuckerverarmung ausgelöst wird, wurden bereits Fütterungsexperimente mit Zuckern durchgeführt (Weltmeier, 2005). Dabei konnte gezeigt werden, dass Saccharose und Glukose, nicht aber 3Orthomethylglukose (OMG) in der Lage sind, die durch Energiemangelbedingungen nach zwei Tagen Dunkelheit ausgelöste Expression von AtbZIP1, und in geringerem Maß auch von AtbZIP53, zu reprimieren. Diese Ergebnisse wurden vor kurzem durch Kang et al. (2010) bestätigt. OMG ist ein Derivat der Glukose, das von der Zelle aufgenommen, aber nicht metabolisiert wird. OMG führt auch nicht wie Glukose oder Saccharose zu einer Aktivierung des Hexokinase abhängigen Zuckersignalwegs (Cortes et al., 2003), was zu der Vermutung führt, dass die transkriptionelle Aktivierung von AtbZIP1 während der verlängerten Nacht durch Zuckermangel über einen Hexokinaseabhängigen Signalweg induziert wird. In Übereinstimmung damit wurde kürzlich durch Kang et al. (2010) gezeigt, dass die Repression der Transkription von AtbZIP1 durch Glukose in der gin2 Mutanten der Hexokinase nur noch eingeschränkt funktioniert. Transkriptomstudien zeigen, dass bereits kleinste Änderungen im Energiezustand der Pflanze zu einer massiven Änderung der Genexpression führen (Usadel et al., 2008). 
Auch AtbZIP1 und AtbZIP53 wurden in dieser Studie transkriptionell aktiviert und als mögliche Regulatoren der Anpassung an Energiemangelbedingungen beschrieben. Es konnte dabei gezeigt werden, dass AtbZIP1 nicht nur durch die Verfügbarkeit von Zuckern, sondern auch durch die innere Uhr transkriptionell reguliert wird. Diese Regulation von AtbZIP1 durch die innere Uhr wurde auch durch eine bioinformatische Netzwerkanalyse bestätigt (Gutierrez et al., 2008). Es konnte zusätzlich durch ChIP Analysen gezeigt werden, dass CIRCADIAN CLOCK ASSOCIATED 1 (CCA1), eine der Hauptkomponenten der inneren Uhr (Yakir et al., 2007), direkt an den AtbZIP1 Promotor bindet (Gutierrez et al., 2008).

Obwohl noch einige Untersuchungen dafür fehlen, deutet vieles darauf hin, dass ein regulatorisches Netzwerk existiert, welches Kohlenstoff- und Stickstoffverfügbarkeit der Pflanze sowie den durch die innere Uhr vorgegebenen Tag-/Nachtrhythmus verarbeitet und so die durch AtbZIP1 regulierte Genexpression kontrolliert. In diesem Zusammenhang wäre es sicherlich lohnenswert eine genaue Analyse des AtbZIPI Promotors durchzuführen, um mögliche cis-Elemente zu finden, die an der Integration dieser unterschiedlichen Signale beteiligt sind, und über diese Elemente vielleicht auch weitere Komponenten der Signalkette oberhalb von AtbZIP1 zu identifizieren.

Zusätzlich zur transkriptionellen Aktivierung wird AtbZIPl möglicherweise auch durch eine Stabilisierung des Transkripts während der verlängerten Nacht reguliert. Die Transkriptmenge von AtbZIP1 steigt in den Pro35S:AtbZIP1 Überexpressionspflanzen während der Dunkelheit an, obwohl der 35S Promotor unter diesen Bedingungen nicht reguliert wird, was z.B. die gleichbleibende Expression von AtbZIP53 in den Pro35S:AtbZIP53 Überexpressionspflanzen zeigt. Durch Verwendung von Primern, die an die DNA-Sequenz des fusionierten HA-Tags binden und so nur das transgene AtbZIP1 in den Pro35S:AtbZIP1 Pflanzen amplifizieren, konnte auch ausgeschlossen werden, dass dieser Anstieg auf die Aktivierung der endogenen AtbZIP1 Transkription zurückzuführen ist.

Neben der transkriptionellen Aktivierung und der möglichen Stabilisierung des AtbZIP1 Transkripts während der verlängerten Nacht gibt es noch einen weiteren Regulationsmechanismus, der nicht nur bei AtbZIP1, sondern auch bei den anderen 
Mitgliedern der Gruppe S1 der bZIP Transkriptionsfaktoren auftritt. Für alle 5 bZIP Faktoren konnte eine posttranskriptionelle Reprimierung der Translation durch Saccharose (SIRT, sucrose induced repression of translation) gezeigt werden (Weltmeier et al., 2009; Wiese et al., 2004; Hanson et al., 2008), die durch untranslatierte Leserahmen (uORFs) im 5'UTR der bZIPs vermittelt wird.

Um die Verteilung der bZIP Proteinmenge in der ganzen Pflanze abschätzen zu können, wurden stabil transformierte Promotor:GUS Linien der bZIP Faktoren hergestellt (Weltmeier, 2005). Unter normalen Langtagsbedingungen ist die Expression von AtbZIP1 und AtbZIP53 auf die jungen ,sink“-Blätter beschränkt (Weltmeier et al., 2009). Während langanhaltender Dunkelheit breitet sich die Expression von AtbZIP1 und AtbZIP53 deutlich aus und ist dann auch in älteren Blättern zu finden (Weltmeier, 2005). Für einen direkten Nachweis der endogenen AtbZIP1 und AtbZIP53 Proteine wären spezifische Antikörper notwendig, deren Produktion trotz mehrerer Versuche bisher nicht erfolgreich war.

Die beschriebenen Regulationsmechanismen führen dazu, dass bei einer ausreichenden Zuckerversorgung sowohl die Transkription als auch die Translation von AtbZIP1 und AtbZIP53 reprimiert wird. Unter Energiemangelbedingungen werden Transkription und Translation dagegen aktiviert, so dass viel AtbZIP1 und AtbZIP53 Protein zur Verfügung steht. Dieses kann dann seine regulatorische Funktion in der Pflanze ausüben und möglicherweise so zur Anpassung des pflanzlichen Metabolismus an Energiemangelbedingungen beitragen.

\subsection{AtbZIP1 und AtbZIP53 führen unter Energiemangel- bedingungen zu einer Umprogrammierung des pflanzlichen Kohlenhydratmetabolismus}

Der während des Tages durch die Photosynthese gewonnene Zucker wird etwa zur Hälfte in Saccharose umgewandelt und in die Teile der Pflanze exportiert, die keine 
Photosynthese betreiben können. Der Rest des Zuckers wird als Reserve für die Nacht in Form von Stärke in den Chloroplasten gespeichert (Smith et al., 2005).

Die Überexpression von AtbZIP53, und im geringeren Maß auch die Überexpression von AtbZIP1, führt tagsüber zu einer massiven Stärkeeinlagerung in diesen Pflanzen. Die sonst im Wildtyp so strikt kontrollierten Prozesse der Stärkesynthese und des Stärkeabbaus (Gibon et al., 2004) sind in den Überexpremierern dereguliert.

Der Phänotyp der Pro35S:AtbZIP53 Pflanzen ähnelt mit seinem Zwergwuchs und der hohen Stärkeeinlagerung stark dem Phänotyp einiger Stärkeabbaumutanten. So ist z.B. die sexl (starch excess 1) Mutante, in der das Enzym GWD1 (GLUCAN-WATER DIKINASE 1) mutiert ist, das für die Phosphorylierung und damit den Abbau des Amylopektins wichtig ist (Abb. 6.1), ebenfalls zwergwüchsig und zeigt wie Pro35S:AtbZIP53 Pflanzen auch während der verlängerten Nacht eine erhöhte Stärkeeinlagerung (Lloyd et al., 2005; Yu et al., 2001). Tatsächlich wird in Pro35S:AtbZIP53 Pflanzen die $\beta$-AMYLASE 5 (BAM5) nicht mehr expremiert. Die Familie der B-Amylasen besteht in Arabidopsis aus 9 Mitgliedern. Generell katalysieren sie den Abbau von Amylopektin und Amylose zu Maltose (Abb. 6.1).

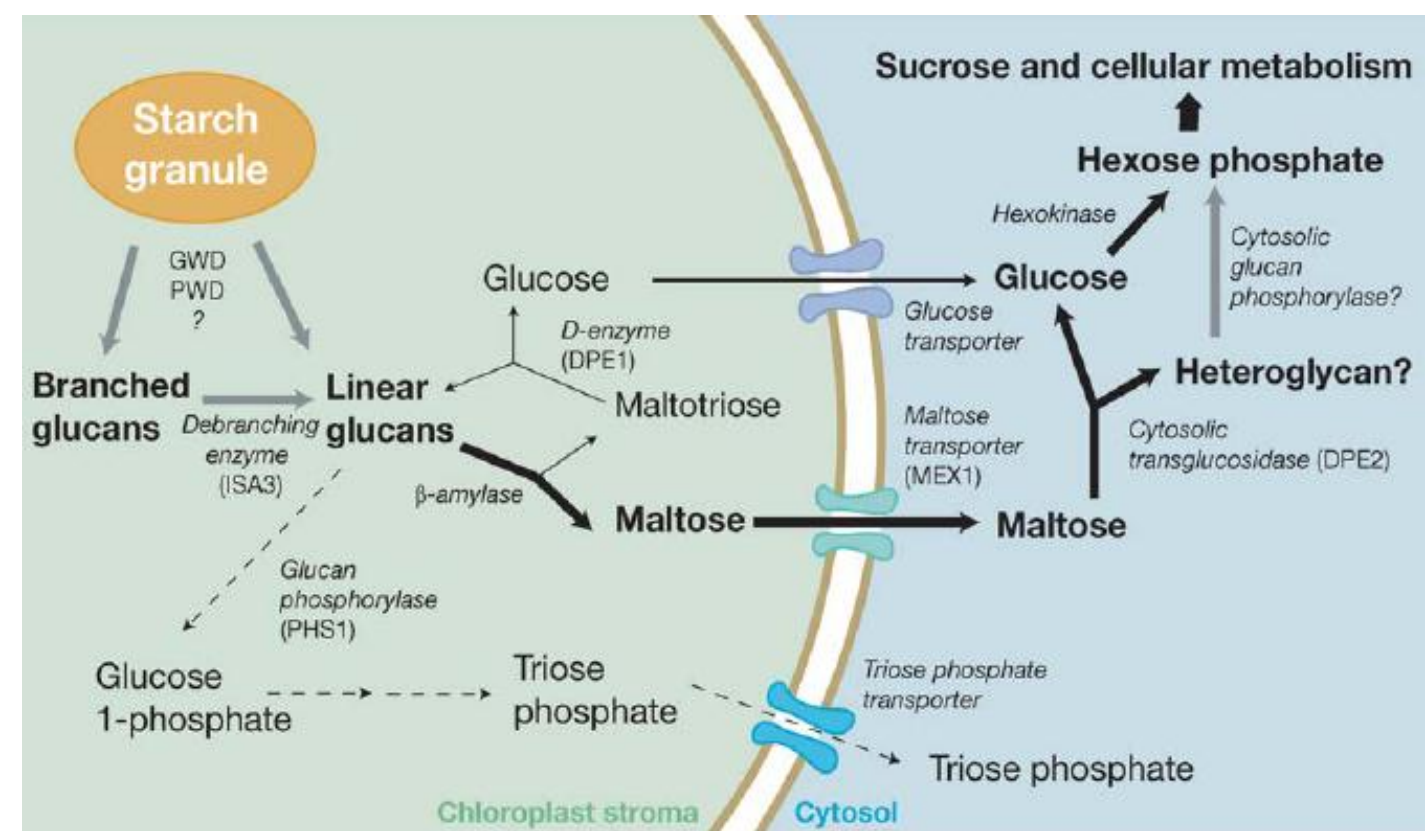

Abb. 6.1: Modell des Stärkeabbaus während der Nacht in Arabidopsis Blättern (Smith et al., 2005) 
Auch $\alpha$-Amylasen sind grundsätzlich dazu in der Lage den Abbau von Amylopektin und Amylose zu Maltose zu katalysieren, in Arabidopsis führt die Mutation aller drei $\alpha$ Amylase-Gene aber zu keiner nennenswerten Veränderung des Stärkeabbaus (Yu et al., 2005). Lediglich vier der neun $\beta$-Amylasen (BAM1, BAM2, BAM3 und BAM4) aus Arabidopsis sind in den Chloroplasten, dem Ort des Stärkeabbaus, lokalisiert (Fulton et al., 2008). Drei von ihnen zeigen eine messbare $\beta$-Amylase-Aktivität, für die BAM4 konnte dies dagegen nicht nachgewiesen werden. Ihr wird statt dessen eine regulatorische Funktion für die anderen drei chloroplastidären $\beta$-Amylasen zugeschrieben (Fulton et al., 2008). Studien mit Mutanten von BAM1, BAM2 und BAM3 zeigen aber lediglich in bam3 erhöhte Stärke- und niedrigere Maltosemengen während der Nacht (Fulton et al., 2008; Lao et al., 1999; Kaplan und Guy, 2005; Sparla et al., 2006). Eine erste Untersuchung der Expression dieser vier B-Amylasen mit Hilfe der qPCR ergab keine großen Unterschiede zwischen Wildtyp und Pro35S:AtbZIP53 Pflanzen. Nur zu einigen Zeitpunkten ist die Expression der vier Gene im Vergleich zum Wildtyp etwas stärker, möglicherweise um den Ausfall der B-Amylase 5 in diesen Pflanzen zu kompensieren. Sie scheinen aber nicht für die Akkumulation der Stärke in den Überexpressionspflanzen verantwortlich sein.

Von den andern fünf $\beta$-Amylasen, die alle außerhalb der Chloroplasten vorkommen, wurde bisher lediglich die BAM5 näher untersucht. Sie ist in den Siebelementen des Phloems lokalisiert (Wang et al., 1995) und 90\% der B-Amylase-Aktivität der Pflanze ist auf die BAM5 zurückzuführen (Laby et al., 2001). Möglicherweise soll diese hohe Expression der BAM5 eine Bildung von Stärkekörnern in den Siebelementen verhindern, da diese den Transport der löslichen Zucker durch die Poren der Siebplatten einschränken könnten (Wang et al., 1995). Eine stark verminderte Expression der BAM5 wie sie in Pro35S:AtbZIP53 Pflanzen zu finden ist, hat also möglicherweise eine „Verstopfung“ der Siebelemente durch Stärkeeinlagerungen zur Folge, was zu einer starken Beeinträchtigung des „Source“ - „Sink“ Transports und damit dem Zwergwuchs der AtbZIP53 Überexpressionspflanzen führen könnte. Dies könnte auch erklären, warum selbst unter Dauerlicht gewachsene Pflanzen immer noch einen starken Zwergwuchs zeigen, obwohl sie durch die ständige Möglichkeit Photosynthese zu betreiben nicht auf den Abbau der chloroplastidären Stärke angewiesen sind. Dagegen spricht allerdings, dass eine Mutation der BAM5 keine sichtbaren Auswirkungen auf die 
Phloemfunktion hat (Laby et al., 2001). Leider konnte in der Metabolomanalyse, die in Kooperation mit W. Weckwerth (Universität Wien) durchgeführt wurde, keine Maltose bestimmt werden. Da der Abbau der Stärke durch die B-Amylasen zur Bildung von Maltose führt, hätten reduzierte Maltosemengen in den Überexpremierern einen weiteren Hinweis auf einen verminderten Stärkeabbau geliefert.

Möglicherweise sind der Zwergwuchs und der erhöhte Stärkegehalt der AtbZIP53 Überexpressionspflanzen auch nicht allein auf den verminderten Abbau der Stärke, sondern auch auf eine verstärkte Stärkesynthese zurückzuführen. Die AGPase ist eines der Schlüsselenzyme der Stärkesynthese (Geigenberger, 2003; Martin und Smith, 1995). In Kartoffel konnte gezeigt werden, dass sowohl Glukose, als auch Saccharose zu einer posttranslationalen Redox-Aktivierung der AGPase führen (Tiessen et al., 2003). Zumindest die saccharoseabhängige Aktivierung der AGPase wird dabei über die Aktivierung von SnRK1 Kinasen und eine anschließende transkriptionellen Regulation vermittelt. Die Versuche in dieser und in anderen Arbeiten (Baena-Gonzales et al., 2007) zeigen, dass die SnRK1 Kinasen eine Gruppe von bZIP Transkriptionsfaktoren aktivieren, zu denen auch AtbZIP1 und AtbZIP53 gehören, die anschließend eine Reihe von Genen des Primärmetabolismus transkriptionell regulieren. Eine Beteiligung von AtbZIP1 und AtbZIP53 an der Stärkesynthese ist damit zumindest nicht ausgeschlossen. Die Expression von wichtigen Genen der Stärkesynthese, wie den kleinen und großen Untereinheiten der AGPase oder verschiedenen Stärkesynthasen, müssten aber noch untersucht werden.

Gegen die These, dass die Stärkesynthese in den Pro35S:AtbZIP53 Pflanzen erhöht ist spricht allerdings die starke Akkumulation von löslichen Zuckern wie Glukose, Fruktose und Saccharose in diesen Pflanzen. Selbst während der verlängerten Nacht weisen sie noch höhere Mengen dieser Zucker auf, als die Wildtyppflanzen während des Tages. Der Abbau von Glukose, Fruktose und Saccharose zur Energiegewinnung erfolgt normalerweise über die Glykolyse und den anschließenden Citratzyklus. Sind während der verlängerten Nacht im Wildtyp keine Zucker mehr vorhanden, die verstoffwechselt werden können, so ist auch Pyruvat, das Endprodukt der Glykolyse nicht mehr messbar. AtbZIP53 Überexpremierer haben während der verlängerten Nacht zwar noch deutliche Zuckerreserven, die Pyruvatkonzentration unterscheidet sich aber kaum vom Wildtyp. 
Überexpremierer von AtbZIP1 weisen zwar auch leicht erhöhte Saccharosekonzentrationen während der verlängerten Nacht auf, die Glukose- und Fruktosemengen unterscheiden sich aber deutlich von denen im Wildtyp und in Pro35S:AtbZIP53 Pflanzen. Schon tagsüber sind diese beiden Zucker in den AtbZIP1 Überexpressionspflanzen kaum messbar, die Pyruvatmenge unterscheidet sich aber auch in diesen Pflanzen nicht signifikant von der des Wildtyps. Die Doppelmutante atbzip1 atbzip53 zeigt generell kaum Unterschiede zum Wildtyp. Hier wäre es interessant auch die Metabolite in den Vierfachmutanten zu bestimmen. Die Komponenten des Citratzyklus, sind in beiden Überexpressionspflanzen in ähnlichen Mengen zu finden wie im Wildtyp und der Doppelmutante. Trotz der stark veränderten Zucker- und Stärkekonzentrationen der Überexpremierer sind die Unterschiede nur minimal und der Citratzyklus in diesen Pflanzen wenig beeinträchtigt. Dies kann nur gewährleistet werden, indem andere Makromoleküle wie z.B. Proteine, Aminosäuren und Lipide abgebaut, und als Zwischenprodukte in den Citratzyklus eingeschleust werden.

\subsection{AtbZIP1 und AtbZIP53 aktivieren unter Energiemangel Gene des Lipid- und Aminosäurestoffwechsels}

Da unter Energiemangelbedingungen wie der verlängerten Nacht eine Kohlenstoffassimilation durch die Photosynthese ausgeschlossen ist, müssen andere Makromoleküle wie Lipide, Proteine und Aminosäuren abgebaut werden, um den bleibenden Energiebedarf der Pflanze zu decken, und ein Überleben zu sichern (Abb. 6.2). AtbZIP1 und AtbZIP53 sind an dieser Anpassung des pflanzlichen Metabolismus beteiligt. Im letzten Kapitel wurde bereits beschrieben, dass die Überexpression der beiden Transkriptionsfaktoren $\mathrm{zu}$ einer Deregulation des Kohlenstoffmetabolismus führt. Dies ist sinnvoll, da die Aktivierung von AtbZIP1 und AtbZIP53 normalerweise unter Bedingungen erfolgt, in denen Kohlenstoff limitierend und die Expression von Enzymen des Kohlenhydratabbaus daher unnötig ist.

Die Überexpression von AtbZIP1 und AtbZIP53 führt dagegen zu einer gesteigerten Expression von Lipasegenen. Lipasen sind Enzyme, die von Lipiden die freien Fettsäuren abspalten. Dieser Degradationsprozess findet in der natürlichen 
Blattseneszenz im Zuge der Mobilisierung von Nährstoffen und deren Recycling für noch wachsende Pflanzenteile statt (Nooden et al., 1997; Buchanan-Wollaston, 1997; Quirino et al., 2000). Entsprechend wurden in der Literatur bereits seneszenzinduzierte Lipasen beschrieben (Hong et al., 2000; Thomson et al., 2000).

Eine mögliche Beteiligung am Lipidabbau während des Seneszenzprozesses wird auch für pflanzliche Lipoxygenasen vermutet (Feussner und Wasternack, 1998). Im tierischen System konnte eine Rolle im Membranabbau bereits für 15-Lipoxygenasen gezeigt werden (Schewe und Kühn, 1991). Die durch die Lipaseaktivität frei werdenden Fettsäuren wie z.B. Linolsäure oder Linolensäure können entweder weiter abgebaut werden und in Form von Acetyl-CoA zur Energiegewinnung in den Citrat-Zyklus eingeschleust werden (Abb. 6.2) oder dienen als Ausgangsmaterial für die Synthese von

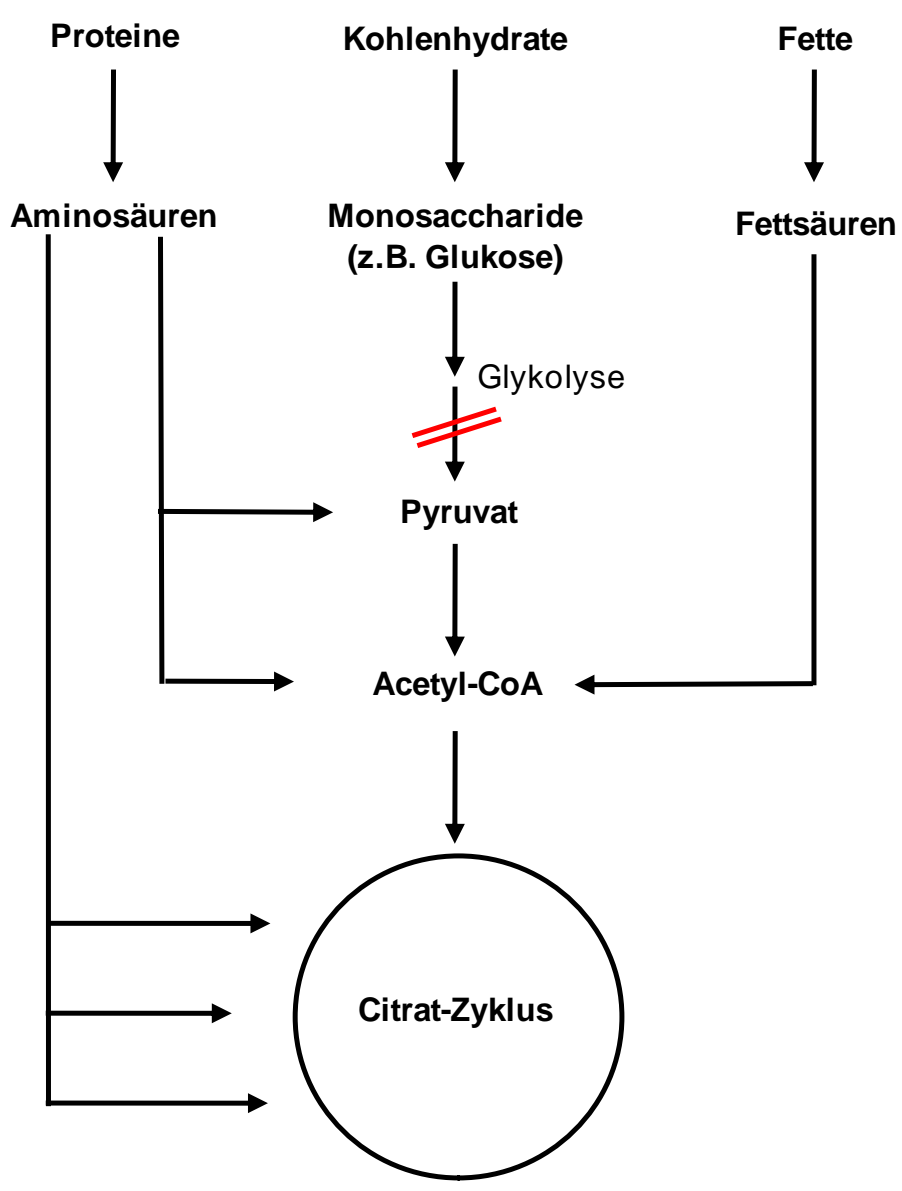

Abb. 6.2: Abbau von Proteinen und Fetten über den Citrat-Zyklus (modifiziert nach Stryer, Biochemie) 
Jasmonsäure (JA) durch sogenannte 13-Lipoxygenasen (Creelman und Mullet, 1997). In dieser Umsetzung von Linol- bzw. Linolensäure zu JA könnte auch eine der Ursachen der Seneszenz liegen, denn JA scheint eine entscheidende Rolle in der Ausprägung der Blattseneszenz zu spielen. Die Konzentration von JA ist in seneszenten Blättern 4fach so hoch wie in nicht seneszenten und eine exogene Behandlung von Blättern mit JA führt zu einem verfrühten Eintritt in die Blattseneszenz (He et al., 2002).

In Arabidopsis existieren 6 verschiedene Lipoxygenasen (Feussner und Wasternack, 2002; Stenzel et al., 2003). Vier von ihnen, darunter auch die in den Arrays der Pro35S:AtbZIP1 Pflanzen verstärkt expremierte LOX2, gehören $\mathrm{zu}$ den 13Lipoxygenasen und können damit den ersten Schritt zur Biosynthese von JA katalysieren. Während der dunkelinduzierten Seneszenz wird ihre Expression allerdings reprimiert, so dass es fraglich ist, ob es auch während dieser Form der Seneszenz zu einer Akkumulation von JA kommt. Eine Messung der JA Konzentration sowie der Konzentration verschiedener Fettsäuren in Blättern während einer verlängerten Nacht könnte Aufschluss über diese Fragestellung geben.

Während der dunkelinduzierten Energieverarmung wird dagegen die LOXI induziert, eine 9-Lipoxygenase, die in Überexpressionspflanzen von AtbZIP1 und AtbZIP53 verstärkt expremiert wird. Die Funktion der 9-Lipoxygenasen ist wesentlich weniger gut untersucht als die Funktion der 13-Lipoxygenasen. Ihre Expression führt nicht zur Biosynthese von JA, sondern zu verschiedenen anderen Metaboliten, für die bisher eine mögliche Rolle in Wurzelentwicklung, Pathogen-Abwehr und Zelltod beschrieben wurde (Abb. 5.8; Melan et al., 1993; Velosillo et al., 2007). Eine Analyse der Überexpressionspflanzen auf mögliche Akkumulationen von 9-LOX-Produkten und eine anschließende Untersuchung dieser Produkte auf ihre Rolle in der dunkelinduzierten Seneszenz würde sich wahrscheinlich lohnen, da die Mutation der LOX1 in den AtbZIP1 Überexpressionspflanzen bereits ausreicht, den Phänotyp des verfrühten Eintritts in die dunkelinduzierte Seneszenz zu verhindern. Da in den Pro35S:AtbZIP1 Pflanzen aber auch die LOX2 verstärkt expremiert wird und deren Expression in der Kreuzung aus Pro35S:AtbZIP1 Pflanzen und LOX1 Mutante ebenfalls beeinträchtigt ist, könnte der beobachtete Phänotyp auch auf eine verstärkte Bildung von JA zurückzuführen sein. Um hier genauere Aussagen treffen zu können, müssten weitere Versuche wie z.B. die Messung der JA Mengen folgen. Die Herstellung von 
homozygoten Pro35S:LOX1 Pflanzen ist in Zusammenarbeit mit E. Hornung und I. Feussner (Universität Göttingen, Abt. Biochemie der Pflanze) bereits in Arbeit. Durch sie könnte geklärt werden, ob allein die starke Expression der LOX1 in den Pro35S:AtbZIP1 Pflanzen für den verfrühten Eintritt in die dunkelinduzierte Seneszenz verantwortlich ist.

Auch Proteine werden während der verlängerten Nacht vermehrt abgebaut. Dies führt zu einem stetigen Anstieg an freien Aminosäuren, die während der Dunkelheit ebenfalls verstoffwechselt werden. Die entstehenden Zwischenprodukte können über den CitratZyklus abgebaut werden. Gene des Aminosäureabbaus wie die ProDH oder die BCAT2 werden dafür transkriptionell aktiviert. Die verstärkte Expression dieser beiden Gene in Überexpremierern von AtbZIP1 und AtbZIP53 führt so auch zu einem reduzierten Gehalt an Prolin und den verzweigtkettigen Aminosäuren Leucin, Isoleucin und Valin im Vergleich zum Wildtyp. Der Abbau von Prolin dient unter diesen Bedingungen als alternative Quelle für Energie (Blum und Ebercon, 1976), Kohlenstoff und Stickstoff (Ahmad und Hellebust, 1988). Diese Dinge werden unter Energiemangelbedingungen gerade in den Überexpremierern von AtbZIP1 und AtbZIP53 mit ihrem deregulierten Kohlenhydratmetabolismus, dringend benötigt. Auch Leucin, Isoleucin und Valin werden in den AtbZIP1 und AtbZIP53 Überexpressionspflanzen verstärkt abgebaut. Die in den Mitochondrien lokalisierte BCAT1 wird bisher als das zentrale Enzym des Abbaus verzweigtkettiger Aminosäuren beschrieben (Diebold et al., 2002; Schuster und Binder, 2005). Die Analyse der 6 BCAT-Gene aus Arabidopsis ergab aber, dass unter den Bedingungen der verlängerten Nacht die $B C A T 2$ die stärkste Induktion zeigt. Die BCAT2 ist in den Chloroplasten lokalisiert und wurde bisher eher der Synthese der verzweigtkettigen Aminosäuren zugeordnet (Schuster und Binder, 2005; Lees und Galili, 2009). Unter Energiemangelbedingungen in der Dunkelheit kommt es im Chloroplasten zum Abbau von Proteinen wie der RUBISCO. Möglicherweise verschiebt sich durch die vielen dabei frei werdenden verzweigtkettigen Aminosäuren das Gleichgewicht, und die BCAT2 katalysiert nun auch den Abbau dieser Aminosäuren. Die Aktivierung des Abbauweges der verzweigtkettigen Aminosäuren durch Leucin in zuckerverarmten Zellen wurde in der Literatur bereits beschrieben (Fujiki et al., 2001). Die durch die BCAT2 katalysierte Deaminierungsreaktion unter Energiemangelbedingungen dient dabei möglicherweise der Synthese von 
Glutaminsäure, die bei dieser Reaktion entsteht (Schuster und Binder, 2005). Glutaminsäure ist essentiell für die Synthese von Asparagin, was, während der Dunkelheit für den Transport und die Verteilung von Kohlenstoff und Stickstoff aus den abgebauten Aminosäuren in der Pflanze sorgt. Die dunkelinduzierte BCAT2 Expression und damit der Abbau verzweigtkettiger Aminosäuren wie Leucin oder Isoleucin ist so möglicherweise eng verknüpft mit der Asparaginsynthese und wird deshalb auch durch die gleichen Transkriptionsfaktoren reguliert. Auch bei dem durch AtbZIP1 und AtbZIP53 regulierten Abbau von Prolin durch ProDH und P5C-DECARBOXYLASE entsteht Glutaminsäure, die ebenfalls für die Synthese von Asparagin genutzt werden kann.

Asparagin ist wegen seines hohen Stickstoff zu Kohlenstoff Verhältnisses eine wichtige Aminosäure für den Stickstoff-Transport in der Pflanze, besonders unter Bedingungen des Kohlenstoffmangels. Außerdem ist es relativ stabil und inert, was es zu einer geeigneten Aminosäure für einen Transport auch über lange Strecken macht und eine Funktion in der Speicherung von Stickstoff zulässt (Lam et al., 1994; Lea und Miflin, 1980; Sieciechowicz et al., 1988).

Versuche mit Überexpressionspflanzen der ASN1, dem zentralen Enzym der Asparaginsynthese, zeigten erhöhte Asparaginmengen im Phloemsaft, die vor allem in „sink“-Gewebe transportiert wurden (Lam et al., 2003).

Während der verlängerten Nacht kommt es zu einer starken Induktion der Gene der Asparaginbiosynthese. Die Expression von ASP3, GDH2, GLNS und ASN1 wird unter diesen Bedingungen koordiniert aktiviert und durch Zucker reprimiert (Lin und $\mathrm{Wu}$, 2004). Dies ermöglicht eine verstärkte Synthese von Asparagin aus den durch den gesteigerten Protein- und Aminosäureabbau zur Verfügung stehenden Metaboliten und eine gleichmäßige Verteilung dieser Stickstoff- und Kohlenstoffreserven in der ganzen Pflanze. Asparagin macht deshalb während der verlängerten Nacht einen Großteil der freien Aminosäuren aus. Über den Abbau zu Oxalacetat kann Asparagin schließlich wieder zur Energiegewinnung in den Citrat-Zyklus eingeschleust werden (Abb. 6.2; Stryer, Biochemie).

Sowohl AtbZIP1 als auch AtbZIP53 ist in der Lage die Expression der Gene der Asparaginbiosynthese $\mathrm{zu}$ regulieren. Während AtbZIP53 die beteiligten Gene konstitutiv, d.h. unabhängig vom Energiezustand der Pflanze, aktivierte, führte die 
Überexpression von AtbZIP1 hauptsächlich während der verlängerten Nacht zu einer deutlichen Steigerung der Expression der Asparaginbiosynthesegene. Dieser Effekt konnte auch schon bei der Expression der ProDH in den beiden Überexpremierern beobachtet werden und deutet auf eine zwar überlappende Funktion aber auch auf deutliche Unterschiede in der Regulation durch die beiden Transkriptionsfaktoren hin. Unterschiede zwischen beiden Überexpremierern finden sich auch in der gemessenen Asparaginmenge. Während die verstärkte Expression der Asparaginbiosynthesegene in Pro35S:AtbZIP53 Pflanzen auch zu einer Steigerung des Asparagingehalts führt, zeigen Pro35S:AtbZIP1 Pflanzen keine erhöhten Asparaginmengen im Vergleich zum Wildtyp. Dies lässt sich auf transkriptioneller Ebene durch die Expression einer ASPARAGINASE (ANS) erklären, die in den AtbZIP1 Überexpremierern, nicht aber in den AtbZIP53 Überexpremierern, zum Abbau von Asparagin zu Aspartat führt (Bruneau et al., 2006).

Die Überexpression sowohl von AtbZIP1 als auch von AtbZIP53 führt also zu einem verstärkten Abbau von Lipiden und Aminosäuren während der verlängerten Nacht. Obwohl grundsätzlich beide bZIP Transkriptionsfaktoren in der Lage sind, die Expression von Lipasen, Lipoxygenasen, ProDH, BCAT2 und Genen der Asparaginbiosynthese wie der ASN1 zu aktivieren, zeigten sich hier doch auch deutliche Unterschiede in der Regulation ihrer Zielgene.

\subsection{AtbZIP1 und AtbZIP53 kontrollieren die Transkription von Genen des Aminosäurestoffwechsels über Bindung an G-Box-, C-Box- und ACTCAT-Promotorelemente}

In dieser Arbeit konnte gezeigt werden, dass die Überexpression von AtbZIP1 bzw. AtbZIP53 zu einer starken Aktivierung von Aminosäuregenen wie der ProDH und der ASN1 führt. Frühere ChIP Analysen belegten bereits eine direkte Bindung von AtbZIP53 an die Promotoren von ASN1 und ProDH (Weltmeier, 2005; Weltmeier et al., 2006), die zu einer Aktivierung der beiden Gene führt. In dieser Arbeit konnte durch weitere ChIP Analysen nun auch die Bindung von AtbZIP1 an beide Promotoren gezeigt werden. Da weder für AtbZIP53 noch für AtbZIP1 spezifische Antikörper 
existieren, obwohl mehrfach versucht wurde sie herzustellen, wurden die ChIP Analysen mit Pflanzen durchgeführt, die mit einem HA-Tag fusioniertes bZIP Protein überexpremieren. Da dieser HA-Tag einen Einfluss auf die Bindung der bZIP Proteine an die DNA haben kann, müssen die aus diesem Versuch gewonnenen Daten mit Vorsicht betrachtet werden.

Eine mögliche Erklärung für die dunkelinduzierte Aktivierung der Gene des Aminosäuremetabolismus wäre, dass eine Bindung der bZIP Transkriptionsfaktoren erst nach einem Stimulus (z.B. Energiemangel) an den Promotor ihrer Zielgene erfolgt, was dann zu einer Aktivierung der Transkription führen würde. Am Beispiel des ProDH Promotors konnte in dieser Arbeit aber gezeigt werden, dass die Bindung von AtbZIP1 schon während des Tages stattfindet und durch vier Tage anhaltende Dunkelheit nicht weiter beeinflusst wird. Hier wäre es allerdings sinnvoll in der Zukunft auch die kürzeren Zeitpunkte der verlängerten Nacht in die Analyse mit einzubeziehen, da sich gerade in den ersten Stunden starke Veränderungen des Primärmetabolismus zeigen.

Untersuchungen in transient transformierten Mesophyllprotoplasten aus Arabidopsis bestätigen eine Bindung der beiden Transkriptionsfaktoren an Promotorelemente von ASN1 und ProDH. Während eine einzelne G-Box (G1) die dunkelinduzierte Aktivierung des ASN1 Promotors durch die bZIPs vermittelt, finden sich im Promotor der ProDH gleich drei cis-Elemente, die für die dunkelinduzierte ProDH Expression wichtig sind. Dabei handelt es sich um zwei ACTCAT Motive und eine C-Box. Ähnliche cis-Elemente, mit ACGT-Konsensussequenz finden sich in allen in dieser Arbeit untersuchten Genen des Aminosäurestoffwechsels (Anhang Tabelle 8.1).

Dass bZIP Transkriptionsfaktoren wie AtbZIP53 an G-Boxen binden können, wurde sowohl in vitro als auch in vivo gezeigt (Alonso et al., 2009). Baena-Gonzales et al. (2007) und Hanson et al. (2008) bestätigen die Bedeutung der G-Box für die Aktivierung der ASN1. Die Sequenzinformation der sechs Nukleotide allein reicht dabei allerdings nicht für die Aktivierung der ASN1 aus, wie Versuche mit Mutationen der G2-Box zeigten. Auch der Promotorkontext, in dem sich das cis-Element befindet, ist wichtig für die Bindung und Aktivierung durch die Transkriptionsfaktoren. In vitro Analysen konnten belegen, dass an die G-Box angrenzende Sequenzen einen Einfluss auf die Proteinbindung haben können (Williams et al., 1992). 
Die C-Box (GACGTC) aus dem ProDH Promotor ist eng verwandt mit der G-Box (CACGTG) des ASN1 Promotors. Palindromische Sequenzen wie diese beiden Boxen, sind bevorzugte Bindemotive der bZIP Transkriptionsfaktoren (Foster et al., 1994; Izawa et al., 1993). Trotzdem reicht die Mutation der C-Box allein nicht aus, um die dunkelinduzierte Aktivierung der ProDH zu verhindern. Erst durch zusätzliche Mutation von einem oder zwei der ACTCAT Motive, für die bereits eine wichtige Rolle in der Regulation der ProDH unter hypoosmotischen Bedingungen beschrieben wurde (Satoh et al., 2002; Satoh et al., 2004; Weltmeier et al., 2006), kommt es zu einer deutlichen Reduktion der dunkelinduzierten ProDH Expression.

Nicht nur die Regulation durch unterschiedliche cis-Elemente unterscheidet diese beiden Promotoren, sondern auch der Einfluss der Überexpression von AtbZIP1 und AtbZIP53 auf die Expression der beiden Gene ist deutlich unterschiedlich. Während der verlängerten Nacht hat die Überexpression von AtbZIP53 einen stärkeren Einfluss auf die Expression der ProDH, AtbZIP1 Überexpression führt unter diesen Bedingungen zu einer stärkeren Aktivierung der Expression der ASN1. Da die bZIP Transkriptionsfaktoren meist als Dimere an die DNA binden (Landschultz et al, 1988), führt die unterschiedliche Struktur der Promotoren von ASN1 und ProDH mit ihren verschiedenen $c i s$-Elementen möglicherweise zu einer Rekrutierung unterschiedlicher Heterodimere von AtbZIP1 bzw. AtbZIP53 mit Mitgliedern der Gruppe C. Diese Heterodimere können sich in ihrer Bindespezifität und dem Aktivierungspotenzial deutlich unterscheiden und so zu einer entsprechend unterschiedlichen Genexpression führen.

\subsection{Unter Energiemangelbedingungen zeigen bZIP Transkriptions- faktoren des C/S1-Netzwerks eine partielle Redundanz}

In allen Versuchen dieser Arbeit ist deutlich zu erkennen, dass die Überexpression von AtbZIP1 bzw. AtbZIP53 einen großen Einfluss auf verschiedene Stoffwechselwege des Primärmetabolismus hat. Die Einzelmutanten atbzipl und atbzip53 sowie die 
Doppelmutante atbzipl atbzip53 zeigten dagegen im Vergleich zum Wildtyp kaum Unterschiede.

Neben AtbZIP1 und AtbZIP53 wird etwa die Hälfte der 75 bZIPs aus Arabidopsis während der verlängerten Nacht induziert, auch wenn AtbZIP1 die stärkste transkriptionelle Aktivierung unter diesen Bedingungen aufweist. Nicht nur AtbZIP1 und 53 sind damit Kandidaten für die Regulation physiologischer Prozesse in der Anpassung an langanhaltende Dunkelheit, sondern auch z.B. Mitglieder der Gruppe C wie AtbZIP9 und AtbZIP63 (At5g24800 und At5g28770), oder auch Mitglieder der Gruppe G wie AtbZIP41 (At4g36730) und AtbZIP54 (At4g01120). All diese anderen bZIP Transkriptionsfaktoren können möglicherweise redundante Funktionen in der Anpassung des Metabolismus während der verlängerten Nacht übernehmen, so dass eine Mutation von nur ein oder zwei dieser Faktoren, wie in der atbzipl atbzip53 Doppelmutante, möglicherweise von anderen Faktoren ausgeglichen werden kann.

Da die Redundanz von Transkriptionsfaktorfamilien die Analyse ihrer biologischen Funktion häufig erschwert, wurde ein alternativer Ansatz zur Verwendung von einzelnen T-DNA-Insertionslinien entwickelt (Hiratsu et al., 2003). Dabei wird ein Fusionsprotein aus dem zu untersuchenden Transkriptionsfaktor und einer 12 Aminosäuren großen EAR-Repressor-Domäne exprimiert, dass als dominanter Repressor spezifisch an Zielgene bindet und so deren Transkription sogar in Anwesenheit von anderen, redundanten Transkriptionsfaktoren reprimiert, da es die Bindestelle für diese anderen Faktoren blockiert (Hiratsu et al., 2003).

Die Expression von EAR-AtbZIP1 bzw. EAR-AtbZIP53 Fusionsproteinen in Arabidopsis Mesophyll Protoplasten führte, im Gegensatz zu den Expressionsstudien der ProDH in T-DNA-Insertionslinien von AtbZIP1 und AtbZIP53, zu einer starken Reduktion der dunkelinduzierten, bZIP-vermittelten ProDH Expression. Dieses Ergebnis zeigt, dass EAR-AtbZIP1 und EAR-AtbZIP53 tatsächlich an cis-Elemente des ProDH Promotors binden, bei denen es sich wahrscheinlich um die zuvor identifizierten ACTCAT Motive und die C-Box handelt, und diese für andere redundante Faktoren blockieren.

Leider funktioniert dieser EAR-Domänen Ansatz nicht für jede beliebige Kombination aus Transkriptionsfaktor und Zielgen. Die Expression der ASN1 wird z.B. durch EAR- 
AtbZIP1 und EAR-AtbZIP53 stärker aktiviert als durch die entsprechenden unfusionierten Proteine. Dieses Ergebnis zeigt ein weiteres Mal die unterschiedliche Regulation von ProDH und ASN1. Erst kürzlich konnte gezeigt werden, dass die Repression der Transkription der Zielgene durch eine Interaktion der EAR-RepressorDomäne mit einer Histon Deacetylase vermittelt wird (Szemenyei et al., 2008). Durch die Deacetylierung der Histone wird ihre Bindung an die DNA ermöglicht und diese dadurch für Transkriptionsfaktoren blockiert. Möglicherweise ist diese Rekrutierung der Histon Deacetylase oder auch ein Bindung der Histone an den ASN1 Promotor aufgrund seiner Struktur nicht möglich.

Gute Kandidaten für redundante bZIP Transkriptionsfaktoren sind die vier Mitglieder der Gruppe C. Neben der Genevestigator Analyse (Hruz et al., 2008) zeigen auch Northern Analysen (Weltmeier, 2005), dass zumindest AtbZIP9, AtbZIP63 und AtbZIP25 durch Dunkelheit aktiviert werden. Außerdem ist bekannt, dass sie mit AtbZIP1 und AtbZIP53 heterodimerisieren können (Ehlert et al., 2006; Kang et al., 2010), was zu einer Verstärkung der Aktivierung ihrer Zielgene führen kann (Weltmeier et al., 2006; Ehlert et al., 2006; Alonso et al., 2009). Ein ähnlicher Mechanismus ist auch während der dunkelinduzierten Expression von Genen wie der ProDH oder der ASN1 denkbar.

Tatsächlich zeigen zwei verschiedene Vierfachmutanten (atbzipl atbzip53 atbzip9 atbzip63 und atbzipl atbzip53 atbzip10 atbzip25) eine deutlich reduzierte dunkelinduzierte ProDH, ASN1 und BCAT2 Expression, obwohl es sich bei atbzip53 und atbzip63 durch eine Insertion der T-DNA im Promotorbereich nicht um vollständige Null-Mutanten handelt. Dieser Effekt ist besonders stark zu den frühen Zeitpunkten der Dunkelinduktion, in denen die Expression dieser Gene im Wildtyp deutlich ansteigt. Zu späteren Zeitpunkten steigt auch in den beiden Vierfachmutanten die Expression der drei Gene an, auch wenn sie immer noch deutlich unter der Expressionsstärke des Wildtyps liegt. Selbst in den Vierfachmutanten findet also während der verlängerten Nacht eine Aktivierung der drei Gene durch andere Faktoren statt, die die Funktion der vier mutierten bZIPs übernehmen können. Deshalb wurde getestet, ob die Expression der unmutierten bZIP Transkriptionsfaktoren in den Vierfachmutanten verstärkt wird. Eine transkriptionelle Aktivierung konnte aber 
zumindest für die anderen Mitglieder der Gruppe S1 und C nicht nachgewiesen werden (C. Carsjens, persönliche Mitteilung). Diese Analyse wurde allerdings nicht unter Energiemangelbedingungen durchgeführt. Interessant wäre ein entsprechendes Experiment während der Dunkelinduktion.

Ein Versuch, eine Fünffach- oder Sechsfachmutante von AtbZIP1 und AtbZIP53 mit allen potentiellen Heterodimerisierungspartnern der Gruppe $\mathrm{C}$ herzustellen, scheiterte. Zwar konnte eine heterozygote Fünffachmutante durch kreuzen gefunden werden (atbzip1 atbzip53 atbzip9 atbzip63 homozygot und atbzip10 heterozygot), diese zeigte aber bereits einen starken Zwergwuchs. Obwohl viele Nachkommen dieser Pflanze in der nächsten Generation getestet wurden, konnte bisher keine homozygote Fünffachmutante gefunden werden. Dies legt die Vermutung nah, dass diese homozygote Mutation der fünf bZIP Faktoren letal ist, was die wichtige Funktion des bZIP-Netzwerks in der Regulation des Primärmetabolismus aufzeigt.

Die Regulation der Zielgene durch ein ganzes Netzwerk aus redundanten, heterodimerisierenden Transkriptionsfaktoren ist deutlicher komplexer als die Regulation durch einen einzelnen Transkriptionsfaktor. Trotz allem kann gerade durch diese Komplexität eine sehr genaue Feinabstimmung der Expression der Zielgene erfolgen, in dem die Verfügbarkeit und Aktivität jedes einzelnen Dimerisierungspartners in den unterschiedlichen Phasen der dunkelinduzierten Seneszenz reguliert wird. Auch in Bezug auf Mutationen einzelner Faktoren ist dieses Regulationsnetzwerk deutlich stabiler als ein einzelner Transkriptionsfaktor es sein könnte.

Genetische Redundanz kommt vor allem bei homologen Genen vor, die durch Genduplikation entstanden sind (Picket und Meeks-Wagner, 1995). Die Genduplikation ist ein wichtiger Bestandteil der evolutionären Entwicklung. Phylogenetische Studien zeigen, dass die Familie der 75 bZIP Transkriptionsfaktoren in Arabidopsis auf wenige Vorläufer zurückzuführen ist (Correa et al., 2008). Die große Gruppe S entwickelte sich erst spät im Laufe der pflanzlichen Evolution und ist wahrscheinlich durch Genduplikation aus der ursprünglichen Gruppe $C$ hervorgegangen. Dies weist auf eine enge Verwandtschaft der Gruppen $\mathrm{C}$ und $\mathrm{S}$ hin und ist eine Erklärung für ihre 
gemeinsame Funktionen in der Kontrolle des Energiestoffwechsels (Correa et al., 2008). Gerade spät entstandenen Gene, wie die der Gruppe S, unterliegen einem geringeren Selektionsdruck und können so langsam unterschiedliche Funktionen übernehmen (Lynch und Katju, 2004). Je nach Entwicklungsstand haben sie dabei aber immer noch teilweise überlappende Funktionen. Dies lässt sich gut am Beispiel der beiden eng verwandten Proteine AtbZIP1 und AtbZIP53 zeigen. Obwohl sowohl für AtbZIP1 als auch für AtbZIP53 in dieser Arbeit eine Beteiligung an der Regulation des Primärmetabolismus gezeigt wurde, gibt es doch auch deutliche Unterschiede in der Funktion der beiden Transkriptionsfaktoren. Dies spiegelt sich z.B. in der Regulation der ProDH und der ASNI wieder. Ein anderes Beispiel für die überlappende aber auch unterschiedliche Funktion von AtbZIP1 und AtbZIP53 zeigt sich in der Samenentwicklung (Alonso et al., 2009; Weltmeier et al., 2009). Die Expression von Samenspeicherproteingenen wie dem ALBUMIN (2S2) wird durch Heterodimere von AtbZIP53 mit Mitgliedern der Gruppe C wie z.B. AtbZIP10 und AtbZIP25 reguliert. Obwohl auch AtbZIPl während der Samenentwicklung expremiert wird und in Protoplasten wie AtbZIP53 die Transkription von 2S2 aktivieren kann, zeigen Pro35S:AtbZIP1 Pflanzen keine gesteigerte 2S2 Expression (Weltmeier et al., 2009).

\subsection{Die SnRK1 Kinasen KIN10 und KIN11 aktivieren unter Energiemangel das C/S1-bZIP Transkriptionsfaktor-Netzwerk wahrscheinlich über eine Phosphorylierung von AtbZIP63}

Schon geringe Änderungen der Proteinmenge von AtbZIP53 führen zu einer Änderung der Genexpression unabhängig vom Energiestatus der Pflanze. AtbZIP1 benötigt dagegen ein weiteres posttranslationales Signal, um aktivieren zu können. Die Überexpression allein führt noch nicht zu einer Steigerung der Genexpression von Zielgenen wie ProDH und ASN1 im Licht. Erst unter Energiemangelbedingungen kommt es in Pro35S:AtbZIP1 Pflanzen ebenfalls zu einer Steigerung der Aktivität dieser Gene. Da auch Transkription und Translation von AtbZIP1 stärker als von AtbZIP53 unter diesen Bedingungen aktiviert werden spricht dies dafür, dass 
hauptsächlich AtbZIP1 nach einer posttranslationalen Aktivierung die Genexpression unter Energiemangel reguliert.

Die beiden SnRK1 Kinasen KIN10 und KIN11 aus Arabidopsis wurden als zentrale Regulatoren eines Netzwerks aus bZIP Transkriptionsfaktoren beschrieben, die die Genexpression unter Energiemangelbedingungen regulieren (Baena-Gonzalez et al., 2007; Baena-Gonzalez und Sheen, 2008). Für weitere Studien der Funktion dieser Kinasen sind Versuche mit transgenen Überexpremierern bzw. Mutanten unerlässlich. Eine Überexpression von KIN10 bzw. KIN11 wurde in dieser Arbeit transient im Protoplastensystem durchgeführt, auch wenn dies transgene Überexpressionspflanzen auf Dauer nicht ersetzen kann. Ein „loss-of-function“-Ansatz ist mit dem Protoplastensystem allerdings nicht möglich. Da durch „virus-induced gene silencing“ (VIGS; Burch-Smith et al., 2006) erzeugte kin10 kin11 Mutanten starke Wuchsdefekte und einen Eintritt in die Seneszenz noch vor der Blütenbildung zeigen (Baena-Gonzalez et al., 2007), arbeiten wir zurzeit an der Herstellung von Pflanzen mit induzierbarer amiRNA, über welche ein Gene-Silencing von KIN10 und KIN11 erst nach Estradiolinduktion erfolgt.

Ein Sequenzvergleich von AtbZIP1 mit dem in Huang und Huber (2001) beschriebenen SnRK-Phosphorylierungsmotiv führte zu einem Serin am C-terminalen Ende von AtbZIP1 bei dem es sich möglicherweise um eine Phosphorylierungsstelle handeln könnte. Ein ähnliches Motiv wurde auch am C-terminalen Ende von AtbZIP53 gefunden.

Aminosäureaustausch-Mutanten von AtbZIP1 und AtbZIP53, mit einem Alanin oder Aspartat statt des zentralen Serins des Motivs, wurden hergestellt (Lendner, 2009). Alanin verhindert eine Phosphorylierung an dieser Stelle und soll somit den nicht phosphorylierten Zustand simulieren. Aspartat ähnelt in seiner räumlichen Struktur und Ladung dagegen dem phosphorylierten Serin (Furihata et al., 2006). Die Expression dieser Mutanten von AtbZIP1 und AtbZIP53 in transient transformierten Mesophyllprotoplasten ergab allerdings keine Unterschiede zur Transformation mit den unmutierten bZIPs. Zumindest diese Motive werden also nicht direkt durch die beiden Kinasen KIN10 und KIN11 phosphoryliert und spielen damit keine Rolle in der posttranslationalen Modifikation der bZIP Faktoren. Dies schließt allerdings nicht aus, dass andere Motive in der Aminosäureabfolge von AtbZIP1 und/oder AtbZIP53 
existieren, die phosphoryliert werden. So beschreiben Halford et al. (2003) z.B. ein SnRK1-Phosphorylierungsmotiv (Hy-X-Ba-X-X-S-X-X-X-Hy), das dem in Huang und Huber (2001) zwar sehr ähnelt, aber an dessen Position -4 vom Serin aus nicht notwendigerweise ein Prolin steht, wie es Huang und Huber (2001) beschreiben. Sucht man dieses Motiv in der Aminosäuresequenz von AtbZIP1 findet man z.B. das Serin S9, das damit auch eine mögliche Phosphorylierungsstelle durch die Kinasen ist. Hier wäre eine Analyse der in vivo Phosphorylierungsstellen von AtbZIP1 und AtbZIP53 aufschlussreich. Diese würden die Zahl der möglichen phosphorylierten Serine einschränken und so eine weitere Untersuchung erleichtern.

Eine solche Analyse wurde bereits für AtbZIP63 durchgeführt (A. Mair, M. Teige, unveröffentlicht). Die Interaktion mit KIN10 und KIN11 aber auch mit anderen Kinasen wie z.B. einer CDPK (Calcium dependent kinase) konnte mit Hilfe einer CoImmunopräzipitation eines GFP-fusionierten AtbZIP63 Proteins gezeigt werden. In einer massenspektrometrischen Analyse von AtbZIP63 Phosphopeptiden konnten die vier phosphorylierten Serine S29, S59, S261 und S300 identifiziert werden. Alle vier Serine sind dabei von Aminosäuresequenzen umgeben, die Übereinstimmungen mit Phosphorylierungsmotiven aus der Literatur aufweisen (Huang und Huber, 2001; Halford et al., 2003). Besonders das Motiv um Serin 300 erfüllt optimal eines der in Huang und Huber (2001) beschriebenen Phosphorylierungsmotive.

Aminosäureaustausch-Mutanten der vier Serine von AtbZIP63 wurden in Zusammenarbeit mit C. Chaban (Universität Tübingen) und J. Lendner (Lendner, 2009) hergestellt und in Protoplasten analysiert. Eine Mutation der entsprechenden Serine von AtbZIP63 führte in diesem Versuch tatsächlich zu einer signifikanten Reduktion der dunkelinduzierten ProDH Aktivität im Vergleich mit dem unmutierten AtbZIP63. Dieses Ergebnis deutet darauf hin, dass KIN10 und KIN11 nicht direkt AtbZIP1 und AtbZIP53, sondern ihren Heterodimerisierungspartner AtbZIP63 phosphorylieren. Die Heterodimerisierung von AtbZIP1 und AtbZIP53 mit den Mitgliedern der Gruppe C (Ehlert et al., 2006; Kang et al., 2010), sowie die Bedeutung dieser redundanten S1 und C bZIP Faktoren für die Regulation der Aminosäuregene unter Energiemangelbedingungen, konnte bereits gezeigt werden. Die Rolle von AtbZIP63 in der Anpassung des pflanzlichen Metabolismus an Energiemangelbedingungen wurde dagegen bisher kaum untersucht. Zwar wird die Transkription von AtbZIP63 während 
der Dunkelheit ebenfalls induziert (Weltmeier, 2005), die Protoplastenanalysen in dieser Arbeit zeigten allerdings keine nennenswerte Aktivierung von ASN1 und ProDH durch alleinige Überexpression dieses Transkriptionsfaktors. Hier wären möglicherweise Protoplastenanalysen aufschlussreich, in denen unterschiedliche Kombinationen von Heterodimeren wie z.B. AtbZIP1 und AtbZIP63 oder AtbZIP53 und AtbZIP63 auf ihre Fähigkeit, die Expression von ProDH und ASN1 zu aktivieren, analysiert werden würden. Auch Untersuchungen von Pro35S:AtbZIP63 Pflanzen und atbzip63 Mutanten auf die Expression von ProDH, ASN1 und BCAT2 wären hier hilfreich. Falls die dunkelinduzierte Aktivierung von z.B. ProDH und ASN1 tatsächlich von der Phosphorylierung von AtbZIP63 durch die Kinasen KIN10 und KIN11 abhängt, sollte in einer entsprechenden Null-Mutante von AtbZIP63 diese dunkelinduzierte Expression unterbunden werden. Tatsächlich zeigte die Vierfachmutante in der die Transkription von AtbZIP63 durch eine Insertion im Promotor beeinträchtigt ist eine deutliche Reduktion der Expression von ProDH und ASN1. Allerdings ist die Transkriptmenge von AtbZIP63 in dieser Mutante nur etwa auf die Hälfte reduziert. Ein vollständigen Knock-Out von AtbZIP63 existiert nun ebenfalls (Vincente-Carbajosa, unveröffentlicht) und kann in zukünftige Analysen mit einbezogen werden.

Interessant wäre auch, ob die in vivo Phosphorylierung von AtbZIP63 erst durch Energiemangelbedingungen stimuliert wird und ob weitere bZIP Transkriptionsfaktoren existieren, die durch die beiden Kinasen phosphoryliert werden. Ein generellerer Ansatz um mögliche weitere Phosphorylierungsziele der Kinase KIN10 zu finden ist deshalb in Kooperation mit W. Weckwerth (Universität Wien) in Planung.

\subsection{Modell: SnRK1 Kinasen und bZIP Faktoren des C/S1 Netzwerks vermitteln eine Reprogrammierung des pflanzlichen Metabolismus unter Energiemangelbedingungen}

Die bisher beschriebenen Daten in der Literatur so wie die Ergebnisse dieser Arbeit führen zu folgendem Modell der Regulation des pflanzlichen Primärmetabolismus unter Energiemangelbedingungen: Transkription und Translation insbesondere von AtbZIP1, aber auch von AtbZIP53, werden durch Zucker reprimiert. Dunkelheit und andere 
Stressbedingungen, die einen Energiemangel verursachen, führen dagegen zur Aktivierung der Transkription und Translation. Auch die Transkription einiger Gruppe C bZIP Faktoren wird unter diesen Bedingungen aktiviert. AtbZIP1 und AtbZIP53 dimerisieren mit Mitgliedern der Gruppe $\mathrm{C}$ und binden als Heterodimere an ACGT- und ACTCAT-Elemente in den Promotoren ihrer Zielgene. Die Aktivität des Gruppe C Faktors AtbZIP63 wird möglicherweise über eine Phosphorylierung durch die SnRK1 Kinase KIN10 beeinflusst, die ebenfalls durch Energiemangel aktiviert wird. Zu den Zielgenen von AtbZIP1 und AtbZIP53 gehören Gene des Aminosäure- und Lipidstoffwechsels. Der Kohlenhydratmetabolismus wird dagegen dereguliert. Unter Energiemangel kommt es so zu einer Anpassung des Primärmetabolismus, um die Grundbedürfnisse an Energie zu decken und der Pflanze ein Überleben zu sichern.

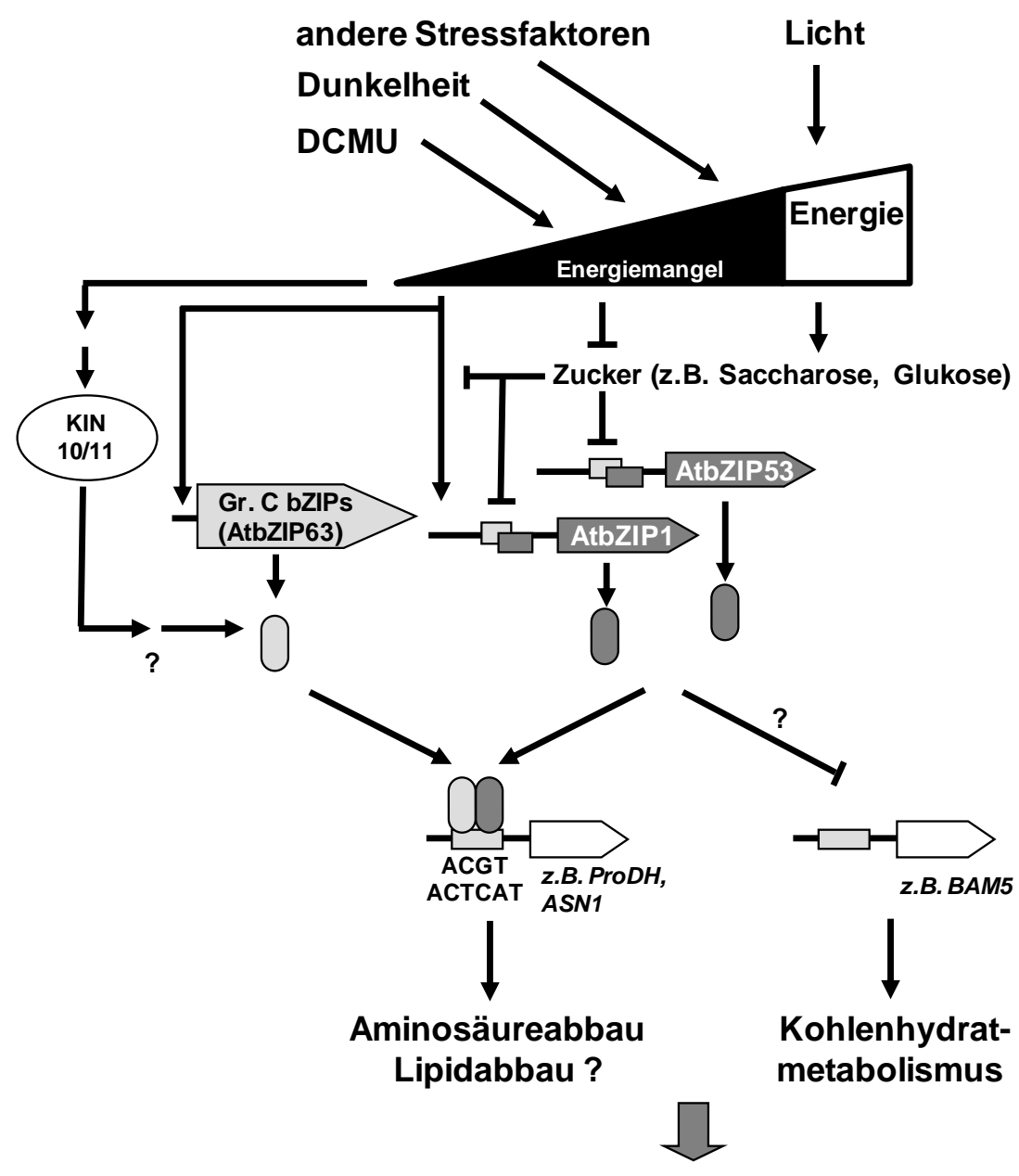

Reprogrammierung des Primärmetabolismus

Abb. 6.3: Modell zur Anpassung des pflanzlichen Metabolismus an Energiemangelbedingungen durch das Netzwerk aus Gruppe C/S1-bZIPs und den Kinasen KIN10 und KIN11 


\section{$7 \quad$ Literaturverzeichnis}

Ahmad I. and Hellebust J.A. (1988): The relationship between inorganic nitrogen metabolism and proline accumulation in osmoregulatory responses of two euryhaline microalgae. Plant Physiology, 88, 348-354.

Alonso R., Oñate-Sánchez L., Weltmeier F., Ehlert A., Diaz I., Dietrich K., Vicente-Carbajosa J. and Dröge-Laser W. (2009): A pivotal role of the basic leucine zipper transcription factor AtbZIP53 in the regulation of seed maturation gene expression based on heterodimerisation and protein complex formation. The Plant Cell, $6,1747-61$.

Alwine J.C., Kemp D.J. and Stark G.R. (1977): Method for detection of specific RNAs in agarose gels by transfer to diazobenzyloxymethyl-paper and hybridization with DNA probes. PNAS, 74, 5350-5354.

Amodeo G.A., Rudolph M.J. and Tong L. (2007): Crystal structure of the heterotrimer core of Saccharomyces cerevisiae AMPK homologue SNF1. Nature, 449.

Baena-Gonzalez E. and Sheen J. (2008): Convergent energy and stress signaling. Trends in Plant Science, 13, 474-482.

Baena-Gonzalez E., Rolland F., Thevelein J.M. and Sheen J. (2007): A central integrator of transcription networks in plant stress and energy signalling. Nature, 448, 938-42.

Baxevanis A. D. and Vinson C. R. (1993): Interactions of coiled coils in transcription factors: where is the specificity? Curr Opin Genet Dev, 3, 278-85.

Bent A.F. (2000): Arabidopsis in planta transformation. Uses, mechanisms, and prospects for transformation of other species. Plant Physiol, 124, 1540-7.

Bernard P., Kezdy K.E., Van Melderen L., Steyaert J., Wyns L., Pato M.L., Higgins P.N. and Couturier M. (1993): The F plasmid CcdB protein induces efficient ATP-dependent DNA cleavage by gyrase. J Mol Biol, 234, 534-41.

Binder S., Knill T. and Schuster J. (2007): Branched-chain amino acid metabolism in higher plants. Physiologia Plantarum, 129, 68-78.

Blasing O.E., Gibon Y., Gunther M., Hohne M., Morcuende R., Osuna D., Thimm O., Usadel B., Scheible W.R. and Stitt M. (2005): Sugars and circadian regulation make major contributions to the global regulation of diurnal gene expression in Arabidopsis. The Plant Cell, 17, 3257-3281. 
Blum A. and Ebercon A. (1976): Genotypic Responses in Sorghum to Drought Stress. III. Free Proline Accumulation and Drought Resistance. Crop Science, 16, 428-431.

Bolton E.T. and McCarthy B.J. (1962): A general method for isolation of RNA complementary to DNA. PNAS, 48, 1390-1397.

Boudsocq M. and Sheen J. (2008): Calcium sensing and signaling. In: Abiotic Stress Adaptation in Plants: Physiological, Molecular and Genomic Foundation (A. Pareek, S.K. Sopory, H.J. Bohnert, Govindjee, eds.), Springer, Dordrecht, The Netherlands. In press.

Bouly J.P., Gissot L., Lessard P., Kreis M. and Thomas M. (1999): Arabidopsis thaliana proteins related to the yeast SIP and SNF4 interact with AKINalpha1, an SNF1-like protein kinase. The Plant Journal, 18, 541-50.

Bruneau L., Chapman R. and Marsolais F. (2006): Co-occurrence of both Lasparaginase subtypes in Arabidopsis: At3g16150 encodes a K+-dependent Lasparaginase. Planta, 224, 668-679.

Buchanan-Wollaston V. and Ainsworth C. (1997): Leaf senescence in Brassica napus: cloning of senescence related genes by subtractive hybridisation. Plant Mol Biol, $33,821-34$.

Buchanan-Wollaston V., Earl S., Harrison E., Mathas E., Navabpour S., Page T. and Pink D. (2003): The molecular analysis of leaf senescence - a genomics approach. Plant Biotechnol Journal, 1 (1), 3-22.

Buchanan-Wollaston V., Page T., Harrison E., Breeze E., Lim P.O., Nam H.G., Lin J.F., Wu S.H., Swidzinski J., Ishizaki K. and Leaver C.J. (2005): Comparative transcriptome analysis reveals significant differences in gene expression and signalling pathways between developmental and dark/starvation-induced senescence in Arabidopsis. The Plant Journal, 42, 567-585.

Burch-Smith T. M., Schiff M., Liu Y. and Dinesh-Kumar S. P. (2006): Efficient virus induced gene silencing in Arabidopsis thaliana. Plant Physiology, 142, 21-27.

Carlson M., Osmond B.C. and Botstein D. (1981): Mutants of yeast defective in sucrose utilization. Genetics, 98 (1), 25-40.

Caspar T., Huber S.C. and Somerville C. (1985): Alterations in Growth, Photosynthesis, and Respiration in a Starchless Mutant of Arabidopsis thaliana (L.) Deficient in Chloroplast Phosphoglucomutase Activity. Plant Physiol., 79 (1), 11-17.

Celenza J.L. and Carlson M. (1989): Mutational analysis of the Saccharomyces cerevisiae SNF1 protein kinase and evidence for functional interaction with the SNF4 protein. Mol Cell Biol., 9 (11), 5034-44. 
Chae M.J., Lee J.S., Nam M.H., Cho K., Hong J.Y., Yi S.A., Suh S.C. and Yoon I.S. (2007): A rice dehydration-inducible SNF1-related protein kinase 2 phosphorylates an abscisic acid responsive element-binding factor and associates with ABA signaling. Plant Mol Biol., 63 (2), 151-69.

Chen J.G., Willard F.S., Huang J., Liang J., Chasse S.A., Jones A.M. and Siderovski D.P. (2003): A seven-transmembrane RGS protein that modulates plant cell proliferation. Science, 301, 1728-1731.

Chen J.G. and Jones A.M. (2004): AtRGS1 function in Arabidopsis thaliana. Methods Enzymol., 389, 338-50.

Chiou T.J. and Bush D.R. (1998): Sucrose is a signal molecule in assimilate partitioning. PNAS, 95, 4784-4788.

Choi H., Hong J., Ha J., Kang J. and Kim S. Y. (2000): ABFs, a family of ABA responsive element binding factors. J Biol Chem, 275, 1723-30.

Chomczynski P. (1993): A reagent for the single-step simultaneous isolation of RNA, DNA and proteins from cell and tissue samples. Biotechniques, 15, 532-4, 536-7.

Chomczynski P. and Sacchi N. (1987): Single-step method of RNA isolation by acid guanidinium thiocyanate-phenol-chloroform extraction. Anal Biochem, 162, 156-9.

Church G.M. and Gilbert W. (1984): Genomic sequencing. PNAS, 81, 1991-5.

Ciceri P., Gianazza E., Lazzari B., Lippoli G., Genga A., Hoscheck G., Schmidt R.J., and Viotti A. (1997): Phosphorylation of Opaque2 changes diurnally and impacts its DNA binding activity. The Plant Cell, 9, 97-108.

Ciereszko I., Johansson H. and Kleczkowski L.A. (2001): Sucrose and light regulation of a cold-inducible UDP-glucose pyrophosphorylase gene via a hexokinaseindependent and abscisic acid-insensitive pathway in Arabidopsis. Biochem. J., 354, 67 72.

Clark J.M. (1988): Novel non-templated nucleotide addition reactions catalyzed by procaryotic and eucaryotic DNA polymerases. Nucleic Acids Res, 16, 9677-86.

Clough S.J. and Bent A.F. (1998): Floral dip: a simplified method for Agrobacterium mediated transformation of Arabidopsis thaliana. Plant J, 16, 735-43.

Cohen S.N., Chang A.C., Boyer H.W. and Helling R.B. (1973): Construction of biologically functional bacterial plasmids in vitro. Biotechnology, 24, 188-92.

Corrêa L.G., Riaño-Pachón D.M., Schrago C.G., dos Santos R.V., Mueller-Roeber B. and Vincentz M. (2008): The role of bZIP transcription factors in green plant evolution: adaptive features emerging from four founder genes. PLoS One, 3 (8), e2944. 
Cortès S., Gromova M., Evrard A., Roby C., Heyraud A., Rolin D.B., Raymond P. and Brouquisse R.M. (2003): In plants, 3-o-methylglucose is phosphorylated by hexokinase but not perceived as a sugar. Plant Physiology, 131 (2), 824-37.

Creelman R.A. and Mullet J.E. (1997): Biosynthesis and action of jasmonates in plants. Annu Rev Plant Physiol Plant Mol Biol., 48, 355-381.

De Pater S., Katagiri F., Kijne J. and Chua N.H. (1994): bZIP proteins bind to a palindromic sequence without an ACGT core located in a seed-specific element of the pea lectin promoter. The Plant Journal, 6, 133-40.

De Risi J.L., Iyer V.R. and Brown P.O. (1997): Exploring the metabolic and genetic control of gene expression on a genomic scale. Science, 278 (5338), 680-6.

Diebold R., Schuster J., Daschner K. and Binder S. (2002): The branched-chain amino acid transaminase gene family in Arabidopsis encodes plastid and mitochondrial proteins. Plant Physiology, 129, 540-550.

Dietrich K. (2006): Die Funktion der Transkriptionsfaktoren AtbZIP1 und AtbZIP53 aus Arabidopsis thaliana unter biotischen und abiotischen Stressbedingungen. Diplomarbeit.

Dijkwel P.P., Huijser C., Weisbeek P.J., Chua N.H., and Smeekens S. (1997): Sucrose control of phytochrome A signaling in Arabidopsis. The Plant Cell, 9, 583-595.

Ehlert A. (2004): Analyse der Dimerisierungs- und Aktivierungseigenschaften von Gruppe C und S bZIP- Transkriptionsfaktoren aus Arabidopsis thaliana. Diplomarbeit.

Ehlert A., Weltmeier F., Wang X., Mayer C.S., Smeekens S., Vicente-Carbajosa J. and Dröge-Laser W. (2006): Two-hybrid protein-protein interaction analysis in Arabidopsis protoplasts: establishment of a heterodimerization map of group $\mathrm{C}$ and group S bZIP transcription factors. The Plant Journal, 46, 890-900.

Ehness R., Ecker M., Godt D.E. and Roitsch T. (1997): Glucose and Stress Independently Regulate Source and Sink Metabolism and Defense Mechanisms via Signal Transduction Pathways Involving Protein Phosphorylation. The Plant Cell, 9, 1825-1841.

Feinberg A.P. and Vogelstein B. (1983): A technique for radiolabeling DNA restriction endonuclease fragments to high specific activity. Anal Biochem, 132, 6-13.

Feinberg A.P. and Vogelstein B. (1984): A technique for radiolabeling DNA restriction endonuclease fragments to high specific activity. Addendum Anal Biochem, 137, 266-7.

Feussner I. and Wasternack C. (1998): Lipoxygenase catalyzed oxygenation of lipids. Fett/Lipid, 100, 146-152. 
Feussner I. and Wasternack C. (2002): The lipoxygenase pathway. Annu. Rev. Plant Biol., 53, 275-297.

Fondy B.R. and Geiger D.R. (1985): Diurnal changes of allocation of newly fixed carbon in exporting sugar beet leaves. Plant Physiology, 78, 753-757.

Fordham-Skelton A.P., Chilley P., Lumbreras V., Reignoux S., Fenton T.R., Dahm C.C., Pages M. and Gatehouse J.A. (2002): A novel higher plant protein tyrosine phosphatase interacts with SNF1-related protein kinases via a KIS (kinase interaction sequence) domain. The Plant Journal, 29 (6), 705-15.

Foster R., Izawa T. and Chua N. H. (1994): Plant bZIP proteins gather at ACGT elements. Faseb J, 8, 192-200.

Fujiki Y., Ito M., Nishida I. and Watanabe A. (2001): Leucine and its keto acid enhance the coordinated expression of genes for branched-chain amino acid catabolism in Arabidopsis under sugar starvation. FEBS Lett, 499 (1-2), 161-5.

Fujiki Y., Yoshikawa Y., Sato T., Inada N., Ito M., Nishida I. and Watanabe A. (2001): Dark-inducible genes from Arabidopsis thaliana are associated with leaf senescence and repressed by sugars. Physiol Plant, 111, 345-352.

Fukazawa J., Sakai T., Ishida S., Yamaguchi I., Kamiya Y. and Takahashi Y. (2000): Repression of shoot growth, a bZIP transcriptional activator, regulates cell elongation by controlling the level of gibberellins. The Plant Cell, 12, 901-15.

Fulton D.C., Stettler M., Mettler T., Vaughan C.K., Li J., Francisco P., Gil M., Reinhold H., Eicke S., Messerli G., Dorken G., Halliday K., Smith A.M., Smith S.M. and Zeeman S.C. (2008): Beta-AMYLASE4, a noncatalytic protein required for starch breakdown, acts upstream of three active beta-amylases in Arabidopsis chloroplasts. The Plant Cell, 20 (4), 1040-58.

Furihata T., Maruyama K., Fujita Y., Umezawa T., Yoshida R., Shinozaki K. and Yamaguchi-Shinozaki K. (2006): Abscisic acid-dependent multisite phosphorylation regulates the activity of a transcription activator AREB1. PNAS, 103, 1988-93.

Furuichi T., Mori I.C., Takahashi K. and Muto S. (2001): Sugar-induced increase in cytosolic $\mathrm{Ca}^{2+}$ in Arabidopsis thaliana whole plants. Plant Cell Physiology, 42, 11491155.

Gan S. (2003): Mitotic and postmitotic senescence in plants. Sci Aging Knowledge Environ., 38, RE7.

Gateway ${ }^{\circledR}$ Technology - The Gateway Manual

Geigenberger P. (2003): Regulation of sucrose to starch conversion in growing potato tubers. J Exp Bot., 54 (382), 457-65. 
Geiger D.R. and Servaites J.C. (1994): Diurnal regulation of photosynthetic carbon metabolism in C3 plants. Annu Rev Plant Biol, 45, 235-256.

Gibon Y., Blaesing O.E., Hannemann J., Carillo P., Höhne M., Hendriks J.H., Palacios N., Cross J., Selbig J. and Stitt M. (2004): A Robot-based platform to measure multiple enzyme activities in Arabidopsis using a set of cycling assays: comparison of changes of enzyme activities and transcript levels during diurnal cycles and in prolonged darkness. The Plant Cell, 16 (12), 3304-25.

Gibon Y., Bläsing O.E., Palacios-Rojas N., Pankovic D., Hendriks J.H., Fisahn J., Höhne M., Günther M. and Stitt M. (2004): Adjustment of diurnal starch turnover to short days: depletion of sugar during the night leads to a temporary inhibition of carbohydrate utilization, accumulation of sugars and post-translational activation of ADP-glucose pyrophosphorylase in the following light period. The Plant J., 39 (6), 847 62.

Gibson U.E., Heid C.A. and Williams P.M. (1996): A novel method for real time quantitative RT-PCR. Genome Res., 6 (10), 995-1001.

Gissot L., Polge C., Bouly J.P., Lemaitre T., Kreis M. and Thomas M. (2004): AKINbeta3, a plant specific SnRK1 protein, is lacking domains present in yeast and mammals non-catalytic beta-subunits. Plant Molecular Biology, 56, 747-59.

Gonzali S., Loreti E., Solfanelli C., Novi G., Alpi A. and Perata P. (2006): Identification of sugar-modulated genes and evidence for in vivo sugar sensing in Arabidopsis. J. Plant Res., 119, 115-123.

Goodacre R., Vaidyanathan S., Dunn W.B., Harrigan G.G. and Kell D.B. (2004): Metabolomics by numbers: acquiring and understanding global metabolite data. TRENDS in Biotechnology, 22, 5.

Gutierrez R.A., Stokes T.L., Thum K., Xu X., Obertello M., Katari M.S., Tanurdzic M., Dean A., Nero D.C., McClung C.R. and Coruzzi G.M. (2008): Systems approach identifies an organic nitrogen-responsive gene network that is regulated by the master clock control gene CCA1. PNAS, 105, 4939-4944.

Gutierrez R.A., Stokes T.L., Thum K., Xu X., Obertello M., Katari M.S., Tanurdzic M., Dean A., Nero D.C., McClung C.R. and Coruzzi G.M. (2008): Systems approach identifies an organic nitrogen-responsive gene network that is regulated by the master clock control gene CCA1. PNAS, 105, 4939-4944.

Halford N.G. and Hey S.J. (2009): Snf1-related protein kinases (SnRKs) act within an intricate network that links metabolic and stress signalling in plants. Biochem. J., 419, 247-259.

Halford N.G., Hey S., Jhurreea D., Laurie S., McKibbin R.S., Paul M. and Zhang Y. (2003): Metabolic signalling and carbon partitioning: role of Snf1-related (SnRK1) protein kinase. J Exp Bot., 54 (382), 467-75. 
Halket J.M., Waterman D., Przyborowska A.M., Patel R.K.P., Fraser P.D. and Bramley P.M. (2005): Chemical derivatization and mass spectral libraries in metabolic profiling by GC/MS and LC/MS/MS. Journal of Experimental Botany, 56, 410, Metabolome Special Issue, 219-243.

Hanahan D. (1983): Studies on transformation of Escherichia coli with plasmids. $J$ Mol Biol, 166, 557-80.

Hanson J., Hanssen M., Wiese A., Hendriks M.M. and Smeekens S. (2008): The sucrose regulated transcription factor bZIP11 affects amino acid metabolism by regulating the expression of ASPARAGINE SYNTHETASE1 and PROLINE DEHYDROGENASE2. The Plant J., 53 (6), 935-49.

Hardie D.G., Carling D. and Carlson M. (1998): The AMP-activated/SNF1 protein kinase subfamily: metabolic sensors of the eukaryotic cell? Annu Rev Biochem., 67, 821-55.

Hartmann L. (2009): Bedeutung des Arabidopsis C-/S1-bZIP TranskriptionsfaktorNetzwerks im Rahmen der pflanzlichen Antwort auf Salzstress. Diplomarbeit.

He Y., Fukushige H., Hildebrand D. F. and Gan S. (2002): Evidence Supporting a Role of Jasmonic Acid in Arabidopsis Leaf Senescence. Plant Physiol, 128, 876-84.

Hecht A., Strahl-Bolsinger S. and Grunstein M. (1996): Spreading of transcriptional repressor SIR3 from telomeric heterochromatin. Nature, 383, 92-6.

Heinekamp T., Kuhlmann M., Lenk A., Strathmann A. and Droge-Laser W. (2002): The tobacco bZIP transcription factor BZI-1 binds to G-box elements in the promoters of phenylpropanoid pathway genes in vitro, but it is not involved in their regulation in vivo. Mol Genet Genomics, 267, 16-26.

Hellmann H., Funck D., Rentsch D. and Frommer W.B. (2000): Hypersensitivity of an Arabidopsis sugar signaling mutant toward exogenous proline application. Plant Physiology, 122, 357-368.

Herrera-Estrella L., Depicker A., Van Montagu M. and Schell J. (1992): Expression of chimaeric genes transferred into plant cells using a Ti-plasmid-derived vector. Biotechnology, 24, 377-81.

Hey S., Mayerhofer H., Halford N.G. and Dickinson J.R. (2007): DNA sequences from Arabidopsis, which encode protein kinases and function as upstream regulators of Snf1 in yeast. J Biol Chem, 282, 10472-10479.

Hildebrand D., Fukushige H., Afitlhile M. and Wang C. (1998): Lipoxygenases in plant development and senescence. In A. Rowley, H. Kuhn, T. Schewe, eds, Eicosanoids and Related Compounds in Plants and Animals. Portland Press Ltd., London, pp 151-181. 
Hiratsu K., Matsui K., Koyama T. and Ohme-Takagi M. (2003): Dominant repression of target genes by chimeric repressors that include the EAR motif, a repression domain, in Arabidopsis. The Plant J., 34 (5), 733-9.

Holden M. (1965): Chlorophylls. In: Chemistry and Biochemistry of Plant Pigments (T. W. Goodwin, ed.), Academic Press, New York, 461-488.

Hong Y., Wang T.W., Hudak K.A., Schade F., Froese C.D. and Thompson J. E. (2000): An ethylene-induced cDNA encoding a lipase expressed at the onset of senescence. PNAS, 97, 8717-8722.

Hruz T., Laule O., Szabo G., Wessendorp F., Bleuler S., Oertle L., Widmayer P., Gruissem W. and Zimmermann P. (2008): Genevestigator V3: a reference expression database for the meta-analysis of transcriptomes. Advances in Bioinformatics, 420747.

Huang J.Z. and Huber S.C. (2001): Phosphorylation of synthetic peptides by a CDPK andplant SNF1-related protein kinase. Influence of praline and basic amino acid residues at selected positions. Plant and Cell Physiology, 42, 1079-87.

Hudson E.R., Pan D.A., James J., Lucocq J.M., Hawley S.A., Green K.A., Baba O., Terashima T. and Hardie D.G. (2003): A novel domain in AMP-activated protein kinase causes glycogen storage bodies similar to those seen in hereditary cardiac arrhythmias. Current Biology, 13, 861-6

Inoue H., Nojima H. and Okayama H. (1990): High efficiency transformation of Escherichia coli with plasmids. Gene, 96, 23-28.

Invitrogen (2001): Proquest Two-Hybrid System. Instruction Manual.

Ito K., Kusano T. and Tsutsumi K.I. (1999): A cold-inducible bZIP protein gene in radish root regulated by calcium- and cycloheximide-mediated signals. Plant Science, $142,57-65$.

Iwata Y., Kuriyama M., Nakakita M., Kojim, H., Ohto M. and Nakamura K. (1998): Characterization of a calcium-dependent protein kinase of tobacco leaves that is associated with the plasma membrane and is inducible by sucrose. Plant Cell Physiology, 39, 1176-1183.

Izawa T., Foster R. and Chua N. H. (1993): Plant bZIP protein DNA binding specificity. J Mol Biol, 230, 1131-44.

Jakoby M., Weisshaar B., Droge-Laser W., Vicente-Carbajosa J., Tiedemann J., Kroj T. and Parcy F. (2002): bZIP transcription factors in Arabidopsis. Trends in Plant Science, 7, 106-11.

Jiang R. and Carlson M. (1997): The Snf1 protein kinase and its activating subunit, Snf4, interact with distinct domains of the Sip1/Sip2/Gal83 component in the kinase complex. Molecular and Cellular Biology, 17, 2099-2106. 
Johnson C., Boden E., Desai M., Pascuzzi P. and Arias J. (2001): In vivo target promoter-binding activities of a xenobiotic stress-activated TGA factor. The Plant J, 28, 237-43.

Jupin I. and Chua N.H. (1996): Activation of the CaMV as-1 cis-element by salicylic acid: differential DNA-binding of a factor related to TGA1a. The EMBO Journal, 15 (20), 5679-89.

Kagaya Y., Hobo T., Murata M., Ban A. and Hattori T. (2002): Abscisic acidinduced transcription is mediated by phosphorylation of an abscisic acid response element binding factor, TRAB1. The Plant Cell, 14 (12), 3177-89.

Kaminaka H., Nake C., Epple P., Dittgen J., Schütze K., Chaban C., Holt B.F., Merkle T., Schäfer E., Harter K. and Dangl J.L. (2006): bZIP10-LSD1 antagonism modulates basal defense and cell death in Arabidopsis following infection. The EMBO Journal, 25, 4400-4411.

Kang S.G., Price J., Lin P.C., Hong J.C. and Jang J.C. (2010): The Arabidopsis bZIP1 Transcription Factor Is Involved in Sugar Signaling, Protein Networking, and DNA Binding. Mol Plant.

Kaplan F. and Guy C.L. (2005): RNA interference of Arabidopsis beta-amylase8 prevents maltose accumulation upon cold shock and increases sensitivity of PSII photochemical efficiency to freezing stress. The Plant Journal, 44 (5), 730-43.

Kirby J. and Kavanagh T.A. (2002): NAN fusions: a synthetic sialidase reporter gene as a sensitive and versatile partner for GUS. The Plant J., 32 (3), 391-400.

Kobayashi Y., Murata M., Minami H., Yamamoto S., Kagaya Y., Hobo T., Yamamoto A. and Hattori T. (2005): Abscisic acid-activated SNRK2 protein kinases function in the gene-regulation pathway of ABA signal transduction by phosphorylating ABA response element-binding factors. The Plant Journal, 44 (6), 939-49.

Koch K.E. (1996): Carbohydrate-modulated gene expression in plants. Annu Rev Plant Physiol Plant Mol Biol., 47, 509-540.

Kolbe A., Tiessen A., Schluepmann H., Paul M., Ulrich S. and Geigenberger P. (2005): Trehalose 6-phosphate regulates starch synthesis via posttranslational redox activation of ADP-glucose pyrophosphorylase. PNAS, 102, 11118-11123.

Koncz C. and Schell J. (1986): The promoter of TL-DNA gene 5 controls the tissue specific expression chimeric genes carried by a novel type of Agrobacterium binary vector. Mol Gen Genet, 204, 383-396.

Kuchin S., Treich I. and Carlson M. (2000): A regulatory shortcut between the Snf1 protein kinase and RNA polymerase II holoenzyme. PNAS, 97 (14), 7916-20. 
Kusano T., Berberich T., Harada M., Suzuki N. and Sugawara K. (1995): A maize DNA-binding factor with a bZIP motif is induced by low temperature. Mol Gen Genet, 248, 507-17.

Kyhse-Anderson J. (1984): Electroblotting of multiple gels: a simple apparatus without buffer tank for rapid transfer of proteins from polyacrylamide to nitrocellulose. $J$ Biochem Biophys Meth, 10.

Laby R.J., Kim D. and Gibson S.I. (2001): The raml Mutant of Arabidopsis Exhibits Severely Decreased $\alpha$-Amylase Activity. Plant Physiology, 127, 1798-1807.

Laemmli U.K. (1970): Cleavage of structural proteins during the assembly of the head of bacteriophage T4. Nature, 227, 680-5.

Lam H.M., Hsieh M.H. and Coruzzi G.M. (1998): Reciprocal regulation of distinct asparagines synthetase genes by light and metabolites in Arabidopsis thaliana. The Plant Journal, 16, 345-353.

Lam H.M., Peng S.-Y. and Coruzzi G.M. (1994): Metabolic Regulation of the Gene Encoding Glutamine-Dependent Asparagine Synthetase in Arabidopsis thaliana. Plant Physiology, 106, 1347-1357.

Lam H.M., Wong P., Chan H.-K., Yam K.-M., Chen L., Chow C.-M. and Coruzzi G.M. (2003): Overexpression of the ASN1 Gene Enhances Nitrogen Status in Seeds of Arabidopsis. Plant Physiology, 132, 926-935.

Landschulz W. H., Johnson P. F. and McKnight S. L. (1988): The leucine zipper: a hypothetical structure common to a new class of DNA binding proteins. Science, 240, 1759-64.

Lao N.T., Schoneveld O., Mould R.M., Hibberd J.M., Gray J.C. and Kavanagh T.A. (1999): An Arabidopsis gene encoding a chloroplast-targeted beta-amylase. The Plant Journal, 20 (5), 519-27.

Lara P., Onate-Sánchez L., Abraham Z., Ferrándiz C., Díaz I., Carbonero P., Vicente-Carbajosa J. (2003): Synergistic activation of seed storage protein gene expression in Arabidopsis by ABI3 and two bZIPs related to OPAQUE2. Journal of Biological Chemistry, 278, 21003-11.

Le Gouill C., Parent J.-L., Rola-Pleszczynski M. and Stankova J. (1994): Analysis of recombinant plasmids by a modified alkaline lysis method. Anal biochem, 219, 164.

Lea P.J. and Miflin B.J. (1980): Transport and metabolism of asparagines and other nitrogen compounds within the plant. In PK Stumpf EE Conn, The Biochemistry of Plants Academic Press, New York, 569-607. 
Lee S.J., Lee M.Y., Yi S.Y., Oh S.K., Choi S.H., Her N.H., Choi D., Min B.W., Yang S.G. and Harn C.H. (2002): PPI1: a novel pathogen-induced basic regionleucine zipper (bZIP): transcription factor from pepper. Mol Plant Microbe Interaction, 15, 5408.

Lejay L., Tillard P., Lepetit M., Olive F., Filleur S., Daniel-Vedele F. and Gojon A. (1999): Molecular and functional regulation of two $\mathrm{NO}_{3}$ - uptake systems by $\mathrm{N}$ - and $\mathrm{C}$ status of Arabidopsis plants. The Plant J., 18 (5), 509-19.

Lejay L., Wirth J., Pervent M., Cross J.M., Tillard P. and Gojon A. (2008): Oxidative pentose phosphate pathway-dependent sugar sensing as a mechanism for regulation of root ion transporters by photosynthesis. Plant Physiol., 146 (4), 2036-53.

Lender J. (2009): Charakterisierung der Arabidopsis Kinasen KIN10 und KIN11 als regulatoren von bZIP Transkriptionsfaktoren. Diplomarbeit.

Less H. and Galili G. (2009): Coordinations between gene modules control the operation of plant amino acid metabolic networks. BMC Syst. Biol., 3, 1-18.

Li X.F., Li Y.J., An Y.H., Xiong L.J., Shao X.H., Wang Y. and Sun Y. (2009): AKINbeta1 is involved in the regulation of nitrogen metabolism and sugar signaling in Arabidopsis. J Integr Plant Biol., 51 (5), 513-20.

Li Y., Le, K.K., Walsh S., Smith C., Hadingham S., Sorefan K., Cawley G. and Bevan M.W. (2006): Establishing glucose- and ABA-regulated transcription networks in Arabidopsis by microarray analysis and promoter classification using a Relevance Vector Machine. Genome Res, 16, 414-427.

Lin J.-F. and Wu S.-H. (2004): Molecular events in senescing Arabidopsis leaves. The Plant Journal, 39, 612-628.

Liu Y., Xu X., Singh-Rodriguez S., Zhao Y. and Kuo M.H. (2005): Histone H3 Ser10 phosphorylation-independent function of Snf1 and Reg1 proteins rescues a gen5mutant in HIS3 expression. Mol Cell Biol., 25 (23), 10566-79.

Lloyd J.R., Kossmann J. and Ritte G. (2005): Leaf starch degradation comes out of the shadows. Trends in Plant Science, 10 (3), 130-7.

Lo W.S., Duggan L., Emre N.C., Belotserkovskya R., Lane W.S., Shiekhattar R. and Berger S.L. (2001): Snf1 - a histone kinase that works in concert with the histone acetyltransferase Gcn5 to regulate transcription. Science, 293 (5532), 1142-6.

Lo W.S., Gamache E.R., Henry K.W., Yang D., Pillus L. and Berger S.L. (2005): Histone $\mathrm{H} 3$ phosphorylation can promote TBP recruitment through distinct promoterspecific mechanisms. The EMBO Journal, 24 (5), 997-1008. 
Lumbreras V., Alba M.M., Kleinow T., Koncz C. and Pagès M. (2001): Domain fusion between SNF1-related kinase subunits during plant evolution. EMBO Reports, 2, $55-60$.

Lunn J.E., Feil R., Hendriks J.H., Gibon Y., Morcuende R., Osuna D., Scheible W.R., Carillo P., Hajirezaei M.R. and Stitt M. (2006): Sugar-induced increases in trehalose 6-phosphate are correlated with redox activation of ADPglucose pyrophosphorylase and higher rates of starch synthesis in Arabidopsis thaliana. Biochem Journal, 397, 139-148.

Lupas A. (1996): Coiled coils: new structures and new functions. Trends Biochem Sci, 21, 375-82.

Lynch M. and Katju V. (2004): The altered evolutionary trajectories of gene duplicates. Trends Genet, 20, 544-549.

Mackintosh R.W., Davies S.P., Clarke P.R., Weekes J., Gillespie J.G., Gibb B.J. and Hardie D.G. (1992): Evidence for a protein kinase cascade in higher plants. 3Hydroxy-methylglutaryl-CoA reductase kinase. Eur J Biochem, 209, 923-931.

Martin C. and Smith A.M. (1995): Starch biosynthesis. The Plant Cell, 7 (7), 971-85.

Martínez-García J.F., Moyano E., Alcocer M.J. and Martin C. (1998): Two bZIP proteins from Antirrhinum flowers preferentially bind a hybrid C-box/G-box motif and help to define a new sub-family of bZIP transcription factors. The Plant Journal, 13 (4), 489-505.

Matt P., Schurr U., Krapp A. and Stitt M. (1998): Growth of tobacco in short day conditions leads to high starch, low sugars, altered diurnal changes of the Nia transcript and low nitrate reductase activity, and an inhibition of amino acid synthesis. Planta, 207, 27-41.

McDonell M.W., Simon M.N. and Studier F.W. (1977): Analysis of restriction fragments of T7 DNA and determination of molecular weights by electrophoresis in neutral and alkaline gels. J Mol Biol, 110, 119-46.

Melan M.A., Dong X., Endara M.E., Davis K.R., Ausubel F.M. and Peterman T.K. (1993): An Arabidopsis thaliana lipoxygenase gene can be induced by pathogens, abscisic acid, and methyl jasmonate. Plant Physiol., 101 (2), 441-50.

Melo-Oliveira R., Olivseira I.C. and Coruzzi G.M. (1996) Arabidopsis mutant analysis and gene regulation define a nonredundant role for glutamate dehydrogenase in nitrogen assimilation. PNAS, 93, 4718-4723.

Menkens A.E., Schindler U. and Cashmore A.R. (1995): The G-box: a ubiquitous regulatory DNA element in plants bound by the GBF family of bZIP proteins. Trends Biochem Sci, 20, 506-10. 
Metallo S. J. and Schepartz A. (1997): Certain bZIP peptides bind DNA sequentially as monomers and dimerize on the DNA. Nat Struct Biol, 4, 115-7.

Mullis K.B. and Faloona F.A. (1987): Specific synthesis of DNA in vitro via a polymerase-catalyzed chain reaction. Methods Enzymol, 155, 335-50.

Murashige T. and Skoog F. (1962): A revised medium for rapid growth and bioassays with tobacco tissue cultures. Physiol Plant, 15, 473-497.

Naar A.M., Lemon B.D. and Tjian R. (2001): Transcriptional coactivator complexes. Anпи Rev Biochem, 70, 475-501.

Nakashima K., Satoh R., Kiyosue T., Yamaguchi-Shinozaki K. and Shinozaki K. (1998): A gene encoding proline dehydrogenase is not only induced by proline and hypoosmolarity, but is also developmentally regulated in the reproductive organs of Arabidopsis. Plant Physiology, 118, 1233-41.

Niu X. and Guiltinan M.J. (1994): DNA binding specificity of the wheat bZIP protein EmBP-1. Nucleic Acids Res, 22, 4969-78.

Noble S.M., Carnahan V.E., Moore L.B., Luntz T., Wang H., Ittoop O.R., Stimmel J.B., Davis-Searles P.R., Watkins R.E., Wisely G.B., LeCluyse E., Tripathy A., McDonnell D.P. and Redinbo M.R. (2006): Human PXR forms a tryptophan zippermediated homodimer. Biochemistry, 45 (28), 8579-89.

Nooden L.D., Guiamet J.J. and John I. (1997): Senescence mechanisms. Physiol. Plant, 101, 746-753.

Oliveira I.C. and Coruzzi G.M. (1999): Carbon and amino acids reciprocally modulate the expression of glutamine synthetase in Arabidopsis. Plant Physiol., 121, 301-310.

O'Shea E.K., Rutkowski R. and Kim P.S. (1989): Evidence that the leucine zipper is a coiled coil. Science, 243, 538-42.

Osuna D., Usadel B., Morcuende R., Gibon Y., Blasing O.E., Hohne M., Gunter M., Kamlage B., Trethewey R., Scheible W.R. and Stitt M. (2007): Temporal responses of transcripts, enzyme activities and metabolites after adding sucrose to carbon-deprived Arabidopsis seedlings. The Plant Journal, 49, 463-491.

Oyama T., Shimura Y. and Okada K. (1997): The Arabidopsis HY5 gene encodes a bZIP protein that regulates stimulus-induced development of root and hypocotyl. Genes Dev, 11, 2983-95.

Palenchar P.M., Kouranov A., Lejay L.V. and Coruzzi G.M. (2004): Genome-wide patterns of carbon and nitrogen regulation of gene expression validate the combined carbon and nitrogen (CN)-signaling hypothesis in plants. Genome Biol., 5 (11), R91. 
Paul M.J. (2008): Trehalose 6-phosphate: a signal of sucrose status. Biochem Journal, 412, e1-2.

Pickett F.B. and Meeks-Wagner D.R. (1995): Seeing double: appreciating genetic redundancy. The Plant Cell, 7 (9), 1347-56.

Pilot G., Stransky H., Bushey D.F., Pratelli R., Ludewig U., Wingate V.P.M. and Frommera W.B. (2004): Overexpression of GLUTAMINE DUMPER1 Leads to Hypersecretion of Glutamine from Hydathodes of Arabidopsis Leaves. The Plant Cell, $16,1827-1840$.

Polge C. and Thomas M. (2007): SNF1/AMPK/SnRK1 kinases, global regulators at the heart of energy control? Trends Plant Sci., 12 (1), 20-8.

Pontier D., Miao Z.H. and Lam E. (2001): Trans-dominant suppression of plant TGA factors reveals their negative and positive roles in plant defense responses. The Plant Journal, 27, 529-538.

Price J., Laxmi A., St Martin S.K. and Jang J.C. (2004): Global transcription profiling reveals multiple sugar signal transduction mechanisms in Arabidopsis. The Plant Cell, 16, 2128-2150.

Quirino B.F., Noh Y.S., Himelblau E. and Amasino R.M. (2000): Molecular aspects of leaf senescence. Trends Plant Sci., 7, 278-82.

Ramon M., Rolland F. and Sheen J. (2008): Sugar Sensing and Signaling. The Arabidopsis Book (C) 2008 American Society of Plant Biologists.

Ringli C. and Keller B. (1998): Specific interaction of the tomato bZIP transcription factor VSF-1 with a non-palindromic DNA sequence that controls vascular gene expression. Plant Mol Biol., 37 (6), 977-88.

Roberts R.J. (1985): Restriction and modification enzymes and their recognition sequences. Nucleic Acids Res, 13, 165-200.

Rolland F., Baena-Gonzalez E. and Sheen J. (2006): Sugar sensing and signaling in plants: conserved and novel mechanisms. Annu Rev Plant Biol., 57, 675-709.

Rolland F., Moore B. and Sheen J. (2002): Sugar sensing and signaling in plants. The Plant Cell, 14, 185-205.

Rook F., Gerrits N., Kortstee A., van Kampen M., Borrias M., Weisbeek P. and Smeekens S. (1998a): Sucrose-specific signalling represses translation of the Arabidopsis ATB2 bZIP transcription factor gene. The Plant Journal, 15, 253-63.

Rook F., Weisbeek P. and Smeekens S. (1998b): The light-regulated Arabidopsis bZIP transcription factor gene ATB2 encodes a protein with an unusually long leucine zipper domain. Plant Mol Biol, 37, 171-8. 
Rugner A., Frohnmeyer H., Nake C., Wellmer F., Kircher S., Schafer E. and Harter K. (2001): Isolation and characterization of four novel parsley proteins that interact with the transcriptional regulators CPRF1 and CPRF2. Mol Genet Genomics, 265, 964-976.

Sambrook, Fritsch and Maniatis (1989): Molecular cloning: A Laboratory Manual. Cold Spring Habor Laboratory Press.

Sanger F., Nicklen S. and Coulson A.R. (1977): DNA sequencing with chainterminating inhibitors. PNAS, 74, 5463-7.

Satoh R., Fujita Y., Nakashima K., Shinozaki K. and Yamaguchi-Shinozaki K. (2004): A novel subgroup of bZIP proteins functions as transcriptional activators in hypoosmolarity-responsive expression of the ProDH gene in Arabidopsis. Plant Cell Physiol., 45 (3), 309-17.

Satoh R., Nakashima K., Seki M., Shinozaki K. and Yamaguchi-Shinozaki K. (2002): ACTCAT, a novel cis-acting element for proline- and hypoosmolarityresponsive expression of the ProDH gene encoding proline dehydrogenase in Arabidopsis. Plant Physiology, 130 (2), 709-19.

Schaller F. (2001): Enzymes of the biosynthesis of octadecanoid-derived signaling molecules. J Exp Bot, 52, 11-23.

Scheible W.R., Morcuende R., Czechowski T., Fritz C., Osuna D., Palacios-Rojas N., Schindelasch D., Thimm O., Udvardi M.K. and Stitt M. (2004): Genome-wide reprogramming of primary and secondary metabolism, protein synthesis, cellular growth processes, and the regulatory infrastructure of Arabidopsis in response to nitrogen. Plant Physiology, 136 (1), 2483-99.

Schewe T. and Kühn H. (1991): Do 15-lipoxygenases have a common biological role? Trends Biochem. Sci., 16, 369-373.

Schindler U., Beckmann H. and Cashmore A.R. (1992): TGA1 and G-box binding factors: two distinct classes of Arabidopsis leucine zipper proteins compete for the Gbox-like element TGACGTGG. The Plant Cell, 4 (10), 1309-19.

Schindler U., Terzaghi W., Beckmann H., Kadesch T. and Cashmore A.R. (1992): DNA binding site preferences and transcriptional activation properties of the Arabidopsis transcription factor GBF1. The Embo Journal, 11, 1275-89.

Schmidt M.C. and McCartney R.R. (2000): Beta-subunits of Snf1 kinase are required for kinase function and substrate definition. The EMBO Journal, 19 (18), 4936-43.

Schmidt R.J., Ketudat M., Aukerman M.J. and Hoschek G. (1992): Opaque-2 is a transcriptional activator that recognizes a specific target site in $22-\mathrm{kD}$ zein genes. The Plant Cell, 4, 689-700. 
Schüller H.J. (2003): Transcriptional control of nonfermentative metabolism in the yeast Saccharomyces cerevisiae. Curr Genet., 43 (3), 139-60.

Schurr U., Walter A. and Rascher U. (2006): Functional dynamics of plant growth and photosynthesis - from steady-state to dynamics - from homogeneity to heterogeneity. Plant Cell Environment, 29 (3), 340-52.

Schuster J. and Binder S. (2005): The mitochondrial branched chain aminotransferase (AtBCAT-1) is capable to initiate degradation of leucine, isoleucine and valine in almost all tissues in Arabidopsis thaliana. Plant Mol Biol, 57, 241-254.

Schütze K., Harter K. and Chaban C. (2008): Post-translational regulation of plant bZIP factors. Trends Plant Science, 13 (5), 247-55.

Sheen J. (1993): Protein phosphatase activity is required for light-inducible gene expression in maize. The EMBO Journal, 12 (9), 3497-505.

Shimizu H., Sato K., Berberich T., Miyazaki A., Ozaki R., Imai R. and Kusano T. (2005): LIP19, a basic region leucine zipper protein, is a Fos-like molecular switch in the cold signaling of rice plants. Plant Cell Physiol, 46, 1623-1634.

Shirra M.K., Rogers .SE., Alexander D.E. and Arndt K.M. (2005): The Snf1 protein kinase and Sit4 protein phosphatase have opposing functions in regulating TATAbinding protein association with the Saccharomyces cerevisiae INO1 promoter. Genetics, 169 (4), 1957-72.

Siberil Y., Doireau P. and Gantet P. (2001): Plant bZIP G-box binding factors. Modular structure and activation mechanisms. Eur J Biochem, 268, 5655-66.

Sieciechowicz K.A., Joy K.W. and Ireland R.J. (1988): The metabolism of asparagine in plants. Phytochemistry, 27, 663-671.

Slocombe S.P., Beaudoin F., Donaghy P.G., Hardie D.G., Dickinson J.R. and Halford N.G. (2004): SNF1-related protein kinase (snRK1) phosphorylates class I heat shock protein. Plant Physiol Biochem., 42 (2), 111-6.

Slocombe S.P., Laurie S., Bertini L., Beaudoin F., Dickinson J.R. and Halford N.G. (2002): Identification of SnIP1, a novel protein that interacts with SNF1-related protein kinase (SnRK1). Plant Mol Biol., 49 (1), 31-44.

Smart C.M. (1994): Gene expression during leaf senescence. New Phytol, 126, 419448.

Smith A.M. and Stitt M. (2007): Coordination of carbon supply and plant growth. Plant Cell Environment, 30 (9), 1126-49.

Smith A.M., Zeeman S.C. and Smith S.M. (2005): Starch Degradation. Annu. Rev. Plant Biol., 56, 73-98 
Smith H.O. and Wilcox K.W. (1970): A restriction enzyme from Hemophilus influenzae. Purification and general properties. J Mol Biol, 51, 379-91.

Smith S.M., Fulton D.C., Chia T., Thorneycroft D., Chapple A., Dunstan H., Hylton C., Zeeman S.C., and Smith A.M. (2004): Diurnal Changes in the Transcriptome Encoding Enzymes of Starch Metabolism Provide Evidence for Both Transcriptional and Posttranscriptional Regulation of Starch Metabolism in Arabidopsis Leaves. Plant Physiology, 136, 2687-2699.

Solfanelli C., Poggi A., Loreti E., Alpi A. and Perata P. (2006): Sucrose-specific induction of the anthocyanin biosynthetic pathway in Arabidopsis. Plant Physiology, $140,637-646$.

Solomon M.J. and Varshavsky A. (1985): Formaldehyde-mediated DNA-protein crosslinking: a probe for in vivo chromatin structures. PNAS, 82, 6470-4.

Solomon M.J., Larsen P.L. and Varshavsky A. (1988): Mapping protein-DNA interactions in vivo with formaldehyde: evidence that histone $\mathrm{H} 4$ is retained on a highly transcribed gene. Cell, 53, 937-47.

Song Y.H., Yoo C.M., Hong A.P., Kim S.H., Jeong H.J., Shin S.Y., Kim H.J., Yun D.J., Lim C.O., Bahk J.D., Lee S.Y., Nagao R.T., Key J.L. and Hong J.C. (2008): DNA-binding study identifies C-box and hybrid C/G-box or C/A-box motifs as highaffinity binding sites for STF1 and LONG HYPOCOTYL5 proteins. Plant Physiology, 146 (4), 1862-77.

Southern E.M. (1979): Measurement of DNA length by gel electrophoresis. Anal Biochem, 100, 319-23.

Sparla F., Costa A., Lo Schiavo F., Pupillo P. and Trost P. (2006): Redox regulation of a novel plastid-targeted beta-amylase of Arabidopsis. Plant Physiology, 141 (3), 84050.

Sprenger-Haussels M. and Weisshaar B. (2000): Transactivation properties of parsley proline-rich bZIP transcription factors. The Plant Journal, 22, 1-8.

Stenzel I., Hause B., Miersch O., Kurz T., Maucher H., Weichert H., Ziegler J., Feussner I. and Wasternack C. (2003): Jasmonate biosynthesis and the allene oxide cyclase family of Arabidopsis thaliana. Plant Molecular Biology, 51, 895-911.

Stitt M. (1990): Fructose 2,6-bisphosphate as a regulatory metabolite in plants. Annual Review of Plant Physiology and Plant Molecular Biology, 41, 153-185.

Strathmann A., Kuhlmann M., Heinekamp T. and Droge-Laser W. (2001): BZI-1 specifically heterodimerises with the tobacco bZIP transcription factors BZI-2, BZI3/TBZF and BZI-4, and is functionally involved in flower development. The Plant Journal, 28, 97-408. 
Stryer L., Berg J.M. and Tymoczko J.L. (2003): Biochemie. 5.Auflage. Spektrum Verlag.

Sugden C., Crawford R.M., Halford N.G. and Hardie D.G. (1999): Regulation of spinach SNF1-related (SnRK1) kinases by protein kinases and phosphatases is associated with phosphorylation of the T loop and is regulated by 5'-AMP. The Plant Journal, 19 (4), 433-9.

Sugden C., Donaghy P.G., Halford N.G. and Hardie D.G. (1999): Two SNF1-related protein kinases from spinach leaf phosphorylate and inactivate 3-hydroxy-3methylglutaryl-coenzyme A reductase, nitrate reductase, and sucrose phosphate synthase in vitro. Plant Physiology, 120 (1), 257-74.

Sulpice R., Pyl E.T., Ishihara H., Trenkamp S., Steinfath M., Witucka-Wall H., Gibon Y., Usadel B., Poree F., Piques M.C., Von Korff M., Steinhauser M.C., Keurentjes J.J., Guenther M., Hoehne M., Selbig J., Fernie A.R., Altmann T. and Stitt M. (2009): Starch as a major integrator in the regulation of plant growth. PNAS, $106(25), 10348-53$.

Swidzinski J.A., Sweetlove L.J. and Leaver C.J. (2002): A custom microarray analysis of gene expression during programmed cell death in Arabidopsis thaliana. The Plant Journal, 30, 431-46.

Szemenyei H., Hannon M. and Long J.A. (2008): TOPLESS mediates auxindependent transcriptional repression during Arabidopsis embryogenesis. Science, 319 (5868), 1384-6.

Takeda S., Mano S., Ohto M. and Nakamura K. (1994): Inhibitors of Protein Phosphatases 1 and 2A Block the Sugar-Inducible Gene Expression in Plants. Plant Physiology, 106 (2), 567-574.

Teng S., Keurentjes J., Bentsink L., Koornneef M. and Smeekens S. (2005): Sucrose-specific induction of anthocyanin biosynthesis in Arabidopsis requires the MYB75/PAP1 gene. Plant Physiology, 139, 1840-1852.

Thimm O., Blasing O., Gibon Y., Nagel A., Meyer S., Kruger P., Selbig J., Muller L.A., Rhee S.Y. and Stitt M. (2004): MAPMAN: a user-driven tool to display genomics data sets onto diagrams of metabolic pathways and other biological processes. The Plant Journal, 37, 914-939.

Thomas P.S. (1980): Hybridization of denatured RNA and small DNA fragments transferred to nitrocellulose. PNAS, 77, 5201-5205.

Thompson J., Taylor C. and Wang T.W. (2000): Altered membrane lipase expression delays leaf senescence. Biochem Soc Trans, 28 (6), 775-7. 
Thum K., Shin M., Palenchar P., Kouranov A. and Coruzzi G. (2004): Genomewide investigation of light and carbon signaling interactions in Arabidopsis. Genome Biology, 5, R10.

Thum K.E., Shasha D.E., Lejay L.V. and Coruzzi G.M. (2003): Light- and CarbonSignaling Pathways. Modeling Circuits of Interactions. Plant Physiology, 132, 440-452.

Tiessen A., Prescha K., Branscheid A., Palacios N., McKibbin R., Halford N.G. and Geigenberger P. (2003): Evidence that SNF1-related kinase and hexokinase are involved in separate sugar-signalling pathways modulating post-translational redox activation of ADP-glucose pyrophosphorylase in potato tubers. The Plant Journal, 35 (4), 490-500.

Toroser D., Plaut Z. and Huber S.C. (2000): Regulation of a plant SNF1-related protein kinase by glucose-6-phosphate. Plant Physiology, 123 (1), 403-12.

Usadel, B., Bläsing O.E., Gibon Y., Retzlaff K., Höhne M., Günther M. and Stitt M. (2008): Global transcript levels respond to small changes of the carbon status during progressive exhaustion of carbohydrates in Arabidopsis rosettes. Plant Physiologie, $146,1834-61$.

Van der Graaff E., Schwacke R., Schneider A., Desimone M., Flügge U.I. and Kunze R. (2006): Transcription analysis of arabidopsis membrane transporters and hormone pathways during developmental and induced leaf senescence. Plant Physiology, 141 (2), 776-92.

Vaughn M.W., Harrington G.N. and Bush D.R. (2002): Sucrose-mediated transcriptional regulation of sucrose symporter activity in the phloem. PNAS, 99, 1087610880 .

Vauquelin L.N. and Robiquet P.J. (1806): The discovery of a new plant principle in Asparagus sativus. Annals de Chemie, 88-93.

Vellosillo T., Martinez M., Lopez M.A., Vicente J., Cascon T., Dolan L., Hamberg M. and Castresanaa C. (2007): Oxylipins Produced by the 9-Lipoxygenase Pathway in Arabidopsis Regulate Lateral Root Development and Defense Responses through a Specific Signaling Cascade. The Plant Cell.

Vincent O. and Carlson M. (1999): Gal83 mediates the interaction of the Snf1 kinase complex with the transcription activator Sip4. The EMBO Journal, 18, 6672-6681.

Vincent O., Townley R., Kuchin S. and Carlson M. (2001): Subcellular localization of the Snf1 kinase is regulated by specific beta subunits and a novel glucose signaling mechanism. Genes Dev., 15 (9), 1104-14.

Vinson C., Myakishev M., Acharya A., Mir A. A., Moll J. R. and Bonovich M. (2002): Classification of human bZIP proteins based on dimerization properties. Mol Cell Biol, 22, 6321-35. 
Wang Q., Monroe J. and Sjolund R.D. (1995): ldentification and Characterization of a Phloem-Specific $\beta$-Amylase. Plant Physiology, 109, 743-750.

Wang R., Okamoto M., Xing X. and Crawford N.M. (2003): Microarray analysis of the nitrate response in Arabidopsis roots and shoots reveals over 1,000 rapidly responding genes and new linkages to glucose, trehalose-6-phosphate, iron, and sulfate metabolism. Plant Physiol., 132 (2), 556-67.

Warden S.M., Richardson C., O'Donnell J. Jr, Stapleton D., Kemp B.E. and Witters L.A. (2001): Post-translational modifications of the beta-1 subunit of AMPactivated protein kinase affect enzyme activity and cellular localization. Biochem J., $354,275-83$.

Weaver L.M., Gan S., Quirino B. and Amasino R.M. (1998): A comparison of the expression patterns of several senescence-associated genes in response to stress and hormone treatment. Plant Mol Biol, 37, 455-69.

Weckwerth W. (2003): Metabolomics in Systems Biology. Annu. Rev. Plant Biol., 54, 669-89.

Weltmeier F. (2005): Ein Netzwerk von heterodimerisierenden C/S1 AtbZIP Transkriptionsfaktoren und seine Funktion in Seneszenz, Stressantwort und Samenentwicklung. Dissertation.

Weltmeier F., Ehlert A., Mayer C.S., Dietrich K., Wang X., Schütze K., Alonso R., Harter K., Vicente-Carbajosa J. and Dröge-Laser W. (2006): Combinatorial control of proline dehydrogenase transcription by specific heterodimerisation of bZIP transcription factors. The EMBO Journal, 13, 3133-43.

Weltmeier F., Rahmani F., Ehlert A., Dietrich K., Schutze K., Wang X., Chaban C., Hanson J., Teige M., Harter K., Vicente-Carbajosa J., Smeekens S. and DrögeLaser W. (2009): Expression patterns within the Arabidopsis C/S1 bZIP transcription factor network: availability of heterodimerization partners controls gene expression during stress response and development. Plant Mol Biol, 69, 107-119.

Wenzler H., Mignery G., Fisher L. and Park W. (1989): Sucrose-regulated expression of a chimeric potato tuber gene in leaves of transgenic tobacco plants. Plant Mol. Biol., 13, 347-354.

White J., Chang S.Y. and Bibb M.J. (1990): A cassette containing the bar gene of Streptomyces hygroscopicus: a selectable marker for plant transformation. Nucleic Acids Res, 18, 1062.

Wiese A., Elzinga N., Wobbes B. and Smeekens S. (2004): A conserved upstream open reading frame mediates sucrose-induced repression of translation. The Plant Cell, 16, 1717-1729. 
Williams M.E., Foster R. and Chua N.H. (1992): Sequences Flanking the Hexameric G-Box Core CACGTG affect the Specificity of Protein Binding. The Plant Cell, 4, 485496.

Woods A., Cheung P. C. F., Smith F. C., Davison M. D., Scott J., Beri R. K. and Carling D. (1996): Characterisation of AMP-activated protein kinase $\beta$ and $\gamma$ subunits: assembly of the heterotrimeric complex in vitro. J. Biol. Chem., 271, 10282-10290.

Woods A., Munday M.R., Scott J., Yang X., Carlson M. and Carling D. (1994): Yeast SNF1 is functionally related to mammalian AMP-activated protein kinase and regulates acetyl-CoA carboxylase in vivo. J Biol Chem., 269 (30), 19509-15.

Yakir E., Hilman D., Hassidim M. and Green R.M. (2007): CIRCADIAN CLOCK ASSOCIATED1 transcript stability and the entrainment of the circadian clock in Arabidopsis. Plant Physiology, 145, 925-932.

Yokoyama R., Hirose T., Fujii N., Aspuria E.T., Kato A. and Uchimiya H. (1994): The rolC promoter of Agrobacterium rhizogenes Ri plasmid is activated by sucrose in transgenic tobacco plants. Mol. Gen. Genet., 244, 15-22.

Yoo S.D., Cho Y.H. and Sheen J. (2007): Arabidopsis mesophyll protoplasts: a versatile cell system for transient gene expression analysis. Nat Protoc., 2 (7), 1565-72.

Yu T.S., Kofler H., Häusler R.E., Hille D., Flügge U.I., Zeeman S.C., Smith A.M., Kossmann J., Lloyd J., Ritte G., Steup M., Lue W.L., Chen J. and Weber A. (2001): The Arabidopsis sexl mutant is defective in the R1 protein, a general regulator of starch degradation in plants, and not in the chloroplast hexose transporter. The Plant Cell, 13, 1907-1918.

Yu T.S., Zeeman S.C., Thorneycroft D., Fulton D.C., Dunstan H., Lue W.L., Hegemann B., Tung S.Y., Umemoto T., Chapple A., Tsai D.L., Wang S.M., Smith A.M., Chen J. and Smith S.M. (2005): alpha-Amylase is not required for breakdown of transitory starch in Arabidopsis leaves. J Biol Chem., 280 (11), 9773-9.

Zeeman S.C. and Smith S.M. and Smith A.M. (2007): The diurnal metabolism of leaf starch. Biochem. J., 401, 13-28.

Zhang Y., Fan W., Kinkema M., Li X. and Dong X. (1999): Interaction of NPR1 with basic leucine zipper protein transcription factors that bind sequences required for salicylic acid induction of the PR-1 gene. PNAS, 96 (11), 6523-8.

Zhang Y., Primavesi L.F., Jhurreea D., Andralojc P.J., Mitchell R.A., Powers S.J., Schluepmann H., Delatte T., Wingler A. and Paul M.J. (2009): Inhibition of Snf1related protein kinase (SnRK1) activity and regulation of metabolic pathways by trehalose 6-phosphate. Plant Physiology. 


\section{$8 \quad$ Anhang}

\subsection{Zusätzliche Informationen}

\subsubsection{Northern Analyse der Expression der Lipoxygenasen LOX3, LOX4, LOX5 und LOX6}

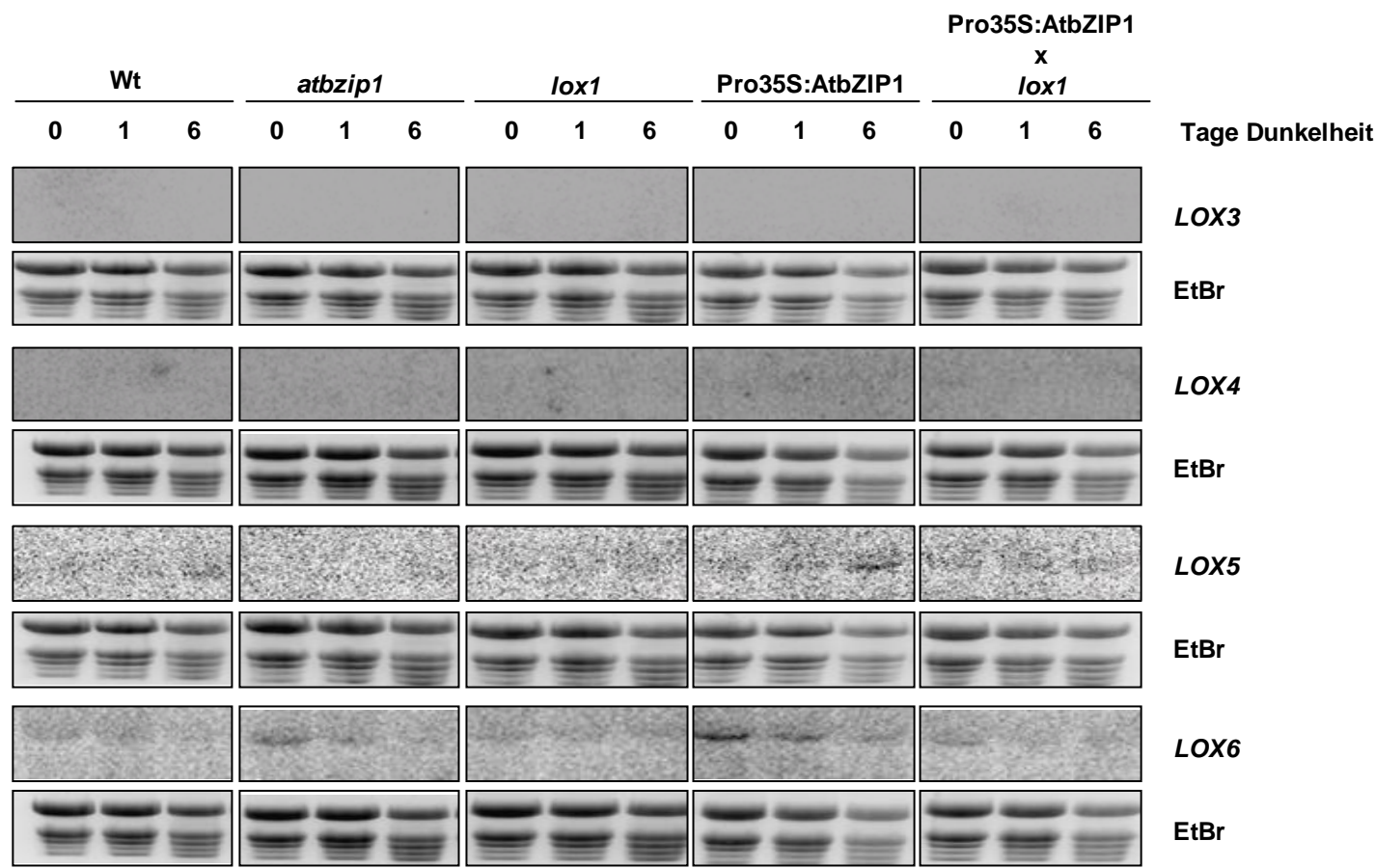

Abb. 8.1: Northern Analyse der Expression von LOX3, LOX4, LOX5 und LOX6

Pflanzen wurden 3-4 Wochen im Langtag angezogen. Anschließend wurden die Pflanzen dunkel gestellt. Zu den angegebenen Zeitpunkten wurden jeweils 8-10 Pflanzen pro Linie geerntet und zusammen aufgearbeitet. Daraus wurde RNA gewonnen und im Northern mit Sonden für die oben angegebenen Gene untersucht. EtBr: Ethidiumbromid-Färbung der verwendeten RNA-Gele zum Nachweis der gleichmäßigen Beladung. 


\subsubsection{Expression der $\beta$-Amylasen $B A M 1-4$ und $B A M 6-9$}
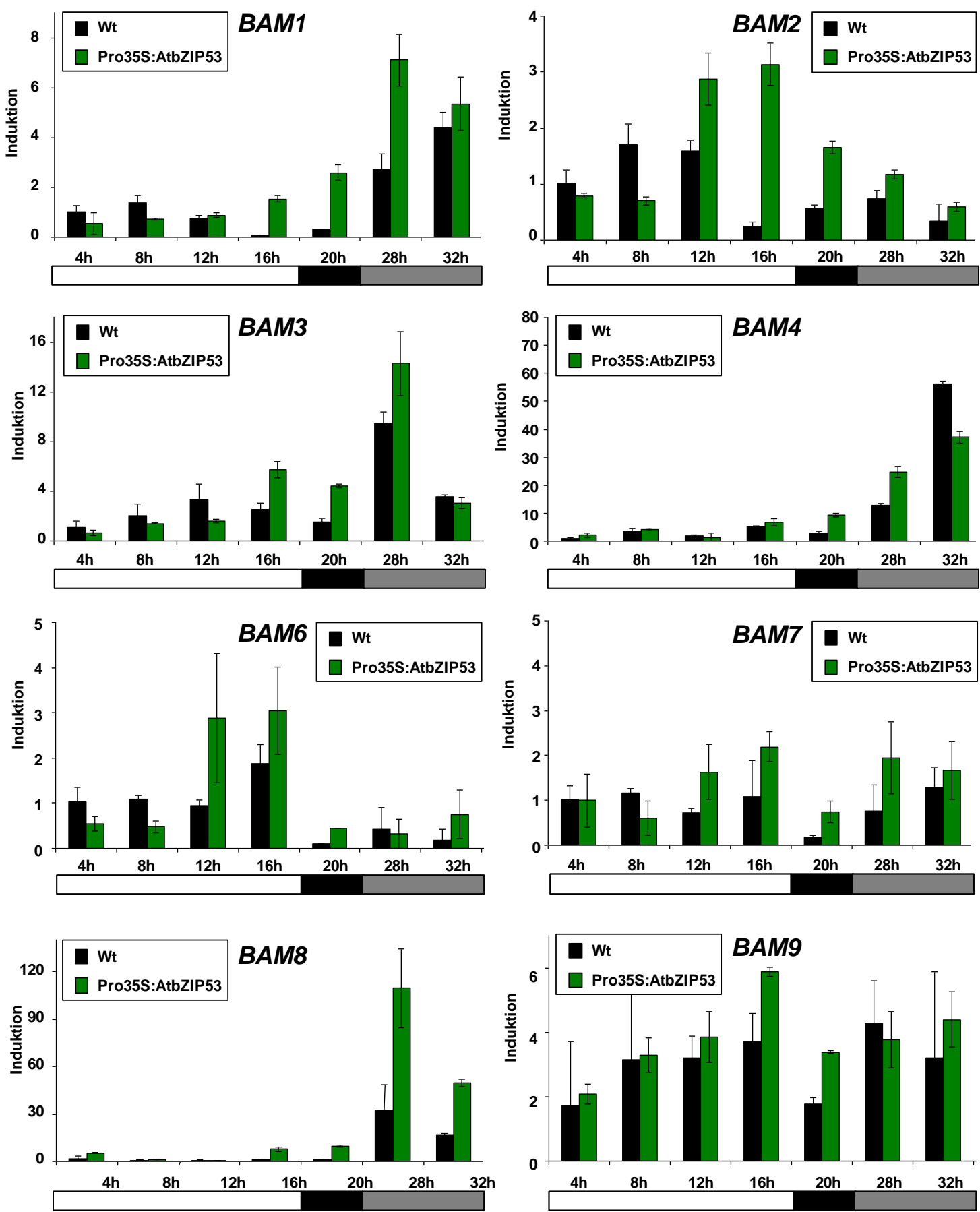

Abb. 8.2: Die Expression der $\beta$-Amylasen in Pro35S:AtbZIP53 Pflanzen und Wildtyp

Wildtyp und Pro35S:AtbZIP53 Pflanzen wurden 3-4 Wochen im Langtag angezogen und danach dunkel gestellt. Zu den angegebenen Zeitpunkten wurden jeweils 8-10 Pflanzen geerntet und zusammen aufgearbeitet. Die cDNA wurde mit Hilfe von quantitativer Real-Time PCR und Primern für die $\beta$-Amylasen untersucht. Angegeben sind die relativen Werte im Vergleich zur Expression nach 4 Stunden Dunkelheit von je zwei Replikaten nach Abgleich mit dem Haushaltsgen Ubiquitin. Der Versuch wurde mit vergleichbarem Ergebnis wiederholt. weißer Balken: normale Lichtphase (16h), schwarzer Balken: normale Nacht (8h), grauer Balken: verlängerte Nacht. 
8.1.3 Expression von AtbZIP1 und AtbZIP53 in Wildtyp, AtbZIP1 und AtbZIP53 Überexpremierern und Doppelmutante
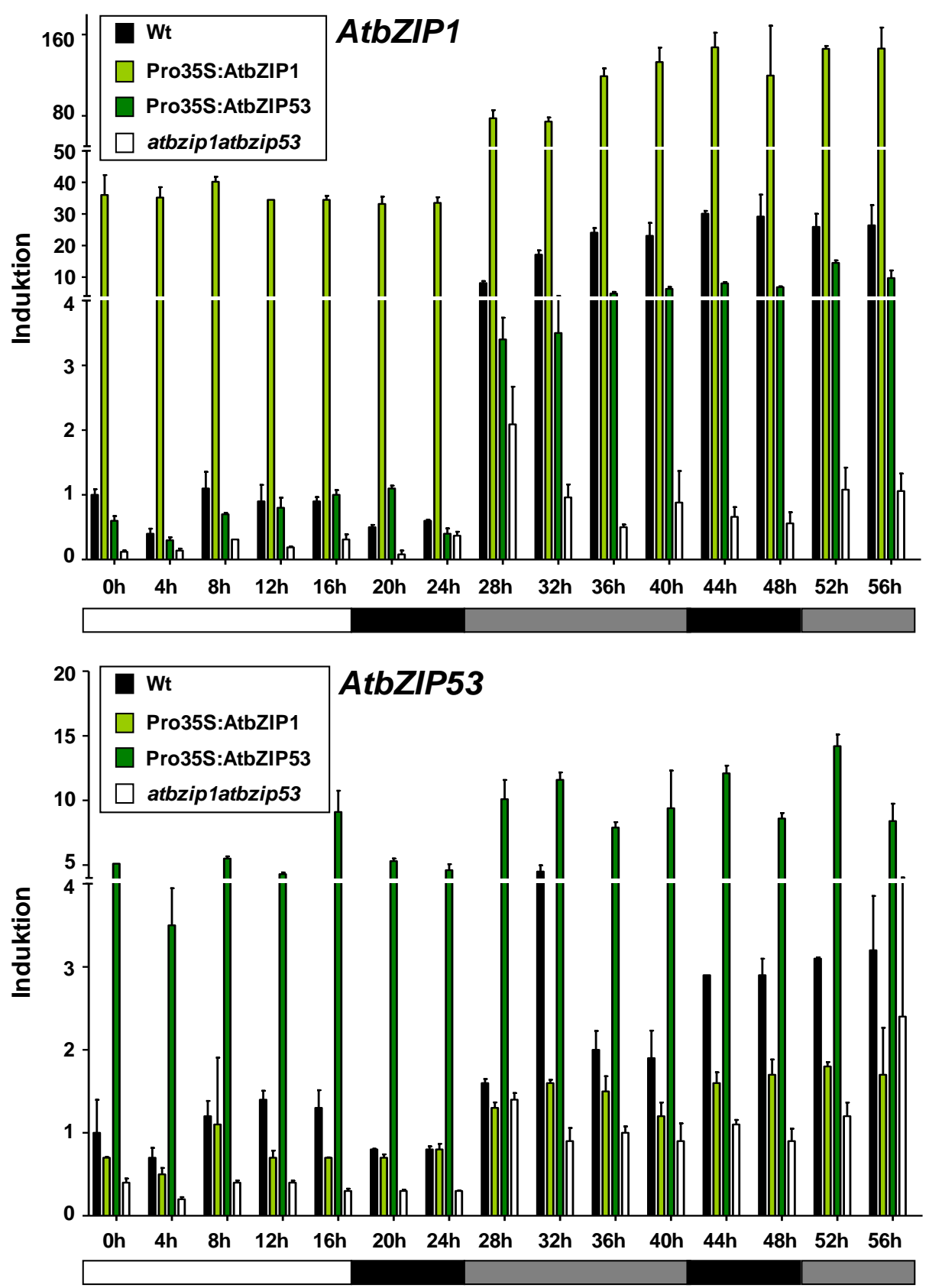

Abb. 8.3: Detaillierte qPCR-Analyse der Expression von AtbZIP1 und AtbZIP53 in Wildtyp, Überexpremierern und Doppelmutante während der verlängerten Nacht

Die Pflanzen wurden 3-4 Wochen im Langtag angezogen und danach dunkel gestellt. Zu den angegebenen Zeitpunkten wurden jeweils 8-10 Pflanzen geerntet und zusammen aufgearbeitet. Die Expression von AtbZIP1 und AtbZIP53 wurde mit Hilfe der qPCR untersucht. Angegeben sind die relativen Werte im Vergleich zur Expression nach 0 Stunden Dunkelheit von je zwei Replikaten nach Abgleich mit dem Haushaltsgen Ubiquitin. Zur besseren Übersicht ist die y-Achse bei AtbZIPI zweimal (bei 4facher und 50 facher Induktion) und bei AtbZIP53 einmal (bei 4facher Induktion) unterbrochen. weißer Balken: normale Lichtphase (16h), schwarzer Balken: normale Nacht $(8 h)$, grauer Balken: verlängerte Nacht 


\subsubsection{Aminosäuresequenz von AtbZIP1}

Serine und Threonin können theoretisch durch Kinasen phosphoryliert werden. Sie sind in der folgenden Aminosäuresequenz von AtbZIP1 rot dargestellt. Das Serin an Stelle 133, das für die Protoplastenversuche durch Alanin ausgetauscht wurde, da die umgebenden Aminosäuren dem in Huang und Huber (2001) beschriebenen SnRKPhosphorylierungsmotiv ähneln, ist zusätzlich gelb hinterlegt.

MANAEKTSSGSDIDEKKRKRKLSNRESARRSRLKKQKLMEDTIHEISSLERRIKE NSERCRAVKQRLDSVETENAGLRSEKIWLSSYVSDLENMIATTSLTLTQSGGGD CVDDQNANAGIAVGDCRRTPWKLSCGSLQPMASFKT

\subsubsection{Aminosäuresequenz von AtbZIP53}

Serine und Threonin können theoretisch durch Kinasen phosphoryliert werden. Sie sind in der folgenden Aminosäuresequenz von AtbZIP53 rot dargestellt. Das Serin an Stelle 140, das für die Protoplastenversuche durch Alanin ausgetauscht wurde, da die umgebenden Aminosäuren dem in Huang und Huber (2001) beschriebenen SnRKPhosphorylierungsmotiv ähneln, ist zusätzlich gelb hinterlegt.

MGSLQMQTSPESDNDPRYATVTDERKRKRMISNRESARRSRMRKQKQLGDLIN EVTLLKNDNAKITEQVDEASKKYIEMESKNNVLRAQASELTDRLRSLNSVLEM VEEISGQALDIPEIPESMQNPWQMPCPMQPIRASADMFDC 


\subsubsection{Aminosäuresequenz von AtbZIP63}

Von AtbZIP63 exisitieren insgesamt drei Splicing Varianten. Für alle gezeigten Versuche in dieser Arbeit wurde die Splicing Variante AtbZIP63.2 verwendet. Sie ist die längste der drei Varianten. Serine und Threonin können theoretisch durch Kinasen phosphoryliert werden. Sie sind in der folgenden Aminosäuresequenz von AtbZIP63 rot dargestellt. Die Serine an Stelle 29, 59, 261 und 300 sind in vivo phosphoryliert (persönliche Mitteilung M. Teige, Universität Wien) und wurden für die Protoplastenversuche durch Alanin ersetzt. Sie sind zusätzlich gelb hinterlegt.

MEKVFSDEEISGNHHWSVNGMTSLNRSASEWAFNRFIQESSAAADDGESTTAC GVSVSSPPNVPVDSEEYRAFLKSKLNLACAAVAMKRGTFIKPQDTSGRSDNGG ANESEQASLASSKATPMMSSAITSGSELSGDEEEADGETNMNPTNVKRVKRML SNRESARRSRRRKQAHLSELETQVSQLRVENSKLMKGLTDVTQTFNDASVENR VLKANIETLRAKVKMAEETVKRLTGFNPMFHNMPQIVSTVSLPSETSNSPDTTS SQVTTPEIISSGNKGKALIGCKMNRTASMRRVESLEHLQKRIRSVGDQ 


\subsubsection{ACGT Elemente in den Promotoren der untersuchten Aminosäuregene}

Tabelle 8.1: Alle in dieser Arbeit untersuchten Gene des Aminosäuremetabolismus enthalten ACGT Elemente in ihren Promotoren

Die ersten 1000bp der Promotoren vor dem Beginn des Start-Codons wurden auf das Vorhandensein von ACGT-ähnlichen Motiven hin untersucht. Angegeben sind Name und AGI Code der untersuchten Gene sowie die Sequenz und Bezeichnung der ACGT-Elemente.

\begin{tabular}{|c|c|c|c|}
\hline Gene & AGI code & $\begin{array}{c}\text { ACGT-like elements } \\
\text { (-1000 bp promoter region) }\end{array}$ & Box \\
\hline$A N S$ & At3g16150 & $\begin{array}{l}-882 \text { attACGTaag }-873 \\
-776 \text { ttgACGTata }-767 \\
-752 \text { ataACGTaga }-743 \\
-511 \text { ctgACGTgga }-502 \\
-361 \text { ataACGTttc }-352\end{array}$ & $\begin{array}{l}\mathrm{A} \\
\mathrm{C} / \mathrm{A} \\
\mathrm{T} / \mathrm{A} \\
\mathrm{C} / \mathrm{G} \\
\mathrm{T}\end{array}$ \\
\hline ASN1 & At3g47340 & $\begin{array}{l}-731 \text { ttaACGTttt }-722 \\
-557 \text { aacACGTgta }-548 \\
-377 \text { cggACGTcgt }-368 \\
-354 \text { aacACGTgga }-345 \\
-167 \text { tctACGTgca }-158\end{array}$ & $\begin{array}{l}\text { T } \\
\text { G2 } \\
\text { C } \\
\text { G1 } \\
\text { A/G }\end{array}$ \\
\hline$A S P 3$ & At5g11520 & $\begin{array}{l}-841 \text { tcaACGTggt }-832 \\
-480 \text { tatACGTtga }-471 \\
-122 \text { cttACGTggc }-113\end{array}$ & $\begin{array}{l}\mathrm{T} / \mathrm{G} \\
\mathrm{A} / \mathrm{T} \\
\mathrm{A} / \mathrm{G}\end{array}$ \\
\hline BCAT2 & At1g10070 & $\begin{array}{l}-804 \text { aaaACGTtgt }-795 \\
-770 \text { ctgACGTggc }-761 \\
-749 \text { acaACGTgtt }-740 \\
-712 \text { aagACGTtga }-703 \\
-633 \text { ccaACGTggc }-624 \\
-337 \text { gacACGTcta }-328 \\
-164 \text { cttACGTgtt }-155\end{array}$ & $\begin{array}{l}\mathrm{T} \\
\mathrm{C} / \mathrm{G} \\
\mathrm{T} / \mathrm{G} \\
\mathrm{C} / \mathrm{T} \\
\mathrm{T} / \mathrm{G} \\
\mathrm{G} / \mathrm{C} \\
\mathrm{A} / \mathrm{G}\end{array}$ \\
\hline GDH2 & At5g07440 & $\begin{array}{l}-974 \text { ctaACGTgga }-965 \\
-737 \text { tccACGTccc }-728 \\
-282 \text { ctgACGTagg }-273 \\
-273 \text { gatACGTcaa }-264\end{array}$ & $\begin{array}{l}\text { T/G } \\
\text { G/C } \\
\text { C/A } \\
\text { A/C }\end{array}$ \\
\hline GLNS & At5g37600 & -157 ttcACGTcac -148 & $\mathrm{G} / \mathrm{C}$ \\
\hline PepCK & At5g65690 & $\begin{array}{l}-738 \text { aaaACGTgct }-729 \\
-524 \text { caaACGTgaa }-515 \\
-467 \text { tgcACGTaaa }-458 \\
-423 \text { tcaACGTaat }-414 \\
-334 \text { ataACGTgag }-325 \\
-76 \text { tatACGTgta }-67\end{array}$ & $\begin{array}{l}\text { T/G } \\
\text { T/G } \\
\text { G/A } \\
\text { T/A } \\
\text { T/G } \\
\text { A/G }\end{array}$ \\
\hline ProDH & At3g30775 & $\begin{array}{l}-842 \text { cACTCATcct }-833 \\
-714 \text { gACTCATcct }-705 \\
-683 \text { ctgACGTcct }-674 \\
-572 \text { ataACGTagc }-563 \\
-197 \text { aaaACGTgta }-188 \\
-171 \text { ttACGTgct }-162 \\
\end{array}$ & $\begin{array}{l}\text { ACT2 } \\
\text { ACT1 } \\
\text { C } \\
\text { T/A } \\
\text { T/G } \\
\text { A/G }\end{array}$ \\
\hline
\end{tabular}




\subsubsection{Charakterisierung der AtbZIP Einzel- und Mehrfachmutanten}

Tabelle 8.2: In dieser Arbeit verwendete Einzel- und Mehrfach-Mutanten

Angegeben sind die SALK-Nr., der Insertionsort der T-DNA und ob es sich laut Real-Time Analysen um einen Knock-Out oder Knock-Down handelt.

\begin{tabular}{|c|c|c|c|}
\hline Mutante & SALK Nr. & Insertion in & $\begin{array}{l}\text { Knock down / } \\
\text { Knock out }\end{array}$ \\
\hline atbzipl & SALK_059343 & ORF & Knock out \\
\hline atbzip53 & SALK_069883 & 5'UTR & Knock down \\
\hline atbzipl atbzip53 & $\begin{array}{l}\text { SALK_059343 } \\
\text { SALK_069883 }\end{array}$ & \begin{tabular}{|l} 
ORF \\
5'UTR
\end{tabular} & $\begin{array}{l}\text { Knock out } \\
\text { Knock down }\end{array}$ \\
\hline atbzipl atbzip53 atbzip9 atbzip63 & $\begin{array}{l}\text { SALK_059343 } \\
\text { SALK_069883 } \\
\text { SALK_093416 } \\
\text { SALK_066531 }\end{array}$ & $\begin{array}{l}\text { ORF } \\
\text { 5'UTR } \\
\text { 3. Exon } \\
\text { 5'UTR }\end{array}$ & $\begin{array}{l}\text { Knock out } \\
\text { Knock down } \\
\text { Knock out } \\
\text { Knock down }\end{array}$ \\
\hline atbzip1 atbzip53 tbzip10 atbzip25 & $\begin{array}{l}\text { SALK_059343 } \\
\text { SALK_069883 } \\
\text { SALK_106031 } \\
\text { SALK_119931 }\end{array}$ & $\begin{array}{l}\text { ORF } \\
\text { 5'UTR } \\
\text { 3. Exon } \\
\text { 1. Exon }\end{array}$ & $\begin{array}{l}\text { Knock out } \\
\text { Knock down } \\
\text { Knock out } \\
\text { Knock out }\end{array}$ \\
\hline
\end{tabular}




\subsection{Tabellarische Darstellung der Originaldaten aus der Aminosäuremessung}

Die folgenden Tabellen zeigen die Mittelwerte (Mean) und Standardabweichungen (SD) der einzelnen Aminosäuregehalte in ng AS / mg Trockengewicht.

\begin{tabular}{|l|rr|rr|rr|}
\hline \multicolumn{7}{|l|}{ Mittelwerte (Mean) und Standardabweichungen (SD) } \\
\hline & \multicolumn{2}{|c|}{ Alanin } & \multicolumn{2}{|c|}{ Aminobuttersäure } & \multicolumn{2}{c|}{ Arginin } \\
\hline [ng/mg Trockengewicht] & Mean & SD & Mean & SD & Mean & SD \\
\hline Wt 0d & 4,13 & 0,56 & 2,07 & 0,37 & 14,13 & 13,29 \\
Wt 1d & 8,05 & 3,25 & 1,61 & 0,54 & 16,88 & 5,13 \\
Wt 4d & 4,73 & 0,64 & 3,03 & 0,17 & 30,80 & 7,62 \\
Wt 6d & 5,46 & 0,43 & 3,40 & 0,09 & 50,78 & 19,91 \\
\hline Pro35S:bZIP1 0d & 3,30 & 0,23 & 1,95 & 0,72 & 11,32 & 0,81 \\
Pro35S:bZIP1 1d & 4,87 & 0,65 & 2,08 & 0,05 & 11,55 & 1,01 \\
Pro35S:bZIP1 4d & 2,88 & 0,54 & 3,41 & 0,04 & 28,76 & 4,10 \\
Pro35S:bZIP1 6d & 2,96 & 1,09 & 3,49 & 1,59 & 28,93 & 8,65 \\
\hline Pro35S:bZIP53 0d & 3,40 & 0,31 & 2,81 & 1,27 & 37,12 & 2,51 \\
Pro35S:bZIP53 1d & 4,53 & 0,40 & 1,93 & 0,11 & 23,74 & 11,72 \\
Pro35S:bZIP53 4d & 2,08 & 0,21 & 3,23 & 0,02 & 105,20 & 7,92 \\
Pro35S:bZIP53 6d & 1,36 & 0,34 & 3,37 & 0,23 & 134,13 & 10,10 \\
\hline atbzip1 atbzip53 0d & 5,10 & 0,01 & 1,60 & 0,47 & 8,41 & 2,32 \\
atbzip1 atbzip53 1d & 6,43 & 0,67 & 1,26 & 0,10 & 8,17 & 0,28 \\
atbzip1 atbzip53 4d & 5,76 & 0,68 & 1,91 & 0,53 & 22,21 & 3,41 \\
atbzip1 atbzip53 6d & 5,86 & 0,90 & 1,86 & 0,18 & 30,39 & 2,51 \\
\hline
\end{tabular}

\begin{tabular}{|l|rr|rr|rr|}
\hline & \multicolumn{2}{|c|}{ Asparagin } & \multicolumn{2}{c|}{ Aspartat } & \multicolumn{2}{c|}{ Citrullin } \\
\hline [ng/mg Trockengewicht] & Mean & SD & Mean & SD & Mean & SD \\
\hline Wt 0d & 19,22 & 10,36 & 9,30 & 0,79 & 2,12 & 0,72 \\
Wt 1d & 44,66 & 7,65 & 11,66 & 3,47 & 2,27 & 0,11 \\
Wt 4d & 143,06 & 12,67 & 6,36 & 0,08 & 1,24 & 0,14 \\
Wt 6d & 280,86 & 124,35 & 11,52 & 7,98 & 1,00 & 0,15 \\
\hline Pro35S:bZIP1 0d & 16,08 & 1,48 & 5,48 & 1,19 & 1,15 & 0,50 \\
Pro35S:bZIP1 1d & 36,50 & 2,97 & 5,60 & 0,65 & 1,48 & 0,48 \\
Pro35S:bZIP1 4d & 121,76 & 23,36 & 3,94 & 0,02 & 0,50 & 0,19 \\
Pro35S:bZIP1 6d & 136,29 & 38,33 & 4,99 & 1,41 & 0,55 & 0,18 \\
\hline Pro35S:bZIP53 0d & 118,80 & 0,39 & 9,43 & 2,69 & 3,55 & 0,13 \\
Pro35S:bZIP53 1d & 98,41 & 7,55 & 8,61 & 0,46 & 1,58 & 0,33 \\
Pro35S:bZIP53 4d & 500,29 & 6,11 & 10,77 & 0,50 & 1,96 & 0,57 \\
Pro35S:bZIP53 6d & 574,13 & 52,91 & 11,48 & 1,38 & 2,15 & 0,25 \\
\hline atbzip1 atbzip53 0d & 12,10 & 1,80 & 4,86 & 0,68 & 0,66 & 0,38 \\
atbzip1 atbzip53 1d & 11,19 & 2,98 & 5,20 & 3,10 & 1,30 & 0,75 \\
atbzip1 atbzip53 4d & 45,92 & 0,43 & 1,88 & 0,14 & 0,69 & 0,08 \\
atbzip1 atbzip53 6d & 109,28 & 5,35 & 3,58 & 0,13 & 0,38 & 0,17 \\
\hline
\end{tabular}




\begin{tabular}{|l|rr|rr|rr|}
\hline & \multicolumn{2}{|c|}{ GABA } & \multicolumn{2}{c|}{ Glutamat } & \multicolumn{2}{c|}{ Glutamin } \\
\hline [ng/mg Trockengewicht] & Mean & SD & Mean & SD & Mean & SD \\
\hline Wt 0d & 0,26 & 0,37 & 18,04 & 4,61 & 38,38 & 18,23 \\
Wt 1d & 1,37 & 0,14 & 24,75 & 16,43 & 61,00 & 11,13 \\
Wt 4d & 1,25 & 0,74 & 28,18 & 11,49 & 41,63 & 21,63 \\
Wt 6d & 4,16 & 0,76 & 33,85 & 26,88 & 42,08 & 16,92 \\
\hline Pro35S:bZIP1 0d & 0,00 & 0,00 & 9,44 & 6,96 & 17,37 & 3,88 \\
Pro35S:bZIP1 1d & 0,00 & 0,00 & 24,13 & 0,04 & 24,73 & 4,05 \\
Pro35S:bZIP1 4d & 2,98 & 0,05 & 41,39 & 3,64 & 17,73 & 4,18 \\
Pro35S:bZIP1 6d & 3,08 & 1,53 & 35,30 & 11,80 & 16,71 & 4,77 \\
\hline Pro35S:bZIP53 0d & 0,89 & 1,26 & 24,55 & 11,84 & 62,73 & 7,01 \\
Pro35S:bZIP53 1d & 1,36 & 0,34 & 14,58 & 1,11 & 47,15 & 20,61 \\
Pro35S:bZIP53 4d & 1,28 & 0,28 & 41,13 & 5,29 & 68,60 & 16,23 \\
Pro35S:bZIP53 6d & 1,90 & 0,16 & 46,73 & 5,77 & 63,88 & 1,22 \\
\hline atbzip1 atbzip53 0d & 0,00 & 0,00 & 12,85 & 6,46 & 47,74 & 0,05 \\
atbzip1 atbzip53 1d & 0,00 & 0,00 & 4,35 & 4,39 & 27,97 & 13,34 \\
atbzip1 atbzip53 4d & 1,58 & 0,83 & 6,74 & 0,86 & 18,80 & 2,75 \\
atbzip1 atbzip53 6d & 2,65 & 0,16 & 17,67 & 2,13 & 46,21 & 3,95 \\
\hline
\end{tabular}

\begin{tabular}{|l|rr|rr|rr|}
\hline & \multicolumn{2}{|c|}{ Glycin } & \multicolumn{2}{c|}{ Histidin } & \multicolumn{2}{c|}{ Hydroxy Lysin } \\
\hline [ng/mg Trockengewicht] & Mean & SD & Mean & SD & Mean & SD \\
Wt 0d & 2,64 & 1,11 & 0,34 & 0,48 & 1,42 & 1,01 \\
Wt 1d & 1,00 & 0,46 & 1,69 & 0,31 & 1,03 & 0,80 \\
Wt 4d & 1,15 & 0,11 & 8,78 & 0,82 & 0,84 & 1,18 \\
Wt 6d & 1,58 & 0,83 & 12,65 & 1,34 & 1,10 & 1,55 \\
\hline Pro35S:bZIP1 0d & 1,61 & 0,24 & 1,32 & 0,38 & 0,35 & 0,50 \\
Pro35S:bZIP1 1d & 0,99 & 0,20 & 1,94 & 0,35 & 1,25 & 1,76 \\
Pro35S:bZIP1 4d & 2,10 & 0,31 & 10,68 & 2,32 & 2,07 & 0,78 \\
Pro35S:bZIP1 6d & 1,38 & 0,47 & 14,23 & 2,85 & 0,20 & 0,28 \\
\hline Pro35S:bZIP53 0d & 9,01 & 1,23 & 1,99 & 0,57 & 1,17 & 0,19 \\
Pro35S:bZIP53 1d & 1,06 & 0,00 & 1,87 & 0,12 & 1,62 & 0,81 \\
Pro35S:bZIP53 4d & 1,08 & 0,09 & 5,99 & 8,47 & 0,97 & 0,44 \\
Pro35S:bZIP53 6d & 1,15 & 0,22 & 28,55 & 3,99 & 0,67 & 0,27 \\
\hline atbzip1 atbzip53 0d & 2,25 & 1,50 & 0,71 & 0,01 & 0,00 & 0,00 \\
atbzip1 atbzip53 1d & 0,88 & 0,28 & 1,17 & 0,45 & 0,00 & 0,00 \\
atbzip1 atbzip53 4d & 0,73 & 0,02 & 5,36 & 0,66 & 1,35 & 1,91 \\
atbzip1 atbzip53 6d & 0,76 & 0,03 & 7,35 & 0,26 & 0,00 & 0,00 \\
\hline
\end{tabular}




\begin{tabular}{|l|rr|rr|rr|}
\hline & \multicolumn{2}{|c|}{ Isoleucin } & \multicolumn{2}{c|}{ Leucin } & \multicolumn{2}{c|}{ Lysin } \\
\hline [ng/mg Trockengewicht] & Mean & SD & Mean & SD & Mean & SD \\
\hline Wt 0d & 0,86 & 0,12 & 0,83 & 0,22 & 0,99 & 0,54 \\
Wt 1d & 2,75 & 0,96 & 3,03 & 1,04 & 3,40 & 0,79 \\
Wt 4d & 9,45 & 1,65 & 6,30 & 0,33 & 5,68 & 0,67 \\
Wt 6d & 9,93 & 1,00 & 5,80 & 0,74 & 5,08 & 0,04 \\
\hline Pro35S:bZIP1 0d & 0,31 & 0,43 & 0,16 & 0,23 & 1,04 & 0,27 \\
Pro35S:bZIP1 1d & 1,95 & 0,47 & 1,34 & 0,35 & 2,44 & 0,03 \\
Pro35S:bZIP1 4d & 3,71 & 0,73 & 1,83 & 0,46 & 2,32 & 0,26 \\
Pro35S:bZIP1 6d & 3,30 & 1,21 & 1,39 & 0,38 & 1,00 & 0,15 \\
\hline Pro35S:bZIP53 0d & 0,77 & 0,48 & 0,64 & 0,39 & 1,26 & 0,21 \\
Pro35S:bZIP53 1d & 1,09 & 0,02 & 0,73 & 0,09 & 1,73 & 0,16 \\
Pro35S:bZIP53 4d & 3,77 & 0,21 & 1,89 & 0,07 & 5,44 & 0,06 \\
Pro35S:bZIP53 6d & 4,36 & 0,64 & 2,25 & 0,53 & 6,54 & 0,52 \\
\hline atbzip1 atbzip53 0d & 0,30 & 0,43 & 0,40 & 0,57 & 0,75 & 0,10 \\
atbzip1 atbzip53 1d & 1,55 & 0,19 & 2,21 & 0,08 & 1,94 & 0,83 \\
atbzip1 atbzip53 4d & 6,77 & 0,48 & 5,26 & 0,21 & 5,69 & 0,19 \\
atbzip1 atbzip53 6d & 7,96 & 0,24 & 5,23 & 0,05 & 5,07 & 0,23 \\
\hline
\end{tabular}

\begin{tabular}{|l|rr|rr|rr|}
\hline & \multicolumn{2}{|c|}{ Met/Cysta } & \multicolumn{2}{|c|}{ Ornithin } & \multicolumn{2}{|c|}{ Phenylalanin } \\
\hline [ng/mg Trockengewicht] & Mean & SD & Mean & SD & Mean & SD \\
\hline Wt 0d & 0,58 & 0,08 & 0,78 & 0,32 & 0,70 & 0,03 \\
Wt 1d & 0,10 & 0,15 & 1,25 & 0,33 & 2,15 & 0,11 \\
Wt 4d & 0,07 & 0,11 & 1,33 & 0,12 & 22,89 & 0,12 \\
Wt 6d & 0,95 & 0,22 & 1,99 & 0,52 & 37,23 & 4,22 \\
\hline Pro35S:bZIP1 0d & 0,00 & 0,00 & 0,67 & 0,28 & 0,88 & 0,42 \\
Pro35S:bZIP1 1d & 0,00 & 0,00 & 0,80 & 0,24 & 2,52 & 0,42 \\
Pro35S:bZIP1 4d & 0,00 & 0,00 & 0,57 & 0,81 & 27,34 & 0,71 \\
Pro35S:bZIP1 6d & 0,36 & 0,23 & 0,00 & 0,00 & 43,99 & 15,15 \\
\hline Pro35S:bZIP53 0d & 0,00 & 0,00 & 2,06 & 0,53 & 1,82 & 0,97 \\
Pro35S:bZIP53 1d & 0,00 & 0,00 & 1,64 & 0,84 & 1,80 & 0,20 \\
Pro35S:bZIP53 4d & 0,73 & 0,08 & 3,03 & 0,34 & 43,05 & 3,47 \\
Pro35S:bZIP53 6d & 0,76 & 0,06 & 3,97 & 1,05 & 60,56 & 0,98 \\
\hline atbzip1 atbzip53 0d & 0,00 & 0,00 & 0,60 & 0,09 & 0,39 & 0,55 \\
atbzip1 atbzip53 1d & 0,00 & 0,00 & 0,28 & 0,40 & 1,41 & 0,33 \\
atbzip1 atbzip53 4d & 0,00 & 0,00 & 1,66 & 0,06 & 11,93 & 2,01 \\
atbzip1 atbzip53 6d & 0,27 & 0,38 & 1,33 & 0,14 & 18,57 & 0,32 \\
\hline
\end{tabular}




\begin{tabular}{|l|rr|rr|rr|}
\hline & \multicolumn{2}{|c|}{ Prolin } & \multicolumn{2}{|c|}{ Threonin } & \multicolumn{2}{c|}{ Tryptophan } \\
\hline [ng/mg Trockengewicht] & Mean & SD & Mean & SD & Mean & SD \\
\hline Wt 0d & 2,68 & 0,06 & 8,61 & 0,52 & 0,00 & 0,00 \\
Wt 1d & 1,63 & 0,19 & 10,79 & 4,30 & 0,00 & 0,00 \\
Wt 4d & 1,88 & 0,01 & 9,75 & 1,36 & 3,80 & 0,89 \\
Wt 6d & 1,27 & 0,23 & 10,99 & 2,89 & 6,30 & 0,28 \\
\hline Pro35S:bZIP1 0d & 1,53 & 0,55 & 4,76 & 1,58 & 0,00 & 0,00 \\
Pro35S:bZIP1 1d & 1,14 & 0,01 & 7,58 & 0,99 & 0,00 & 0,00 \\
Pro35S:bZIP1 4d & 1,12 & 0,18 & 4,55 & 1,10 & 6,89 & 0,28 \\
Pro35S:bZIP1 6d & 1,19 & 0,34 & 3,65 & 1,28 & 7,95 & 4,72 \\
\hline Pro35S:bZIP53 0d & 0,42 & 0,05 & 12,58 & 2,14 & 0,00 & 0,00 \\
Pro35S:bZIP53 1d & 0,59 & 0,05 & 6,98 & 1,18 & 0,00 & 0,00 \\
Pro35S:bZIP53 4d & 0,56 & 0,27 & 15,05 & 1,98 & 5,15 & 0,49 \\
Pro35S:bZIP53 6d & 0,91 & 0,08 & 11,32 & 4,04 & 8,56 & 0,07 \\
\hline atbzip1 atbzip53 0d & 1,87 & & 4,35 & 1,16 & 0,00 & 0,00 \\
atbzip1 atbzip53 1d & 1,81 & 0,07 & 3,28 & 1,76 & 0,00 & 0,00 \\
atbzip1 atbzip53 4d & 1,76 & 0,51 & 3,43 & 0,50 & 3,17 & 0,30 \\
atbzip1 atbzip53 6d & 1,30 & 0,14 & 7,35 & 0,26 & 3,60 & 0,79 \\
\hline
\end{tabular}

\begin{tabular}{|l|rr|rr|rr|}
\hline & \multicolumn{2}{|c|}{ Tyrosin } & \multicolumn{2}{c|}{ Serin } & \multicolumn{2}{c|}{ Valin } \\
\hline [ng/mg Trockengewicht] & Mean & SD & Mean & SD & Mean & SD \\
\hline Wt 0d & 0,35 & 0,50 & 17,50 & 3,12 & 1,99 & 0,20 \\
Wt 1d & 1,71 & 0,55 & 16,62 & 6,61 & 5,28 & 1,73 \\
Wt 4d & 3,41 & 0,91 & 22,95 & 1,58 & 21,67 & 2,15 \\
Wt 6d & 4,13 & 0,31 & 42,52 & 18,54 & 27,26 & 2,98 \\
\hline Pro35S:bZIP1 0d & 0,19 & 0,27 & 12,05 & 5,06 & 1,57 & 0,36 \\
Pro35S:bZIP1 1d & 1,70 & 0,06 & 14,23 & 2,14 & 4,01 & 0,28 \\
Pro35S:bZIP1 4d & 1,97 & 0,44 & 23,94 & 4,65 & 15,15 & 1,17 \\
Pro35S:bZIP1 6d & 1,30 & 0,42 & 26,64 & 12,29 & 18,79 & 10,82 \\
\hline Pro35S:bZIP53 0d & 0,81 & 0,24 & 21,47 & 3,42 & 1,86 & 0,80 \\
Pro35S:bZIP53 1d & 0,87 & 0,01 & 9,40 & 0,40 & 2,18 & 0,13 \\
Pro35S:bZIP53 4d & 1,49 & 0,16 & 33,25 & 3,40 & 11,37 & 0,85 \\
Pro35S:bZIP53 6d & 2,10 & 0,01 & 30,43 & 0,78 & 12,46 & 2,19 \\
\hline atbzip1 atbzip53 0d & 0,30 & 0,43 & 15,09 & 4,13 & 1,17 & 0,04 \\
atbzip1 atbzip53 1d & 1,23 & 0,16 & 5,79 & 2,48 & 2,77 & 0,04 \\
atbzip1 atbzip53 4d & 2,91 & 0,05 & 7,94 & 0,06 & 14,04 & 1,38 \\
atbzip1 atbzip53 6d & 2,74 & 0,04 & 20,65 & 0,97 & 18,19 & 0,30 \\
\hline
\end{tabular}




\begin{tabular}{|l|rr|rr|}
\hline & \multicolumn{2}{|c|}{ Ammonium } & \multicolumn{2}{c|}{ Gesamte AS } \\
\hline [ng/mg Trockengewicht] & Mean & SD & Mean & SD \\
\hline Wt 0d & 7,20 & 1,22 & 168,30 & 41,45 \\
Wt 1d & 12,15 & 1,07 & 247,78 & 51,42 \\
Wt 4d & 49,25 & 11,41 & 448,20 & 16,81 \\
Wt 6d & 122,47 & 29,12 & 776,10 & 235,34 \\
\hline Pro35S:bZIP1 0d & 7,05 & 0,38 & 113,14 & 17,21 \\
Pro35S:bZIP1 1d & 18,25 & 9,87 & 193,37 & 8,38 \\
Pro35S:bZIP1 4d & 98,83 & 3,09 & 469,78 & 32,05 \\
Pro35S:bZIP1 6d & 158,86 & 61,61 & 559,47 & 181,09 \\
\hline Pro35S:bZIP53 0d & 9,01 & 4,73 & 340,85 & 29,23 \\
Pro35S:bZIP53 1d & 12,33 & 5,32 & 258,24 & 48,25 \\
Pro35S:bZIP53 4d & 53,56 & 23,55 & 955,92 & 39,69 \\
Pro35S:bZIP53 6d & 70,63 & 4,10 & 1124,67 & 40,75 \\
\hline atbzip1 atbzip53 0d & 8,33 & 5,21 & 136,81 & 16,18 \\
atbzip1 atbzip53 1d & 5,77 & 3,22 & 102,63 & 26,27 \\
atbzip1 atbzip53 4d & 27,83 & 1,60 & 210,83 & 10,66 \\
atbzip1 atbzip53 6d & 37,59 & 5,06 & 371,50 & 11,13 \\
\hline
\end{tabular}




\section{Abkürzungsverzeichnis}

\subsection{Allgemeine Abkürzungen}

\begin{tabular}{|c|c|}
\hline ABA & Abscisinsäure \\
\hline $\mathrm{ABI} 3$ & ABA insensitive 3 \\
\hline ADP & Adenosindiphosphat \\
\hline AMPK & AMP-activated proteine kinases \\
\hline A.t. & Arabidopsis thaliana \\
\hline AtbZIP & Arabidopsis thaliana basischer Leucinzipper \\
\hline AtbZIP-TF & Arabidopsis thaliana basischer Leucinzipper Transkriptionsfaktor \\
\hline Amp & Ampicillin (resistent) \\
\hline ANS & Asparaginase \\
\hline ASN1 & Asparagine Synthetase \\
\hline ASP3 & Aspartat Aminotransferase 3 \\
\hline ATP & Adenosintriphosphat \\
\hline BAM & ß-Amylase \\
\hline BCAT & Branched chain amino acid transaminase \\
\hline bidest. & bidestilliert \\
\hline bp & Basenpaare \\
\hline BPB & Bromphenolblau \\
\hline bZIP & basischer Leucinzipper \\
\hline bzw. & beziehungsweise \\
\hline ca. & circa \\
\hline $\mathrm{CAB}$ & Chlorophyll A/B Binding Protein \\
\hline CCA1 & Circadien Clock Associated 1 \\
\hline cDNA & komplementäre DNA \\
\hline ChIP & Chromatin Immunopräzipitation \\
\hline $\mathrm{CO}_{2}$ & Kohlendioxid \\
\hline d.h. & das heißt \\
\hline ddNTPs & Didesoxyribonucleotide \\
\hline dNTP & Desoxyribonukleotide \\
\hline DIN & dark induced \\
\hline DNA & Desoxyribonukleinsäure \\
\hline ECL & Enhanced Chemilumineszenz \\
\hline E. coli & Escherichia coli \\
\hline EDTA & Ethylendiamintetraessigsäure \\
\hline et al. & und andere (et alii) \\
\hline $\mathrm{EtBr}$ & Ethidiumbromid \\
\hline etc. & und so weiter (et cetera) \\
\hline $\mathrm{EtOH}$ & Ethanol \\
\hline GDH2 & Glutamat Dehydrogenase 2 \\
\hline GLNS & Glutamin Synthase \\
\hline GUS & $\beta$-Glucuronidase \\
\hline $\mathrm{H}_{2} \mathrm{O}$ & Wasser \\
\hline $\mathrm{HCl}$ & Salzsäure \\
\hline HEPES & 2-[4-(2-Hydroxyethyl)-1-piperazino]-ethansulfonsäure \\
\hline
\end{tabular}




\begin{tabular}{|c|c|}
\hline HXK & Hexokinase \\
\hline JA & Jasmonsäure \\
\hline $\mathrm{kb}$ & kilo Basen(paare) \\
\hline $\mathrm{kDa}$ & Kilodalton \\
\hline KIN10 & SnRK1-Kinase10 \\
\hline KIN11 & SnRK1-Kinase11 \\
\hline LB & Luria-Bertani Broth \\
\hline LEA & late embryogenesis abundant \\
\hline LOX & Lipoxygenase \\
\hline $\mathrm{MgCl}_{2}$ & Magnesiumchlorid \\
\hline Min. & Minuten \\
\hline MOPS & Morpholinopropansulfonsäure \\
\hline mRNA & messenger RNA \\
\hline $\mathrm{NaCl}$ & Natriumchlorid \\
\hline NADH & Nicotinsäureamid-Adenin-Dinukleotid \\
\hline NADPH & Nicotinsäureamid-Adenin-Dinukleotid-Phosphat \\
\hline NAN & Derivat des nanH-Gens, welches eine Sialidase codiert \\
\hline OD & optische Dichte \\
\hline OEX & Überexpression \\
\hline o.g. & oben genannten \\
\hline OMG & Orthomethylglukose \\
\hline ORF & offener Leserahmen (Open Reading Frame) \\
\hline PAGE & Polyacrylamidgelelektrophorese \\
\hline PCR & Polymerasekettenreaktion (Polymerase Chain Reaction) \\
\hline $\mathrm{pH}$ & negativ dekadischer Logarithmus der Protonenkonzentration \\
\hline PIPES & 1,4-Piperazin-bis-(ethansulfonsäure) \\
\hline Pro35S & 35S-Promotor aus Cauliflower Mosaic Virus \\
\hline ProDH & Prolin Dehydrogenase \\
\hline PVDF & Polyvinylendifluorid \\
\hline RNA & Ribonukleinsäure \\
\hline Rnase & Ribonuclease \\
\hline rpm & Umdrehungen pro Minute (rounds per minute) \\
\hline RT & Raumtemperatur \\
\hline SA & Salizylsäure \\
\hline SAG & senescence associated gene \\
\hline SDS & Natriumdodecylsulfat (sodiumdodecylsulfate) \\
\hline SNF1 & Sucrose non-fermenting 1 \\
\hline SnRK & Snf1 related kinases \\
\hline SSC & Standard Saline Citrat Puffer \\
\hline T6P & Trehalose-6-Phosphat \\
\hline Taq & Thermus aquaticus (DNA-Polymerase aus T. aquaticus) \\
\hline TBE & Tris-Borat-EDTA-Puffer \\
\hline TBS & Tris buffered saline \\
\hline T-DNA & Transfer-DNA \\
\hline TE & Tris-EDTA-Puffer \\
\hline $\mathrm{TF}$ & Transkriptionsfaktor \\
\hline $\mathrm{Tm}$ & Schmelztemperatur \\
\hline Tris & Tris(hydroxymethyl)aminomethan \\
\hline
\end{tabular}


u. a.

unter anderem

ü. N. über Nacht

uORF upstream open reading frame (offenes Leseraster im 5'-UTR)

UTR untranslatierte Region

UV Ultraviolettes Licht

$\mathrm{v} / \mathrm{v}$

Vol.

$\mathrm{w} / \mathrm{v}$

$\mathrm{Wt}$ Volumenprozent (volume per volume)

\section{Volumen}

$\mathrm{X}$-Gal Gewichtsprozent (weight per volume)

YLS3

Wildtyp

z. B. 5-Brom-4-chlor-3-indolyl- $\beta$-D-galactopyranosid

z. T. Yellow Leaf Specific 3 zum Beispiel

$\lambda$

zum Teil

Bakteriophage Lambda

\subsection{Einheiten}

$\begin{array}{ll}\Omega & \text { Ohm } \\ { }^{\circ} \mathrm{C} & \text { Grad Celsius } \\ \mathrm{A} & \text { Ampère } \\ \mathrm{D} & \text { Dalton } \\ \mathrm{E} & \text { Einstein (1E = 1 Mol Photonen) } \\ \mathrm{F} & \text { Farad } \\ \mathrm{g} & \text { Gramm, Erdbeschleunigung } \\ \mathrm{h} & \text { Stunde } \\ \mathrm{l} & \text { Liter } \\ \mathrm{M} & \text { Molar } \\ \mathrm{min} & \text { Minute } \\ \mathrm{ppb} & \text { parts per billion } \\ \mathrm{s}, \text { sek } & \text { Sekunde } \\ \mathrm{U} & \text { definierte Einheit der Enzymaktivität (unit) } \\ \mathrm{V} & \text { Volt } \\ \mathrm{W} & \text { Watt }\end{array}$

\subsection{Präfixe}

$\begin{array}{lll}\mathrm{k} & \text { kilo } & \left(10^{3}\right) \\ \mathrm{m} & \text { milli } & \left(10^{-3}\right) \\ \mu & \text { mikro } & \left(10^{-6}\right) \\ \mathrm{n} & \text { nano } & \left(10^{-9}\right) \\ \mathrm{p} & \text { pico } & \left(10^{-12}\right)\end{array}$

\subsection{Aminosäuren}
A
Ala
Alanin
C
Cys
Cystein 


$\begin{array}{lll}\text { D } & \text { Asp } & \text { Asparaginsäure } \\ \text { E } & \text { Glu } & \text { Glutaminsäure } \\ \text { F } & \text { Phe } & \text { Phenylalanin } \\ \text { G } & \text { Gly } & \text { Glycin } \\ \text { H } & \text { His } & \text { Histidin } \\ \text { I } & \text { Ile } & \text { Isoleucin } \\ \text { K } & \text { Lys } & \text { Lysin } \\ \text { L } & \text { Leu } & \text { Leucin } \\ \text { M } & \text { Met } & \text { Methionin } \\ \text { N } & \text { Asn } & \text { Asparagin } \\ \text { P } & \text { Pro } & \text { Prolin } \\ \text { Q } & \text { Gln } & \text { Glutamin } \\ \text { R } & \text { Arg } & \text { Arginin } \\ \text { S } & \text { Ser } & \text { Serin } \\ \text { T } & \text { Thr } & \text { Threonin } \\ \text { V } & \text { Val } & \text { Valin } \\ \text { W } & \text { Trp } & \text { Tryptophan } \\ \text { Y } & \text { Tyr } & \text { Tyrosin }\end{array}$

\section{$9.5 \quad$ Nukleotide}

$\begin{array}{ll}\text { A } & \text { Adenosin } \\ \mathrm{C} & \text { Cytosin } \\ \mathrm{G} & \text { Guanosin } \\ \mathrm{T} & \text { Thymin } \\ \mathrm{U} & \text { Uracil }\end{array}$




\section{Danksagung:}

Wolfgang Dröge-Laser möchte ich an dieser Stelle dafür danken, dass ich diese Arbeit bei ihm schreiben durfte, und natürlich auch für die vielen hilfreichen Tipps und Tricks während der letzten vier Jahre. Frau Professor Gatz danke ich für die Aufnahme in die Arbeitsgruppe und für die Übernahme des Korreferats.

Unserem Kooperationspartner Klaus Harter (Universität Tübingen) danke ich für die Möglichkeit die Aminosäuregehalte messen zu können. Ein ganz besonderer Dank geht dabei an Bettina Stadelhofer, die für diese Messungen viel Zeit investiert hat und mir alles so ausführlich erklärte.

Bei Christina Chaban (Universität Tübingen) möchte ich mich dafür bedanken, dass sie mir die AtbZIP63 Alanin Mutante zur Verfügung gestellt hat.

Wolfram Weckwerth (Universität Wien) und seiner Abteilung danke ich dafür, dass sie mir die Möglichkeit gegeben haben, am Metabolomics-Praktikum in Wien teilzunehmen, und mich daran anschließend eine Woche bei sich in der Abteilung für die Messung meiner Proben aufgenommen haben. Ein Besonderer Dank geht hier an Lena, die einige Abende im Labor verbringen musste, damit meine Proben noch übers Wochenende gemessen werden konnten.

Johannes Hanson (Universität Utrecht) möchte ich für die Einführung in die Array Auswertung und die ersten Einblicke in den Umgang mit $\mathrm{R}$ danken, die er uns im Rahmen eines Workshops in Utrecht gewährt hat.

Auch unseren Kooperationspartnern Sjef Smeekens, Markus Teige und Jesus VicenteCarbajosa aus der bZIP-Gruppe danke ich für einen regen Informationsaustausch und schöne Aufenthalte in Madrid, Utrecht und Wien während unserer halbjährigen Treffen.

Ellen Hornung und Ivo Feussner (Universität Göttingen, Biochemie der Pflanze) möchte ich für die Zusammenarbeit bezüglich der loxl Mutante und der LOX1Überexpremierer danken. 
Ein ganz großer Dank geht auch an meine beiden Diplomandinnen Johanna und Laura. Die Zusammenarbeit mit euch hat mir viel Spaß gemacht.

Meinen Laborkollegen Christoph, Tim, Andrea, Caro, Nora und Jenny möchte ich für eine sehr schöne Zeit danken. Ihr habt mir bei all den kleinen und großen Problemen des Laboralltags geholfen, und ihn durch eine lockere Atmosphäre und viele gemeinsame Kaffeepausen, Grillabende etc. aufgeheitert. Von den Ehemaligen danke ich vor allem Fridtjof dafür, dass ich sein erfolgversprechendes Thema weiterführen durfte. Auch bei den Mitgliedern der AG Gatz möchte ich mich für die nette Zusammenarbeit bedanken.

Nicht zuletzt danke ich meiner Mutter und meiner Schwester für ihre Unterstützung und für die Planung des Urlaubs, auf den ich mich schon während der Schreibphase freuen konnte. Der größte Dank geht aber an meinen Freund Stefan, der mich die letzten Wochen bei sich aufgenommen hat, immer für mich da war und einfach zwischendurch auch mal auf andere Gedanken brachte. Ohne ihn hätte ich diese Arbeit sicher nicht so ruhig beenden können. 


\section{Lebenslauf:}

\section{Persönliche Daten:}

$\begin{array}{ll}\text { Name: } & \text { Katrin Dietrich } \\ \text { Geburtsdatum: } & 07.10 .1980 \\ \text { Geburtsort: } & \text { Wilhelmshaven } \\ \text { Staatsangehörigkeit: } & \text { deutsch }\end{array}$

Schulbildung:

1987-1988 Grundschule Worpswede

1988-1991 Paul-Sillus-Grundschule Jever

1991-1993 Orientierungsstufe Jever

1993-2000 Mariengymnasium Jever

Abschluss: Abitur, Note 2,1

\section{Studium:}

Oktober $2000 \quad$ Beginn des Biologiestudiums an der Georg-August Universität Göttingen

Juli 2002

Vordiplom in den Fächern Botanik, Mikrobiologie, Chemie und Physik mit der Gesamtnote, Sehr gut ${ }^{6}$

April 2005

Diplomprüfung in den Fächern Botanik, Biochemie und Mikrobiologie mit der Gesamtnote ,Sehr gut ${ }^{\star}$

bis April $2006 \quad$ Anfertigung der Diplomarbeit am Lehrstuhl für „Allgemeine und Entwicklungsphysiologie der Pflanze“ bei PD Dr. W. DrögeLaser mit dem Thema: „Die Funktion der Transkriptionsfaktoren AtbZIP1 und AtbZIP53 aus Arabidopsis thaliana unter biotischen und abiotischen Stressbedingungen"; Note ,Sehr gut"

2006-2010

Anfertigung der vorliegenden Dissertation am Lehrstuhl für „Allgemeine und Entwicklungsphysiologie der Pflanze“ des Albrecht-von-Haller Instituts für Pflanzenwissenschaften der Georg-August-Universität zu Göttingen bei PD Dr. W. DrögeLaser. 


\section{Bisherige Publikationen:}

Weltmeier F., Ehlert A., Mayer C.S., Dietrich K., Wang X., Schütze K., Alonso R., Harter K., Vicente-Carbajosa J. and Dröge-Laser W. (2006): Combinatorial control of proline dehydrogenase transcription by specific heterodimerisation of bZIP transcription factors. The EMBO Journal, 13, 3133-43.

Alonso R., Oñate-Sánchez L., Weltmeier F., Ehlert A., Diaz I., Dietrich K., Vicente-Carbajosa J. and Dröge-Laser W. (2009): A pivotal role of the basic leucine zipper transcription factor AtbZIP53 in the regulation of seed maturation gene expression based on heterodimerisation and protein complex formation. The Plant Cell, $6,1747-61$.

Weltmeier F., Rahmani F., Ehlert A., Dietrich K., Schutze K., Wang X., Chaban C., Hanson J., Teige M., Harter K., Vicente-Carbajosa J., Smeekens S. and DrögeLaser W. (2009): Expression patterns within the Arabidopsis C/S1 bZIP transcription factor network: availability of heterodimerization partners controls gene expression during stress response and development. Plant Molecular Biology, 69, 107-119.

Dietrich K., Weltmeier F., Ehlert A., Weiste C., Stahl M., Harter K. and DrögeLaser W. Heterodimers of the Arabidopsis Transcription Factors bZIP1 and bZIP53 Reprogram Amino Acid Metabolism during Low Energy Stress. Eingereicht bei The Plant Cell. 
